\title{
The Digital Design Coach \\ Enhancing Design Conversations in Architectural Education
}

\author{
by
}

Rohan O’Neil Bailey

A thesis submitted to the Victoria University of Wellington in fulfillment of the requirements for the degree of Doctor of Philosophy in Architecture

\section{Victoria University of Wellington 2005}


Changes in society, technology, and practice have created a significant demand for architectural graduates who can balance practical concerns with critical and abstract thinking. The current model of architectural education as it exists in academia, is hard pressed to supply this demand.

This thesis seeks to redress this situation by connecting three maxims:

1) Strengthening the master-student dialogue is key to adequately exposing student designers to the issues involved in designing buildings that are fit for purpose, cost effective, sustainable and a delight to clients and users.

2) Sketching, a "designerly" way of thinking, is an integral part of this dialogue.

3) The computer in design education should directly contribute to helping students design buildings that are fit for purpose, cost effective, sustainable and a delight to clients and users.

The thesis argues that due to the myriad of issues connected with architecture in today's society, the effectiveness of the student/master dialogue in architectural education has been weakened somewhat. At the centre of this dialogue is the sketch - a conversation between head and hand. The thesis will argue that by furnishing students with an "expert hand", the sketch becomes so empowered as to enrich the dialogue, raising the level of students' exposure to architectural issues. The suggested medium for this empowerment is the computer.

Moving sketching into the digital realm as a direct means of thinking and learning is an innovative way of providing students with an "expert" digital hand. The sketch, for the student, becomes an intelligent conscious tool that supports and informs exploration. In turn, the empowered sketch presents the student with the many issues that comprise contemporary design problems. The result of this upliftment is a richer dialogue between student and teacher about architecture that is fit for purpose, economical and environmentally aware. 
Y ears ago as a student I discovered Christopher Alexander's Pattern Language. Alexander's book laid out for me a smorgasbord of architectural ideas that were subsequently incorporated into the design projects of my student years. My grades not only improved but I had what can only be called an epiphany; I "got" it. I did not arrive at this understanding merely because I used the Pattern Language, but rather, in using a "language" when communicating with my teachers, I learned about the issues that made architecture work. Those pieces that comprised my "language" are still with me as I recombine and re-interpret them for new design situations.

Today, I am a studio teacher. When I talk to students and enquire about practical aspects of their schemes, they look at me with blank expressions. I've since discovered that, when designing, students rarely use reference books. They often speak of being stuck when something as simple as the location of a window (which has a lot to do with comfort, quality, meaning, poetics or simply, the way rooms are inhabited) could liberate them and carry the scheme forward. I often find that I have to repeat the same fundamental information (found in most reference books) to ten different students in a row. I have also noticed that when architectural students lack understanding about the things that make architecture work - fundamental ideas like inhabitation, user comfort, circulation, sensory stimulation and their relation to the form of space - my job becomes harder and more frustrating.

This thesis is a bit like solving a design problem. The "problem" in this case is the apparent inability of the teacher-student dialogue to provide students with the confidence to design buildings that are habitable, sustainable and constructible. In design, it is possible to arrive at a solution by developing an argument. Let us use the analogy of a window (something that will feature a lot in this work) as a basis for laying out the argument (see table P1 below).

As demonstrated in the table, research is a little like design. Each situation is linked to other "problems" and it is through reconciliation and iteration that a possible solution can be arrived at. 


The Window Problem
The room is dark
Why is the room dark?
Because there is no light.
Why do we need light?
We need light to use the room for a
particular function.
The aim therefore is to let in adequate light.

How do you admit light?

Light is transmitted through windows.

How do windows transmit light?

What is the component that transmits light?

Glass Transparency is one option.

How does glass transmit light?

What if we change glass transparency?

Experiment with different glass types.

Clear glass recommended option.

Why clear glass?

Specifications

Let there be light.

Testing the glass.
The Education Problem

Design Education is challenged to produce graduates that know real buildings.

Why is this so?

Design Education is in trouble because it is stuck in academia. Students do not get enough practical knowledge

Why should we care?

Architects lack confidence of the public, status in society and position in industry.

Aim is to facilitate practical knowledge in graduates and create a reasonable balance in commodity, firmness, and delight.

How is this practical knowledge passed on?

Design studio facilitates the transference of knowledge.

How does studio work?

Which aspect of studio is responsible?

The part that does it is the deskcrit

How does deskcrit facilitate transference of knowledge?

What ifs.

Experiments to find questions students ask and answers tutor would give if they were right there

The computer as a solution

Why the computer?

Definitions

A digital design coach

Testing the design coach.

\section{Table P.1. The problem of the window.}

The thesis presents a solution that is by no means the only answer but rather one elegant answer. The result is a digital design coach that, through sketching and in enriching the relationship between teacher and student, teaches the student about architecture that is habitable, sustainable and constructible. 


\section{Acknowledgements}

The writing of a thesis is often likened to a lonely struggle. While writing was a singular effort, its accomplishment however, could not have been achieved without the help of a few people.

First, my greatest gratitude to my supervisor David Kernohan, for pushing when I needed to be pushed, and waiting when patience was needed. By listening and giving advice, David has opened my eyes to research - asking questions, expressing ideas and being persistent in achieving goals.

Thanks to students of ARCH212 2000, Victoria University and students of the Caribbean School of Architecture for their help in the head and hand studios.

My appreciation to Vicki Lebowitz, Emina Petrovic, Amanda Bulman, and Amy Matthews for their help as subjects for the first set of hand and head experiments.

For help on the Design Coach, I'd like to thank my research assistants - Emma Christie and Janine Morris. For the development of the html pages I'd like to thank Raffe Smith and Thanh Nyugen

Thank you to students of ARCH211/2 2001 (especially Ben, Greta, Louise, David) for their help in testing the coach.

Thank you to staff at Victoria University, School of Architecture (especially Mike Donn and Henry Skates) for taking an interest in my work; Ellen Yi-Luen Do (Univ. of Washington) for her support and encouragement as a fellow researcher; and Emina Petrovic for sharing in the struggle with her own thesis and for being a rather pleasant office mate.

I want to express appreciation to my family and friends for their support and patience, especially my Mother for her help with proofreading and for teaching me the value of education.

These last 30 months of work on the thesis has coincided with one of the best periods of my life, thanks to the love, companionship and support of Fiona Balmforth. She has been an anchor in the darkest parts of the storm and I look forward to a fulfilling future with her by my side. 


\section{Abstract 3}

Preface 5

Acknowledgements 7

Table of Contents 9

List of Illustrations and Tables 13

\section{Introduction 1}

Aim 2

Three Domains 3

Research Methods used in this study 5

Significance of Study 11

The Thesis 12

A Design Coach 16

Finally 16

References 17

\section{Part 01 Architectural Education}

\section{Origins of the Challenges facing Architectural Education today 21}

Educating Architects - From Vitruvius to Alberti 25

Academia and Architecture Education 34

British Architectural Education 41

From the Bauhaus to Oxford 48

Education in the late Twentieth Century 56

Conclusion or the Room is Dark 60

References 63

\section{Challenges facing Architectural Education 67}

Challenges to lighting the room 68

Conclusion 82

References 84

\section{The Design Studio 87}

The Design Studio 88

Anatomy of the design studio 93

Conversations 103

Conclusion 104

References 106

4. Student and Master 109

The Master and the Student 111

Pedagogy 113 
Reciprocal reflection in action 116

Zone of Interaction 123

The Sketch as Context and Medium. 127

Conclusion 129

References 131

\section{Part 02 Sketching}

\section{Sketching 135}

Images and the Design Process 138

The Sketch 145

Conversations 146

The Sketch and the Student 150

Conclusion 153

References 156

\section{Heads and Hands 159}

Head and Hand Studio at Victoria University of Wellington 160

Head and Hand Workshop at Caribbean School of Architecture 165

Conclusions of the Head and Hand Studios 168

The Double H Experiment 168

Four Dimensions: a detailed analysis of a Double H protocol 180

Additional Double $\mathrm{H}$ Experiments 187

Observations 188

Conclusions 190

References 192

\section{Novice and Experts 195}

Novices and Experts 196

The Expert Hand in Design Education 200

Conclusion 204

References 206

\section{Part 03 Computers}

\section{Computers and Architectural Designing 209}

Computers: Architecture 211

CAAD, CAD or CADD? 214

A Concise History of Computers in Architecture 215

Current State of the field 229

A New Paradigm 232

Conclusion 235

References 237 


\section{Computers and Architectural Education 241}

Digital Technology and Architectural Education 242

A Teaching Tool 253

Conclusion 257

References 258

\section{Sketching in the Digital Realm [or Digital Sketching] 261}

Recognition Technology 262

A Short History of Digital Sketching 263

Relevant Research 269

A Design Partner 274

Conclusion 274

References 277

\section{Part 04 Towards a Design Coach}

\section{Defining a Digital Design Coach 281}

Behind the tool 283

Design Problems 286

Computer Assisted Learning Theories 293

Dealing with Learning Styles 298

Sketching 302

Conclusion 303

References 306

\section{Testing the Digital Design Coach 309}

Experiments 310

Preliminary test 311

Greta and Ben 316

David and Louise 317

Results from the exercise 319

The Revised Design Coach 323

The Coach in Design Studio 326

Student Reaction 329

Conclusion 335

References 337

\section{The Design Coach 339}

The Design Coach 340

Interface 342

Recognition 345

Content 346

Experience 349

Using the Coach 351

Conclusion 353 
References 355

\section{Conclusion 357}

Design Education 360

The Sketch 364

The Computer 365

The Design Coach 365

Conversations 367

Limitations of this Research 368

Future Directions 369

In the End 370

\section{Appendices 355}




\section{List of Illustrations and Tables}

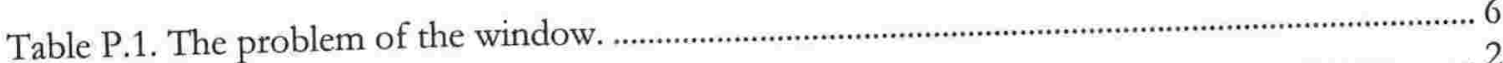

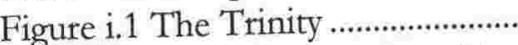

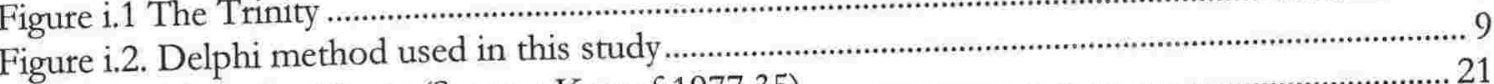

Figure 1.1. Early Architects (Source: Kostof 1977:35) .................................................................... 21

Figure 1.2. Vitruvius's classification of temples according to the arrangement of colonnades

Figure 1.3: Working on a mediæval site (Source: Harvey 1972:cover) ............................................. 27

Figure 1.4. The temporary structure that often made up the lodge seen in this image on the right.

The lodge was essentially a workshop made of timber and thatch where students learned the craft

of making buildings. (Source: Coldstream 2002).

Figure 1.5. Notebook from a master, 13th Century. The notebook was meant as an aid for the practitioner, teaching him techniques of carpentry and masonry and the art of drawing. Such pattern books recorded the accumulated knowledge of the lodge and the author's own experience. They were not meant to circulate beyond the closed circle of the trade. (Source: Kostof 1977:90)29 Figure 1.6. A building site in the fifteenth century (Source: Coldstream 2002) ............................... 30 Figure 1.7. A Roman mosaic showing Plato's Academy (Source: http://www-history.mcs.st-

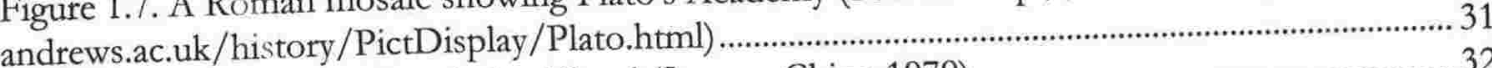

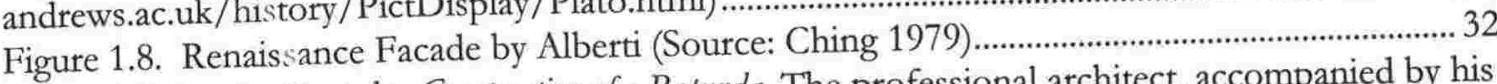
Figure 1.9. Jacopo Bertola, Construction of a Rotunda. The professional architect, accompanied by his scholarly advisors, presents his plans to the manual workers who will carry them out. (Source: Kostof 1977: 146).

Figure 1.10. Interior court of the Ecole des Beaux-Arts. The court contained plaster casts of Greek and Roman Sculpture for students to study. It also included part of the Parthenon restored.

Figure 1.11. An atelier at the turn of the century. (Source: Drexler 1977:91) .................................. 36 Figure 1.12. Student project at the Ecole des Beaux-Arts, 1891. On the left is the esquisses and on

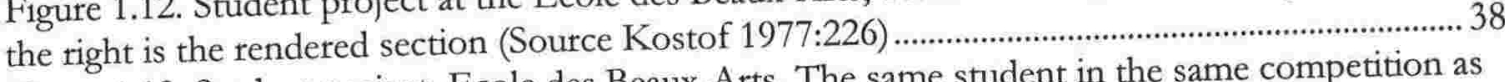
Figure 1.13. Student project, Ecole des Beaux-Arts. The same student in the same competition as figure 1.12 did this rendered section. Note the "white" area for the roof structure. (Source: Kostof

Figure 1.14. Scene from Martin Chuzzlewit (Source: Crinson and Lubbock 1994) ........................... 42 Table 1.1 Documentation of work done by a pupil in John Soane's office (Source: Jenkins 1961) 43 Figure 1.15. Crystal Palace, by Joseph Paxton, at London, England (then Sydenham), 1851, moved 1852, burnt 1936. Heralded at the time as high technology, the exhibition hall was built out of prefabricated and wrought iron elements. The 'ridge and furrow' roof glazing system was specially devised for the occasion. (Source: Great Buildings Online -

http://www.greatbuildings.com/buildings/Crystal_Palace.html.

Table 1.2. A Comparison between the British educational offering and that of the French. (Source:

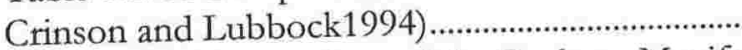

Figure 1.16. Frontispiece of the Bauhaus Manifesto (Source: Westphal 1991:7) .............................. 48

Figure 1.17. Bauhaus Metal Workshop (Source: Westphal 1991:83) ................................................ 50

Figure 1.18 Left: Space-Time Construction, Theo van Doesburg, 1923. Right: Gerrit Rietveld, Red

blue chair

(Sources: www.mtholyoke.edu/courses/mtdavis/243/destijl/doesburg.html;

http:/ /www.mtholyoke.edu/courses/mtdavis/243/destijl/index 5.html) ......................................5 51

Figure 2.0 EAAE Survey Results (Source: (EAAE \& CEMBUREAU 2001) .................................... 67 
Table 2.1 Comparing instruction with application.

Table 2.2. How is knowledge delivered in Architectural Education? The table shows the distribution between lecture courses and design studio at two schools of architecture (Source Victoria University of Wellington Prospectus 2002 \& Caribbean School of Architecture Prospectus 2001/03).

Figure 3.0 A Design Studio at Victoria University of Wellington.

Figure 3.1. Architecture students trying hard to meet a deadline in design studio. .......................... 89

Figure 3.2 Scene from Victoria University Studios - 2nd year and Final year ................................. 94

Figure 3.3. Students come from diverse backgrounds. (Source: Architectural Record, Aug

2002:84)

Figure 3.4. Beginning student design projects ranging from abstract issues of form and shape to

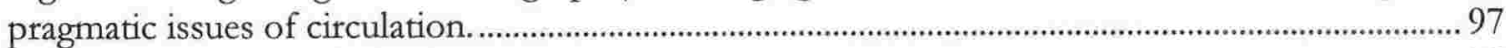

Figure 3.5. A typical desk crit............................................................................................................... 99

Figure 3.6. An group discussion comprising of students of one tutorial sub-group...................... 100

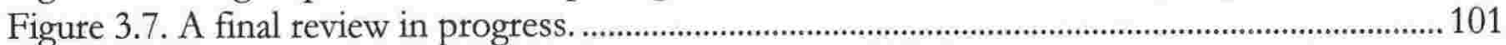

Figure 3.8. Students interact informally by working in close proximity......................................... 102

Figure 4.1. A desk crit in session

(source:http://online.caup.washington.edu/dmg/presentations/ecaade2000.brj/2.Traditional\%20

studios/3.Crits.html)

Figure 4.2. K. Anthony confirms the value of the desk crit by reporting that students feel they

learn most from informal discussions and desk crits with their instructors and least from final reviews, (Source: Anthony 1991)

Figure 4.3. A desk crit with two students (Source: http://www.forgemind.net/diary/2002/2002-

01/photo/diary-2002-01-photo-2002013103.JPG) ............................................................................... 112

Figure 4.4. Reciprocal reflection-in-action. Student on the left, tutor on the right.......................116

Figure 4.5. Petra's diagrams (Source: Schön 1985) ........................................................................ 118

Figure 4.6. Quist's Drawings (Source: Schön 1985) ……..............................................................119

Figure 4.7. The sites of antiquity provided context for the zone of interaction. ............................ 124

Figure 4.8 Today the zone of interaction exists outside of the reality of the building................... 124

Figure 5.1. Leonardo da Vinci, study sketches for a new Palazzo Medici in Florence, c. 1515..... 135

Source: http://www.lboro.ac.uk/departments/ac/tracey/somag/gabi.html] ...............................135

Figure 5.2. There is nothing as simple, loose and disposable as a traditional hand sketch............. 137

Figure 5.3. Mies van der Rohe sketching (Source: www.designboom.com/portrait $/ \mathrm{mies} / \mathrm{bg}$.html)

Figure 5.4 Design sketch of Tugenhadt House by Mies van der Rohe........................................ 138 Figure 5.5. Three images of Foster's bank in Hong Kong illustrating the levels of image "sharing" - the private schematic, the drawing for the client and the building for the public. (Source: www.greatbuildings.com)

Figure 5.6 Example of a referral drawing. A House in Georgetown, Guyana. (Source: Patrick Forbes)

Figure 5.7 Part of the London Underground Map - a diagram (Source: www.thetube.com) ....... 143

Figure 5.8 Presentation Drawing, Modern Art Museum, Tadao Ando (Source:

www.arcspace.com/architects/ando/modern_art_museum/test.htm

Figure 5.9. A design study drawing.

Figure 5.10 Thomas Mayne, Sixth Street Residence, Ocean Park, California, screenprint after composite drawing, 1988 (source www.wesleyan.edu/dac/ exhb/past/2001d.html)

Figure 5.11. Sketching

Figure 5.12. Having a design conversation. 1) Seeing the image with the eye. 2) Creating an image in the mind. 3) Generating a modified condition. 4) Drawing in relation to the modified vision 
with the hand. Number five (not shown) would be the action of "seeing" the modified image and

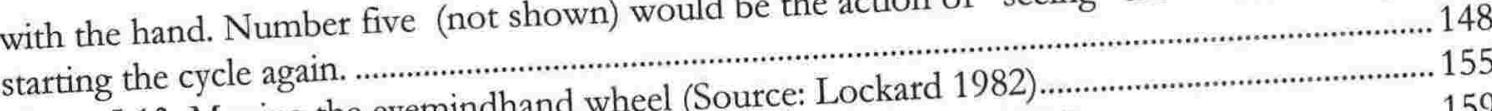

Figure 5.13. Moving the eyemindhand wheel (Source: Lockard 1982) .........................159

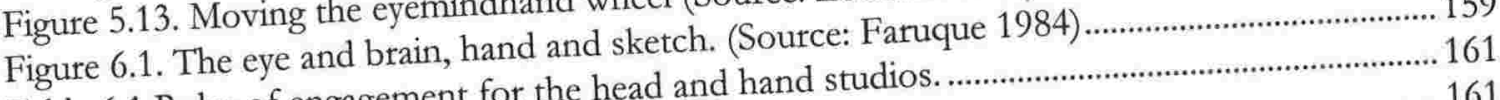

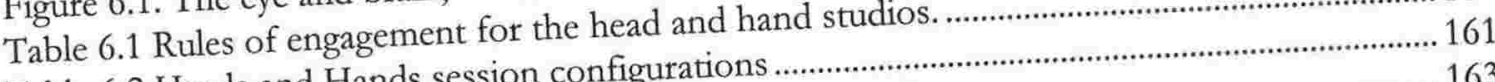

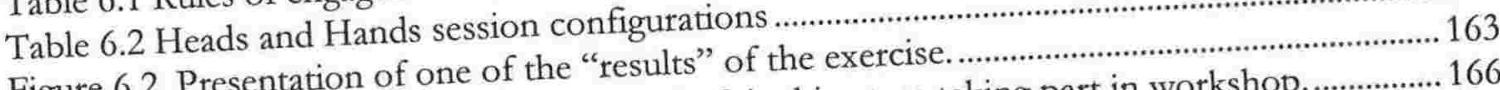

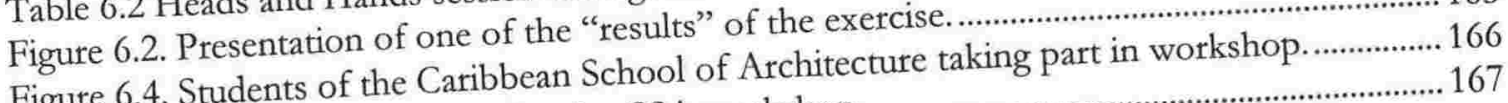

Figure 6.4. Students of the Caribbean School of Architecture taking part in workshop...........167

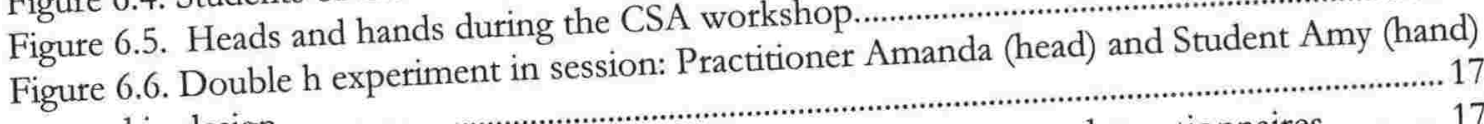

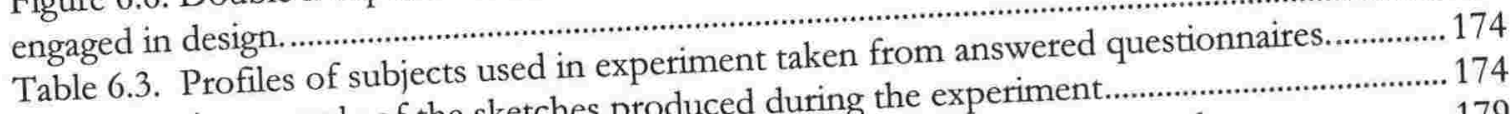

Figure 6.7. An example of the sketches produced during the experiment......................................174

Table 6.4 Transcript excerpt from design session 1. $\mathrm{M}=\mathrm{Head}$ and $\mathrm{H}=\mathrm{Hand}$...........................179

Table 6.5 Design Domains (Source: terms - Schön 1985, exa double h sessions .............................. 188

Figure 6.8. Keith (the practitioner) with Steven and Ellen in double h sessions ....

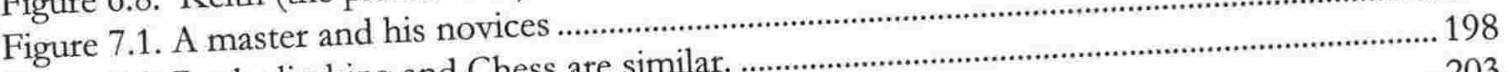

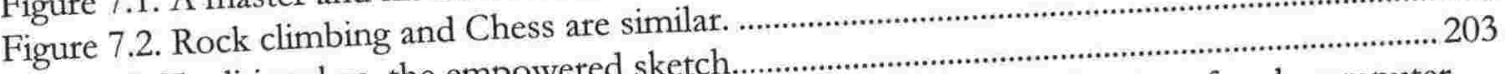

Table 7.1. Traditional vs. the empowered sketch..........................

Figure 8.1 The ENIAC of faster and powerful than the ENIAC a machine several times larger

Figure 8.2 This image attempts to explain the use of the computer to generate forms through

algorithms. Nodes within a field interact with each other as the computer calculates conditions of

balance between the nodes. A state of equilibrium is achieved as the nodes (rooms) combine into a

single surface incorporating the entire program. (Source: Pontgratz and Perbellini 2000) ............211

Figure 8.3 From left: The Guggenheim Museum in Bilbao, Toyo Ito's Mediatheque exterior and

interior of information floor. (Source: Chollet 2001 and Barrie 2001) ........................................... 212

Figure 8.4. The intelligent house. (Source: unknown).................................
Figure 8.5. The Virtual and Physical Floors of the NYSE (Source: (online -

www.architect.org/features/nysecc/nysecc3.html and

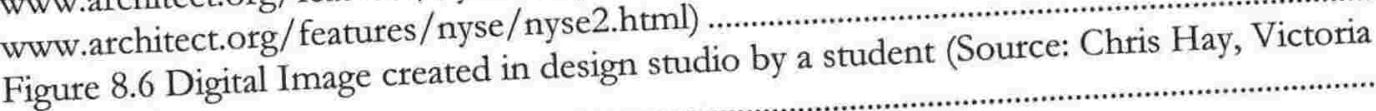

University)

Figure 8.7 A similar system to Sketchpad (Fallon 1997).

Figure 8.8 The Architecture Machine (Source:

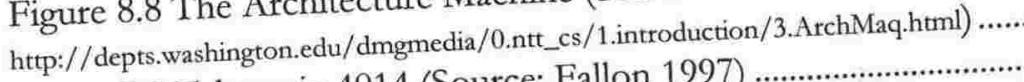

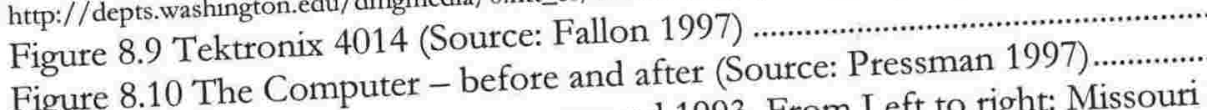

Figure 8.10 The Computer - before and after (Source: Pressman 1997) .................................

Figure 9.1 Students and computers an, Texas A \& M University, University of Oregon, University of

New Jersey Institute of Technology,

South California. (Source: Architecture Sept Architecture, Victoria University of Wellington........... 243

Figure 9.2 Computer lab at the School of Architecture, Victor (Source: Chris Hay, Victoria
Figure 9.3 Digital Image created in design studio by a student (S...244

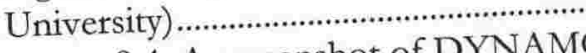

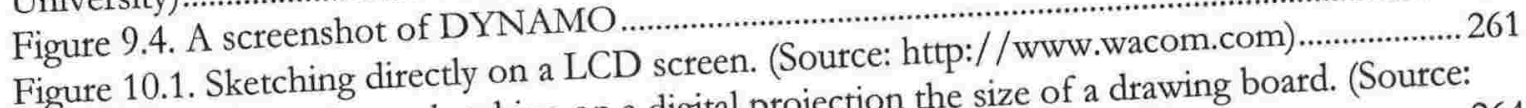

Figure 10.2. The designer sketching on a digital projection the size of a drawing board. (Source:

http://www.lema.ulg.ac.be/) ......................................................................................................2. 264

Figure 10.3 Photo of HUNCH in use (Source: Taggart 1975) 
Figure 10.4 The Wacom Cintiq LCD tablet allows the designer to draw directly on screen. (Source:

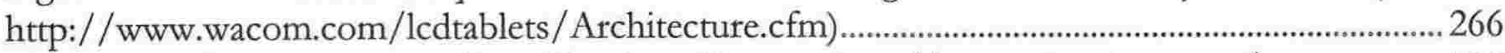

Figure 10.5. A screen capture from Sketchup (Source: http://www.sketchup.com/)................... 268

Figure 10.6. The Electronic Cocktail Napkin drawing board ............................................................ 271

Figure 10.7. The Right Tool Right Time manager - The symbols and the tools they activate clockwise from left: (1) 3D modelling, (2) Case libraries, (3) Sketch book, (4) Visual Analysis, (5)

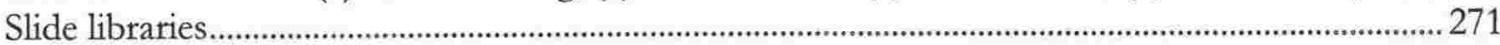

(Source: http://depts.washington.edu/dmgmedia/0.intuitive/3.sketch/02RTRT.html) .................................................. 271

Figure 10.8 EsQUIsE developed by Pierre Leclercq. Clockwise from left: 1 - Capture, 2 -

Synthesis, 3 - Topologies, 4 - Analysis, 5 - 3D modelling. (Source:

http://www.lema.ulg.ac.be/Tools/Esquise/Esquise-Home.html) ................................................2.273

Figure 11.1. Opening screen for design coach prototype................................................................ 281

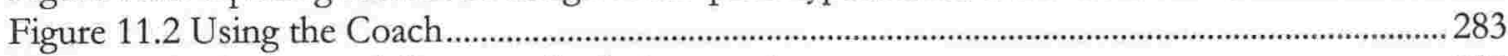

Figure 11.3. Conceptual diagram of a design coach............................................................................2 284

Figure 11.4 Some of the complex array of issues concerning windows. (Source: Lawson 1997).. 289 Figure 11.5 Decomposition of issues related to the design of an Indian village (Source: Alexander

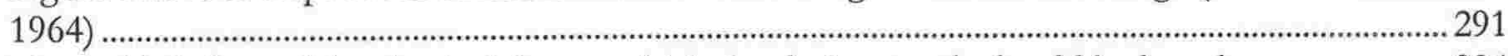

Figure 11.6. Consolidated principles on which the design coach should be based. ....................... 304

Figure 12.1 Starting matrix for design coach ....................................................................................309

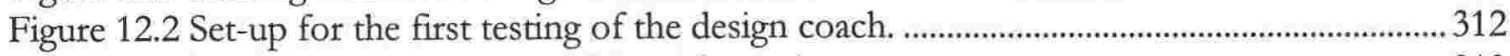

Figure 12.3 The interconnectedness of the information. ...................................................................313

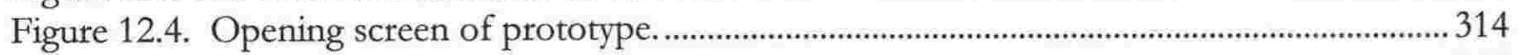

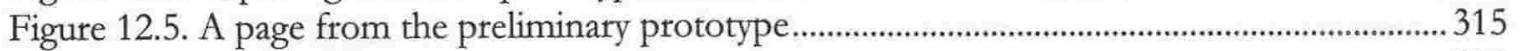

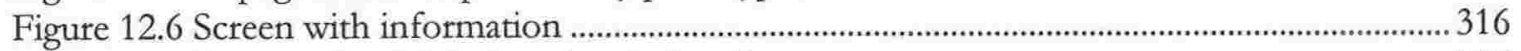

Figure 12.7 Ben (on the right) directing the hand......................................................................... 317

Figure 12.8 Louise sketching with the researcher observing. Note drawing covering screen........319

Figure 12.9 A detailed graphic (left) and a more general graphic (right) from the prototype........ 321

Figure 12.10 Examples of graphic information and text based information.................................... 324

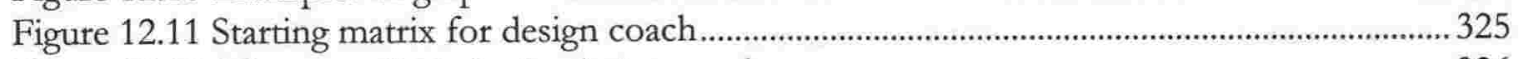

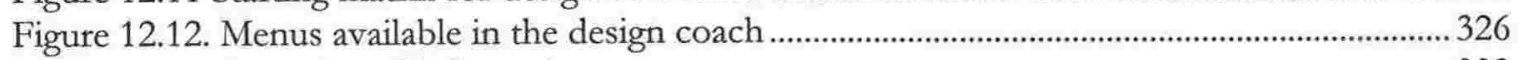

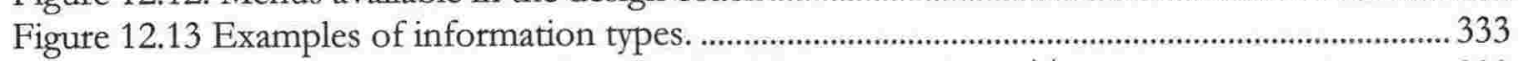

Figure 13.1. Digital Design Coach. (Source of original image: http://www.wacom.com) ............ 339

Figure 13.2. Parts of the design coach.................................................................................................. 341

Figure 13.3. Interface with the coach should be like having a conversation. ....................................342

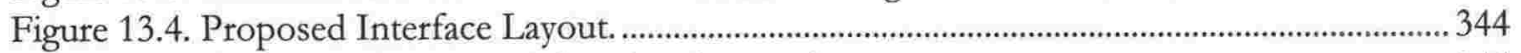

Figure 13.5. Sequence of events while using the coach. ................................................................... 345

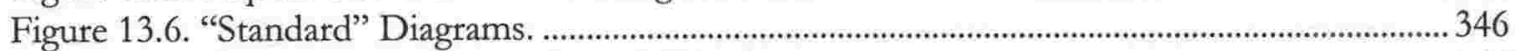

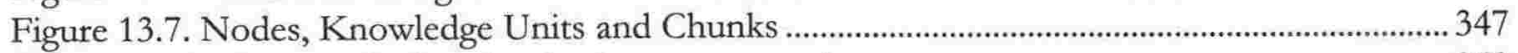

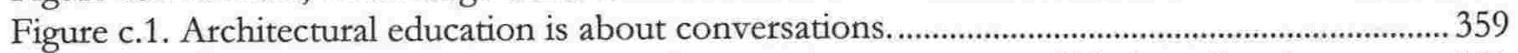

Figure c.2. The teacher student dialogue is the most important part of design education..............361

Figure c.3. The master in the struggle to balance theory and practice.............................................. 362

Figure c.4.The sites of antiquity (A) provided a context for the zone of interaction while today, (B)

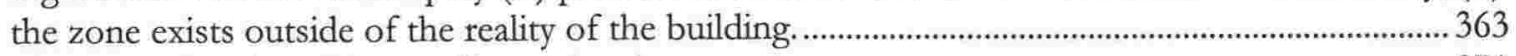

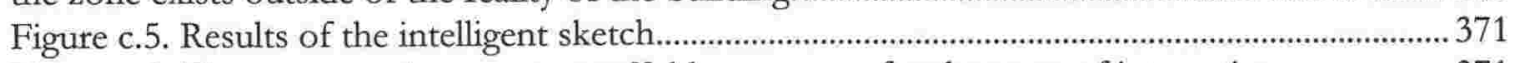

Figure c.6. The computer becomes a scaffold or support for the zone of interaction. .................. 371 
Introduction 


\section{Introduction}

$54 \%$ of respondents who had at least started taking the ARE [Architectural Registration Exam] said that their education did not prepare them well for the exam... (2003 Internship \& Career Survey).

rchitecture today is an increasingly complex affair. In
addition to new social and cultural norms, architects are
inundated with constantly changing information regarding new materials, sustainable processes and complex building types. This inundation is made arduous with the current trends of sustainability bolstered by eco-friendly legislation, standards and codes. As a result, schools of architecture are under pressure from the profession and society to provide graduates of architecture with the requisite skills that characterise good design thinking strategies as well as promote responsible design. Welldocumented reports commissioned by the professional bodies over the last few years also indicate a growing divide between the worlds of architectural education and practice. Schools of architecture, especially in the last decade, have been accused of not doing enough to educate the student about the needs of building users today. Practitioners claim among other things, recent graduates are technically incompetent, lack a sensibility to the real world of architectural practice and are a burden to train.

This situation has dire consequences for the practice of architecture and the architect's position in the building industry. Due to a lack of familiarity with the information required for building, architects are slowly relinquishing control of the building process. They are no longer seen as the building team leaders and, due to the proliferation of project managers, are sometimes viewed as "design consultants". Not only is the profession regarded in a bad light by the industry but also the perception of the public about architects and architecture is also seemingly negative. Architects are often perceived as arrogant and aloof without empathy for the plight of the building user. Not being 
adequately informed about how buildings work denies the young architects the opportunity to build and win the trust of a truly sustainable community.

To avert the gradual decline of the profession there must be a concerted effort to effect a revitalisation in architectural education. By aligning it with the demands of a post twentieth century society there is ample opportunity to redress some of the professional and societal perceptions of architectural education and architecture.

\section{Aim}

Redressing this situation is the overarching aim of this thesis. The intention is to search for and provide a means through which students may be helped to produce more effectively, culturally and socially significant architecture that is fit for purpose, cost effective, environmentally friendly and pleasing to both client and user. In other words, the provision of an architecture that works. The end result as proposed by this thesis is the implementation of a teaching and learning tool that combines three domains: the design studio, the act of sketching and the computer.

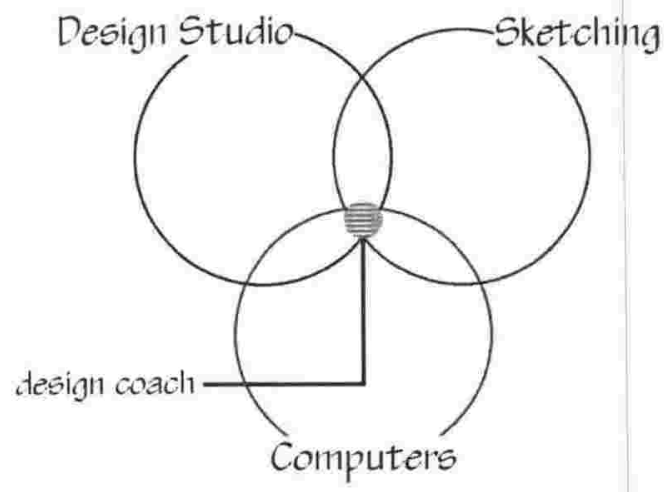

Figure i.1 The Trinity 


\section{Three Domains}

\section{Design Studio}

A thousand years ago, Vitruvius determined that architecture is co-dependent on theory and practice (Rowland and Howe 1999). Architectural design is therefore best learnt by applying acquired knowledge (theory) to the task at hand (practice). The main instrument for the dissemination of design knowledge in this way is the design studio. In a situation that closely echoes the apprentice/master model of antiquity, students learn design by working through series of design problems with close interaction with the studio master.

This model, however, has evolved from the practice oriented realtime training of apprentices in the past, to its existence within an architectural education embedded in academia. In the past the student learned the craft in the time and space of actual building sites, but today studios are places where theoretical notions about architecture are considered without being adequately grounded in the reality of how architecture works or is used. Despite this the studio remains the most desirable means of teaching architectural students. Any attempt to introduce effective tools and methods in design education that can address the current situation should therefore exist within the design studio.

\section{Sketching}

Architects solve problems by thinking visually. This activity where images are used as fundamental objects for decision making has been called graphical thinking, design drawing or simply sketching ${ }^{1}$. It can also be defined as the reflective conversation

\footnotetext{
"Decision making in design not only employs the use of "pen and paper" but can also take the form of quick scale model constructs to visualise in a predominantly three dimensional way. The emphasis of the thesis, however, is on the kinds of sketching seen in the works of Da Vinci, Corbusier, Kahn and others and is seen as an integral part of the tradition of architectural design. The plicate the simplicity discussed could be extended to physical or digita
and clarity of the ideas proposed in the thesis.
} 
with images and ideas conveyed by the act of drawing and making. Most design decisions are generally based on the ability of designers to take advantage of sketching and use the "conversation" as an aid to their powers of visualisation. When sketching, the designer understands an idea by putting it down on paper "to see if it works". It is the medium through which design is realised. It is also the one of the means through which students and tutors communicate in design studio. The design expert sees more design issues in the sketch than the student. The sketch however allows the easiest means of exposing students to design issues by application. It will be argued that any intervention in design studio therefore should include the sketch as part of the solution.

\section{The Computer}

The computer - the ubiquitous technology of the late twentieth century - has in recent years significantly redefined the product and process of architecture. Both practice and architectural education have been affected by the dominance of computing. The classroom, design studio and curriculum of schools of architecture are now overwhelmed with digital technology. The computer, however, is extensively used for representation, communication and the generation of form. Nevertheless, despite the innovative and imaginative deployment of design computing, the teaching of architectural design has been affected little and proceeds much as it has done before computers were introduced into design schools.

There is great potential in using the computer as a teaching tool. Technology's dominance ensures its presence in any effort to significantly enhance how architecture is taught and understood. In order to take advantage of the computer's potential however there needs to be a change in attitude in education's approach to the tool. 


\section{Integrating the domains}

These three domains - design studio, computers and sketching form the nucleus of this thesis. By examining them separately and in combination, it will be demonstrated that, by integrating the strengths of sketching and computing, there is a viable opportunity to provide in the design studio a more balanced group of skills. In this way we can influence architectural students towards a more responsible attitude to design. Architectural practice also stands to benefit from this alternative as it opens up opportunities for continuing education, assistance in specialised fields and keeping abreast of technical knowledge.

\section{Research Methods used in this study}

Research is not simply searching for information, but also making good use of what is found, so it can lead to discovery (Orna \& Stevens, 1995).

This thesis is an exercise in qualitative research and utilises a number of inquiry tools to develop a grounded theory. Qualitative research, in this case, is defined, as "any kind of research that produces findings not arrived at by any means of statistical procedures or other means of quantification" (Strauss and Corbin 1990). There are different approaches to qualitative research; three of the most common ones in architectural research are grounded theory, ethnography, and interpretivism (Groat and Wang 2002). Grounded theory was used as the main strategic approach taken by this research.

\section{Grounded Theory}

Grounded theory, as defined by Groat and Wang (2002), is a strategic approach to qualitative research where the "researcher seeks to enter a setting without preset opinions or notions, lets the goings-on of the setting determine the data, and then lets a theory emerge from the data. Once the theory is proposed, other similar settings can be studied to see if the emergent theory has 
explanatory power" (Groat and Wang 2002). In other words the research is undertaken without a preconceived theory or a hypothesis per se and, similar to the design process, allows a theory or understanding to emerge from the data. This subsequently determines the direction of and ensuing actions in the study.

The grounded theory methodology is associated with sociologists Barney Glaser and Anselm Strauss (Groat and Wang 2002). Strauss describes the approach as "the development of theory, without any particular commitment to specific kinds of data, lines of research, or theoretical interests" (cited in (Groat and Wang 2002)). Because grounded theories are drawn from theories they "are likely to offer insight, enhance understanding, and provide a meaningful guide to action" (Groat and Wang 2002). An important feature of this approach is the use of an intensive, open-ended, and iterative process that involves at the same time:

- Data collection

- Coding or data analysis

- Memoing or theory building

(Groat and Wang 2002)

Grounded theory involves the movement back and forth between these three activities before a theory can emerge.

The current study was an open ended, iterative process of discovery similar to how designers design. Like design, the work evolved as a series of moves in which an idea was questioned, tested and confirmed subsequently informing and directing the next move or idea. Also, like design; it was neither wholly ad hoc nor haphazard and involved a selection of techniques and tools based on a general idea or direction for the research. 


\section{Evolution}

Increasingly architectural researchers have been advocating for a more integrative approach to research (where multiple methods are incorporated in one study) (Groat and Wang 2002). This work is a continuation of that trend. The study started as an investigation into the absence of computers at the front end of the design process and emerged proposing a possible aid for use in the teaching of design. It used various research instruments for analysis and testing. It then used the resulting information to advance and direct the research. Therefore, with the use of various primary information gathering techniques, the work evolved in the following steps:

1. An inquiry (using the delphi method) into the use of computers in architecture from the view point of students, educators and practitioners;

2. As a response to the findings, a special protocol analysis was designed to determine the kinds of information exchanged in the conversations designers engage in with the sketch. This was used in two situations. One situation was a design studio (for a larger sample) and it was determined that it was also a good way of encouraging students to explicitly express design ideas and moves. Two design studios in two different countries were used. The second situation involved a student and a practitioner;

3. Then, the data gathered through questionnaires and observations was examined, compared, and analysed;

4. Out of this, a prototype of a design coach was designed and tested in an experimental situation using the protocol analysis technique designed earlier;

5. Finally, the prototype was upgraded for wider use and tested in an actual design studio. 


\section{Secondary Information Sources}

Throughout the research, secondary information sources (literature review) were used to inform the process and align the grounded theories with established works. This included sources on the history and use of computers in architecture (Negroponte 1975; McCullough 1996; Fallon 1997), on sketching (Laseau 1989; Lockard 1982; Herbert 1993, Goldschmidt 1991), digital sketching (Gross 1996; Do and Gross 2001), design methods (Alexander 1964; Archer 1979), design thinking (Rowe 1987; Lawson 1997), history and theories in architectural education (Crinson and Lubbock 1994; Kostof 1977; Chafee 1977). Of note was an excellent resource in design teaching methodology - The Design Studio by Donald Schön (1983) - that, even though dated, provided the framework that focused the research. In addition to books and monographs other information sources tended to be periodicals (especially Design Studies and the Journal of Arcbitectural Education) and conference proceedings generated by the CAADRIA, ECAADE, ACADIA and CAAD Futures organisations. Secondary sources were also consulted for the definition of the appropriate research methods, as a background for understanding results.

\section{Primary Information Sources}

Primary information sources were diverse and incorporated several different forms of inquiry and in some cases integrated and transformed existing forms. Tools of discovery included:

- Aspects of the delphi method for arriving at a consensus.

- A special protocol analysis in a quasi-experimental setting.

- Informal interviews and paper based questionnaires.

The method of obtaining users opinions and attitudes towards technology used in this work was a truncated version of the 
Delphi method. Olaf Helmer and Norman Dalkey of the Rand Corporation first developed the Delphi Method during the 1960s. Although it was originally developed for technological forecasting, it is now used in several fields ranging from business and education to science and medicine.

The goal of the Delphi method is to arrive at a group consensus about an issue under investigation through the exchange of information and ideas. This is done by giving each participant an equal opportunity to voice opinions whilst preventing bias due to position, status or dominant personalities, as is characteristic of group dynamics. The method is usually conducted asynchronously by transmitting a series of questionnaires either by mail or online, to a pre-selected group of experts or individuals whose opinions or judgments are of interest.

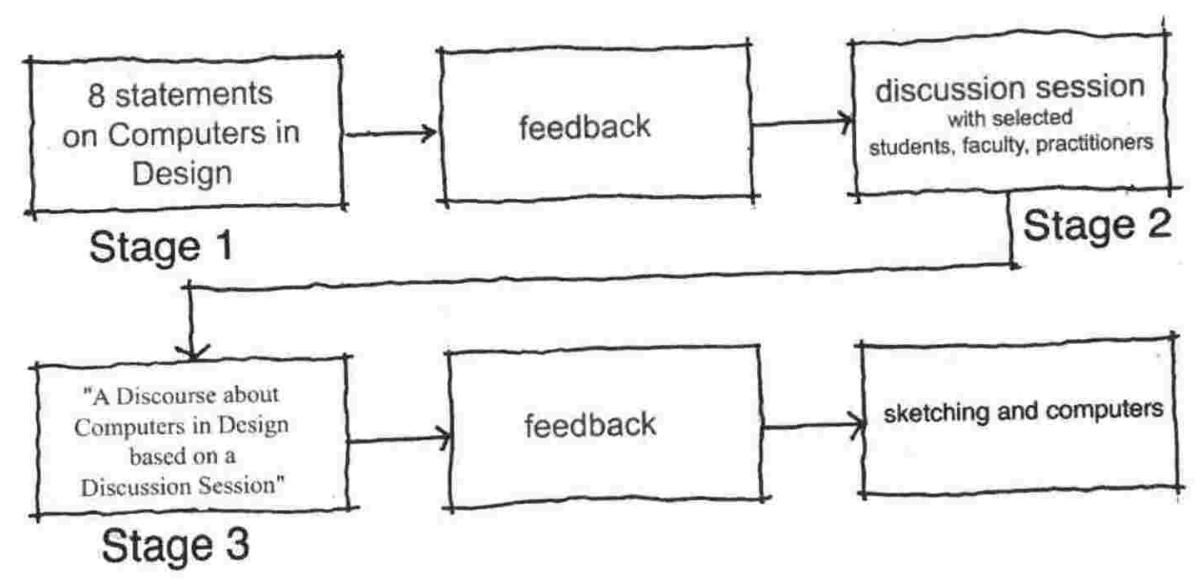

Figure i.2. Delphi method used in this study

Due to time constraints, it was thought that the Delphi method was ideal for this research because it could provide an immediate consensus on the issues surrounding computers in architecture. The variation of the Delphi method used by this study therefore comprised of three stages (enough to get a "feel" of the subject matter for further investigation). 
The original quest was to find what were the issues involved in using computers in architecture. Provocative statements were distributed to practitioners and students.

The first stage involved sending questionnaires in the form of eight provocative statements to leading architectural practitioners in the city, faculty members of the Victoria University of Wellington School of Architecture, and students from the Computers in Architecture course at the school. Responses to the statements were interesting and comprised of diverse answers. From these, a small representative section of the practitioners, members of faculty (with extensive practical experience) and the students, who took part earlier, were selected and invited to a discussion session. This session (stage 2) sought to clarify issues, as well as expand on items, that arose in the stage one. The final stage involved sending a report of the discussion session to the participants and soliciting feedback.

Protocol analysis used in the field of psychology, has been used extensively by design researchers (starting in the early 70s) as a method to elicit information about design thinking. Protocol analysis was chosen in this research because of its ability to examine closely designers' activity. Based on the presupposition that sketching can be seen as the meeting of the "hand" and "head" to achieve a design solution, a unique protocol analysis experiment (termed Double $\mathrm{H}$ ) that put human subjects in both these roles was developed for this work. One subject plays the role of the "hand" while the other is the "head"- the two elements that are involved in the design "conversation" called sketching. By breaking down and considering sketching in this way, this variation of classical protocol analysis could (it was postulated) discover how "intelligent" the hand should be to enhance design by reflection. This experiment was repeated on several occasions; in some cases with large amounts of subjects. 
In addition to these two forms of gathering data, questionnaires with both multiple-choice and open questions were used throughout to assess students' reactions, attitudes and beliefs.

Due to time constraints, it was impossible to assess other factors, such as influences on studio work in the long term. It must also be acknowledged that the study can only be used to indicate the reaction of one set of architecture students educated in New Zealand. It considered and selected a limited number of individuals from among a small population of architecture students and practitioners as opposed to random selection from a large diverse population. The display of the questionnaire results in charts, therefore, should not be interpreted as a strategy to generalise the findings, but rather as a visual, easy-to-understand format for justifying the conclusions, whose external validity limitations are acknowledged. In the future this study can be carried out with other students in another culture or geographical location.

\section{Significance of Study}

The education of the architect has not changed significantly since Vitruvius wrote about it in his ten books on architecture. While it has moved from the building sites of antiquity into academia, it has maintained an apprenticeship model that has come up short in recent years. There has been criticism from the public, profession and governments and allegations that the current model of architectural education are not providing students with the requisite skills sought by potential employers. Schools have been accused of producing graduates that lack adequate preparation for the demanding world of practice.

The challenge appears to be the provision of an innovative and effective way of facilitating a suitable balance between the learning of design and practical issues. The context for this 
particular challenge are the current situation in architectural education and the advances in technology available today.

The significance of the study exists linking ideas about learning by sketching, digital sketch recognition, and computer based education we can influence the capabilities of architectural students towards a more responsible consideration of design. Architectural practice also stands to benefit from this demonstration as it opens up opportunities for continuing education, assistance on specialised fields and also as checklists. An instance of this is shown that the computer when used in conjunction with the sketch can transform how design is taught in schools of architecture and by extension how practice can best benefit from an interactive design aid.

In the end this research is about providing students and tutors with quality conversations about architecture.

\section{The Thesis}

This dissertation is broken into 4 parts; each part is further divided into chapters.

\section{Part One}

Architectural Education - exposes the misalignment between teaching and practice. This misalignment, brought on by the immersion of studio in academia, is discussed against the background of the development of design studio. After tracing the origins of the modern design studio and stating the challenges that exist, the composition of the studio is next analysed to reveal that any intervention in the studio has to be established within the context of the student/master dialogue. It should be noted that the word master is used throughout this thesis to mean both male and female studio teachers. The word is used to create a closer connection to the medieval masters who tutored their apprentices or students. 
The thread of argument for this part is as follows:

1. A critical examination of design education and its disconnection to practice.

2. A critical examination of design studio as a vital component of education.

3. An examination of the master/student relationship as a critical part of learning about architecture.

\section{Part Two}

Having determined the importance of the relationship between tutor and student, the medium of design and interaction is next examined. The sketch, the central element in design, is examined through literature before empirical studies of the relationship between head and hand are carried out.

Supported by empirical work using experts and novices, and analysing interactions between Quist and Petra (Schön's examples in his book Design Studio), we establish the interaction between "expert" and "novice" revealing that there are basic fundamentals that are told to students that could be obtained in reference books if they knew that they could find them there. Second is the determination of what these basic fundamentals or competencies are using empirical evidence gathered from protocol analysis and a unique experiment called "double h" (Heads and Hands). What skills are needed to be a designer? How do designers separate what is in the head from what is in the heart. There are some fundamentals that transcend time and place, for example the need for natural light. These make up the factual context that determines architecture. Fundamentals include environmental factors and physical factors (vertical movement). This empirical work leads towards a design coach that teaches students of architecture basic competencies needed for creative leaps and includes interviews, protocol analysis and discussions. 
Steps in this part include:

1. Establishing sketching as the medium for design.

2. Reporting on empirical studies that involve master and student.

3. Identifying the relationship between novice and expert, and aspects in the tutor/student interaction that can be enhanced by the empowered sketch.

\section{Part Three}

In part three, the role of the computer in architectural practice and education is critiqued. The first traces early work in the field of architectural computing from Ivan Sutherland's thesis on computer graphics to current studies in photo-realism and genetic form modelling. This examination presents a clear picture of the changing influence of technology on architecture. It also suggests the development of a new paradigm for man-machine interaction. The next chapter then shifts attention from the general to the specific. It concentrates on architectural education with a specific aim. The main purpose is to establish the fact that schools of architecture largely consider the computer as a form of media or tool, for which students need to develop a proficiency for utilisation in practice. The use of computers in schools should (it is suggested) take a much larger role in helping tutors educate students.

The steps for this part will be thus:

1. Examine the use of computers in architectural practice and education. Demonstrate that despite innovation in the use of computer, how design is approached has remained essentially the same.

2. Demonstrate that the computer is undervalued as a tool to teach design and show the need for computer-aided teaching in architecture. 
3. Reveal current technology in sketch recognition that automates the process.

\section{Part Four}

Part Four will discuss the nature of a digital design tool. The first chapter sets about defining the principles and assumptions that would govern the tool. We will define and reveal the structure of the tool. The next chapter will present empirical evidence of the information component of the tool in use. Finally students (and tutors) are provided with a learning tool that helps beginning students grasp the idiosyncrasies associated with bringing diverse and often conflicting concepts together. The student's handle on these issues allow for a much more liberated dialogue between teacher and student. The steps in Part four are:

1. Define the concepts behind the design coach.

2. Show empirical evidence of the tool in action.

3. Speculate on the "final" form of the design coach.

\section{Conclusion}

Finally, the conclusion to this work will discuss the potential role such a tool can take in education and practice (as an aid for new building types) and how education will be transformed by the tool. It will discuss limitations and advantages, placing a high value on the tool and will define where it will fit in education and practice. The tool also has the potential for use in practice possibly in the continuing education of practitioners. Some preliminary conclusions will be drawn, as well as a preview of possible future consequences and the suggestion of further work in the area. 


\section{A Design Coach}

This thesis takes the view that the current flux of information in education and practice demands the use of technology as a close partner in the design learning process. This work, as described before, is an iterative cycle of observation, analysis, and discovery; an activity not unlike the design process. The design coach proposed at the end of the study, like the products of design, is simply a possible solution to an existing situation. The circumstances being, a discernable lack of awareness of architectural graduates to the issues that contribute to an architecture that works. Also, like design, it is indeed possible that this solution can be implemented (with some adjustment) in a different context. In this case, it can be used to facilitate the continued education of the architect in a modern society, where information shifts and changes. By enhancing and enriching the zone of interaction we can effectively improve on the studentteacher dialogue allowing higher quality learning and a greater response to the challenges of education.

\section{Finally}

The two concepts that underpin this thesis are hence:

1. If architecture students are to appreciate and produce architecture that is habitable, functional, cost effective, sustainable, environmentally friendly, meaningful and a delight to clients and users then the conversations that occur in the zone of interaction between student and teacher must be supported and enhanced.

2. The sketch, which exists at the centre of the zone, when empowered by digital technology can help to accomplish this. 


\section{References}

Alexander, Christopher. 1964. Notes on the Synthesis of Form. Cambridge: Harvard University Press.

Archer, L. Bruce. 1979. Whatever Became of Design Methodology? Design Studies 1, no. 1: 17-18.

Chafee, Richard. 1977. The teaching of architecture at the Ecole des Beaux-Arts. In The architecture of the Ecole des Beaux-Arts, edited by Arthur Drexler, 61. Cambridge, MA: MIT Press.

Crinson, M., and J. Lubbock. 1994. Architecture: Art or Profession? Manchester: Manchester University Press.

Do, Ellen Yi-Luen, and Mark D. Gross. 2001. Thinking with Diagrams in Architectural Design. Artificial Intelligence Review 15, no. 1/2 (Mar): 135-49.

Fallon, Kristine K. 1997. The AEC Technology Survival Guide: managing today's information practice. New York: John Wiley \& Sons Inc.

Goldschmidt, Gabriela. 1991. The Dialectics of Sketching. Creative Research Journal 4, no. 2: 123-43.

Groat, Linda, and David Wang. 2002. Architectural Research Methods. New York: John Wiley \& Sons Inc.

Gross, Mark D. 1996. The Electronic Cocktail Napkin - computer support for working with diagrams. Design Studies 17, no. 1: 53-70.

Herbert, Daniel M. 1993. Architectural Study Drawings. New York: Van Nostrand Reinhold.

Kostof, Spiro, ed. 1977. The Architect: Chapters in the bistory of the Profession. New York: Oxford University Press.

Laseau, Paul. 1989. Graphic Thinking for Arcbitects and Designers. 2nd ed. New York: Van Nostrand Reinhold Company Inc.

Lawson, Bryan. 1997. How Designers Think: The Design Process Demystified. Third ed. Oxford: Architectural Press.

Lockard, William K. 1982. Design Drawing. Tucson, AZ: Pepper Publishing.

McCullough, Malcolm. 1996. Abstracting Craft: the practiced digital hand. Cambridge Massachusetts: MIT Press.

Negroponte, N., ed. 1975. Reflections on Computer Aids to Design and Architecture. London: Mason/Charter Publishers, Inc.

Rowe, Peter G. 1987. Design Tbinking. Cambridge, Mass.: MIT Press. 
Rowland, Ingrid D., and Thomas N. Howe, eds. \& trans. 1999. Vitruvius: Ten Books on Architecture. Cambridge: Cambridge University Press.

Schön, Donald A. 1985. The Design Studio: An exploration of its traditions and potential. London: RIBA Publications Ltd.

Strauss, Anselm, and Juliet Corbin. 1990. Basics of Qualitative Research: Grounded theory procedures and techniques. Newbury Park, CA.: Sage Publications.

Turoff, Murray. 1998. "Delphi Method." 14 Nov 1998. [cited 1 April 2005]. Available from <http://pespmc1.vub.ac.be/asc/Delphi_metho.html>.

Unknown Author. "The Delphi Method." [cited 1 April 2005]. Available from <http://www.iit.edu/ it/delphi.html>. 
Part 01 Architectural Education 


\section{Origins of the Challenges facing Architectural Education today} "We are operating a 1900-year-old education program directed toward delivery of a 500 -
year-old model architect as we head into the $21^{\text {st }}$ century" (Professor Gregory Palermo
cited in Boyer \& Mitgang 1996:13)

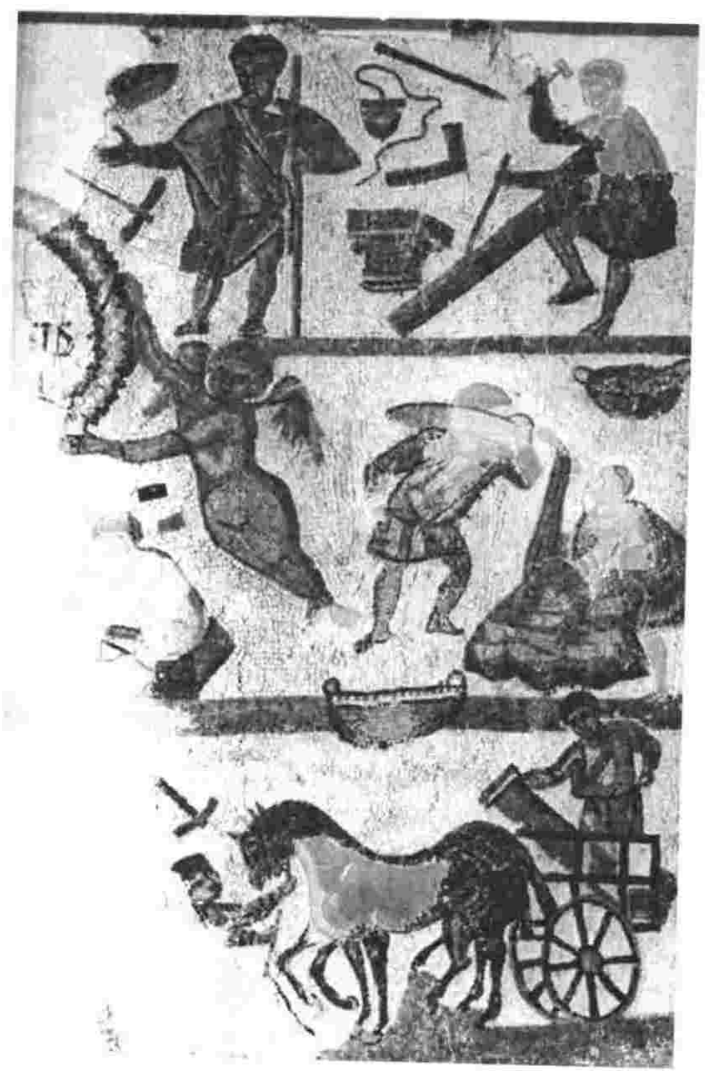

Figure 1.1. Early Architects (Source: Kostof 1977:35)

rchitecture is one of the oldest professions that exists in contemporary
society. It has accumulated knowledge and traditions (like other
professions of similar age) that can be traced back thousands of years. For instance: the three "characteristics" of architecture (utilitas, firmitas, venustas") as proposed by the Roman architect Vitruvius two thousand years ago, are still referred to in schools of architecture around the world. As in other professions, these traditions and principles are transferred from one generation to another through a rigorous system of education, internship and initiation that takes

\footnotetext{
${ }^{2}$ Translated - utility, firmness and delight
} 
several years before the fledgling professional is deemed fit to be a part of the profession.

The education of the architect has changed significantly since Vitruvius described it in Decem libri de Architectura (Ten Books on Architecture) (Rowland and Howe 1999). Since then the "young" professional's training has evolved from the building sites of antiquity - where the student was exposed to the nuances of architecture by actually doing it - through the Middle Ages, the humanism of the Renaissance, the academies of the $18^{\text {th }}$ and $19^{\text {th }}$ centuries, articled pupillage and the Modernist ideals of the $20^{\text {th }}$ century, to digital studios. Today, schools of architecture, located in universities, continue the transfer of knowledge, tradition and praxis in the profession ${ }^{3}$.

This evolution, however, has not been without its consequences. In the last decade, the education of the architect has come under sharp criticism. There have been allegations from numerous critics that current students are led "far from the fundamental disciplines of architecture and into the realms of bad art" (Buchanan 1989). Other critics claim that the current system of learning is remote from reality and the process of design (Crinson and Lubbock 1994). Some claim "design education as undertaken in the schools of architecture appears to be preparing students for models of practice that are no longer in full accord with the current professional context" (Nicol and Pilling 2000).

In 1993 the collateral architecture organisations in America - The American Institute of Architects (AIA), American Institute of Architecture Students (AIAS), Association of Collegiate Schools of Architecture (ACSA), National Architectural Accrediting Board (NAAB) and National Council of Architectural Registration Boards (NCARB) - commissioned a three-year study into the profession of architecture. The final report was released in 1996 and given the title: Building Community - A New Future for Architecture Education and Practice (it is frequently referred to as "The Boyer Report" in honour of the late Ernest Boyer, one of the authors, who died during the production of the report). In the muchcited report, Boyer and Mitgang (1996) advocated a renewal in architectural

\footnotetext{
${ }^{3}$ There are some schools however that are wholly independent of the university. The Architectural Association in London and the Boston Architectural Centre are two such schools.
} 
education and practice based on essential goals, one of which was a curriculum connected to practice.

The NCARB subsequently created a taskforce, composed of both educators and practitioners, and charged them to evaluate the issues raised and recommendations made in the Boyer report. From the report the task force identified seven essential issues for education of which priority one was:

Students need greater exposure to real and practical architectural experiences during school, including exposure to the business of architecture (Hill 2000)

To address this issue they recommended among other things:

- the name 'design studio' be changed to 'architecture studio' to more accurately reflect the entire integrative process;

- that architecture studio be the bridge between education and practice;

- there be a better balance/integration between the study of design and the study of practical issues in school.

More recently, in 1999, the RIBA commissioned a review of architectural education. Led by the respected practitioner Sir Colin Stansfield Smith, the committee found:

...growing anomalies between architectural education as translated by the universities and the training and education of architectural students as a vocation (Smith 1999).

This was further interpreted as a sense of disconnection between practice and academia. They recommended the following:

- A seven-year continuum of credits to replace the RIBA Parts 1, 2 and 3;

- the promotion of specialisms and research;

- practical and management skills to be integrated into the curriculum;

- the promotion of interdisciplinary project work in the design studios as part of the core curriculum.

(Smith 1999).

In July 2001, the Commonwealth Association of Architects (CAA) hosted a conference in Hong Kong. The conference, with the theme of "Remaking the Framework of Architectural Education for the $21^{\text {st }}$ Century", sought to initiate 
critical dialogue within the framework of education to reach a social consensus (processes and outcomes) on the significance of architecture for the $21^{\text {st }}$ century. According to the conference organisers:

The symmetrical clarity of [apprenticeship/practice and academia] is increasingly confined by the lack of innovative visions and parallel strategies to engage the conditions of uncertainty and inconsistencies in the new social and cultural environment (Taken from the CAA Brochure for the event).

The need for change in order to produce architects capable of dealing with an increasingly complex and ever changing society was also emphasised by the organisers.

Finally, in Europe a recent survey of architectural educators by the European Association for Architectural Education (EAAE) revealed that there was a significant lack of confidence regarding architectural education's role in producing architects who respond well to the contemporary challenges in architecture. When asked an open-ended question about the single most important challenge in architectural education respondents answered with comments such as:

- "Bridging the gap between academic theory and everyday design practice",

- "More practical aspects about technologies with the aid of exercises",

- "To stop thinking architectural design is only a matter of formal design."

The teaching of sustainable architecture, environmentally responsible and practical design, was seen as a high priority. In fact, when prompted, nearly $90 \%$ of the respondents voted for a high consideration of "Sustainable Development" in future architectural education. This left the EAAE to recommend one of the challenges facing education as "unique contributions to the implementation of Sustainable Development in the world of designing space, buildings, and constructions (EAAE \& CEMBUREAU 2001).

This section of the thesis (Part 1 - Architectural Education) charts the history of architectural education; the challenges associated with it and outlines a reasonable direction towards meeting those challenges. This chapter, in particular, provides the background for the challenges facing architectural education today. It is presented as a concise history of architectural education 
focussing on the movement of learning from the sites and workshops of the masters to the classrooms of academia. It illustrates the separation of the intellectual act of "design" from practical knowledge (how architecture is constructed and inhabited). This metamorphosis, which illustrates the move from the real to the virtual, has had a far-reaching effect on the education of the architectural student creating new challenges for $21^{\text {st }}$ century education.

\section{Educating Architects - From Vitruvius to Alberti}
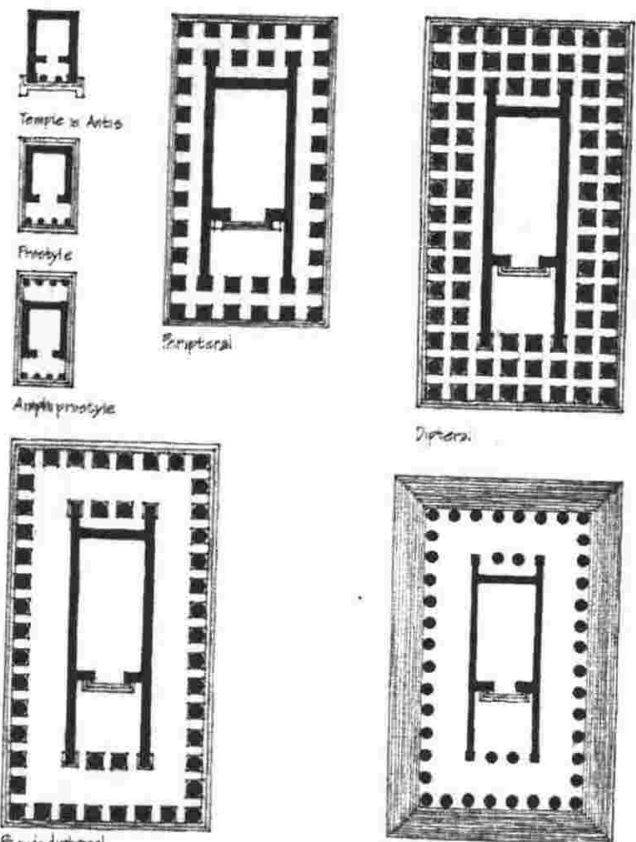

Frande dipteral

CLASGIFEATION TEURLES ACCORDING TO THE ARRANGEMENTS OF

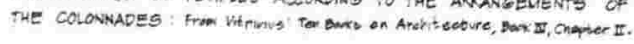
Figure 1.2. Vitruvius's classification of temples according to the arrangement
of colonnades (Source: Ching 1979)

Vitruvius

Marcus Vitruvius Pollio, in Decem libri de Arcbitectura, stated that all works executed by the architect's expertise (enhanced by various disciplines and specialized knowledge) were evaluated by seasoned judgment that was informed by practice and reasoning (Rowland and Howe 1999). With this in mind, Vitruvius considered theory and practice learned simultaneously to be essential 
to the architect's education. He prescribes that the education of the architect was subject to:

Reasoning [or theory] ... the ability to demonstrate and explain... [skill in] the principles of Proportion (Broadbent 1995)

and

Practice... the continuous and regular exercise of employment where manual work is done... according to the design of a drawing (Broadbent 1995).

He expands this by suggesting that the architect be educated and among other things be:

skilful with the pencil, instructed in geometry, know much history, have followed the philosophers with attention, instructed in geometry... (Broadbent 1995).

An architect's education in ancient Greece ${ }^{4}$ and Rome therefore had two components; theory that to Vitruvius would include such things as proportion and the orders and practice, which would be training on the job of the actual building (with the associated technical knowledge). Geoffrey Broadbent (1995), in his article Architectural Education indicates that in his opinion nothing has changed in the education of the architect since Vitruvius' description. He says:

Our students are 'skilful with the pencil' - or these days the computer; they do indeed 'know much history' and, in the most productive schools, 'have followed the philosophers with attention', even though the philosophers may have changed from Plato to Heidegger. Certainly they are 'instructed in geometry', although that may be computer-aided (ibid.).

If we accept this statement, then the significant difference between what happens today and Vitruvius's era described previously is not the knowledge that is or was taught but rather its delivery and effectiveness thereof.

\footnotetext{
${ }^{4}$ Broadbent implies that the Roman methods were based on the earlier Greek model.
} 


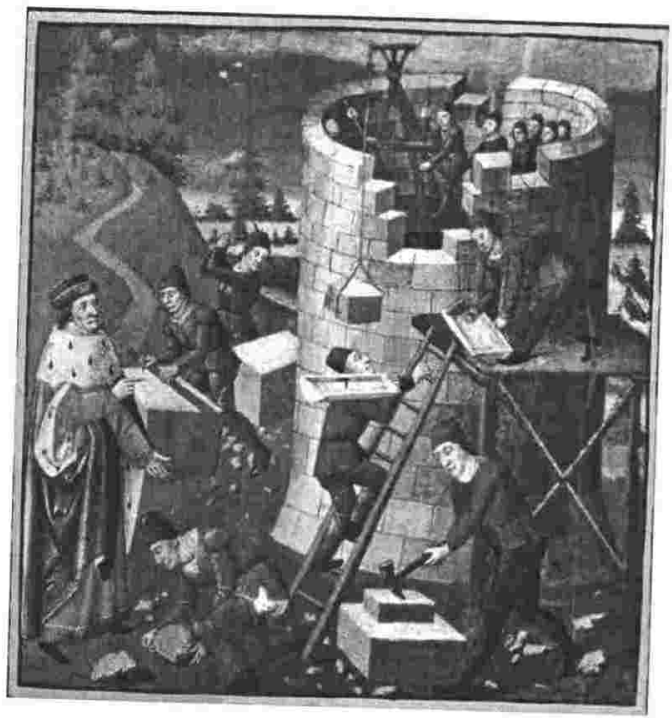

\section{Figure 1.3: Working on a mediæval site (Source: Harvey 1972:cover)}

When speaking about delivery, the point we should be observing about this period in time in history is the phrase "on the job". Most of the temples in Greece and Rome were drawn full size on the surfaces from which they were constructed. The student or apprentice would have done, or at least assisted in the layout, geometry and other activities, learning the craft as they went along. By actually engaging with the task at hand the students were in fact learning by doing, or applying knowledge to a real task, an important characteristic of learning. When applying knowledge to practice the apprentice would be exposed to how materials and processes fit within the architecture and how the architecture should respond to human habitation (among other things). This could be regarded as practical knowledge. As we shall see, over the ages the two (theory and practice) have been essential parts of the architect's education. Today, however, there is a distinct favouring towards the theoretical side. While what can be regarded as theory has been greatly expanded, the teaching of practical knowledge (or the things that contribute to constructible and habitable buildings) has been left to lectures divorced from the teaching of design. 


\section{Lodges and Guilds}

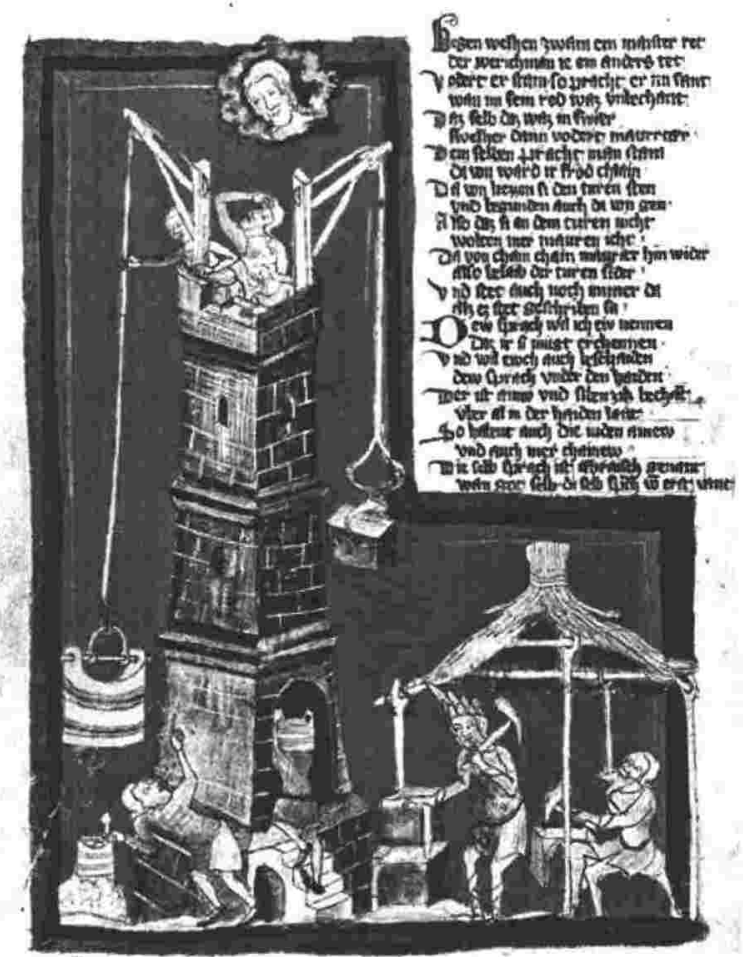

Figure 1.4. The temporary structure that often made up the lodge seen on the right in this image. The lodge was essentially a workshop made of timber and thatch where students learned the craft of making buildings. (Source: Coldstream 2002)

The origins of studio-based architectural training have their roots in the craft guilds of the Middle Ages. The craft guilds seem to have originated in the Roman collegiums, which were voluntary associations of trades that were eventually taken under state control in late antiquity. Membership in the guild was hereditary until about the 13th century when the craft guilds fully emerged and the system of apprenticeship gained currency (Coldstream 2002, Kostof 1977). The medieval architects were guild members, master-builders who were carpenters or masons and moved from site to site setting up their workshops or lodges (figure 1.4) as bases from which to conduct their work. In these lodges apprentices worked and learned the skills of the master designer or artist. They also learned all aspects of the profession from carpentry or stone cutting to business administration to planning, mathematics, and engineering in the guilds and family workshops (Rosenfield 1977). 
Behind every architect stood the education of the lodge and the often fanatically guarded formulae of the trade. These lodges while maintaining the master/apprentice relationship for training acted as "schools" where "secrets" or the procedures for achieving certain results were passed on to the next generation of craftsmen. Distinguished practitioners added to core knowledge by setting down exemplars derived from their own experience (Kostof 1977). These exemplars in the form of model books (figure 1.5) were not meant for general circulation, but only for the teaching of the initiated (who were instructed not to divulge trade secrets to outsiders).
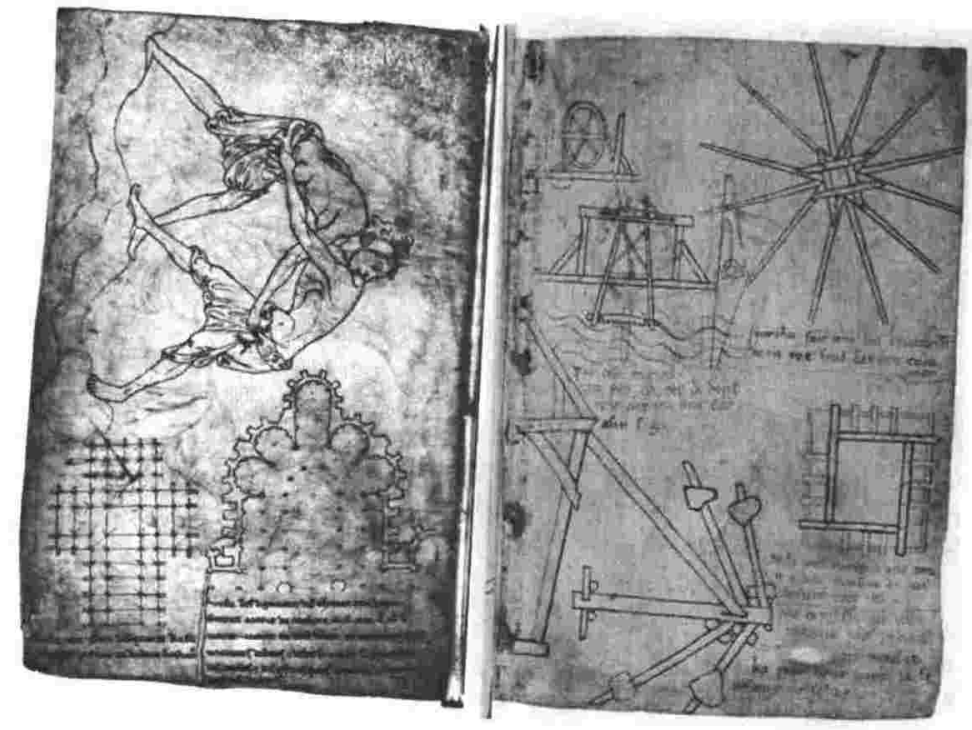

Figure 1.5. Notebook from a master, 13th Century. The notebook was meant masonry and the art of doner, teaching him techniques of carpentry and accumulated knowit of drawing. Such pattern books recorded the were not meant to circulate beyond the and the author's own experience. They Kostof 1977:90)

Apprenticeships usually lasted seven years, beginning at age thirteen or fourteen. This was followed by three more years of improvement as a journeyman in which time was spent on the job gaining practical experience in different types of work. Apprentices were trained to master and to memorize the many problems in practical geometry which were solved by means of rule and compass, learned by rote and passed down from generation to generation (Herbert 1993). A lot of the training was based on established tradition and happened on site. Drawings consisted largely of geometric layouts derived from and functioning directly within the construction process (Herbert 1993). 
Drawings having to do directly with laying out the work were often contained within the building itself (Herbert 1993) and inscribed on the walls and floors. These used primary tools like the straightedge, square, compass, and dividers and tended to be rule-bound mechanical construction drawings that relied on practical (rather than theoretical) geometric principles. The design of allimportant details was executed on the building site itself. The hand of the architect was to be found everywhere on the actual fabric and with it that of his apprentice. Today this is no longer so. Today, through the act of drawing the designer is divorced from the reality of the site. This separation of the architectconceiver from the reality of the building process actually began to occur during the Italian Renaissance.

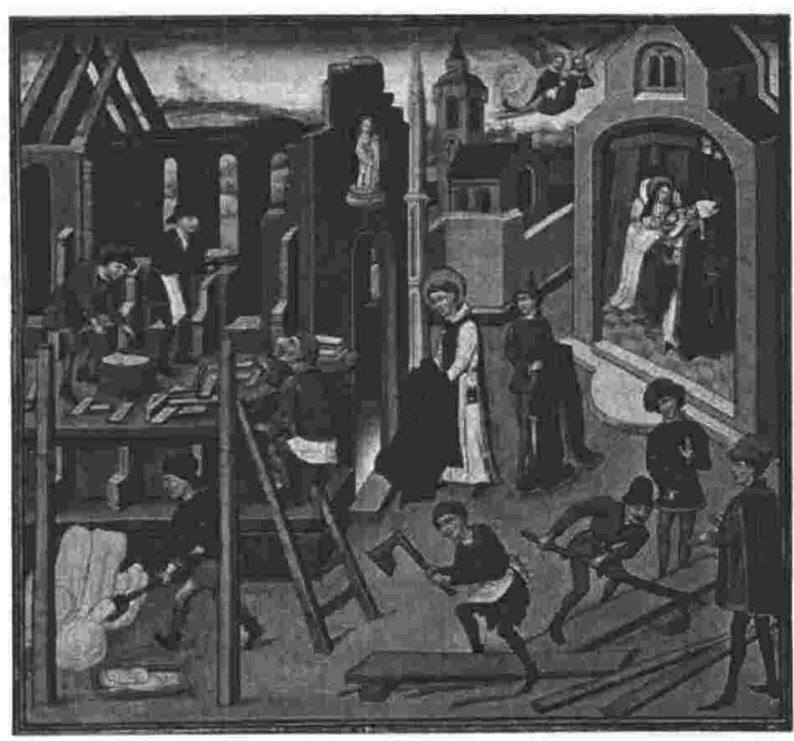

Figure 1.6. A building site in the fifteenth century (Source: Coldstream 2002)

\section{A Private School}

During the Renaissance small groups of humanists would gather informally to discuss philosophy. These groups were called Academies after the philosophical school conducted by Plato in the garden known as Academe, near Athens (Egbert 1980). These academies started out as free discussions of literary and philosophical topics but eventually became more structured with established courses of lectures by experts in specific fields like architecture. 


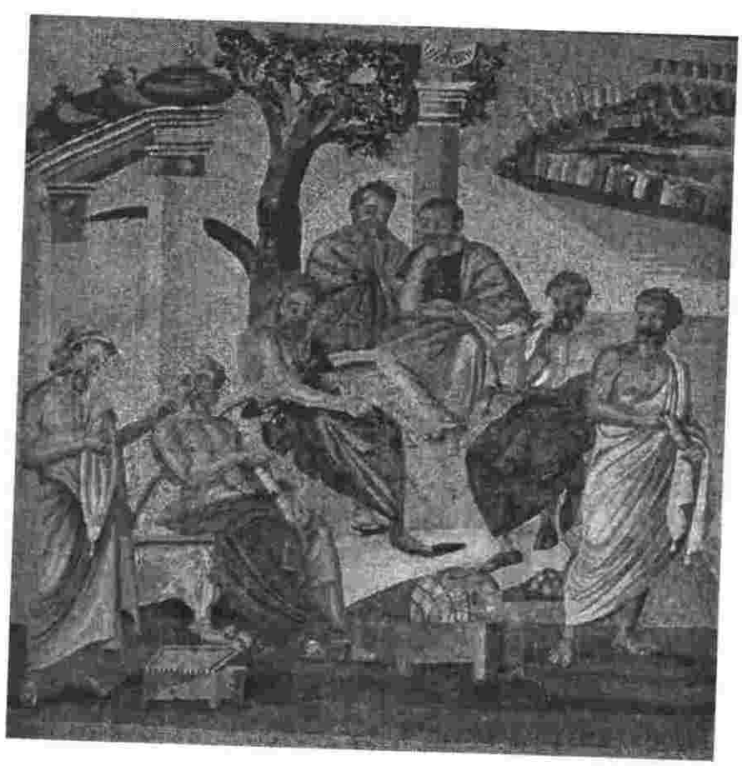

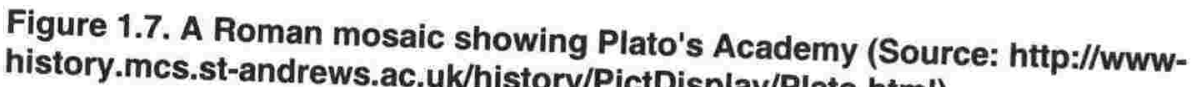
history.mcs.st-andrews.ac.uk/history/PictDisplay/Plato.html)

Architectural training began to change during the 1470 s with the establishment of a private school by Lorenzo de Medici of the great Florentine family. The school was influenced by the writings of Leon Battista Alberti (Broadbent 1995). In his treatises Alberti reasoned that of all the arts, architecture was the most predisposed to theory and unlike painting, sculpture, literature and poetry, it (architecture) could be developed philosophically (Broadbent 1995). Modelling his stance on that of Vitruvius that stated the architect should be immersed in both theory and practice, Alberti suggested that the architect was a scholar when he wrote, in the preface of his treatise (De re aedificatoria), "an architect is not a carpenter...the manual worker being no more than an instrument to the architect." In the eyes of the humanists and scholars of the Renaissance, the traditional medieval master mason was no longer sufficiently educated to adequately deal with the tasks of building with knowledge and understanding (Ettlinger 1977). Renaissance artists sought to distance themselves from the craftsmen and made it their business to bring out the intellectual elements in their art (Jenkins 1961). 


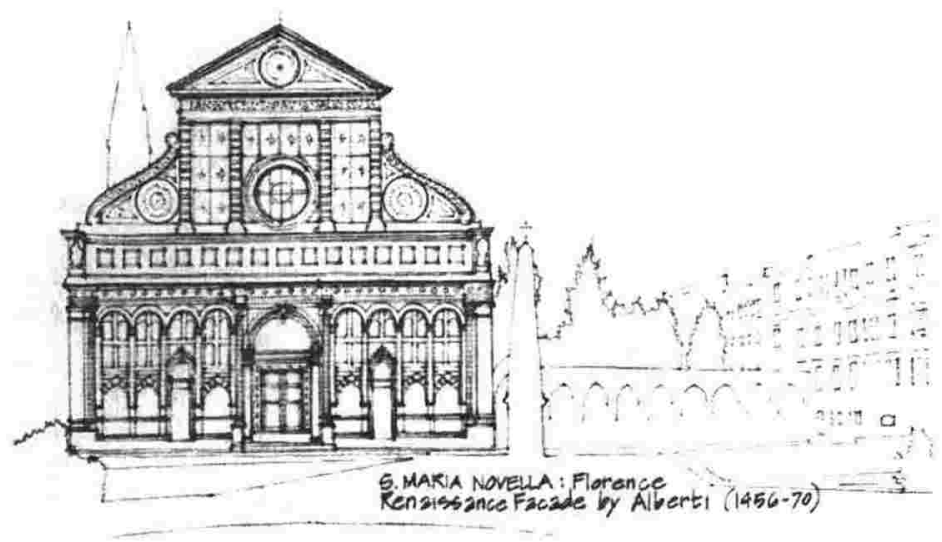

Figure 1.8. Renaissance Facade by Alberti (Source: Ching 1979)

Lorenzo's school, therefore, was set up in direct opposition to the apprenticeship system, which had still survived from the Middle Ages. The Academia Platonica, as it was called, was sited in a garden, which Lorenzo owned on the Piazza San Marco in Florence. He appointed Bertoldo di Giovanni, a sculptor who had studied with Donatello, as his Director and personally selected the students who studied, ate and slept in buildings within the garden. In the garden, students studied first hand, sculptures, drawings and models by contemporary masters. As an indication of quality; graduates from the Academia included Leonardo da Vinci, who entered in 1475, and Michelangelo, there from 1480. No doubt, Alberti's treatises were used in the "classroom" but as Broadbent points out:

The crucial point is that an Academy... proved a more than viable alternative to simply working on the job with a master by which architects, painters and sculptors had been taught until then (Broadbent 1995:85).

Here, architects were taught to think more philosophically whilst the learning of practical matters became one step removed from the reality of the site. The shifting of architectural education from learning firsthand on the job to learning in academia had begun. 


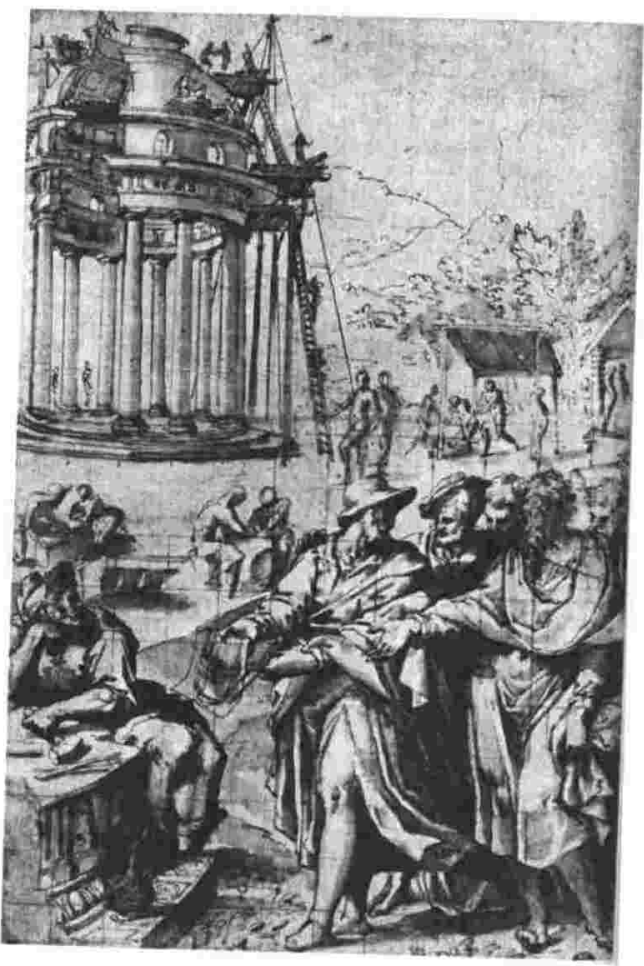

Figure 1.9. Jacopo Bertola, Construction of a Rotunda. The professional architect, accompanied by his scholarly advisors, presents his plans to the manual workers who will carry them out. (Source: Kostof 1977: 146)

\section{The influence of drawing}

The change in thinking and training was reinforced by a shift in the role of drawing in design. Around 1500 the sketch or study drawing emerged as a design tool among architects. Study drawings made it possible to set out graphic conjectures portraying innovative and not yet existing architectural forms. It effectively separated design from the physical act of construction by its emphasis on manipulating graphic symbols, or representations (Herbert 1993). Herbert in linking this fundamental change to current design practice today refers to the sketch increasingly separating the designer from the reality of construction (figure 1.9):

...the transition from medieval to Renaissance design altered the fundamental codes that determined the role of drawing in design, establishing the empirical graphic approach to design still in use today. This approach offered Renaissance designers greater opportunities for graphic manipulation at the cost of increasing the separation of design from construction. Today, new questions concerning representation, transparency, and access to an external reality - questions that challenge the existing fundamental codes suggest the potential for another change in the relation of drawing to construction
(Herbert 1993). 


\section{Academia and Architecture Education}

The Ecole des Beaux-Arts.

Inspired by the Italian renaissance and post renaissance models, the European academies of the $16^{\text {th }}, 17^{\text {th }}$ and $18^{\text {th }}$ centuries sought to satisfy the demand for more practitioners by centralizing those aspects of architecture that could be taught in lecture classes (Beinhart 1981). The French, in particular, set up several academies aimed at countering the trade guilds that were not under royal control. This was not unlike Lorenzo's motives earlier in Florence. The first academy - the Académie Francaise - was founded around 1635 and it wasn't until 1671 before the Académie Royale d'Architecture was founded under Louis XIV (Egbert 1980). Initially a "discussion group" of eminent architects who advised the King on architectural matters, this group also sought to "bring forth a more exact knowledge and a more correct theory" (Broadbent 1995). The Académie (as a result) set up a school so that young architects could share in the expertise of the academicians. The new school gave public lectures twice a week with subjects ranging from arithmetic, geometry and perspective to stone cutting, mechanics, and military architecture. By 1717 these were transformed into a two or three year course with a clear intention to:

...elevate the architects from the construction sites and studio workshops, or ateliers, to a structured institutional environment (Yee 2001).

Or as Broadbent states:

Raise architects from the status of craftsman to that of philosopher (Broadbent 1995).

The master/apprentice model of passing on knowledge still prevailed, for whilst the school offered only lectures, no design studies were taught. The actual learning of drawing and design took place in the studios or ateliers of the patron/practitioners (masters), independent of the Académie. Following the trend set during the Renaissance, the workshop was no longer at the construction site but had become a studio or atelier located elsewhere. Drawing, understandably, became the first skill a student would learn (Chafee 1977). Within this education system originated the split between lectures and studio as observed in modern architectural education. 

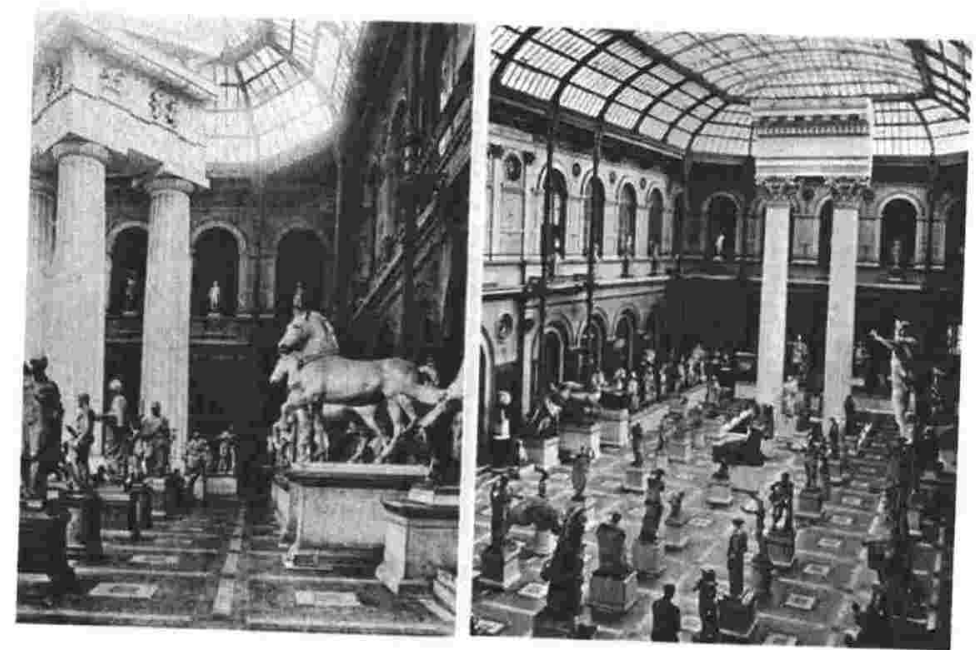

Figure 1.10. Interior court of the Ecole des Beaux-Arts. The court contained plaster casts of Greek and Roman Sculpture for students to study. It also 1977)
included part of the Parthenon restored. (Source: Kostof 1977:213, Drexler

The Ecole des Beaux-Arts emerged in 1819 after widespread reforms to the academies during and after the French Revolution. The Ecole charged no tuition and was open to Frenchmen and foreigners between the ages of fifteen and thirty who could pass the entrance exams. Students enrolled as aspirants after providing proof of age and a letter of recommendation. After choosing an atelier they began preparing for the entrance examinations, which took about two years or less. The exams, both written and oral, tested such subjects as mathematics, history and drawing. After passing the exams the student was admitted to the Ecole in the second class. At this point the student was called an élève de l'Ecole des Beaux-Arts and moved on into the first class after fulfilling various obligations and gathering enough valeurs or points from the problems/projects or competitions (called concours) attempted. This took anywhere from two to four years. Once in the first class the student took part in concours that were more complicated than the class below. The student could stay here until he was thirty entering as many concours as he wished. The final step reserved for the best students was the competition for the Grand Prix de Rome. Offered to only one student, the prize sent the winner to the French Academy in Rome for four to five years, at the expense of the government. On his return the student was likely to be employed by the state. 


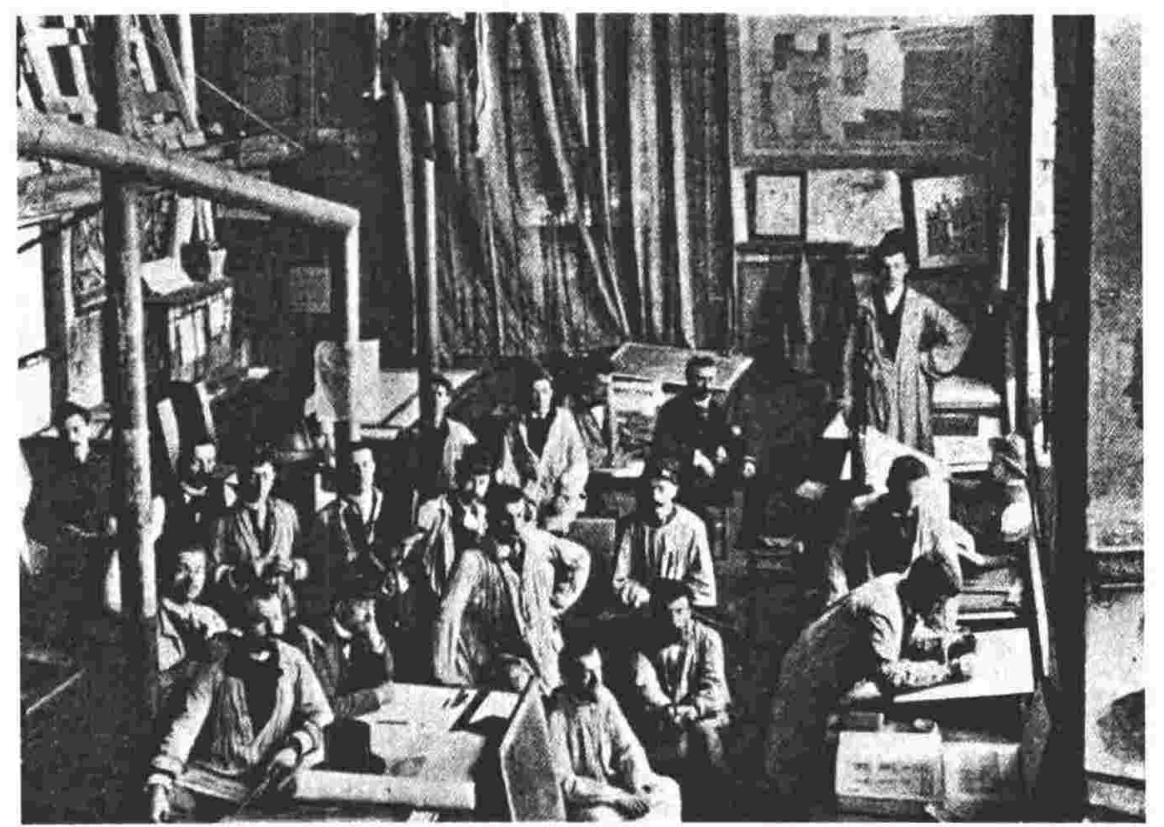

Figure 1.11. An atelier at the turn of the century. (Source: Drexler 1977:91)

\section{Ateliers}

Certainly from the beginning of the 19th century, the work of the students was directed by the Ecole which provided resources (like an excellent library), provided lectures, set the problems or competitions (concours) to be worked on, presided over the first twelve hours of the students' design (en loge), administered the final juries and displayed the results. The task of teaching design was still the prerogative of the master or patron as he was called. The patrons, though still practising architects, usually had their own offices (separate from the ateliers) where they carried out their own commissions. The ateliers at this point ceased to become practising offices but rather private design schools (Yee 2001).

Whilst the patron was the head of the atelier, the ateliers were actually run by the students (élèves). One member was elected to collect dues, which would pay for rent, coal, books and the patron's fee. It was the patron's job to pass by the atelier two to three times a week to comment on students' preparations for the concours. Under an air of "profound ceremonial respect" (Chafee 1977) he would spend the time moving from student to student giving criticism. At each table he was followed by most of the élèves who stood behind him listening to every 
word. The patron would show what needed to be developed, point out erroneous aspects, and comment on proportions and facades among other things. At the end of twenty or more such "conversations" he would leave the atelier, which would erupt in discussions and explanations as soon as he departed. Chafee (1977) reports on an account of the patron Jean-Louis Pascal in the 1870 s...

In the atelier it did not seem to take him an instant to realize the possibilities of any sketch that his pupil might put before him, and he always left us either happily artistic possibilities in it of which worth further trouble, or with our eyes opened to the days and nights required to we had not dreamed, giving us courage to go through accepting the conception of his pupil and helping hing. He had a wonderful power of (Chafee 1977).

These patron-pupil "conversations" characterised how teaching was done in the atelier. By criticising and talking about students' designs each patron transmitted their theories of architecture in the most effective way, face to face with their students (Chafee 1977). Architecture as taught at the Ecole des Beaux-Arts was not learnt in the actual environment, but rather in isolated studios during conversations where the subject matter and objects of learning were hypothetical projects in Architectural Composition.

\section{The Project}

The focus of the Ecole des Beaux-Arts, the design project, was emphasised by the importance of architectural composition and the concours d'emulation. Lectures were given in subjects like theory of architecture, mathematics, physics, chemistry, perspective, building law and construction but they were mostly optional. Chafee reiterates this observation:

None of [the] lectures were compulsory at any stage of the curriculum. Only those on scientific subjects were followed by exams, and a student could prepare for the exams
without hearing the lectures. Only dutifully attended; many of the others seem to have construction seem to have been 

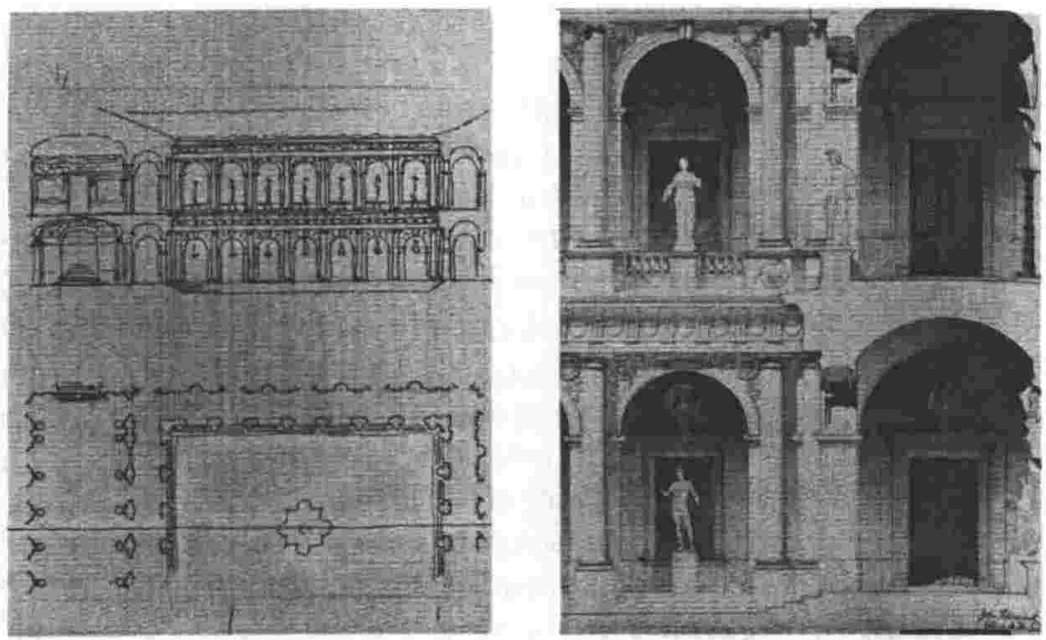

Figure 1.12. Student project at the Ecole des Beaux-Arts, 1891. On the left is the esquisses and on the right is the rendered section (Source Kostof 1977:226)

After students moved up the ladder from being an aspirant and admitted to the Ecole as élève de l'Ecole des Beaux-Arts they endured several competitions or concours d'émulation. These competitions were the method by which students' learnt how to design. There were two types: esquisses (sketches) and projets rendus (rendered projects). Issued monthly, the programs for the concours alternated between esquisses and projets rendus. For the second class, the programs for esquisses that required one drawing after twelve hours of study were often parts of buildings, facades or even a village fountain. For the projets rendus that required three large drawings submitted after two months the programmes repeatedly used were a small school, an assembly hall, a small railway station and so on (Chafee 1977). For the first class the programs were a bit more complicated. Typical first class esquisses might be parts of larger buildings (entrance ways, single bay of a large hall) or small single purpose buildings (boutique, clock tower). Typical first class projets rendus were schools, museums, hotels, theatres and large houses (Chafee 1977). The major concours for the Grand Prix de Rome had even more complex programs (usually for a monumental public building) and included: museums, hospitals, universities, embassies and cathedrals. At the end of intense competition the students submitted beautifully drawn projects in a mostly neoclassical style and theorising and architectural speculation were encouraged (Chafee 1977). These 
submissions were often defensible subjectively (only on grounds of "good taste" and intuition). A jury of professors and guest architects judged projects, usually without the students present and used the same criterion by which the students designed, that is "good taste."

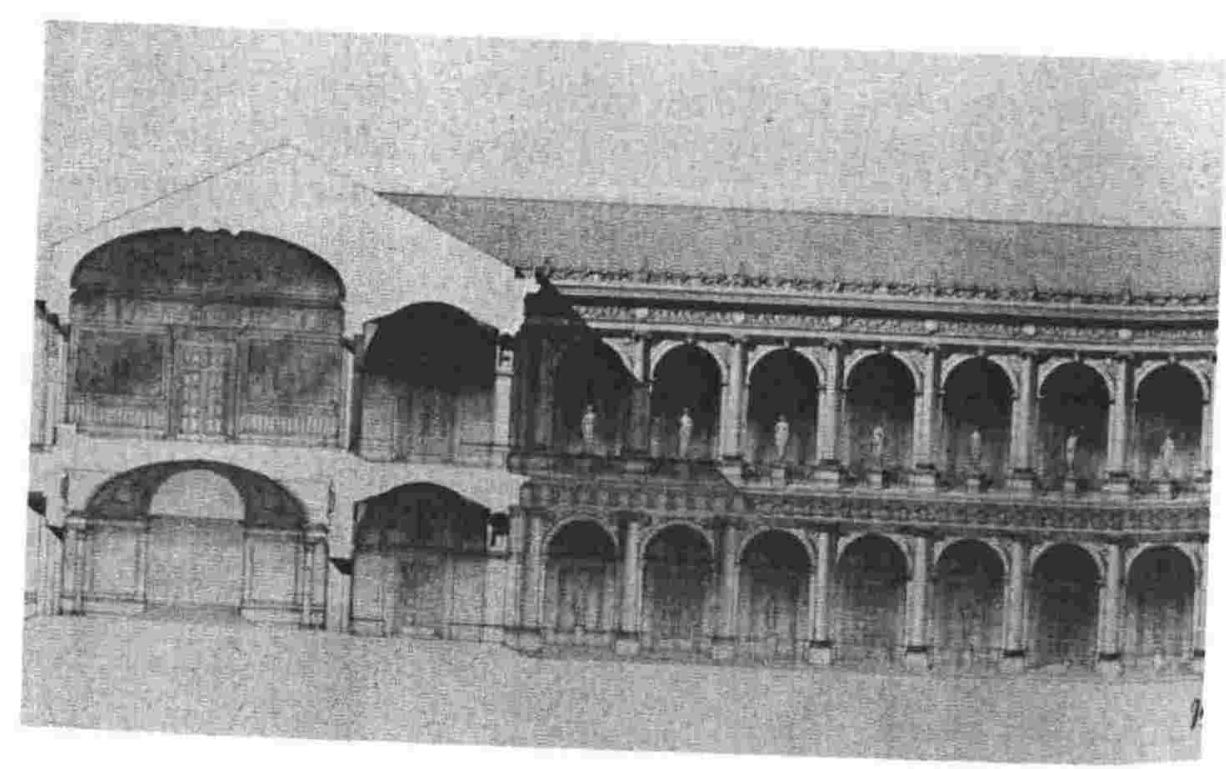

Figure 1.13. Student project, Ecole des Beaux-Arts. The same student in the
same competition as figure 1.12 did this rendered area for the roof structure 1.12 did this rendered section. Note the "white" area for the roof structure. (Source: Kostof 1977:226)

\section{Technical Attitude}

The attitude of the Ecole to technical matters was reflected in a declining emphasis on construction, the difficulties students had passing construction and in the drawings produced for the concours. From 1823 there were four construction concours - wood, iron, stone and construction générale - each lasting about four months. To be promoted the student had to get credit in each of the four concours. Interestingly, in 1867 construction was made into a single concours, lasting only three months. The construction concours required about a dozen drawings, showing how a projected building would be put together, with attention to the detailing of stone, iron and wood, and with mathematical calculation that the building would stand. According to Chafee, passing the construction requirement seems to have been the hardest task in the second class (Chafee 1977). The lack of interest by students in construction was 
reflected also in the drawings produced in the design concours. Although the concours (especially the Grand Prix) encouraged students to arrive quickly at the essentials of a large architectural problem without being bogged with detail, this led to the subsequent neglect of ornamental or structural details. The requirements by early concours of a "profile" drawing, communicated a preference for beautiful and appropriate general forms instead of details of the structure of roofs, floors and walls. In early competitions (as early as 1759) the roof structure was indicated in detail but in later competitions was soon replaced by an area of white paper (fig. 1.13). The system was subsequently deemed by its critics as "displaying a deplorable lack of interest in and knowledge of modern developments in structure" (Egbert 1980).

\section{The Beaux-Arts in America}

Across the Atlantic, during the late 19th century, the Beaux-Arts system of architectural education was being imported into the United States. The conventional method of training at the time was an office training system interestingly called apprenticeship. Here students worked for a small wage or no wage at all in an architect's office and attended courses offered by technical schools or institutes in the evening (Schoenauer 2002). Another more elitist method was for the student to head off to Paris for education at the Ecole des Beaux-Arts. The demand of a rapidly expanding country for practitioners eventually surpassed the supply of trained architects (from the few established offices or abroad)(Jenkins 1961). In addition to this, members of the profession became aware of the need for an increased scientific content in architectural education. This need, it was assumed, could be met only in a formal educational setting like a university (Schoenauer 2002). The establishment of a school of architecture at the Massachusetts Institute of Technology (MIT) in 1865 satisfied this. MIT was followed by the University of Illinois at Urbana in 1867 and Cornell University in 1871. By end of the century there were no less than ten schools of architecture located in Universities.

For these schools the Ecole des Beaux-Arts was seen as the ultimate model for architectural training. The reason for this is obvious. At the time the only teachers of architecture were trained at or influenced by the Ecole e.g. Richard 
Morris Hunt. Hence, the influence of the Ecole was quite strong, both through educators with the experience of the environment returning from Paris ${ }^{5}$ and by institutions deliberately emulating the French system (Crinson and Lubbock 1994). By 1920 most schools of architecture were located within universities and employed the French system of education.

\section{British Architectural Education}

\section{Articled Pupillage}

The state directed education of the Ecole des Beaux-Arts supported by ateliers contrasted with the system in Britain that was running parallel with it at the time - Articled Pupillage. Articled pupillage was a modification of the medieval apprenticeship system, the difference being - under apprenticeship an apprentice exchanged his labour for instruction from a master; but under pupillage an articled pupil paid a premium to be taught. By the end of eighteenth century it was the most common (but not the only) system of training architects in Britain. About $50 \%$ of all entrants to the occupation of architecture were trained through pupillage by 1800 (Stevens 2002). Although its structure was never universally defined, its commonality was maintained throughout the nineteenth century. The $50 \%$ ratio rose quickly in the opening decades of the nineteenth century to displace other entry points into the occupation, such as through the building trades. Pupillage was not seen as sufficient training in and of itself and was often followed by foreign travel. When the "graduate" returned from overseas he usually entered several of the competitions used to select architects for projects. Winning a competition would denote that an architect was competent to practice by himself.

\footnotetext{
${ }^{5}$ Hundreds of Americans were educat least one Paris trained professor during the early part of the century.
} 


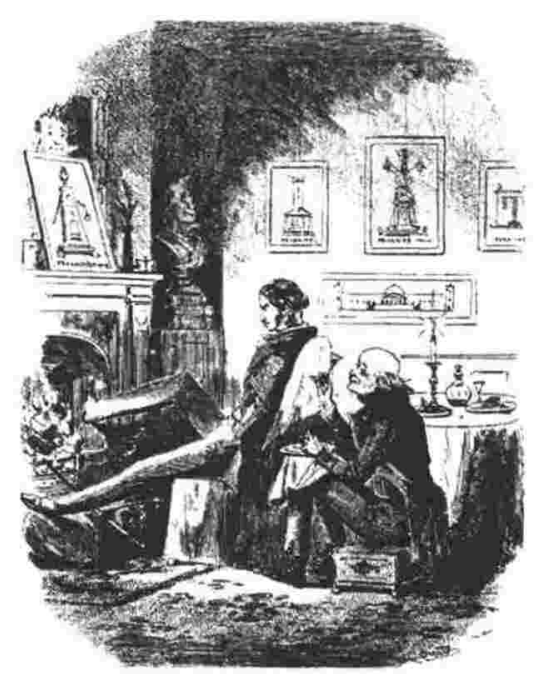

Figure 1.14. Scene from Martin Chuzzlewit (Source: Crinson and Lubbock 1994)

For the "student", the period of pupillage lasted for an average of five to six years. Candidates started at age fifteen or sixteen (occasionally it would begin at twenty-one after a university education) and were often expected to have a background in languages and some knowledge of mathematics, geometry and drawing. After paying the required premium, the pupil was expected to learn the "art or profession of an architect". Although there were various interpretations of what this meant, it was generally understood that the pupil would be trained in architectural drawing, measuring, site work and the general running of an office (there were often variations on this) (Crinson and Lubbock 1994).

The quality of the system (which was largely unregulated) depended a great deal on the qualities (and integrity) of the pupil master. Architects could exploit the system by taking the premium and simply using their pupils as assistants. A good example of this abuse is Charles Dickens' Mr Pecksniff in his 1844 novel Martin Chuzzlewit (figure 1.14). Even though this form of training was open to abuse there were architects that saw the potential of the system as a better way of educating architects. Crinson and Lubbock (1994) speak of a lecture delivered by Robert Sandeman at the London Architectural Society in 1847:

Sandeman directed the pupil-master to oversee a progressive development of the pupil's abilities. In the first year there would be drawing instruction by stages and directed reading, 'keeping the Poetry of the Art from [the pupil]'. The second year would have a variety of office work with as much drawing to scale as possible. The third year would concentrate on visiting and reporting on works and assistance in surveys, giving liberty for the pupil to follow up sciences and practice perspectives. In the fourth year the pupil would be chief assistant at every survey or levelling and would develop elevation 
drawings, perspectives and colouring. In the final year the pupil would be given designs to proportion and execute, he would take out quantities, level, survey and make calculations (Sandeman 1847 cited in Crinson and Lubbock 1994).

Here they further describe the activities of the pupils of Richard Norman Shaw's office:

In Shaw's office they were given several weeks' trial period before any articles were signed. Then they were usually articled for three to five years on premiums between $£ 100$ and $£ 300 \ldots$ (ibid.).

Table 1.1 displays Jenkins' (1961) documentation of work done by an articled pupil in John Soane's Office.

\begin{tabular}{|l|l|}
\hline Date & Activity \\
\hline 19 December 1810 & George Basevi, at the age of sixteen, enters Soane's office \\
\hline February 1811-1812 & $\begin{array}{l}\text { - Successfully completes trial period, takes up articles with his master } \\
\text { - Commences his studies in the office by drawing out the Orders, spending } \\
\text { one day on mouldings and another on the Tuscan Order. The Doric Order } \\
\text { takes two days, while four are spent on the lonic. These studies culminate } \\
\text { with an elaborate drawing of the Corinthian Order on which he spends } \\
\text { eleven days. } \\
\text { - Engaged in making a survey of a house in Montague Place and } \\
\text { producing drawings for the work at Dulwich College. }\end{array}$ \\
& $\begin{array}{l}\text { - Works on some of the drawings to illustrate his master's lectures at the } \\
\text { Royal Academy }\end{array}$ \\
\hline Summer of 1813 & $\begin{array}{l}\text { - Produces a bird's-eye view of London from the top of 13 Lincoln's Inn } \\
\text { Fields, (Soane's as yet uncompleted residence.) } \\
\text { - Practical matters-checking the Chelsea Hospital accounts (early in 1814), } \\
\text { squaring carpenters' dimensions from detail plans for a vicarage, and } \\
\text { recording the progress of the work on the entrance to the Rotunda at the } \\
\text { Bank of England. }\end{array}$ \\
\hline Early 1816 & $\begin{array}{l}\text { Spends a considerable amount of time on designs for a tomb for Mrs. } \\
\text { Soane, (who died the previous November) }\end{array}$ \\
\hline Late 1816 & \begin{tabular}{l} 
Completes articles and sets off on a three-year tour of Italy and Greece. \\
\hline
\end{tabular} \\
(Sable 1.1 Documentation of work done by a pupil in John Soane's office
\end{tabular}

Often this preparation, which included the non-designing tasks (which actually took up most of the time in a typical nineteenth-century office) of practice, was supplemented with complementary classes at the Royal Academy (for lectures and exercise in drawing from the cast) or in the many provincial architectural clubs and associations such as those at Glasgow, Edinburgh, Newcastle, Manchester and Birmingham, which gave prizes and ran occasional classes (Crinson and Lubbock 1994). In 1890 the RIBA issued a model form of agreement for pupils and masters. This article specified that permission should 
be granted for pupils to attend lectures and classes in order to prepare for the RIBA examinations (Crinson and Lubbock 1994).

The system of pupillage when used to its maximum benefit effectively gave the young architect the advantage of being taught in an environment where architecture was actually practiced. Even though the office was separated from the site, learning was connected indirectly to the act of making and the realities of architecture by making the student learn on "real" projects.

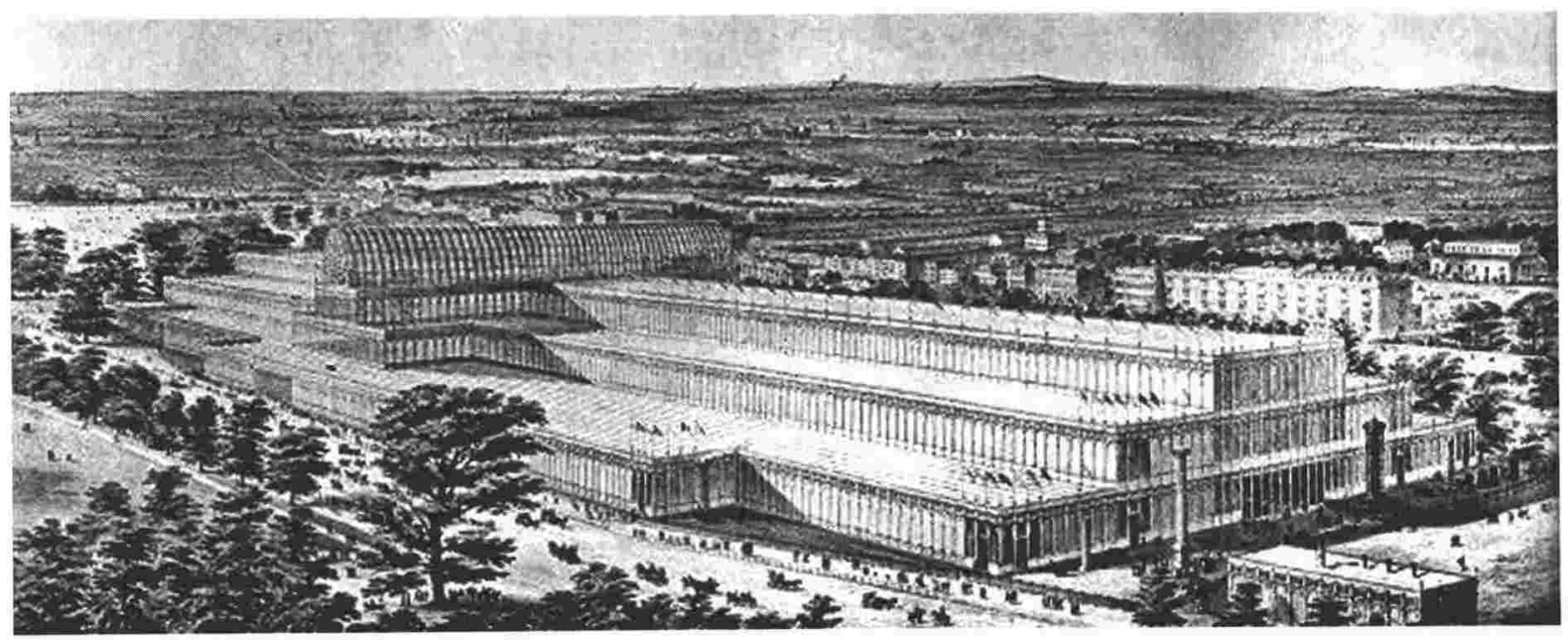

Figure 1.15. Crystal Palace, by Joseph Paxton, at London, England (then Sydenham), 1851, moved 1852 , burnt 1936 . Heralded at the time as high technology, the exhibition hall was built out of prefabricated and wrought iron elements. The 'ridge and furrow' roof glazing system was specially devised for the occasion. (Source: Great Buildings Online - http://www.greatbuildings.com/buildings/Crystal_Palace.html)

These realities eventually became complicated in the context of the industrial revolution. New materials like steel and glass demanded new construction techniques (fig 1.15); new building types like railway stations and factories (spawned from the invention of the steam engine) were commissioned; and new science meant different configurations and planning for hospitals. This made the educational process facilitated by pupillage more difficult. Although small offices provided some experience in building and office practice, the best experience of pupillage was generally gained where the office was large. There, fledgling architects could undertake a variety of graduated tasks on a number of types of commission. The complexity of practice no longer afforded the student a balanced and structured education within the traditional period of time.

This state of affairs subsequently influenced the questioning of architectural education. By the mid-19th century there was a growing dissatisfaction with the 
system of training. This dissatisfaction in addition to other complaints led to an increasing number of potential British practitioners becoming interested in or gaining experience in the French system in Paris or the American schools. To cope with the increasing complexity of practical building requirements and methods of building construction, other institutions were introduced. These institutions or technical colleges provided evening class instruction in the more technical aspects of architecture (Russell 2002). Dissatisfaction from young architects also led to the establishment (in 1847) of the Architectural Association (AA) School, the first school of architecture in Britain. The final model to be used in Britain, however, did not emerge without debate and some experimentation.

\section{Education and the Arts and Craft}

The movement from pupillage to organised day architectural schools in Britain pursued a path of experimentation largely influenced by the "Profession or Art" debates that occurred during the last decade of the century. The debate, which took its impetus from issues surrounding the syllabus of the RIBA examination, sharply divided the architectural world (Powers 1984, Davey 1989). It also brought into the open ideas about the true nature of architecture that had been growing in importance since the 1860 s and through the 1880 s. Even though it seemed solely about the RIBA and the Parliamentary Bill for registration, the "Profession or Art" (a title invented by a Times sub-editor) debate of 1891, argues Alan Powers (1984), was in fact about the "training and qualification of architects". This was reflected in the wide experimentation with education that occurred at the time.

One of the experiments used an arts and crafts approach, involved the practical aspects of architecture to tackle what was perceived as the shifting of architecture from the practicalities of building and inhabitation. Architects like Norman Shaw, T.G. Jackson and William Lethaby pursued this approach. Collectively they argued for more practical instruction in architectural training.

T.G. Jackson stated this position clearly when he wrote in an essay:

Our proper field is not confined to the office; we are, or should be, still more at home in the craftsman and the arting sheds; our brethren are not the lawyer and the doctor, but 
craftsman and carry out personally the works he designed, he would be doing what was done by our predecessors, whose handwork we now take for a model Jackson cited in Powers 1984).

Jackson and others advocated the pursuance of this thinking in the emerging schools and criticised those schools that did not pursue this system. In a paper to the Architectural Association in 1891, Jackson criticised the design work done in the school for its lack of contact with the realities of building:

What struck me as particularly amiss was that the authors of these designs had seldom or never considered how their designs were to be carried out. There were open timber roofs that looked pretty enough on paper, but which I was obliged to point out could not be constructed because timber was not to be had $3 \mathrm{ft}$ wide (Jackson cited in Powers 1984)

Lethaby also criticised student work in a school in Birmingham:

...few of the students show a tendency to think over much of their design as a pretty thing on paper rather than as a representation of a building designed for common use. Such students should think more of what would make a strong, serviceable, pleasant looking building, than of what will look like a picturesque and 'artistic' design (Lethaby cited in Powers 1984)

The approach as advocated by Lethaby and others focussed on teaching the practicalities of design. Courses repeatedly focused on the sensitivity of materials, the ability to adapt form and materials to a given problem and the sense of place expressed through building. Experiments in such training occurred mainly in London schools. At the AA's "School of Design and Handicraft" Owen Fleming put practical work before design work and used such techniques as practical demonstration or participation in brickwork, carpentry and other trades. Visitors also came in rotation to criticise the practical work of the class and at one point the foreman for a major construction work was invited (Powers 1984). At the LCC Central School where Lethaby was principal, subjects were treated "from the point of view that architecture should respond to the facts of modern life." (Ricardo quoted in Powers 1984). Building trades schools were founded in Brixton and Regent Street (which subsequently became parts of polytechnics), which, while they did not convince about the merits of practical training, facilitated young building students to cross over into architecture (Powers 1984). Outside London, further experimentation occurred in Glasgow, Edinburgh, Leicester, Manchester and other places, which varied in their leaning towards arts and crafts. 
Around 1906 the system of architectural education in Britain began to shift towards academia. Although interest in the "arts and crafts" approach was high initially, it declined in the face of the perceived superiority of the French system (Jenkins 1961, Crinson and Lubbock 1994) (table 1.2). The American model was also viewed favourably since it integrated the French approach within universities. Consequently, universities, led by such schools as Liverpool University, gradually offered architectural education on more conventional lines drawing inspiration from the French Ecole des Beaux-Arts and the American university schools. Architecture was seen in these schools as an "abstract visual art with rules of composition to be understood" (Powers 1984).

\begin{tabular}{lll} 
& British & French \\
\cline { 2 - 3 } Lectures & 6/year & 2/week \\
\hline Library & $\begin{array}{l}\text { Open twice a week for a } \\
\text { designated period with } \\
\text { some students having } \\
\text { superior collection. }\end{array}$ & 2 libraries constantly available \\
\hline $\begin{array}{l}\text { Traveling } \\
\text { scholarships }\end{array}$ & Once in three years & Grand Prix de Rome - every year \\
\hline $\begin{array}{l}\text { Maintenance } \\
\text { and duration } \\
\text { while in } \\
\text { Rome }\end{array}$ & $\begin{array}{l}\text { Small allowance for 2-3 } \\
\text { years }\end{array}$ & $\begin{array}{l}\text { 5 years with a guaranteed government job } \\
\text { after }\end{array}$ \\
\end{tabular}

\section{Table 1.2. A Comparison between the British educational offering and that of the French. (Source: Crinson and Lubbock1994)}

The Beaux-arts (or rather the American version) gradually became the system of choice for education in Britain. Changes in the architectural education landscape reflected this. For instance, after 1911, the RIBA examinations were altered to include a final thesis subject (which demanded classical solutions), the Rome scholarship was established and work was being carried out on the creation of a central school of advanced architectural study (like the BeauxArts) before being interrupted by the war of 1914 (Powers 1984). By 1914, the dominant model of architectural education (certainly in most western countries) was variations of the Beaux-Arts system located in Universities. 


\section{From the Bauhaus to Oxford}

Bauhaus

The approach used by the Ecole des Beaux-Arts towards education maintained the perception of the architect as the producer of drawings and co-ordinator of works. This was in lieu of the idea of the architect as someone involved in the making of architecture. The architect was seen as totally separate from the builder, engineer or surveyor and so "study in schools was considered more professional the more elevated it was from hands-on building ...[with] less emphasis on construction" (Crinson \& Lubbock 1994).

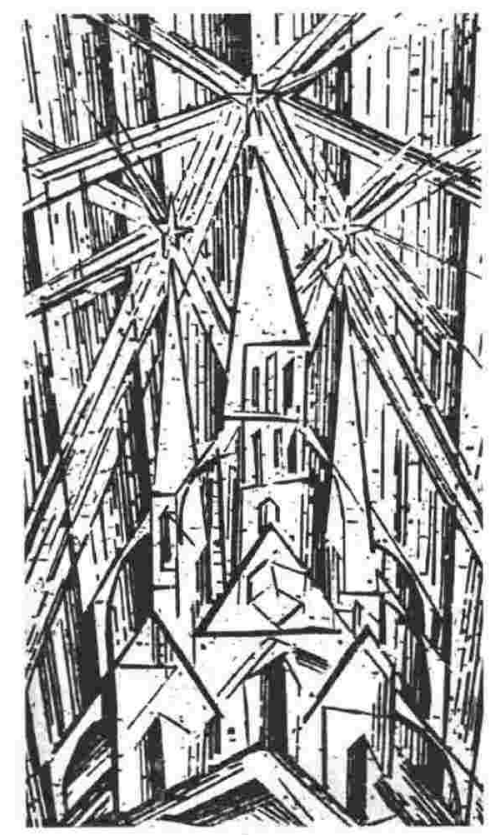

Figure 1.16. Frontispiece of the Bauhaus Manifesto (Source: Westphal 1991:7)

The modernist reaction to this perception at the end of the First World War was embodied in the establishment of the Bauhaus - the most influential design school of the twentieth century. The Bauhaus was set up in 1919 under the direction of Walter Gropius at Weimar, Germany and combined the existing Academy of Art with the School of Arts and Crafts. The basic philosophy of the new school used the ideal of the medieval workshop and craft guilds for inspiration. It argued that in order to produce a totally designed and unified environment through standardization, creativity, and rational analysis all art and craft had to be integrated. Gropius made this explicit in the Bauhaus Manifesto: 
Architects, sculptors, painters, we must all turn to the crafts. Art is not a 'profession'. There is no essential difference between the artist and the craftsman. The artist is an exalted craftsman. In rare moments of inspiration, moments beyond the control of his craft is essentil of heaven may cause his work to blossom into art. But proficiency in his craft is essential to every artist. Therein lies a source of creative imagination.

...let us create a new guild of craftsmen, without the class distinctions which raise an arrogant barrier between craftsman and artist (Gropius 1919 cited in Westphal 1991).

The school vowed to generate a guild spirit linking artists and craftsmen. This would be expressed by living and working as a community like the anonymous humble stonemasons, carpenters and others from the craft guilds who built the great cathedrals.

In the early years of the Bauhaus, students were trained in craft, drawing and painting, science and theory. The educational methods employed in the Bauhaus were influenced by Johannes Itten who taught there between 1919 and 1922. Itten himself was influenced by educational theorists like Froebel, Dewey and Cizek. The educational methods (intended to be applied to children's education) focused on studies and findings of child learning (Crinson and Lubbock 1994). This was expressed in the six-month basic course or Vorkurs devised and run by Itten that dealt with analysis of form, colour contrasts, composition with textures, problem solving and expressive freedom. The Vorkurs moved from simple concepts and progressively became more complex. To Itten, the Vorkurs was a spiritual rebirth for his students, returning them to a child-like state, from which they would (with his help) develop their inborn abilities. According to Crinson and Lubbock (1994), the Vorkurs marked a radical shift away from the ideas underlying both academic training and pupillage that objective knowledge and skills were built on the basis of prior learning. In contrast, Itten advocated that every problem had to be thought out from scratch (Crinson and Lubbock 1994). The idea was that each problem existed on its own merit and you basically reinvented the wheel each time. 


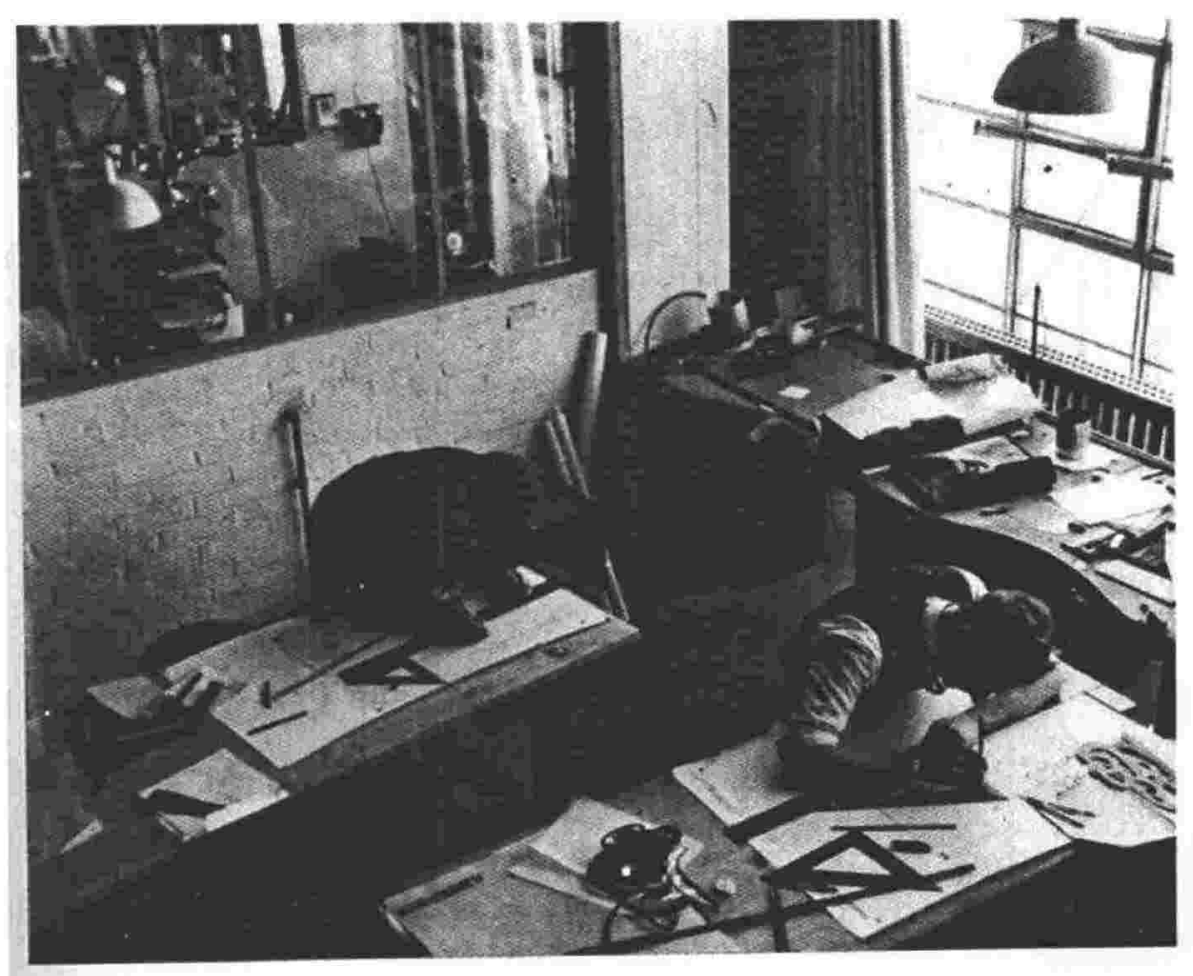

Figure 1.17. Bauhaus Metal Workshop (Source: Westphal 1991:83)

After the Vorkurs, students spent the next three years learning craft in a workshop with a "workshop master" in charge. There were workshops that individually dealt with different materials: wood, metal, fabrics, glass etc. The workshops were used to produce products for sale, therefore reinforcing the craft/work ethic - the practical approach - of the Bauhaus. In line with the workshop/craft philosophy, students were called apprentices, journeymen, and junior masters and the general programme was based on: "manual skills, avoidance of rigidity, creativity and individual freedom of expression" (Brown 2002). The principal idea of the training was: learning by (through) doing or making. Even the painters who came to the Bauhaus, taught art skills in this situation: not "high art" theory, but the theories and practice of colour, geometry and the analysis of form (Brown). In this environment, students were immersed in the realities of their craft. 

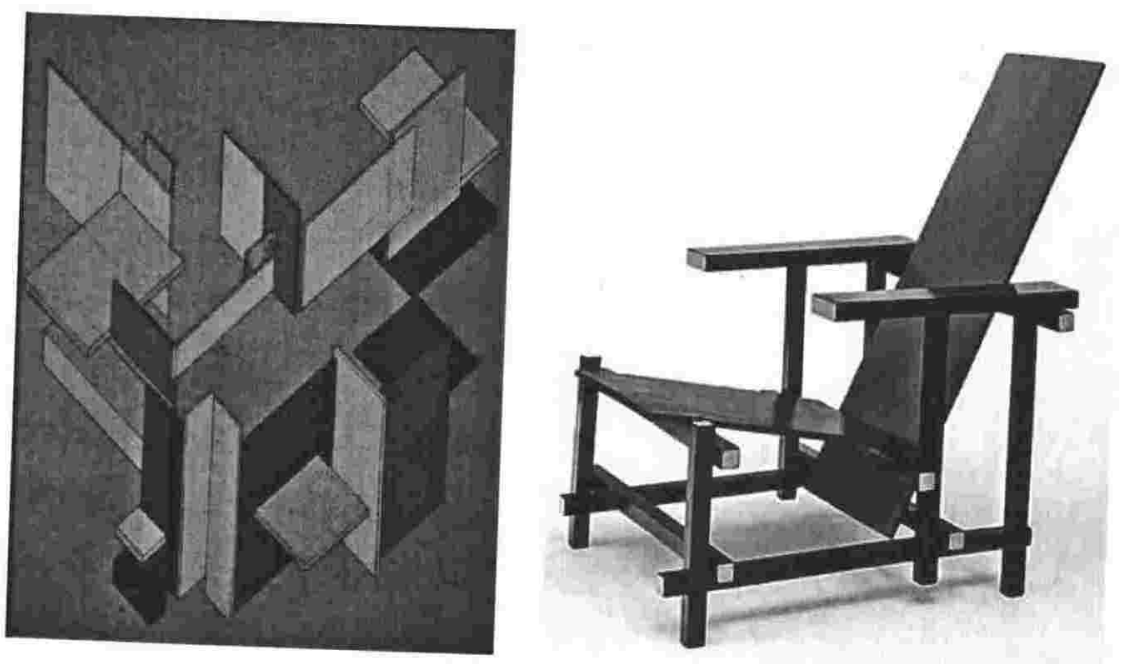
Figure 1.18 Left: Space-Time Construction, Theo van Doesburg, 1923. Right:
Gerrit Rietveld, Red blue chair (Sources: www.mtholyoke.edu/courses/mtdavis/243/destijl/doesburg.html; http://www.mtholyoke.edu/courses/mtdavis/243/destijl/index5.html)

The Bauhaus was always in a constant state of flux. In the early years (before 1922) there was a "mixture of social commitment, expressionism, and craft based mystical romanticism" (Brown 2002) partially due to the influence of Itten (who wore priestly robes and had a mystic air about him). During this early period the workshop was seen as a "sacred place" equivalent to a monastery in the Middle Ages with all craft workers (masters and apprentices) dedicated to a great creative harmony (Brown 2002). Around 1922 the Bauhaus began to succumb to the influences of the Dutch De Stijl movement (fig. 1.18) and Russian Constructivism. A crafts approach to design was not actively embraced by these movements that saw the process of design as one of form making derived from an analysis of function. Under De Stijl and Constructivist influence, the workshops were no longer seen as craft training places where design arose out of craft techniques but rather centres for the production of design prototypes - which were designed first in studios. Design and craft (the making of things) were split into two different processes - design and production (Crinson and Lubbock 1994, Brown). The design studio hence became the most important part of the Bauhaus teaching environment where design then production became the key sequence. Whereas before the workshop had been the centre of the Bauhaus, now it was the design studio. 


\section{Architecture at the Bauhaus}

It is interesting to note that architectural training did not appear at the Bauhaus until after the shift in focus to the design studio. For a long time in its history, the teaching of architecture did not take place at the Bauhaus (it previously occurred in the office of Walter Gropius). Gropius' aim was to have the crafts well established before the architecture course began (Broadbent 1995). It was not until 1928 when Gropius felt that the crafts had matured enough that he introduced a nine-semester architecture course headed by Hannes Meyer. A year after the introduction of the architecture course Gropius resigned from his position and Meyer was appointed Bauhaus director. Meyer radically changed the program to one that emphasised the architect's social responsibility and research-based design methods (Risebero 1979). He further divided the course into two parts: theory and practical building. Subjects taught included psychology, sociology, economics and engineer-taught subjects like heating, daylighting, ventilation, statics, building design and technical drawing (Broadbent 1995). When Mies van der Rohe replaced Meyer as director in 1930 he eliminated psychology and sociology from the curriculum and replaced them with "handicraft, technical and artistic training" (Mies cited in Broadbent 1995). Students could bypass the basic course (Vorkurs) and could enter, with no experience in the other craft workshops, the workshop on principles of building. In addition to the previously mentioned environmental subjects students were taught building law, mathematics and physics, apartment and town planning and design of urban infrastructure. Mies himself taught studio in the last three semesters. These modifications effectively shifted the training away from actual construction to where, according to Broadbent: "there were no live projects any more or any social content in the work" (Broadbent 1995).

The "radical" methods of the Bauhaus however were not tolerated by several conservative groups in Germany most important being the Nazis. The ideals of the school - freedom of thought for the individual along with responsibility to society - found itself at odds with the authoritarian nature of the Hitler government (Westphal 1991). After moving from Weimar to Dessau and going 
through three directors - Gropius, Meyer and Mies Van der Rohe - the school was eventually shut down by the Nazis in 1933 .

In the 1930s many schools in Britain and America made a dramatic shift away from the French methods of the Beaux Arts toward those of the Bauhaus school. This shift can be linked to the new German immigrants escaping the Nazis during the mid-30s. For instance: Walter Gropius became the head of the architecture department at Harvard University in 1936 while Ludwig Mies van der Rohe became the head of the architecture school at the Illinois Institute of Technology in 1938. These changes resonated among the schools in America and Britain.

The Bauhaus had tremendous influence on design thinking and teaching. It influenced the change from learning design according to preset requirements (aesthetics) to the actual learning of design as an activity of individualism. Unlike the Beaux-Arts, which depended on copying and understanding historical styles and methods, teaching in the Bauhaus centred on teaching individual creativity as a means of problem solving. This was something the Beaux-Arts had refused to accept. Also like apprenticeship and pupillage, instruction at the Bauhaus was of a practical nature, providing actual work with materials in the shops and on buildings under construction.

Unfortunately, the Bauhaus also defined the further separation of design from the act of making completing the shift of learning from the building sites into the classrooms. Although the Bauhaus challenged the Beaux-Arts tradition of design education, the basic studio-based learning model remained unchanged. This model involved the student doing a hypothetical task and being criticised by a studio tutor or master. While this was termed "learning by doing" and was celebrated as a merit of the Bauhaus, it is clearly not similar to the learning by doing experienced prior to the Renaissance. Learning design hence became an abstract activity divorced from the realities of building. Because students no longer had an investment in the tangible product, they relied heavily on idealised notions of it. This was a continuance of the diminishing of practical knowledge from the act of designing. In the end the Bauhaus, which started out as an "antidote" to the Beaux-Arts approach to architecture and teaching, ended up reinforcing it. 


\section{The Oxford Conference}

For three days in April 1958, hand picked educators and members of the RIBA Board of Architectural Education met at Magdalen College, Oxford to discuss the state and future of British architectural education. At the end of the "Oxford Conference" six "recommendations for action" were decided upon:

1) The level of education for entry upon training should be raised to correspond with that for university entrance;

2) Entry to the profession through courses based on, and leading to, the external examinations of the RIBA were restricting to the development of a full training for the architect and should be discouraged and eventually abolished;

3) All suitable architectural schools should be 'recognised' and situated in universities or institutions where courses of comparable standard can be conducted;

4) Courses of training should be either full-time or combined or sandwich courses in which periods of training in a school alternate with periods of training in an office;

5) Other forms of training should be provided for students who do not wish or are not likely to become qualified architects; and

6) The development of post-graduate studies in architecture should be encouraged so as to enlarge the range of specialised knowledge and advance the standards of teaching and practice.

Jenkins 1961, Martin 1958)

This was the turning point or "epochal event" (Russell 2002) that defined the form of education that exists today (in Britain at least). Crinson and Lubbock (1994), however, argue that this was simply the consolidation of a series of events involving the modernist elements of the RIBA. According to Crinson and Lubbock (1994), these elements sought to eliminate the RIBA examinations (which they thought were out of date) and advocated an academic approach to 
architecture that was best, suited to "the modernist ethos". Here they offer an explanation:

[The conference] clearly expressed the growing sense that [RIBA examinations] were inappropriate and out of touch with contemporary needs; that an attempt to assess social and tecquisition of a static body of knowledge was incompatible with the flux of the also enable many schools Examinations also enabled to remain relatively immune from reforming policies. associations with the continuation of pupillage with all its accumulated associations with the ad hoc, and its myths of neglectful and corrupt practices.

... those very examinations were now seen as supporting the continuation of a practice that excluded the range of modernist interests and forms of training. The accumulative, skill- and knowledge-based aims of pupillage were anathema to these bureaucratic and

The schools rather than pupillage would now be the ideal place for modernist initiatives, especially those versions of the Bauhaus method which were inconceivable outside
them... (Crinson and Lubbock 1994).

Regardless, the "Oxford Conference" made colleges, universities and polytechnics responsible for the transmission of knowledge in architectural education. Raising the standards of entry into architectural schools and recommending that courses should be full-time (or sandwich) ${ }^{6}$ and held in universities $^{7}$ or similar institutions made sure the architect's education was more academic rather than practical. Leslie Martin confirmed this by stating in his report of the incident "[the universities] will expect and have a right to expect that knowledge will be guided and developed by principles: that is, by theory" (my emphasis) (Martin 1958). The education of the architect (by virtue of its location) was directed to a vision of Architecture as an academic pursuit, rather than a practical discipline, with design more rigorously underpinned by theory (Crinson and Lubbock 1994). The process of distancing the architect from the act of building begun so many years ago during the Renaissance was now complete. The subsequent movement of architectural training from the site and into the studios of academia (a culmination of 2000 years of change) is characterised today in a distinct (or seemingly so) separation of theory/design from the realities of architecture. At the source of this claim or observation is the current challenges faced by schools of architecture today.

\footnotetext{
${ }^{6}$ A sandwich system meant three years in, one year out, followed by two years in and one year out-the system that
generally prevails today in British Schools. In America there is no time spent out.
University level architectural
} 


\section{Education in the late Twentieth Century}

During the 1970s as Modernism lost its credibility and architectural thought retreated into the academy, an explosion of architectural theory spearheaded by personalities like Venturi, Tschumi, and Eisenman occurred in most schools of architecture. Academic location facilitated this trend as schools were pressured to achieve the same standards, academic norms and values as other disciplines within the university (Gutman 1987, Stevens 2002). Technical research became an important criterion for appointment and promotion and while important for informing teaching and increasing the knowledge base, it became increasingly theoretical. Research was not necessarily practice-oriented and took place in particular sub-disciplines, e.g. lighting research as a branch of physics, engineering or physiology (Stevens 2002). However, the areas that took up most architectural focus were (and probably still are) history, theory and criticism. Architectural trends like postmodernism, deconstruction, neoclassicism, and the current enthralment with genetic algorithms was a result of this focus. Architectural schools became places for such activity where academicians frequently referred to the work of philosophers like Foucault and Derrida.

The last three decades of the twentieth century more or less maintained this direction as established by the Oxford Conference and other initiatives in American Education (for instance; studying architecture solely at the graduate level). By the start of the 21 st century, the transference of knowledge, tradition and praxis in the profession was carried out by schools of architecture located in universities and quality controlled by local architectural bodies (like the AIA or RIBA).

\section{Architecture Education Today}

Architectural education in 2003, while largely diverse has several elements in common. Generally ${ }^{8}$ most schools start with an introductory first-year course devoted to the fundamentals of architecture. This resembles in some way the Bauhaus Vorkurs and embodies the Bauhaus philosophy of unlearning or deschooling. This is followed by three or four years of study culminating in a

\footnotetext{
${ }^{8}$ There may be subtle differences depending on the location of the school.
} 


\begin{abstract}
"first degree". In Britain and some Commonwealth countries students spend a year out in an architectural practice after finishing their first degree (RIBA Part I). This is followed by a two-year diploma course in which students continue the pattern of the second and third years. In America' and other countries (like New Zealand) students do not take a "break" but rather stay in school for five years before doing two years of "internship" before registration.
\end{abstract}

There are some schools however that are independent of the academy namely the Architectural Association (AA) in London and the Boston Architectural Centre (BAC). It is interesting to note that Boston Architectural Centre utilises a system of education to integrate both academic study and professional experience. This is quite similar to pupillage and pre $20^{\text {th }}$ century British education where students work in the design profession during the day and attend classes at night. In contrast the Architectural Association (AA) while separate from universities and "academic" teaching engages in "avant-garde elitism" (Crinson and Lubbock 1994). They, more than any other school, are theoretically based.

"Study" in schools of architecture consists of work done in design studio and other supporting courses. Studio is the focal point as it was in the Beaux-Arts tradition and the part of it that is least questioned. Although, on paper, studio takes about $40 \%$ of the curriculum, time and effort usually takes up roughly $60 \%$ to $80 \%$ of the total time. According to Crinson and Lubbock; "No such studios existed either in pupillage or in the building lodge, where learning to design was an integral part of learning to draw and the other functions of an office apprenticeship." (Crinson \& Lubbock 1994). As in the Ecole des BeauxArts, studio projects (usually four to twelve weeks long) generally grow in complexity and scale as the year(s) progresses. In addition to design studio there are lectures on the history of architecture, structures, construction and other subjects. These subjects are usually assessed by examinations or ongoing coursework. In all cases the final year design project usually requires students to design a complex scheme of their own choice, a kind of "masterpiece"

\footnotetext{
${ }^{9}$ In America there are actually two p and a two-year graduate Master of Architecture architectural programs. A five-year Bachelor of Architecture program becomes three years if the student has no prior architectural coursework. not to eliminate the B.Arch degree in favour of a single professional degree.
} 
reminiscent of the final project in the Ecole des Beaux-Arts. This scheme is usually hypothetical and lacks most of the variables that govern the realities of architecture.

If we look closely at today's education we can see it is essentially not much different from the Ecole des Beaux-Arts. The following similarities exist:

- Training for architecture is firmly established in some kind of academy (university-level institutions) where the design project dominates the curriculum.

- Studio teaching takes up a large portion of the syllabus and is located in a studio or atelier with a culture of its own.

- Teaching in studio is accomplished primarily through individual rather than group instruction. The teacher interacts with the student at set intervals to review the student's work so far.

- Students are given increasingly complex problems as they move up in years. There is a grand project at the final year where the student espouses a personal theoretical position.

- Design projects are supplemented by lectures and elevated above technical aspects of the curriculum.

- Students' work is assessed by a jury system that uses outside evaluators.

- Technical (and other) subjects are taught outside of studio in lectures.

- Words such as charette and jury still exist in the vocabulary of some schools.

\section{A Difference}

It can be argued that despite these similarities one (seemingly) major difference in education today is the application of digital technology in schools of architecture. In some studios, the drawing board has been shunted aside in favour of the computer. The architecture school at Columbia University, for instance, recently established a design course called "Paperless Studio" because all the design phases in the third-year digital media architecture courses were 
done on computers (Pontgratz and Perbellini 2000). Many other schools have established similar programs (Boyer and Mitgang 1996) with a growing number requiring students to purchase CAD-capable laptops (Mitgang 1997). Soon (within the next five, ten or more years) students of architecture worldwide will be using the computer as the main instrument for producing design work for examination. Physical models will still be used but they will be generated from a computer-milling machine using the latest CAD/CAM technologies. The use of freehand sketching will take place on a digital tablet and study drawings will be digital representations of architecture and other digital design iterations. Facilitated by Internet technologies, researchers and educators are experimenting with Virtual Design Studios (VDS) and are being immersed in Virtual Design Studios that are a means of linking studios separated by distance and in some situations, time. A few schools have also begun "online juries" where students are critiqued by practitioners and faculty around the world (Mitgang 1997).

The influence of the Beaux-arts on education today is enduring, and the change in tools from the pencil and drawing board to the computer seems to be the only major difference between education today and that of a century ago. Despite its novelty, however, the computer has been adapted to the culture and rituals of architectural education. The 500-year journey from pen and paper to computers has provided the context for a design education that has remained basically the same: students learn in a studio by doing hypothetical projects and being criticised while knowledge is supplemented by lectures.

Architectural education, regardless of media and environment, remains immersed in the teaching model of the Ecole des Beaux-Arts and hence inherits its problems. Far reaching advances in building technology and science has only intensified the same flaws that characterised the French system. As a result, the same criticisms of the Ecole can somehow be levelled at the current model of education, that is: producing students who display a lack of interest in and knowledge of modern technologies, issues and processes that affect (and are affected by) architecture. 


\section{Conclusion or the Room is Dark}

More than a thousand years ago Vitruvius stressed that an architect's education should result in the mastery of both practice and theory. He said:

Architects who have aimed at acquiring manual skill without scholarship have never been able to reach a position of authority to correspond to their pains, while those who relied only on upon theories and scholarship were obviously hunting the shadow, not the substance... (Rowland and Howe 1999).

This position embraced the need for a marriage of theory and practice in architectural education. This marriage was evident on the building sites of the Middle Ages where the student was exposed to the theories of geometry and the knowledge of construction within the project itself. The direct involvement in the planning and realisation of actual building projects facilitated a wholesome integrative education for the aspiring architect.

This environment for learning was eventually transformed, during the Renaissance, as a result of the profession's shift from manual processes to the art and theory of design. Alberti advocated this shift by seeding the idea that architecture was predisposed to theory. The use of the sketch or study drawing influenced the shift by allowing Renaissance architects to become scholars and artists who investigated theories and conjectures through drawing. The status of the architect was thus elevated from "one who made" to "one who designed".

The next significant step in the evolution of design teaching from apprenticeship in medieval society to studios within academia was embodied in the institutionalisation of architectural education between the $17^{\text {th }}$ and $19^{\text {th }}$ centuries. Alberti's viewpoint was maintained through the Académie Royale d'Architecture (which was in turn modelled on the academies of the Renaissance). The Ecole des Beaux-arts, which emerged out of reforms to the academy, promoted the split between technical knowledge and design. Technical knowledge was acquired through optional lectures in lecture theatres while design was taught abstractly in an atelier. The Ecole des Beaux-Arts established the atelier (or design studio) as the centrepiece of learning and used the hypothetical project as a tool for learning.

Alternate approaches to this model either failed to challenge or reinforced it. The counter approach to the French, the pupillage system in Britain, failed to 
evolve into a credible form of structured practical training in the face of rapid technological advances. Experimentation with alternate models, in particular the arts and craft approach to education, failed to offer an alternative to the highly touted French and American education systems. Subsequent approaches (like the Bauhaus) completed the separation of practical and/or technical knowledge from the learning of design and emphasised theory as the focus of design.

Today, education is characterised by elements of the Beaux-Arts model of design education. Design is taught in design studios, technology is taught in lecture theatres, the focus of education is the project and students' works are assessed by juries. Along with the characterisation come the weaknesses of the Beaux-Arts. Design (an integrative activity) is separated from the requisite technical knowledge base (which is delivered in a different environment). The Beaux-Arts model of "learning by doing" used today is devoid of much connection to the real world. Hypothetical design projects offer little opportunities to test solutions by exposing them to the rigors of design decision-making and judgment as they occur in reality.

These weaknesses are highlighted by the significant differences from the educational practices of the middles ages. Even though architectural education is still about mentorship and apprenticeship in which the student learns the skills (theory and practice) needed for his/her craft by watching and mirroring the more experienced master, this has changed significantly. In the past, the project was realised to the end and not subject to other timelines. The student would see firsthand the projects impact on context and use. Today design problems attempted by students are rarely more than ten weeks long, leaving students with no time for resolution, appreciation or reflection. During the middle ages, ancillary knowledge (e.g. structures, services) was learned at the same time while doing the project. Today they are taught in different courses from studio leaving it to the student to make the connection.

It would be reasonable to say, current architectural training is attributable to the evolution of teaching from apprenticeship in medieval society to university lecture theatres, seminar rooms and studio today. It is also reasonable to contend that the dilemmas identified above in the prevailing model of design education are consequences of the location of education in academia. Loosely 
speaking, one would associate the academy with the act of thinking and creating knowledge, however, thinking requires hypothetical premises. Architecture, unfortunately, exists in the "real" just as it is located in the "imagined". In the medieval lodges students did not just learn how to design or think but also how to integrate all the many aspects of architecture (and literally witness their integration) on an actual site. The academy as it stands, counters this, making it a difficult environment for effective instruction in architecture.

The position, with regards to the academy, suggests a pressing need for a possible "relocation" of architectural education. There are several reasons why this would not be a good idea:

"Relocating" is expensive. The strong influence of the Ecole des Beaux-Arts, for one, has produced a design studio so embedded in architectural education and reliant on the academy that any changes would require significant restructuring of the prevailing system. This would be an expensive (time and money) proposition even at the best of times.

Problem Based Learning. Learning techniques based on the project are "widely promoted as a method of achieving deep learning and simultaneous mature participation within the educational process" (Skinner 2000). Removing the project from teaching would deny students the advantages of experimentation and focus.

Alternate systems might not support teacbing. Giving the student the opportunity of watching an experienced designer tackle a problem, go about implementing its solution, and reflecting on the end-product (as was done during pupillage) would be an ideal situation. The complexity of building and the motivation of market forces make this a difficult option. It would be difficult for firms to find the time, adequate projects or staff to provide adequate coaching that balances the intellectual and the practical in a structured environment.

The reputation of the academy. Institutionalised education promotes learning outcomes that are more easily predicted, controlled and standardised in the institution. There is also the general perception in society that anything outside formalised, institutional education is of lesser value and lower calibre. 
Since it is clear that architectural instruction in academia will not or cannot be abolished, there may be no alternative but to continue with the current model. It may however be possible to remedy some of the apparent deficiencies of the "simulated" studio setting by modifying selected aspects as well as the manner in which the student interacts with the traditional studio project. This move nonetheless embodies some challenges (inherent in the present model) that conspire against such remedy. In the next chapter we will look closely at the consequences of the current pedagogical model and the resultant challenges facing any effective remedies to architectural education.

\section{References}

Beinhart, J. 1981. Structure of the content of Design. In Architecture Education Study, Volume I - the papers.
Andrew W

Boyer, E., and L. Mitgang. 1996. Building Community: A new future for Architecture Education and Practice: $A$ Special Report. Princeton: The Carnegie Foundation for the Advancement of Teaching. Broadbent, Geoffrey. 1995. Architectural Education. In Educating Architects, edited by Martin Pearce
and Maggie Toy, 10-23. London: Academy Editions.

Brown, Alex. 2002. "The Modern Movement in Design". [cited 1 Jul 2002]. Available online from <http://www.geocities.com/archinode/modern_movement.htm>. Buchanan, Peter. 1989. What is Wrong with Architectural Education? - Almost Everything. The
Architectural Review 1989, no. 07: 24-26.

Chafee, Richard. 1977. The teaching of architecture at the Ecole des Beaux-Arts. In The architecture of the Ecole des Beaux-Arts, edited by Arthur Drexler, 61. Cambridge, MA: MIT Press.

Coldstream, Nicola. 2002. Medieval Architecture. Oxford: Oxford University Press. Crinson, M., and J. Lubbock. 1994. Architecture: Art or Profession? Manchester: Manchester University
Press.

Davey, Peter. 1989. Profession or Art? The Architectural Review 1989, no. 07: 59-66.

EAAE \& CEMBUREAU. 2001. The Educational Community's Views of Challenges in Architectural Education. Pan-European Survey 2001: Interpretative Report, 8 November 2001.

Egbert, Donald Drew. 1980. The Beaux-Arts Tradition in French Architecture. Princeton: Princeton
University 
Ettlinger, Leopold D. 1977. The Emergence of the Italian Architect during the Fifteenth Century. In The Architect: Chapters in the History of the Profession, edited by Spiro Kostof, 96-123. New York: Oxford University Press.

Gutman, Robert. 1987. Education and the World of Practice. Journal of Architectural Education 40, no. 2: 24-25.

Harvey, John. 1972. The Mediaval Architect. London: Wayland Publishers.

Herbert, Daniel M. 1993. Architectural Study Drawings. New York: Van Nostrand Reinhold.

Hill, Pamela J. 2000. "Report of the NCARB Carnegie/Boyer Review Task Force." April 2000. [cited 17 May 2003]. Available from <http://www.ncarb.org/forms/carnegie.pdf>.

Jenkins, Frank. 1961. Architect and Patron. London: Oxford University Press.

Kostof, Spiro, 1977. The Architect in the Middle Ages, East and West. In The Architect: Chapters in the History of the Profession, edited by Spiro Kostof, 59-95. New York: Oxford University Press.

Martin, Leslie. 1958. RIBA conference on architectural education. Architects' Journal 127 (22 May): $772-$ 77.

Mitgang, Lee D. 1997. Saving the Soul of Architectural Education: four critical challenges face today's architecture schools. Arcbitectural Record, no. 5 (May): 124-30.

Nicol, David, and Simon Pilling. 2000. Architectural Education and the Profession: Preparing for the future. In Changing Architectural Education: Towards a new professionalism, edited by D. Nicol and S. Pilling, 1-26. London: Spon Press.

Pontgratz, C., and Maria Rita Perbellini. 2000. Natural Born CAADesigners: Young American Architects. Basel: Birkhäuser.

Powers, Alan. 1984. Architectural Education and the Arts and Crafts Movement in Britain. Architectural Education 3: 42-70.

Risebero, Bill. 1979. The Story of Western Architecture. London: Herbert Press Ltd.; Cambridge, Mass.: MIT Press.

Rosenfield, Myra Nan. 1977. The Royal Building Administration in France from Charles V to Louis XIV. In The Architect: Chapters in the History of the Profession, edited by Spiro Kostof, 161-79. New York: Oxford University Press.

Rowland, Ingrid D., and Thomas N. Howe, eds. \& trans. 1999. Vitruvius: Ten Books on Architecture. Cambridge: Cambridge University Press.

Russell, T. 2002. "Professional Studies in Architecture: Architectural Education and Work-Based Learning." 9 Jan 2002. [cited 17 Apr 2003]. Available from <www.cebe.ltsn.ac.uk/learning/wbl/ case-studies/trussell.pdf>.

Schoenauer, Norbert. 2002. "History." 18 Jul 2002. [cited 12 Jul 2003]. Available from <http://www.mcgill.ca/architecture/introduction/history/>. 
Skinner, Peter. 2000. "Studio Teaching in Architecture." 16 Jan 2002. [cited 1 Aug 2002]. Available from <http://www.tedi.uq.edu.au/conferences/teach_conference00/papers/skinner.html>.

Smith, Sir Colin Stansfield. 1999. Architecture Education for the 21st Century. RIBA Review of Architectural Education, October 1999, Chaired by Sir C S Smith. Supported by the Thomas Cubitt Trust, the Interbuild Fund and the RIBA.

Stevens, Garry. 2002. "A brief history of architectural education." 6 Feb 2005. [cited 1 April 2005]. Available from <http://www.archsoc.com/kcas/Historyed.html $>$.

Westphal, Uwe. 1991. The Baubaus. London: Studio Editions Ltd.

Yee, Susan. 2001. Building communities for design education : using telecommunication technology for remote collaborative learning. Ph.D. Thesis, Cambridge, Mass.: Massachusetts Institute of Technology, Dept. of Architecture. 


\section{Challenges facing Architectural Education}

"A lot of architecture school talk is more of art chat and literary theory than architecture. In either case, students are deflected from the true nature of architecture: the elevation, through education, of pragmatics to the level of poetics" (Robert Stern quoted in Architecture, August 1996 p. 90)

\section{VIEWS OF ARCHITECTURAL EDUCATION in general Single most important Challenge to be met in Architectural Education
(open-ended responses, $n=614$ )}

O sustainable architecture, soc, resp. architects

- Improve transter theory $\rightarrow$ construction/practice

- enhance interdisciplinary/conceptual strength

Censure better funding/stafing In arahit. educ.

- put more/less weight on certain subjects

- consider urgent needs in urban development

- Improve role of architects in publlic, in practice

- needs of structural change of educ. system

- put more focus on architecture as a business'

other mentions, generic statements, unreadablo

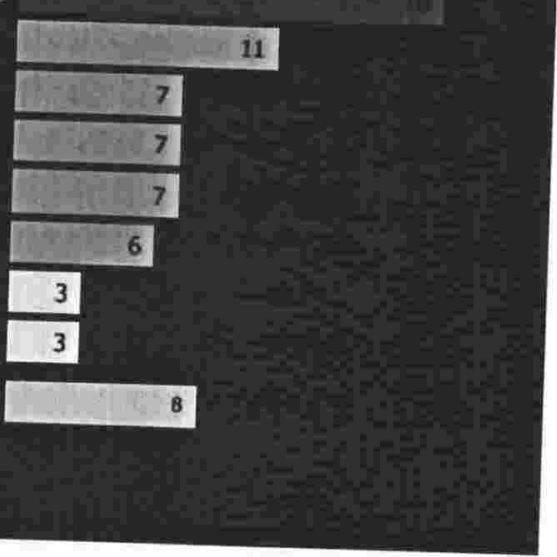

Figure 2.0 EAAE Survey Results (Source: (EAAE \& CEMBUREAU 2001)

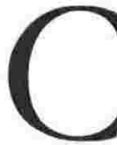

urrent educational methods to prepare students for contemporary practice have been a cause for concern in several architectural organisations around the world. Mitgang and Boyer in reporting to the Association of Collegiate Schools of Architecture (ACSA) claimed to have found a serious "disconnection...between the two separate worlds of architecture education and practice" (Boyer and Mitgang 1996). These and other negative observations and comments (Crosbie 1995, Gutman 1996, Gutman 1987, Stevens 2002) make it evident that architectural education is failing in some way to provide graduates with the kind of education needed for practice. These criticisms place schools of architecture (which, according to Yatt (1993), already emphasise theory) under significant pressure from the 
profession. Schools are therefore compelled to teach a suitable balance of skills that produces students with adequate practical knowledge.

This compulsion has been confirmed by several reports on the subject. In the Mitgang and Boyer report of 1996, as part of a framework for renewing education to deal with the challenges of architecture today, the authors recommended a reconnection between education and practice (Boyer and Mitgang 1996). In addition, a recent survey by the European Association for Architectural Education (EAAE) found that in the opinion of European architectural educators, "sustainable architecture and societally responsible architects" and the "better transfer [of knowledge] from theory to practice" were the most important challenges facing the education of architects (EAAE \& CEMBUREAU 2001). In response to these recommendations there needs to be a viable means of helping students produce architecture that is inhabitable, functional and responsible environmentally. This should be done without diminishing the value of history, culture and theory in architectural education.

Chapter one traced the issues outlined above to the location of architectural education in academia. It was determined that relocation was not a viable option to remedying the situation. Instead it was recommended that any remedy should address the deficiencies in the model and selectively modify aspects that could contribute to teaching students about architecture that is inhabitable, functional and responsible environmentally. This chapter (Challenges facing Architectural Education) outlines some of the features of architectural education that pose challenges to effectively defining a path of renewal. Meeting these challenges forms the basis for any response to the concerns of the previously outlined reports and findings. The chapter concludes by identifying the design studio as the setting for such change.

\section{Challenges to lighting the room}

As observed, most writers, critics, committees on architectural education have identified a common challenge facing architectural education today: students seem to lack the practical knowledge needed to create architecture that is fit for purpose, cost effective, sustainable and a delight to clients and users. As explained in the previous chapter this situation is borne out of the acute 
separation of designing from the sites of building. Remedying this apparent lack of practical knowledge is influenced by the following characteristics:

- Architecture is considered an intellectual pursuit or "high art".

- The product of design is often valued above the process.

- The overwhelming complexity of technology restricts the time allocated for technical studies.

- The split in curriculum between taught courses and studio affects students' perception of their integration.

- Adding an important dimension like sustainability places pressure on the students' workload.

These features translate into the challenges to be overcome and the opportunities to anticipate if students are to recognise that architecture is cost effective, sustainable, constructible and a delight to users in addition to embodying abstract ideas.

\section{Architecture - "high art?"}

The location of schools of architecture in academia favours the perception of architecture as high art. This is reinforced by the continued discernment of architects (by architects) as elite professionals who are independent and superior to other players in the building industry (Buchanan 1989). It is indeed this attitude that has governed the transformation of architectural education; from the building sites through the Renaissance to its current status or existence within the universities and academia. Locating design education in academia has given (perhaps unintentionally) legitimacy to the experimentation of new forms and abstract ideas. This ultimately separates the aim of experimentation from the idea that architecture is immersed in reality. Yatt (1993) confirms this by arguing that schools of architecture tend to emphasise personal vision over and above problem solving skills resulting in the narrow definition that design is "the exploration of proportional, aesthetic, possibilities only" (Yatt 1993). Crinson and Lubbock (1994) also argues: 
... despite the thetoric of functionalism, the space [made vacant by the abolition of the Orders and other Beaux-Arts paraphernalia] was filled by the discretion awarded to teachers within the studio. Design, emptied of culture or notions of tradition, became the result either of abstractions from manifold reality or of personal expressive impulses. The obvious and to some extent admitted casualties of this were a marked diminution of interest in established notions of sound building, as well as in practical building skills and drawing ability (Crinson and Lubbock 1994).

The result of this approach is particularly apparent in the final projects undertaken by senior students in architectural schools. In most schools the final project is chosen and programmed by the student and attempts to make a "grand architectural statement of surpassing generality, even perhaps siteless in its effort to render fully the purity of its intellectual endeavour" (Hogben 1989). To Peter Buchanan (1989), these studio projects are increasingly graphically elaborate, visually compelling, concerned with immediacy and impact and yet lacking elements that make it fit for purpose, cost effective and sustainable (Buchanan 1989).

The reason for this, theorises Yatt (1993), is the notion that students are being taught that architecture as art is exciting, creative, intellectually gratifying and celebrated. On the other hand architecture as technology and practice is tedious, has no room for creativity, and is something to be learned after the exciting years of architecture school (Yatt 1993). In his article entitled: What is urong with Architectural Education? Almost Everything, Peter Buchanan (1989) is a bit less forgiving as he claims that reality is dismissed as too mundane and demeaning to stimulate students' creativity (Buchanan 1989).

Responding to this could involve emphasising technical knowledge in schools over and above intellectual pursuits. However, all "the constraints and complexities required by society, users and clients are critical to the vitality of the architecture" (Yatt 1993). The critical thinking and problem-solving skills acquired in a theory-oriented course is essential for students to approach the new challenges of sustainable growth and technological building in the $21 \mathrm{st}$ century. An intellectual approach enables students to critically adjust their thinking to adapt to and accommodate rapid changes taking place in culture and technology. This requires or demands an equal consideration of art (or theory meaning) alongside science or technology. The challenge is, therefore, to make technical knowledge available and more interesting to students while 
maintaining suitable investigations in the aesthetic and theoretical aspects of architecture.

\section{Product or Process?}

Another circumstance that is related to the current state of architectural education is the prevailing favourable attitude towards the architectural product at the expense of the process of design. As a legacy of Beaux-Arts education, architectural form as a product that exists for its own merit is communicated (intentionally or unintentionally) to students as important. In the design studio the student is taught how to design or synthesis disparate elements by means of criticisms, demonstrations, and instruction. The students' ability to pull various pieces of knowledge together to make architecture should be enough to determine their competencies to make architecture. However, in current education, the dynamic, interactive process of design is rarely evaluated and acknowledged. According to Claridge (1979):

Design competence is "judged almost exclusively on the final product - the physical product as represented, usually, through drawings and models (Claridge 1979, 8).

Claridge's observation is particularly evident in the effort students put into architectural presentations (graphic or otherwise) and the assessment of these "products" by tutors in order to furnish grades. One main reason for this bias lies in the process of conducting a "final review", which normally privileges the ability to produce stylish "presentation" drawings, no matter how inadequately the underlying design issues may have been worked out. In reviews (or final crits), reviewers comment on the "objects" students present before them rather than the realisation of the product. There is also no explicit reward for students' comprehension or analysis of user or client needs (Nicol and Pilling 2000). Rarely does an evaluation of student work include examination of the many steps that led to a final design: the multitude of ever-changing sketches and alterations to models. Rarely also does it involve consideration of a diary of decision-making showing awareness of the many complex parameters of a given project (Weber and Schnier 1999).

The use of computers or digital technology in education perpetuates this problem by offering exciting new prospects in graphic representation and 
visualisation. With architectural education being product centred, students tend to think of design computing more as a way of improving a) the image of the product or b) simply, the product (Dutton et al. 2002).

Additionally, while the product is rewarded and assessed, the process is left largely for the student to learn or "pick up". The consequence of this is the fact that students of design often miss the evasive notion that design is a deliberate and conscious act. According to Andy Pressman: "students should be made conscious of the design process" and focus less on the product since this tends to narrow the focus for architectural practice (Pressman 1997). They miss that not only is the design process important, but also the knowledge that there is a process to be learnt and mastered. It is therefore important for the student to realise the existence of a conscious process of putting the parts together. Any other focus offers little opportunity to make useful explorations of alternative methods and approaches to design.

Because emphasis on appearance takes precedence over the process and the quality of ideas behind the design project, students often forget about life within their buildings and instead tend to get carried away with the notion of the building as an aesthetic envelope. The student then fails to consciously employ a means to assemble a product that is safe for users, fit for purpose and pleasing to the senses. To make matters worse, the student as a result is penalised when this ability to synthesise is not reflected in the final product. Unfortunately, due to the myriad of technical issues involved in design, the teacher rarely has time to show students any explicit or systematic method of design. Also, due to implicit messages transmitted by design teachers, it is not communicated enough to students that learning design not only involves creation but also largely involves the recognition and analysis of problems and the contexts within which they exist (Ledewitz 1985, Dutton 1987).

A sensible response to these issues would be to change the attitude of students towards process. This can be achieved by promoting the learning of process as the main objective of design teaching. By understanding the student's design process and communicating that understanding, the teacher can encourage the student to recognise and understand the "discovery - invention - production process" (Ledewitz 1985). This requires more time allocated to teaching and 
learning. This promotion would give the student a grasp for manipulating the issues of design or at least an awareness when there are essential issues missing from the finished product.

\section{Too much technology, not enough time}

Another argument that seems equally valid claims that the difficulty in achieving a proper skills balance by students is attributable to the sheer volume of work that characterises architectural education. In the 1940s, Harvard's Joseph Hudnut calculated the length of time it would take to learn everything on a list of all the subjects that he deemed essential for a sound and complete architectural education. The result was 22 years (ACSA 2003). Architectural students today have even more on their plate to grapple with than their predecessors of fifty years ago since the technological achievements of the last 50 years have dramatically increased the number of issues that exists within architecture. Today, there is a great deal more to the building disciplines than ever realised in the previous 2,000 years. We know more about buildings than at any other time in history and have a finer control over the environment. This increased scale of building and fine-tuning results in a greater complexity in plan, structure and fabric. Robert Gutman confirms this by observing that this intricacy is caused by:

(an) increasing number and diversity of activities included in buildings leading to the
invention of many new building types; the variation in size and design requirements of
rooms and spaces; and most important, the development of many separate technical and
environmental control "systems" which must be integrated in the total design (Gutman
1988).

Technology is not the only contributor to the volume of work in education. Due to widespread changes in society such as changing patterns of living and working, an ageing population and concern for the environment in terms of sustainability and conservation, architects are increasingly called on to demonstrate greater sensitivity in their designs to the needs of building users, society and the environment (Nicol and Pilling 2000). This "social" sensitivity, coupled with the technical complexity of buildings, can only be achieved with more than a passing knowledge of the issues. 
The pressures for the modern student to know more and assume greater responsibility upon graduation is overwhelming, even when tempered with the realization that not all needs be learned in school. Though no architecture course today is 22 years long, the student is expected to know as much as possible from Hudnut's list in the four to five years of study. $\mathrm{He} / \mathrm{she}$ is expected to accumulate this knowledge from a very wide base ranging from factual matters to conceptual ones, from being scientifically and practically based to less tangible matters (Claridge 1979). The student is also required to select from this the information relevant to each particular design task, and to seek out additional information appropriate to particular needs (Claridge 1979). The difficulty to achieve this lies not only in the "short" time span of education but also the fact that studio teaching is not sufficient to cover all the areas of knowledge in architectural education. This is also made difficult because there is usually time and energy for only one studio course each semester. Also, if the only source of knowledge for the student is the studio then he/she could not attain the required body of knowledge in the few studios during his/her studies. This problem has been recognised and responded to in various ways. One response to this increasing complexity is usually to cover more material in existing courses or add new courses (adding to the courseload of students or decreasing the number of electives or general study courses). According to Brady (1996), architecture is already infamous for high workloads, which causes increased pressures on students and an unhealthy studio culture. Other solutions include applying studio-type problems to lecture courses and sharing studio with other courses. However, students would find it difficult to find time to do so many studio problems adequately and it is sometimes difficult to coordinate because courses often do not coincide in terms of pace, personnel and time (Brady 1996).

Due to the changeability of the issues and the rapid acquisition of information about the world we live in, no matter what action is taken to minimise the imbalance between time and technology it still remains a concern. The current situation has been proven incapable of supporting the amount of practical knowledge that the student has to learn to create an architecture that works. Since the studio is not linked to an ongoing project where technical knowledge 
is dispensed when it is needed, there needs to be a means or method through which relevant, practical knowledge is transmitted to the student. The challenge therefore is to find some means of dispensing technical knowledge into studio at the right time without compromising the teaching of design. The response to this challenge is linked inextricably to the problem of integration.

\section{Disintegration of courses}

Successful architecture occurs when the various disciplines are effectively integrated into a cohesive project. To achieve this cohesion is one of the essential skills of the architect. Other skills involved in seeing possibilities and proposing design solutions to complex and contradictory problems, include the ability to interpret problems holistically, to see the connections not just the parts, and to provide a medium in which things can come together (Smith 1999). These skills, which are required for a multi-disciplinary context, are not only practised during actual construction, but are honed and developed when learning to design. According to Stansfield Smith:

There is a dynamic equivalence between the skills needed to develop a design proposal and the skills needed to realise a design proposal - from identifying the possibility to post occupancy evaluation (Smith 1999).

The complexity of modern buildings and the need for multi-disciplinary teamwork almost dictates that an important challenge to architectural education is the successful integration of other specialist disciplines (structures, systems etc.) into design studio.

This challenge is difficult to overcome when the nature of design education is taken into consideration. In keeping with the Beaux Arts model, most schools of architecture have a basic curricular split between lectures and design studios. In lectures, the student is expected to learn general principles and fundamental bodies of knowledge, which direct and inform all aspects of the design. This includes such subjects like history and theory, structures, environmental systems, and costing. In the studio, the student is expected to apply this universal knowledge to the solution of a particular design problem. In other words, "lectures provide the basic knowledge without which design would be 
random and arbitrary, the studios apply this knowledge creatively and make it concrete" (Gelernter 1988).

This split in the curriculum has had far reaching effects on design education. As it stands, students are expected to refer to the large body of knowledge built up through lectures for use in studios. However, lecture teachers in many schools complain that the essential concepts taught do not seem to show up in students design schemes; and design teachers complain that students do not know the first thing about, say, structures, even though they have spent years in lectures about structures ${ }^{10}$ (Gelernter 1988). This dilemma can be attributed to the fact that separation of activities in studio from those in lectures contributes to the misperception that the activities are separate (Ledewitz 1985). As a result students often miss the connection between acquired knowledge (lectures) and applied knowledge (studio). The technological aspects that influence inhabitation are therefore lost on students as they fail to connect the two. To make matters worse, lecture courses and studio courses rarely complement each other $^{11}$ (Gelernter 1988) and those who teach design are typically not the same people who teach in the knowledge areas. This is perpetuated because, as argued by Purcell and Sodersten (2002), "at a fundamental level there is no direct connection between knowledge that is relevant to what is to be designed and the process of learning how to design" (Purcell and Sodersten 2002). In effect, the students seem to be expected to work out the relationship for themselves.

Gelernter argues the point further by claiming that this situation is a result of a "naive and misleading conception of how knowledge is acquired and applied" (Gelernter 1988). How knowledge is acquired and applied has to be carefully considered if a truly integrative education is to be achieved. In his finalist essay for the AIA/ACSA Walter Wagner Forum entitled: What is the most important single change necessary in the education of architects? Barry Yatt (1993) describes these two kinds of learning as Instruction and Application (see table).

\footnotetext{
${ }^{10}$ This has also been the experience of this writer.

${ }^{11}$ Lecture courses seem to stick to one timetable (sometimes four years long) while studios deal with issues that require technical knowledge that students (especially beginners) will acquire years later (Gelernter 1988).
} 
Instruction

Teacher is active, student absorbs

Imparts "Body of Knowledge"

Lecture

Vicarious learning: passes on what others have learned

Imparts knowledge to student

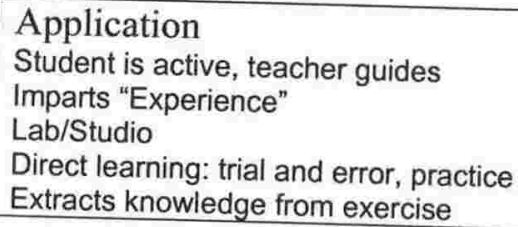

\section{Table 2.1 Comparing instruction with application.}

Both types of learning are interdependent and essential towards the deep understanding of a particular field or subject especially if the student is to achieve any self-sufficiency (Yatt 1993). According to Yatt, instruction without application may be considered irrelevant and application without instruction may reinforce bad habits or simply be too slow (Yatt 1993). Gelernter sees interdependence as unavoidable since:

Knowledge offered in advance of any attempt to apply it cannot find a conceptual schema in the student's mind in which to reside, for the required schema can only be developed while struggling with a particular problem (Gelernter 1988).

and

...attempting to struggle with a design problem in advance of commanding any cognitive schemata, or solution types, is doomed to failure, for the student will not possess the essential starting point from which design ideas evolve (Gelemter 1988).

As stated in Chapter One, architectural design exists as theory and practice or principles and their application. For the student to consciously apply what they learn to produce an architecture that works, application and acquired knowledge must be allowed to evolve in such a manner as to support, adjust and define each other.

The lack of integration of relevant knowledge into the design process is widely recognised as an important issue within schools and some attempts have been made to deal with the situation (Yavuz 1999). Some schools try to integrate knowledge by linking studio with other subject areas. Recognising that integration is difficult while a student is just gaining proficiency with a subject, they purposefully insert studios with a focus on integration, utilising knowledge that was to be gained earlier in the course (Dutton et al 2002). In these instances, studios are taught by faculty teams who jointly formulate the assigned project and work together to create course materials that are mutually reinforcing. One such example occurs at Victoria University of Wellington 
where the central emphasis of the studio in question is to address the attributes of the thermal, acoustic, and visual in the making of architecture. Both the measurable and poetic attributes of the sensory are worked with as a means of enriching the language of students' architecture (Donn and Daish 1998). Tutors, however, have to deal with more issues in this format because of the double emphasis of the studio.

Other schools attempt to make studios dependent on all other coursework or tie coursework to studios. This is difficult to maintain and often results in a restricted curriculum. Some schools do not attempt to reconcile lectures and studios but rather fall back on the premise that the university is the place for conceptual work, and that the reality of design projects will become evident once a student begins work in an architectural office (Weber and Schnier 1999). With the pressures of today's society, most practices hardly have time to expose the students in a structured way to the practical issues connected to design.

The challenge for design education therefore is making the knowledge relevant to design, an integral part of learning to design, while maintaining the integrity of that knowledge area. The fact is, only through such integration can students fully appreciate the relative importance of specialized areas of knowledge to the whole. This would at least approach the condition earlier found in apprenticeship and pupillage where the student was given the opportunity to acquire practical knowledge while experiencing its application. Then, a strong link between the two was consequently clear and indivisible to the apprentice. At no time has a response to this challenge been more critical than in the 21 st century where sustainability is essential for the built environment.

\begin{tabular}{|l|l|}
\hline $\begin{array}{l}\text { Typical Lecture } \\
\text { or seminar }\end{array}$ & $\begin{array}{l}\text { Victoria - 20pts during one school year. } \\
\text { CSA - 4 pts during one school year }\end{array}$ \\
\hline $\begin{array}{l}\text { Design studio } \\
\text { with its system of } \\
\text { critiques }\end{array}$ & $\begin{array}{l}\text { Victoria - 40pts during one school year. } \\
\text { CSA - 16 pts during one school year }\end{array}$ \\
\hline
\end{tabular}

Table 2.2. How are courses weighted in Architectural Education? The table shows the difference in credit points between lecture courses and design studio at two schools of architecture (with different systems) (Source: Victoria University of Wellington, Prospectus 2002 \& Caribbean School of Architecture, Prospectus 2001/03). 


\section{Sustainable Architecture}

Today, more than any other period in history, an integrated approach to architecture is necessary for success. Current concerns about the well being of the planet places architects in the responsible position of leading the way to a more environmentally friendly architecture. This move (which takes place on several fronts) to protect the planet has placed particular importance on the idea of "Green Architecture" or an architecture of sustainability. Darlene Brady (1996) defines "Green Architecture" as a "term used to identify environmentally sound buildings that incorporate ecologically sensitive products, energy efficiency, adaptive reuse, and building permanence" (Brady 1996). One of the challenges in the EAAE survey was the notion of sustainable architecture in schools. Sustainable architecture is complex and multifaceted. It involves several issues: building for posterity, maintaining, preserving, and adapting existing building stock and being environmentally responsive (sun, wind, light, site). It involves social and cultural responsibility and awareness and understanding of how users perceive an architectural design from the point of view of inhabitation, "complete with scale, colour, and light" (Brady 1996). Those core competencies that students need to know in order to produce responsible sustainable design require a solid grasp of the several issues that impact on sustainable design. Responsible design involves examining and manipulating the issues as specialist items but most importantly also as parts of an integrated system. As Brady states quite emphatically: "The key to achieving sustainability, whether in architecture, business or the environment, is the ability to understand the larger context" (Brady 1996). The place for learning this integration is the design studio; unfortunately as outlined earlier, issues such as linking studio with other courses, the attitude of students to technical subjects and a neglect for the notion of process all conspire to undermine this objective. Though an essential part of the issue of integration, sustainability is crucial enough for special attention. While designing, the student must be aware of the issues that affect architecture in general and sustainability in particular. The challenge, therefore, would be to encourage an awareness of sustainability by 
allowing those issues that directly affect this important concern to be accessible to the student when designing.

\section{Virtual Environment}

Imagine a musician learning to play the piano just by reading books about music or practising on a wooden replica with painted notes (Weber and Schnier 1999). Imagine a juggler learning to juggle by simply reading about it. Just as the musician needs to play on a real instrument to learn and the juggler needs to appreciate the weight of the balls and the reality of gravity, so should it be favourable that the architect learns about architecture through the actual making of architecture. This scenario (by no means perfect) occurred during the Middle Ages in the lodges of the guilds. Since then, however, the environment for learning about making architecture has become increasingly virtual. According to Weber and Schnier (1999), this fails to properly prepare students, because it "rests on the erroneous assumption that theory can adequately simulate practice" (Weber and Schnier 1999).

In studio, students undertake projects that simulate and simplify practice. Schön calls this a "virtual world"; relatively free of the pressures, distractions and risks of the real world to which it nevertheless refers (Schön 1985). In this virtual environment students prepare for professional practice through hypothetical design exercises that simulate problems encountered in the real architectural world. This has its benefits. Teaching in a virtual environment allows the teacher to focus on particular themes or issues in the studio. The projects used (most times) are therefore typically the construct of the teacher, and reflect any particular focus of the studio. This allows the student the opportunity to engage with particular notions. However, learning in a virtual environment often cuts the student off from other issues that impinge on decisions in the real world. Lack of outside variables and evaluation parameters exacerbates the virtuality of learning.

Architectural design is a complex shifting endeavour. It requires that a designer constantly make decisions according to parameters, few of which he or she actually controls. In the real world, outside influences on the design process include the demands of users, clients, building regulations, engineers, and 
quantity surveyors. Design is therefore a matter of constant negotiation, in which the designer must consider, appraise and reconcile many aspects of the final product. When the studio projects are set up, however, there are little external variables included for student decision-making. A virtual environment creates a vacuum for students to design in. This leaves students in nearly full control of all variables, creating a false sense of the design process. They do not as a result care enough about the impact that the design has on surrounding environment and the people who use it. In turn they rely on the tutor to tell them what is needed.

A further dilemma arises when the criteria used to appraise student work does not match those applied to real buildings. Final "reviews" often give students many false impressions about the quality of their work, and objective criteria are rarely introduced, even though they exist in actual architectural practice. By contrast, "real projects must ultimately pass the test of time and be measured against actual contextual, aesthetic, constructive and economic goals and standards" (Weber and Schnier 1999).

The virtual world, while having a clear advantage over real sites (by allowing experimentation and focus), displaces the student's learning from the realities of architecture. In it, the student (who has little experience of the "real" world) struggles to define a realistic model of the problem or come to terms with the rules embedded within it. $\mathrm{He} / \mathrm{she}$ has no idea how the design will perform in the physical world and so is more willing to suspend "physical rules" and ignore limitations. This is replaced by aesthetic rules, which require no testing. Consequently the student designer has no appreciation of the issues concerned in making the environment cost effective and responsive to the user. It is therefore the teacher's responsibility to reveal the realities lacking in the student's vocabulary. This subsequently reduces the time afforded to other aspects of teaching design. Practical knowledge is gained in the context of reality (or the rules of such reality). Since it is physically impossible to teach within actual projects, the challenge therefore, would be to embed the rules of reality in the virtual environment, while allowing particular foci as needed. 


\section{Conclusion}

At the beginning of the 21 st century there is a general belief within the architectural profession that schools of architecture are not doing their best to prepare students for the rapidly changing world of practice. Students, according to critics, are not getting enough exposure to the practical issues of architecture. It is the opinion of practitioners that schools should be doing more to integrate realism into its "theoretical" curriculum. At present there is a call for positive action in architectural education by integrating practical knowledge in design projects. A certain means of achieving this is the broadening of studio to allow students to explore the science and practice of architecture in addition to traditional explorations of the art (Yatt 1993). For a solution, the teaching of theoretical knowledge (creativity, intuition) has to be balanced with practical knowledge.

To illustrate the importance of this balance let us use the analogy of the artist (someone the architect is considered to be). An artist can scarcely produce a good work of art based simply on a personal vision of the piece. For the artist's vision to be effective the artist must have an intimate knowledge of his/her media and tools. $\mathrm{He} / \mathrm{sh}$ must know the reaction of the brush through oil or watercolour and the effect of the stroke on the texture of the canvas etc. This technical knowledge enables him/her to create a richer result. Similarly the sculptor cannot in fairness create a meaningful piece of work without knowledge of the materials he/she uses in his/her task. And so it is with the architect, practical issues such as environmental control, structure and other technical issues are a part of the palette for architectural creativity. If the architect does not have a grasp of the tools and materials related to his/her craft then how can he/she create architecture?

A current debate within the American profession surrounds the AIA's endorsement of the idea that students should be allowed to take the Architectural Registration Examination (ARE) immediately after graduating. In a poll on this issue, $55 \%$ of respondents (all in practice) agreed with the idea while only $40 \%$ disagreed (Mitgang 1999). In the same poll, $66 \%$ voted that there should be a better balance between time spent in design studio and time 
devoted to other subjects such as technical and business aspects of the profession (Mitgang 1999). If implemented this could mean that schools would have to emphasise more practical and technical knowledge to meet the requirements of the examination. Achieving this would require a shift in architectural pedagogy but without losing the benefits of the studio design culture.

Balancing theory with practical and technical knowledge in the curriculum would help students to produce architecture that is inhabitable, experiential, functional and responsible. The way forward, therefore, is overcoming the challenges facing education today as a result of education's existence in academia. The challenges are:

- The current model is incapable of supporting the amount of technology to be transferred.

- Schools value or favour theory and the product above practice and process.

- Studio is disconnected from acquired knowledge making it difficult to implement important issues like sustainability.

- Design is taught in a virtual environment.

There must be a possible channel for this resurgence or renewal that does not require restructuring and changing what is considered by some as a good way of teaching design. This solution should:

- Create an environment where a balance between theory and practice can exist.

- Create an environment where a balance between product and process can exist.

- Create a virtual environment that contains relevant experiences from the real world.

- Allow timely, relevant and integrative knowledge of technical issues.

- Allow an accurate awareness of sustainability through integrative and timely dissemination in studio. 
The enduring legacy of apprenticeship in architectural education is the notion that the student will receive a deeper knowledge by learning through the process of doing and mirroring the processes of the master. This indicates that the solution must be implemented in an environment where the student is exposed to the challenges of design by actually engaging with the task (real or hypothetical) and master. With origins in the 19th century Ecole des Beaux Arts this environment, the design studio, is the primary means of teaching design in architectural education today. It is, apparently, the only place available to architectural education where students are expected to bring together knowledge from the different disciplines to inform the development of their architectural designs (Nicol and Pilling 2000). The only opportunity students have to learn by experience, to grow by exploration, to integrate all they've learned, is in the studio (Yatt 1993). Studio work must broaden to provide a forum for exercising all the skills taught in architecture schools. Any attempt therefore to introduce effective tools and methods in design education that can remedy the current situation has to be within this realm. When one starts to propose a new approach to an existing condition or a new tool it is important to explain the existing circumstances and expose any drawbacks that the new approach or tool is meant to address. This is done by examining the place where it all happens... the design studio.

\section{References}

Association of Collegiate Schools of Architecture (ACSA). 2003. "History of Architectural Education". [Accessed December 2003] Available online at www.acsaarch.org/architecturalEd.html.

Boyer, E., and L. Mitgang. 1996. Building Community: A new future for Architecture Education and Practice: A Special Report. Princeton: The Carnegie Foundation for the Advancement of Teaching.

Brady, Darlene A. 1996. The Education of an Architect: Continuity and Change. Journal of Arcbitectural Education 50, no. 1: 32-49.

Buchanan, Peter. 1989. What is Wrong with Architectural Education? - Almost Everything. The Architectural Review 1989, no. 07: 24-26.

Claridge, P. G. B. 1979. Studio Design Work in First Year Architectural Education. Adelaide: Advisory Centre for University Education, The University of Adelaide. 
Crinson, M., and J. Lubbock. 1994. Arcbitecture: Art or Profession? Manchester: Manchester University Press.

Crosbie, Michael J. 1995. The Schools: How They're Failing the Profession (and what we can do about it). Progressive Arcbitecture (Sep): 47-51.

Donn, M., and J. Daish. 1998. The Sensory into Architecture - Ars Sine Scientia Nihil Est. In Science and Design: Oppurtunities for a cooperative spirit in the creation of architecture, Proceedings of the 32 nd annual conference of $A N Z S_{C} A$, edited by G. Baird and W. Osterhaus, 295-302. Wellington, New Zealand: School of Architecture Publications.

Dutton, Thomas A. 1987. Design and Studio Pedagogy. Journal of Architectural Education 41, no. 1: 16 25.

Dutton, Thomas A., Aaron Koch, Katherine Schwennsen, and Deanna Smith. 2002. "The Redesign of Studio Culture. A Report of the AIAS Studio Culture Task Force, December 2002." [cited 23 Jan 2003]. Available from <http://www.aiasnatl.org/resources/r_resources_studioculturepaper.pdf > .

EAAE \& CEMBUREAU. 2001. The Educational Community's Views of Challenges in Architectural Education. Pan-European Survey 2001: Interpretative Report, 8 November 2001.

Gelernter, Mark. 1988. Reconciling Lectures and Studios. Journal of Architectural Education 41, no. 2.

Gutman, Robert. 1987. Education and the World of Practice. Journal of Arcbitectural Education 40, no. 2: 24-25.

Gutman, Robert. 1988. Architectural Practice - A Critical View. New York: Princeton Architectural Press.

Gutman, Robert. 1996. Redesigning Architecture Schools. Architecture (Aug): 87-89.

Hogben, Gavin. 1989. Studio Words and Studio Deeds. The Arcbitectural Review 1989, no. 07: 38-.

Ledewitz, Stefani. 1985. Models of design in studio teaching. Journal of Architectural Education 38, no. 2 : 2-7.

Nicol, David, and Simon Pilling. 2000. Architectural Education and the Profession: Preparing for the future. In Changing Architectural Education: Towards a new professionalism, edited by D. Nicol and S. Pilling, 1-26. London: Spon Press.

Pressman, Andy. 1997. Professional Practice 101: a compendium of business and management strategies in Architecture. USA: John Wiley \& Sons, Inc.

Purcell, T., and K. Sodersten. 2002. Design Education, Reflective Practice and Design Research. Paper presented at Design Thinking Research Symposium 5: Designing in Context, Delft University of Technology, The Netherlands, 18-20 December 2001.

Schön, Donald A. 1985. The Design Studio: An exploration of its traditions and potential. London: RIBA Publications Ltd. 
Smith, Sir Colin Stansfield. 1999. Architecture Education for the 21st Century. RIBA Review of Architectural Education, October 1999, Chaired by Sir C S Smith. Supported by the Thomas Cubitt Trust, the Interbuild Fund and the RIBA.

Stevens, Garry. 2002. "A brief history of architectural education." 15 Aug 2002. [cited 26 Aug 2002]. Available from <http://www.archsoc.com/kcas/Historyed.html $>$.

Weber, Ralf, and Jorg Schnier. 1999. Designing Design Exercises: An investigation of different styles of designing and their consequences for architectural design education. Workshop presented at 33rd EAAE, Bucharest, 26-30 May 1999.

Yatt, Barry D. 1993. "What is the most important single change necessary in the education of architects?" [cited 27 Aug 2002]. Available from $<$ http://archprac.cua.edu/olce/papers/items/wagner.htm>.

Yavuz, Sevinç. 1999. Fact or Fiction: Integration of Technology and Design. Paper presented at Morbidity and Morality: Why Projects Unexpectedly Die, ACSA Southwest Regional Meeting Hosted by Louisiana Tech University, School of Architecture. 1999. Also available online: http://www.latech.edu/tech/liberal-arts/architecture/ACSASW99/sessions.htm 


\section{The Design Studio}

The advanced work in design is carried on, as in all our schools of architecture, by means of problems and criticisms. The designs are always started by eight-hour preliminary sketches made by the student without guidance or assistance. These sketches are criticized before the class and then each student elaborates his design, with such modifications as are suggested, under the daily criticism of the instructors over the drawing boards. The problems usually occupy a month or six weeks.

Report on the School of Architecture at Harvard in the Architectural Record-June 1907

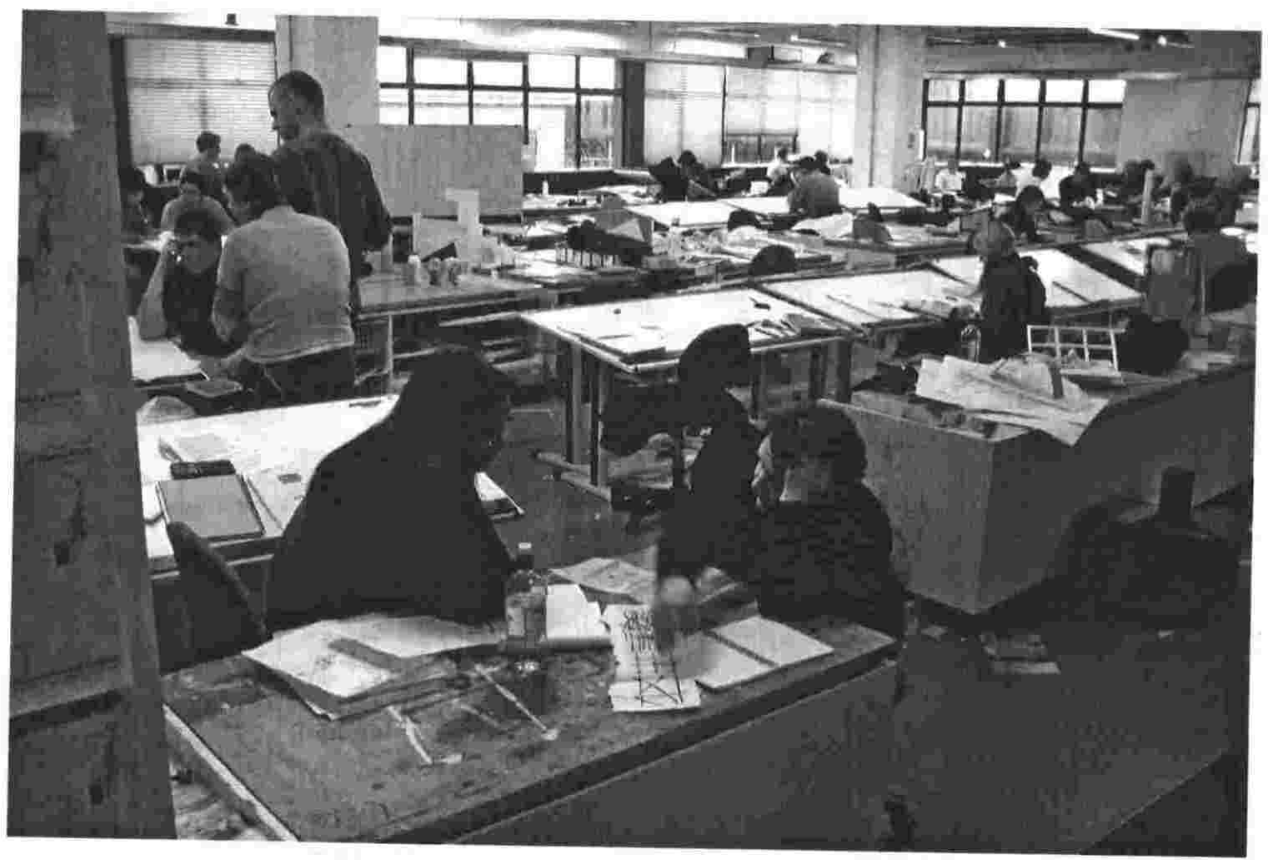

Figure 3.0 A Design Studio at Victoria University of Wellington.

continuing concern of architectural practitioners is the perception
that graduates leave schools of architecture with insufficient awareness
of the technical and practical aspects of architecture. This occurs as a result of the institutionalisation of architectural learning. The features of this institutionalisation are challenges, extolled in the last chapter, that face architectural education today. We have examined the cause and effects of these challenges and finally stated that in order to meet those challenges we must understand the place that is most affected by them - the design studio. 
The design studio has many strengths and weaknesses. On one hand design studio fosters creative discovery, exploration of ideas, and critical discussions (Dutton et al. 2002). On the other hand, this method of teaching (or its results) has not kept pace with the changing context of society and practice. As a result, the studio has been linked to the inability of students to grapple with issues that face $21^{\text {st }}$ century society (Chapter 2 ).

Having stated the problem, the aim of this chapter is to commence the progression towards a reasonable solution. It begins the process by critically describing and analysing the design studio, searching for aspects that could lead to its strengthening. Beginning with the pedagogical aims of studio, the chapter proceeds to discuss the various elements and events that characterise the design studio and support its methods. It will be revealed that learning occurs during the conversations the student engages in during these events. The pros and cons of this style of teaching is debated before isolating the key component of studio that can assist in addressing the critical issues that face architectural education today.

\section{The Design Studio}

The design studio socially, physically and pedagogically occupies premier position in design education. The extract at the beginning of the chapter was taken from a report on the School of Architecture at Harvard in 1907. It could have been written exactly word for word about any school of architecture in 2003, almost 100 years later. Today, studio continues to retain certain academic and social traditions that characterised architectural education one hundred years ago, namely, its perceived importance in the curriculum of schools. Despite changing educational and professional attitudes, the typical design studio has not diminished in its importance as an academic subject and physical place within architectural education.

The design studio is still portrayed as "active sites where students are engaged intellectually and socially, shifting between analytic, synthetic and evaluative modes" (Dutton 1991). Writers and commentators have referred to it as the "heart and soul" (Ryan et al. 1991) of architectural education or the "distinctive holy-of-holies of architectural education" (Boyer and Mitgang 1996). Others 
view it as the place where "the ethos of a profession is born" (Cuff 1991) or as the synthesiser of architectural knowledge:

At its best, the design studio sequence provides the connective tissue that brings together, progressively, the many elements of architecture education (Boyer and Mitgang 1996).

Donald Schön and other writers view studio teaching as a "useful model for the creative and self-critical learning necessary to develop reflective professional practice" (Skinner 2000) and a "model of excellent learning” (Mitgang 1997), making it the "very model of education in all the professions" (Broadbent 1995, Skinner 2000).

Design studio commands from both students and faculty the most time, energy and resources in the school. Students consciously spend a high proportion of their academic energies in studio. Other courses like structures, environmental science, construction, history and professional practice get scarce attention and some students have been known to neglect classes and assignments from other subject areas in order to complete a studio project.

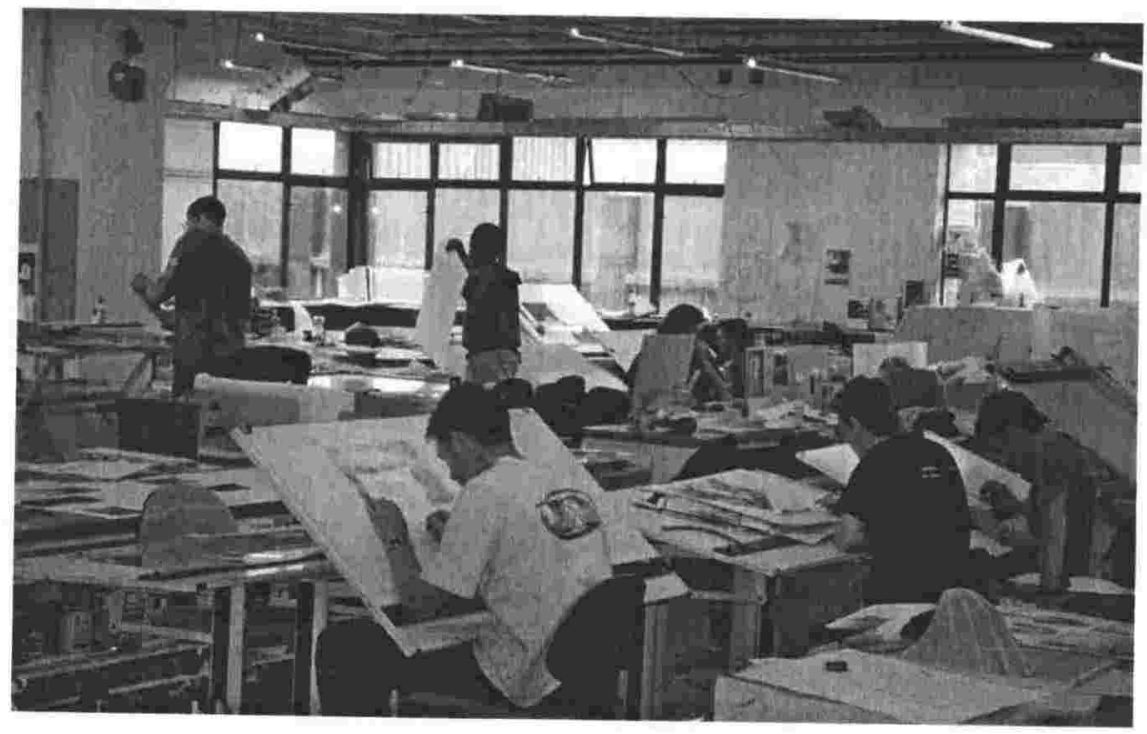

\section{Figure 3.1. Architecture students trying hard to meet a deadline in design} studio.

The importance of the design studio is evident in its role in defining the relationship architecture school has with the rest of the university. It is the design studio that accentuates the uniqueness of architectural school in the 
university. One of its unique features is the student-teacher contact time since the highest amount of student-teacher contact hours in the universities are often located in the design studio. In some cases, this ranges from 8 to 12 hours a week for a group of students and sometimes as much as 90 minutes of oneon-one contact per student per week. At present, architectural schools sit academically uncomfortably (with only a few exceptions notably Architectural Association and the Boston Architectural Centre which do not sit at all) within the university environment. The design studio reinforces this discomfort by being craft like and imprecise without the rigour of the intellectual arts and without the objective methodology of the natural sciences (Johnston 1995).

\section{Aims of design studio}

As a social experience, the design studio is a phenomenon that fledgling architects carry with them for the rest of their careers. If asked, many architects can reminisce about and acknowledge the late nights, exciting projects, a sense of community and personal sacrifice that characterised the studio. However, while there is general agreement among commentators about the social role the studio plays within schools and the value it has, there seems to be a lack of consensus as to the pedagogical aims of design studio.

Besides its complexity, the diversity of opinion about the aims and objectives of the studio is perpetuated by the fact that adopting the design studio as used in schools of architecture was no singular deliberate act. It was not formulated as a result of careful research, testing and implementation but rather based on established and successful architectural traditions (such as apprenticeship) and modified to fit the era in which it existed. Studio work in schools of architecture has been so well established that the basis on which it proceeds has become uncritically accepted. This is not to say that design education doesn't have its aims and objectives, but, rather implies that most written material about its aims and objectives tend to be hindsight and interpretive. Each interpretation is inherently based on the interpreter's bias and educational beliefs. As a result there are conflicting views as to what the outcome of a studio education should entail. 
Some commentators link design studio education to a specific way of seeing designing. Belkis Uluoglu (2000), for instance, sees design as praxis where actions are not impulsive or habitual but rather conscious and intelligent. To him, design is not merely an activity based on skills. Subsequently he describes design teaching as providing the student with a self-conscious experience about what $s$ /he is doing (Uluoglu 2000). In addition to this, design teaching is supposed to embody knowledge of architecture and design in general while providing the individual with the tools of using this general knowledge to the solution of specific cases and with a personal style (Uluoglu 2000). Stacie Burtelson claims that design is a process of making decisions where each decision has a rationale, argument and a reason behind the decision. According to her, students are expected to learn the process of design, which is a certain way of thinking or acting in a certain design situation (Burtelson 1998).

Other commentators go beyond simple statements to create lists of aims that intersect. Stefani Ledewitz (1985) at the start of her article Models of design in studio teaching in the Journal of Architectural Education lists three basic facets that the studio has the responsibility of teaching. The first is the acquisition of new skills. According to Ledewitz:

It is where students learn and practice a number of new skills, such as visualization and representation (Ledewitz 1985).

Students express, explore, and manipulate ideas through drawing and generally "discover" by having a conversation with the drawing. Secondly, design studio provides students a new language with which to communicate (Ledewitz 1985). She goes further to quote Donald Schön describing design as:

...a 'graphic and verbal language game', in which drawing and talking are
complementary and inextricably linked (Ledewitz 1985). According to Ledewitz:

Words like "form" and "scale" have new and complex meanings that are not easy to internalise. Learning to explore and communicate ideas through drawing is a new experience for most students (Ledewitz 1985).

Finally Ledewitz claims that the studio is a place where students learn to 'think architecturally' (Ledewitz 1985). 
She goes on further to say each of these three aspects - new skills, new language and "architectural thinking" are actually interdependent for the student to get a complete learning experience. It is difficult and ineffective to isolate each element, as each becomes a means of learning the others, therefore integrating these is a big part of learning to design, for instance (and using Ledewitz's examples):

Drawing skills... are essential to learning to communicate spatial concepts. ... Learning to recognize architectural issues can inform and aid the development of visualization skills (Ledewitz 1985).

John Wade (1977) when speaking about studio instruction in his book Architecture, Problems and Purposes has other views of the intentions of studio learning:

The student designer, in his experience of studio instruction and of both the informal and formal criticism process, learns a great deal about design and about problem solving. The learning occurs in a number of distinct areas.

First, the design student learns a great amount about the problem solving process. He learns design in the same way that some people have supposedly learned to swim - by being thrown into the water. Learning design by being thrown into an ocean of design problems is certainly not a painless way to learn, but having learned, there is much the designer knows.

Second, the design student learns a great amount about what things influence design solutions. He sees how different students produce different kinds of solutions and how different time limits affect the kind of solution a student is able to produce. In addition to learning how to design he learns what some of the influences on design are and can thus exert some control over the quality of solution he achieves.

Third, the design student learns a great amount about cooperative problem solving. The social interactions he experiences in his first team problems are among the most intense in his school career. He learns, some of the essential communication techniques required in any cooperative effort. If it is possible to say what some of these are. It may be possible to help the student take better advantage of what he has learned as he moves into practice (Wade 1977).

More recently other commentators have taken a broader view and see design education as a means of learning skills for life. According to Nicol and Pilling (2000), architecture students do not need to learn just about architecture and design skills but also how to learn, manage and take responsibility for their own learning throughout life (Nicol and Pilling 2000). Doing this involves learning the process of identifying, accessing and evaluating new information and relating it to the task at hand effectively. To Broadbent, design is about asking the right questions. He claims teaching design is about finding what the question actually is rather than simply being a matter of teaching how to solve 
problems (Broadbent 1995). Guita Farivarsadri (2001) perceives design education as the means of educating "people who are aware of what happens in the world around them, who can criticize the existing situation, produce solutions, and at the same time accept the responsibility for the decisions they make" (Farivarsadri 2001). A key component of this is the ability to criticise the work of others as well as your own work.

Despite the apparent lack of consensus about what the design studio should be teaching there are a few features that remain constant in most contributions to the debate. Foremost, design is seen as a conscious (and personal) and deliberate activity and teaching in studio should reflect this. Students should be taught that design involves decision-making. Successful decision-making involves asking the right questions by being critical of existing conditions and critical of self-generated conditions. This is best achieved by using acquired skills, acquired language, acquired information and personal insight as tools of criticism. The student has to have the ability to construct and reconstruct information - relating ideas - by identifying and criticising issues involved in making the "right" decisions. For this to happen, the student has to be acutely aware of the issues involved. These issues or conditions are based on context, resources and meaning conveyed. It is important to reiterate that the design studio is highly praised as an effective method of teaching architecture students. The question is, however, whether the studio is well suited to making the student aware of the issues that constitute or contribute to the right decisions in the $21^{\text {st }}$ century.

\section{Anatomy of the design studio}

The form and composition of the design studio varies from school to school. In some schools, studio is segregated into years and develops with each successive year (building up on material from the year before). Other schools while keeping the years separate, teach each year as separate units not connected to previous years save the skills required to achieve the goals set out. Some schools (like Royal Melbourne Institute of Technology (RMIT) and the Architectural Association) utilize a unit system where an instructor who declares a clear architectural position coordinates each unit. Students then choose to join 
one of these design units, in which they remain for the year, being taught together with upper year (or lower year) students. In other schools the studio might be linked to a community project or employed by other courses (e.g. structures, construction) where students are given hands on experience. Sam Mockbee's Rural Studio at Auburn University is an example of this. Despite this diversity in approach, the events, rituals and people of the studio itself vary very slightly from school to school.

So, what happens in the contemporary studio?

\section{The Scene}

The importance of the design studio today in architectural schools is seen in physical terms by its relationship to other spaces within the school ${ }^{12}$. This is manifested clearly by its usage and location. Unlike other courses where students spend time in lecture theatre and classrooms for up to 2 hours, studios are occupied and used for 24 hours. A physical position in the studio represents to the student a home base in which other activities in addition to designing can take place.
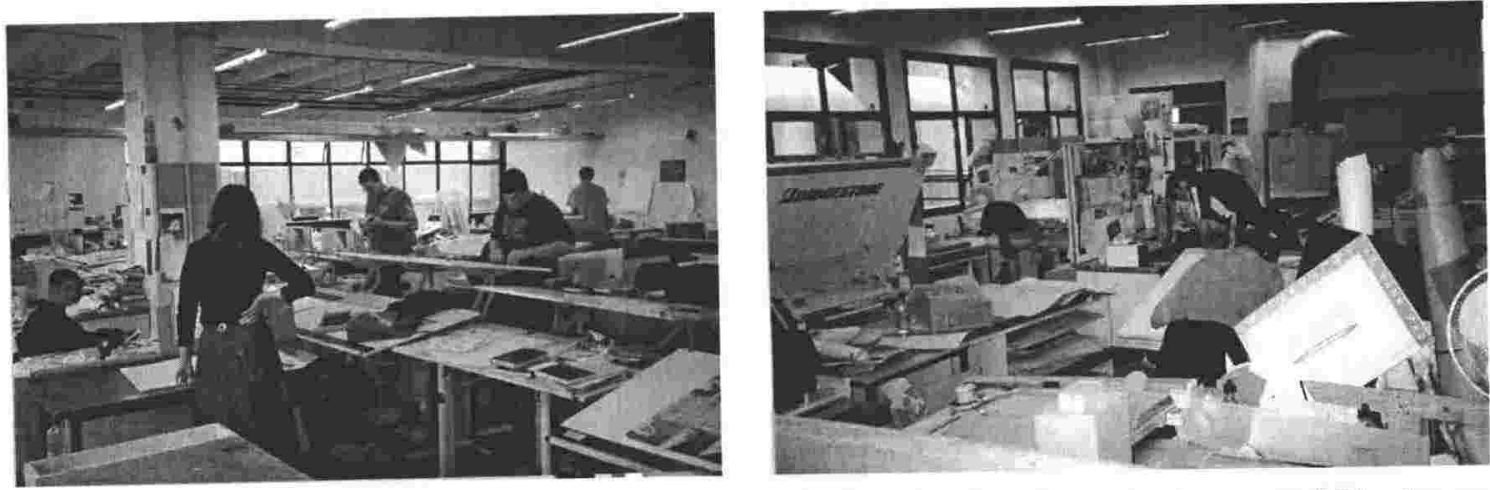

Figure 3.2 Scene from Victoria University Studios - 2nd year and Final year

The studio scene often occurs in an open space with drawing desks arranged in a formal or informal pattern depending on the structure of the school. In some studios, desks are arranged inwardly building work niches for particular groups of students who like to work in the same vicinity. Increasingly today computers are part of the mix. The studio usually contains students of the same year although it is quite common to integrate students of adjacent years. The walls

\footnotetext{
${ }^{12}$ It should be noted that there are some schools of architecture that do not have studios or spaces for students to work together. In these schools students work at home and come in to meet with their tutors for deskcrits.
} 
and pinup boards in the studio are often covered with images and sketches. Half finished models lie around with waste material on the floor while friendly banter floats across the room. Peter Monaghan (2001) sums it up well when he describes a design studio at the University of Minnesota:

...a crowded room of beat-up tables squeezed together in happenstance combinations.
From numerous vases, cups, and coffee cans sprout pens and pencils, felt-tip pens,
pastels, as well as many other drawing tools. Pins, tacks, nuts, bolts are scattered about.
Cardboard and balsawood models sit half-finished or half-recycled amid scraps of the
raw materials that went into them. A cut-up running shoe? A hard hat? In drawers
beneath the drafting tables lie the auxiliary tools of the trade: a broken portable CD
player, coffee cups, a plastic bottle of Tylenol (Monaghan 2001).

\section{The Players}

There are several players involved in design studio: the key players being the studio instructor and the student (see chapter 4). The studio instructor or master is often an experienced practitioner and/or academic. The instructor coordinates the studio, determines the educational aims of the project, sets the design problem, assembles and makes available reference material, conducts the desk crits, usually orchestrates the formal review(s) and does final assessment and grading. Depending on the size of the design class, the studio master is assisted by studio tutors who are usually practitioners, academics, or recent graduates. Tutors (including the studio master) are charged with the task of opening students up to the intricacies of designing by "modelling appropriate behaviour, values, design strategies, and thought processes" (Schön 1984) These tutors are given charge of a manageable group of students (about 12)13.

Students vary in age, race, gender and often background. They can be teenagers recently graduating from high school, persons who have spent a large amount of time working as architectural draughtspeople and are now getting a formal education or persons who spent undergraduate years doing majors slightly related (or not related) to architecture. Usually the prior educational experiences of new students do not prepare them sufficiently for the pedagogical aspects of the design studio.

\footnotetext{
${ }^{13}$ Reported experiences have shown the studio dynamic changes significantly if the ratio exceeds 13 to one. (Ochsner
2000 ).
} 


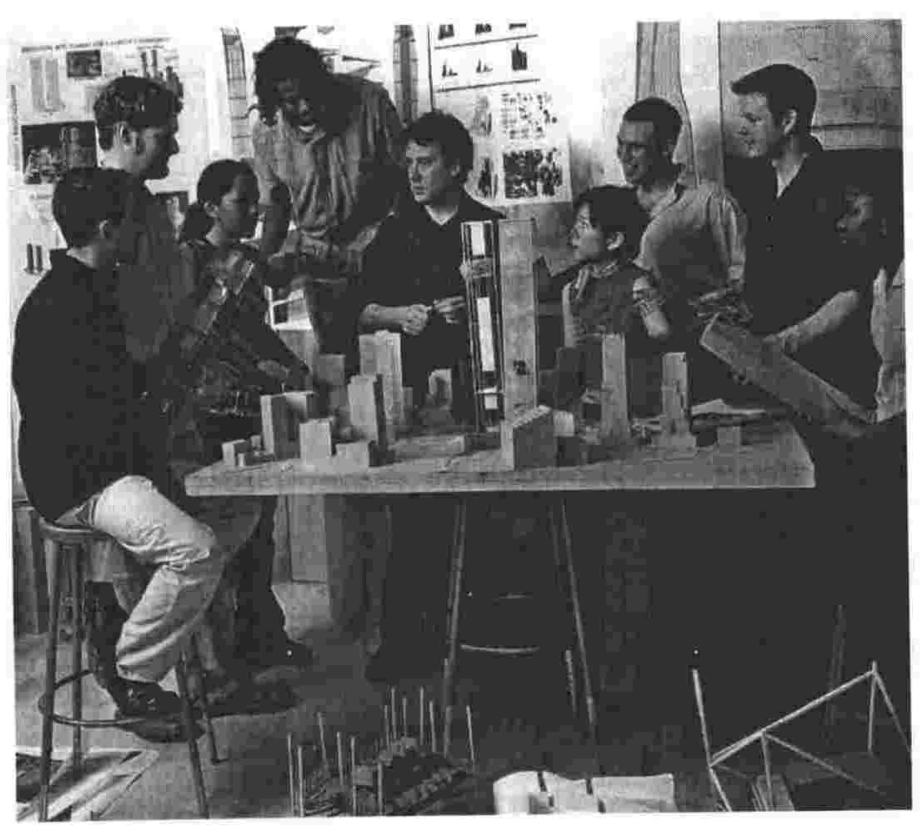

Figure 3.3. Students come from diverse backgrounds. (Source: Architectural Record, Aug 2002:84)

Other parties involved in the studio are external critics as well as other students in the school. External critics are usually academics/practitioners (sometimes celebrated) not directly involved in the setting of the educational objectives of the studio.

\section{The Project}

The pedagogical experience of the design studio is rooted in the technique of "learning by doing". As practiced in the Beaux-Arts model, students are presented with a hypothetical "design problem" and allowed to explore solutions, encountering failure, success and frustration along the way. This approach to teaching has been formalized in recent years under the heading: Problem-Based Learning (PBL). The basis of problem-based learning is the setting of a problem allowing the student to direct their own learning through the seeking of solutions to the problem. Under close supervision and tutelage, they engage in a search for solutions, learning not only the facts of the situation and possible solutions but also the process of discovery. Recently, it has also been found that other professional disciplines such as medicine, engineering and mathematics, among others, use variations of this technique. In architecture it is the foundation of the design studio. 
In the studio, each learning expedition revolves around a particular project or series of projects for the semester. The project or task is formulated based on the objectives the instructors want to achieve during the period. Projects usually involve the design of parts of buildings, whole buildings, building complexes, or parts of cities and towns. These, typically, comprise of a design problem in the form of a building program - a stipulated set of design requirements. The program comprises of one or some of these elements:

- A social condition in which students have to grapple with cultural issues related to a particular building type. e.g. the design of a small art museum or church.

- A theoretical position or attitude towards architecture that requires investigation.

- List of rooms (accommodation) with respective sizes and specific functional requirements.

- A site (real or imagined) or context is also given as part of the design problem.
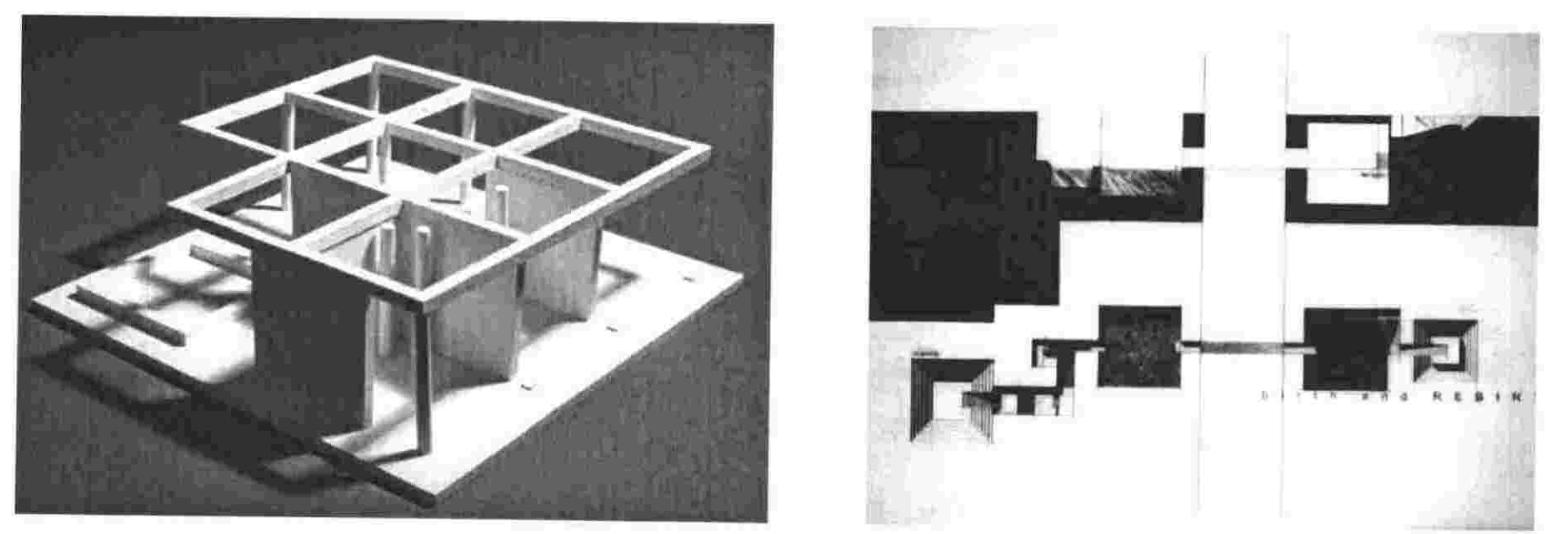

Figure 3.4. Beginning student design projects ranging from abstract issues of form and shape to pragmatic issues of circulation.

Projects usually increase in complexity and objectives throughout the academic life of the student. Beginning students usually start by receiving projects that develop an understanding about architectural principles, spatial concepts, functional organisation, and visual composition. As the student moves through architectural school, projects get longer (final year students sometimes work on projects one school-year-long), more complex and more "architectural" in 
nature. Advanced levels projects incorporate the opportunity for the student to express his/her personal theoretical position(s). Here students sometimes formulate their own programs. Complexity, however, does not necessarily depend on size or cost. It depends on the number and difficulty of the design issues involved in a given project. A house for a family with a strong cultural identity on a restricted site could be more complex than an office building or factory.

The life of a project comprises of a series of events. The issue of the project is the first event and sometimes involves talking about the program, discussing logistics and answering any questions for clarity. Depending on the educational motives of the problem, the instructor might talk about any technical, theoretical and social/cultural positions the project is meant to address. At this point the class will probably visit the site (in cases where a real site is used) and interview clients (in cases where a real client is used). Students are then left to start developing schemes that address design issues embedded in the project.

Unlike the classroom or lecture theatre, the real work of the design studio as a vehicle for student learning and skills development occurs when the student puts forward ideas representative of a proposed solution. In addressing the problem the student goes through several evolving forms from the barest of sketches in a notebook through computer explorations to fully developed drawings and models (physical or digital). All these forms are used to address in one way or another all aspects of the problem the student is aware of. At various points during the project the student may be asked or required to present his or her project for evaluation and criticism. The studio master has to see the project and give a critique before the student moves on. Learning and teaching in the studio therefore does not take place in one scenario but through a series of situations (stops and starts) in which students are criticised and given feedback about their work. These situations take the form of desk crits, group crits or pin ups, intermediate reviews, and the often-controversial final review. Together, these situations, contribute jointly to "the refining of knowledge through the reflective act of design" (Boyer and Mitgang 1996). 


\section{The Desk crit(ique)}

A key component of studio instruction is the individual desk crit ${ }^{14}$. Short for critique; the desk crit is where students attempt to reconcile the problem with individual tutors providing support in a one-on-one situation. This dialogue takes place in the studio at the desk of the student. During these meetings the tutor helps the student:

Work through difficult issues, demonstrating appropriate design thinking, and often making normative remarks about design objectives, strategies, and techniques (Schön 1985).

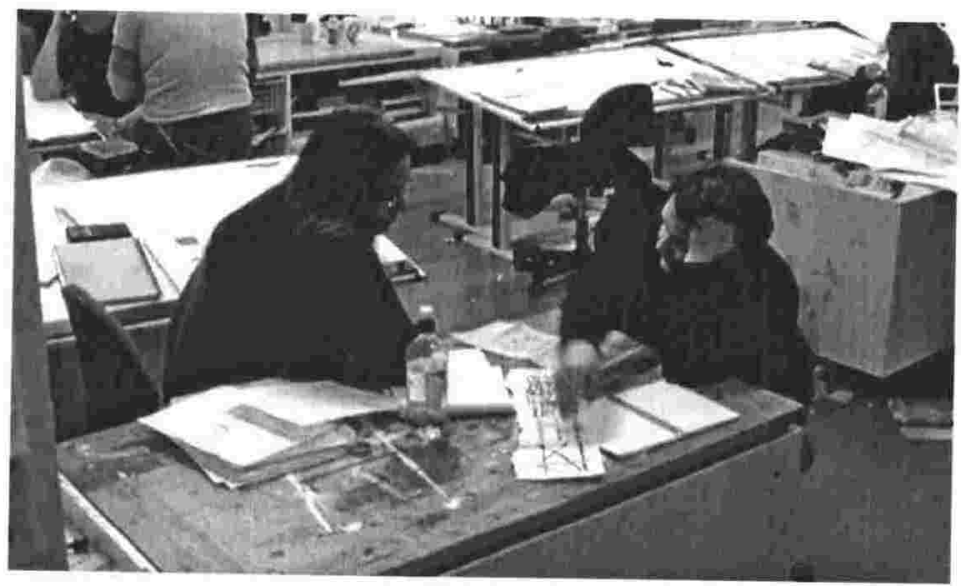

\section{Figure 3.5. A typical desk crit}

The material that forms the basis for these discussions are typically rough sketches, or rough physical models. These are often multiple in intent and unresolved. In the conversation with the tutor, the student will restate the problem as they understand it, outline any issues being addressed to solve the problem, present their solution (or series of alternate solutions) and any problems encountered. The tutor then responds by 1) exposing any problems with the chosen direction, 2) making the design situation clearer to the student and/or 3) pointing out any impracticalities or technical difficulties involved in the proposal. The student then goes away, takes or leaves the advice, before returning to repeat the dialogue.

\footnotetext{
${ }^{14}$ This has been called other things in different schools around the world - tutorials, desk reviews, consultations. In this
thesis it will be termed desk crit.
} 


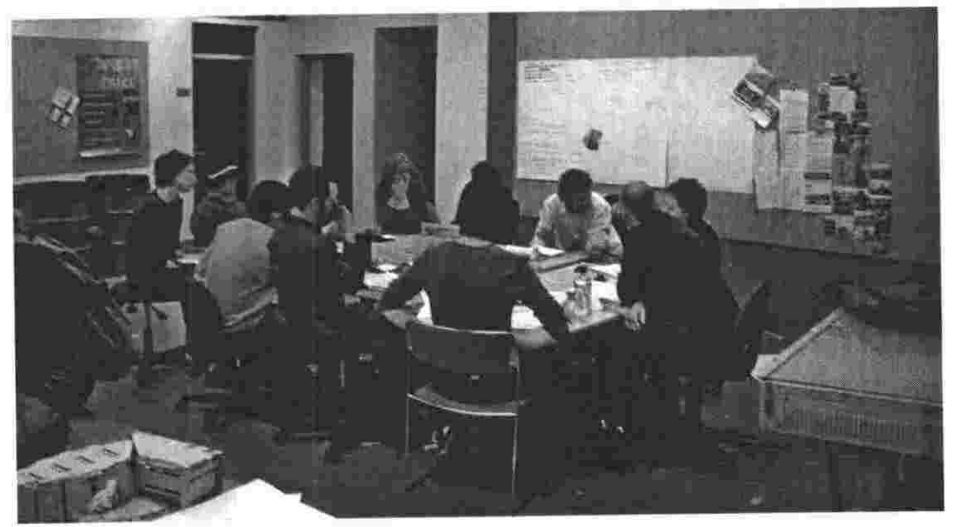

\section{Figure 3.6. An group discussion comprising of students of one tutorial sub- group.}

\section{The Group Crit}

The group crit is a slightly expanded version of the desk crit. In it the student is a part of a small selection of the class (sometimes a group of four to six) who pin up work or gather around someone's desk with the tutor. The student whose work is being examined will restate the problem, outline any issues being addressed to solve the problem, present their solution (or series of alternate solutions) and describe the process used to arrive at that point. Once this is done the work is open to criticism and discussion by both the tutor and the group. The advantages of this review include (in addition to generating different, sometimes conflicting, comments about the student's project) exposing the student to the multitude of attitudes and approaches towards the project as demonstrated in the other proposed schemes as well as helping the student develop a sense of self-criticism. The student is taught critical awareness, to think critically, to understand criticism as the central theme of learning to design.

\section{The Interim Crit}

The "interim" crit or review is often seen as preparation for the final crit but compared to the final review it is decidedly informal. An important distinction of this crit is that it often occurs at specific points in the life of the project, for instance after the site analysis, or the first notion of form. Involving students of the entire class, this crit requires that students present their latest solution to a 
small jury or panel. This panel includes other studio instructors from the school of architecture, practitioners, even clients intimately familiar with the design problem in practice.

\section{Formal Reviews}

The review or jury is a distinct relic of the Beaux-Arts education where the submissions from students were judged by external critics and awarded points or valeurs. Today the main form of assessment in design studio (in most schools) is the final review. Formal reviews give students a chance to practice both their verbal and graphic presentation skills. The students are expected to explain their design response, through words and drawings, to an audience which sometimes does not share the history of the studio, and which may be sceptical or hostile to their approach. Most students view this as one of the more important forms of critique, as the procedure is more rigorous and it is often scheduled at the end of the design project.

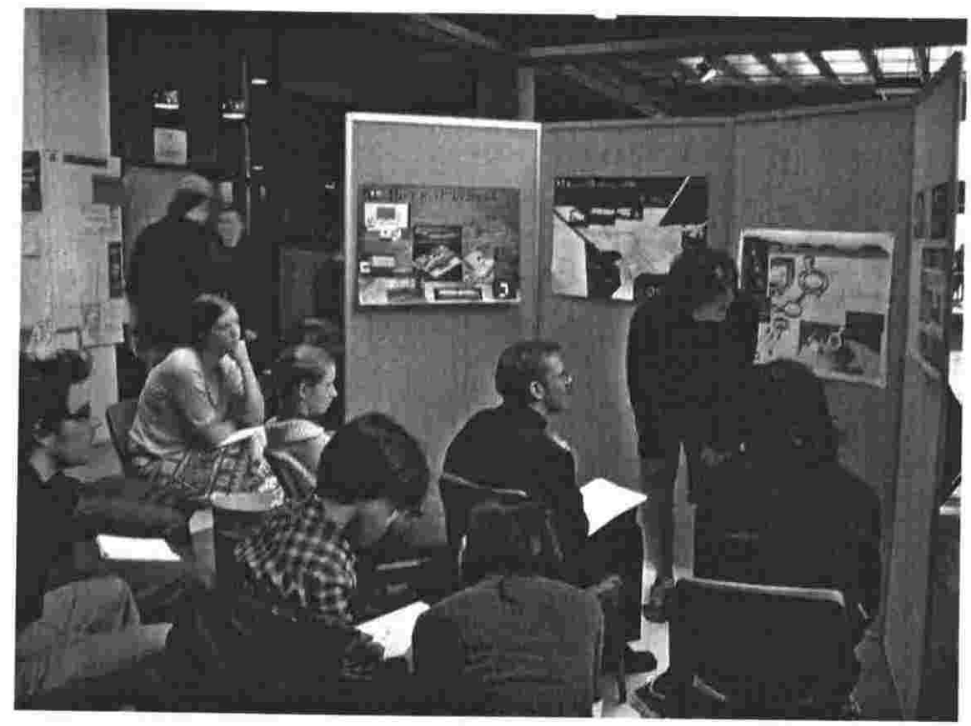

Figure 3.7. A final review in progress.

The final review, crit or jury as it is called in some schools have come under severe criticism recently. Nicol and Pilling argues that the review lays the foundations for an adversarial relationship between presenter and listener, which is then taken forward into the professional's dealings with non-architects (Nicol and Pilling 2000). Another criticism claims that it is the breeding ground of architectural jargon (Cuff 1991). Here, the architect does not learn how to 
talk to the layman (the future client) but rather engages in "architecture speak" with the critics. Others claim that the jury system is the cause of untold psychological distress among students and if handled improperly does not contribute to learning (Anthony 1991). Writers have also written books on the subject and suggested alternatives to the crit (Doidge et al. 2000; Anthony 1991). Interestingly, when asked if the jury system of evaluating design work was abusive, undermines teamwork and should be reconsidered, $69 \%$ of respondents to a recent Architectural Record poll disagreed (Mitgang 1999).

\section{The lecture/ discussion session}

Adjunct to one on one exchange and reviews, the studio instructor may meet with the entire studio class or small groups to discuss various aspects of the problem under investigation. The format of these "meetings" which may take place on a weekly basis can either be in the form of a lecture or seminar. Matters discussed or presented often include the review and critique of a number of design precedents, theoretical and cultural issues and special skills or techniques, for example computer skills that will help to successfully address the problem. Students are given the opportunity here of discovering abstract ideas about architecture and applying it directly to their work.

\section{Informal interaction}

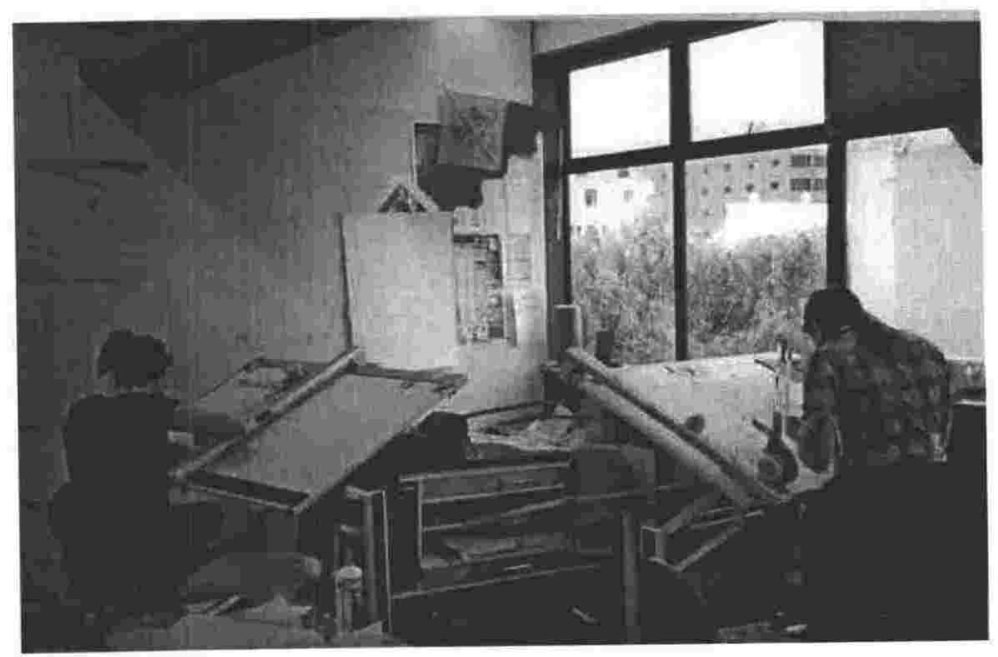

Figure 3.8. Students interact informally by working in close proximity. 
Alongside these "organised" learning situations, students are immersed in the informal learning that takes place as a result of close interaction with their peers. The attempt to capitalize on informal learning is reflected in the usual open layout of the studio, where students can monitor each others' progress and overhear comments by the instructors on other students' work. Students will informally critique each other's projects, compare approaches and in the process learn various design skills, drawing and model construction techniques from each other. As a result, the studio takes on a life of its own often reflecting the morale of the students. According to Cuff: "good students exhibit certain behaviour: they produce more drawings, sketches, models and studies of alternatives than anyone else, and in so doing set the pace for the entire studio" (Cuff 1991). A consequence of this is a culture of cooperation that defines the studio experience for students as one student commented to Dana Cuff:

The long hours of work in a common studio space forged us into a close knit group of men and women who were marked by our dedication, endurance and talent. We shared the excitement of learning to see the world in a new way... (Cuff 1991).

J.M. Richards even goes as far to say, "even in the best equipped schools [students] learn more from their fellow students than from the staff appointed to instruct them." (Richards 1974). This is no different from the ateliers of old, which were actually run by the students (élèves). Younger students learnt from older students as they assisted the best students in their preparation for the competition for the Grand Prix de Rome and discussed amongst themselves the comments of the patron.

\section{Conversations}

The design studio is the main teaching tool in architectural education. Its presence is a result of tradition rather than purposeful implementation and like countless other traditional activities it is accepted uncritically and rarely examined for flaws. The challenges outlined in chapter 2 show clearly that the features that make it unique also add to its inability to prepare the graduate for practice. Fortunately, it is one of those features that ultimately can resolve the current situation.

The feature referred to is the pedagogical nature of the studio. This nature can be described as Socratic or conversant: a dialogue between student and the 
emerging design, between student and instructor, between student and peers, between student and jurors, as well as between the student and the societal context to which the design is meant to address (Cuff 1991; Schön 1984; Ochsner 2000; Dutton 1991). This differs from other teaching practices that present wide-ranging concepts and assess students' skill through particular and directed application (chapter 2). This nature is made explicit through the events of the project. The events are actually different conversations the students has during the life of the project that contributes to his/her critical awareness.

Conversations inform the design decision making of the student. The student assesses and criticises each decision based on his or her conversations. The nucleus of value lies in the feedback the student gets from the conversations. The value or impact of each event (it is argued) is based on the level and quality of the feedback. For instance, the final review has a low level of feedback because the student is intimidated, the jurors sometimes do not discuss the main educational objectives of the project and it occurs only once in the project. On the other hand, the feedback from group crits is higher since the student has more time to ingest what is being said, is intimate with the projects being discussed, the situation is less formal, and he or she can actually have a conversation with the persons involved. Based on this scale, it can be deduced, that the feedback from the one-on-one conversations with the tutor offers an extremely high level of feedback. In fact it is second only to the conversations the student has with his/her own work. Enhancing this conversation in studio is the key to meeting and overcoming the challenges facing studio.

\section{Conclusion}

The main pedagogical tool at the heart of architectural education is the design studio. Teaching in studio is achieved through project based learning techniques where projects are a variety of real or hypothetical situations where the student is expected to take certain decisions, become critically aware and express his or her intentions or choices through coherent visual form. These problems or projects are diverse situations with different approaches, themes, focuses, and contexts requiring the student to rely on the conversations that come out of a series of events which individually and collectively, contributes to these 
objectives. These events ranging from the public arena of the final review to the informal with peers in studio and the one-on-one session with the studio master involve a Socratic "give and take" about the design proposal under development. It is through this "give and take", interactions, conversations that the student learns about architecture.

Success in conversations is dependent on the information available to the student for use during the conversation. The more information about a situation a designer has, the more readily he/she can make a decision or contribution to a conversation. The right decision or contribution is based on the relevant information for a specific situation. Although this information is readily available, a beginning designer sometimes has no idea such issues exist or even where to look. More often than not, in the opinion of the student, these are the very issues that seem to "get in the way" of the solution. Unless the project is technically oriented, the student is usually expected to self learn from reference books, the technical and social paradigms that have implications for the users of the solutions proposed.

Remedying this situation requires the student to be more aware during conversations to get more valuable feedback. We have already established in Chapter Two that weaknesses in the features of studio (attitude to process, information overload etc) conspire to make this difficult. Challenging this mandates empowering the student, to get maximum feedback. Of all the interactions or conversations in studio, the most valuable for design feedback is the desk crit.

If design education revolves around the design studio, then the deskcrit is the linchpin that provides the support. The deskcrit, the interaction between student and master is that aspect of design education that most closely echoes the apprentice/master relationship of antiquity. It is also the most private of the critical arenas that students find themselves in and the closest to self-criticism. The interaction and quality thereof between student and teacher is at the heart of design education. It makes the biggest contribution to the students understanding of architecture. It is this interaction that determines how the student views the world and comes to an understanding about architectural design. Examining this interaction gives the greatest possible chance of deriving 
a means of enhancing the relationship. Enhancement subsequently will aid to an extent the closing of the gap between academia and practice.

\section{References}

Anthony, Kathryn H. 1991. Design Juries on Trial: The Renaissance of the design studio. New York: Van Nostrand Reinhold.

Boyer, E., and L. Mitgang. 1996. Building Community: A new future for Architecture Education and Practice: $A$ Special Report. Princeton: The Carnegie Foundation for the Advancement of Teaching.

Broadbent, Geoffrey. 1995. Architectural Education. In Educating Architects, edited by Martin Pearce and Maggie Toy, 10-23. London: Academy Editions.

Burtelson, Stacie. 1998. "Advancing Information Technology and the Year Four Student.". [cited 7 May 2003]. Conference Proceedings - ECAADE 98. Available from <http://www.parisvaldemarne.archi.fr/archive/ecaade $98 / \mathrm{html} / 25$ burtelson $/>$.

Cuff, Dana. 1991. Architecture: The Story of Practice. Cambridge, MA: MIT Press.

Doidge, Charles, Rosie Parnell, and Rachel Sara. 2000. The Crit: An Arcbitectural Student's Handbook. London: Architectural Press.

Dutton, Thomas A. 1991. The Hidden Curriculum and the Design Studio. In Voices in Architectural Education: Cultural Politics and Pedagogy, edited \& compiled by Thomas A. Dutton, 165-94. New York: Bergin and Garvey.

Dutton, Thomas A., Aaron Koch, Katherine Schwennsen, and Deanna Smith. 2002. "The Redesign of Studio Culture. A Report of the AIAS Studio Culture Task Force, December 2002." [cited 23 Jan 2003]. Available from

<http://www.aiasnatl.org/resources/r_resources_studioculturepaper.pdf>.

Farivarsadri, Guita. 2001. A Critical View on Pedagogical Dimension of Introductory Design in Architectural Education. presented at Architectural Education Exchange 2001 - Architectural Educators: Responding to Change, Cardiff, Wales, 11th -12th September 2001.

Johnston, Lindsay. 1995. Structure and Methodology in Architectural Education. In Aspects of Quality in Australian Architectural Education, edited by Desley Luscombe and Steve King, 45-56. Potts Point, NSW: Royal Australian Institute of Architects, New South Wales Chapter.

Ledewitz, Stefani. 1985. Models of design in studio teaching. Journal of Architectural Education 38, no. 2 : $2-7$.

Mitgang, Lee D. 1997. Saving the Soul of Architectural Education: four critical challenges face today's architecture schools. Architectural Record 185, no. 5 (May): 124-30.

Mitgang, L. 1999. Back to School: Architects sound off on 10 critical issues facing architectural education. Architectural Record, no. Sept 99: 112-20. 
Monaghan, Peter. 2001. The 'Insane Little Bubble of Nonreality' That Is Life for Architecture Students. The Chronicle of Higher Education, A34.

Nicol, David, and Simon Pilling. 2000. Architectural Education and the Profession: Preparing for the future. In Changing Architectural Education: Towards a new professionalism, edited by D. Nicol and S. Pilling, 1-26. London: Spon Press.

Ochsner, Jeffrey K. 2000. Behind the mask: A psychoanalytic perspective on Interaction in the Design Studio. Journal of Architectural Education 53, no. 4: 194-206.

Richards, J. M. 1974. Architecture. Newton Abbot, Devon: David \& Charles (Holdings) Ltd.

Ryan, C., J. Broadbent, D. Healy, and G. Byrne. 1991. Design Education in Australia For the 1990's \& Beyond. Melbourne: Centre for Design @ RMIT.

Schön, Donald A. 1984. The Architecture Studio as an Exemplar of Education for Reflection-inAction. Journal of Architectural Education 38, no. 1: 2-9.

Skinner, Peter. 2000. "Studio Teaching in Architecture." 16 Jan 2002. [cited 1 Aug 2002]. Available from <http://www.tedi.uq.edu.au/conferences/teach_conference00/papers/skinner.html>.

Uluoglu, Belkis. 2000. Design knowledge communicated in studio critiques. Design Studies 21, no. 1: 3358.

Wade, John W. 1977. Architecture, Problems and Purposes. New York: John Wiley and Sons. 


\section{Student and Master}

The mark of a successful educator is not skill in persuasion - but the ability to dialog (sic) with the educatees in a mode of reciprocity (Paulo Freire cited in Dutton 1987:18)

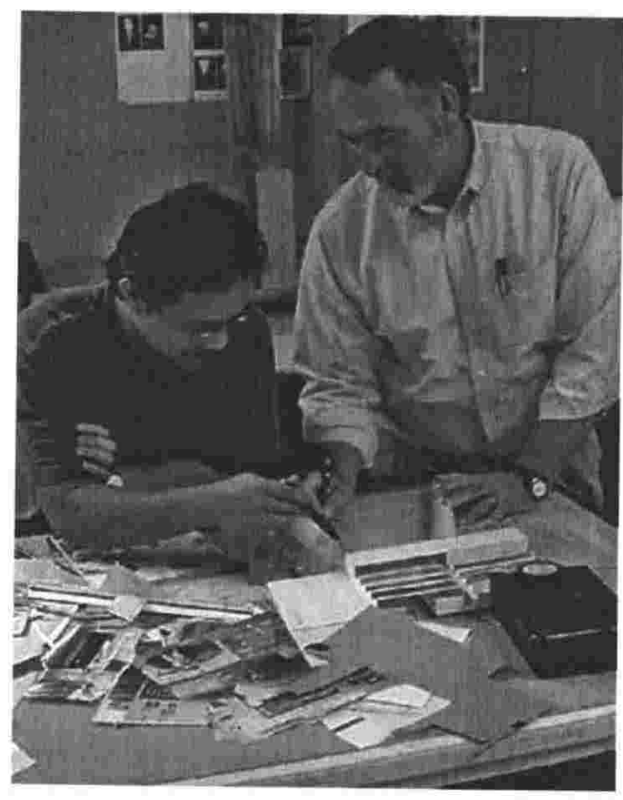

Figure 4.1. A desk crit in session

(source:http://online.caup.washington.edu/dmg/presentations/ecaade2000.brj/ 2.Traditional\%20studios/3.Crits.html)

$\mathrm{P}$

revious chapters have revealed that practitioners regularly complain that recent architecture graduates lack the skills needed to make the transition from academia to practice, less arduous. We have documented leading commentators on the profession and commissioned reports lamenting the discord between practice and education, and recommending that more attention should be given to such "practical" matters like sustainability, energy conservation and community. We have established that the "place" where the requisite renewal or transformation within architectural education should be located, is the design studio.

Whereas design studio is the most important element of design education, the regular meetings the student has with the design tutor is the chief component in design studio that gives it definition and validation. The desk crit has always been the core of educational activity in the studio and while embodying the 
master-apprentice model this dynamic relationship is perhaps the richest (Cuff 1991) and certainly the most important found in architecture school. It has been equated to the psychoanalytic relationship that exists between a patient and therapist and includes psychoanalytic characteristics such as mirroring, transference and counter-transference (Ochsner 2000). Helena Webster (2002) describes it as:

...a kind of 'ritualised transaction' in which students (as novices wishing to join the architectural community) present their architectural 'understanding' through drawings and words for legitimation by their tutors (as 'experts' and 'gatekeepers' to the community) (Webster 2002).

The interaction of student and teacher is considered by students as a rich source of learning (Figure 4.2) and sometimes results in lifelong friendships between faculty and students (Anthony 1991). It is this relationship that distinguishes schools of architecture from other departments within the university. The amount of contact hours between teacher and student is among some of the highest, with students and tutors spending as much as 90 minutes per week in "casual" conversation about a design project.

STUDENTS' RESPONSES TO:

HOW MUCH DO YOU USUALLY LEARN FROM...?

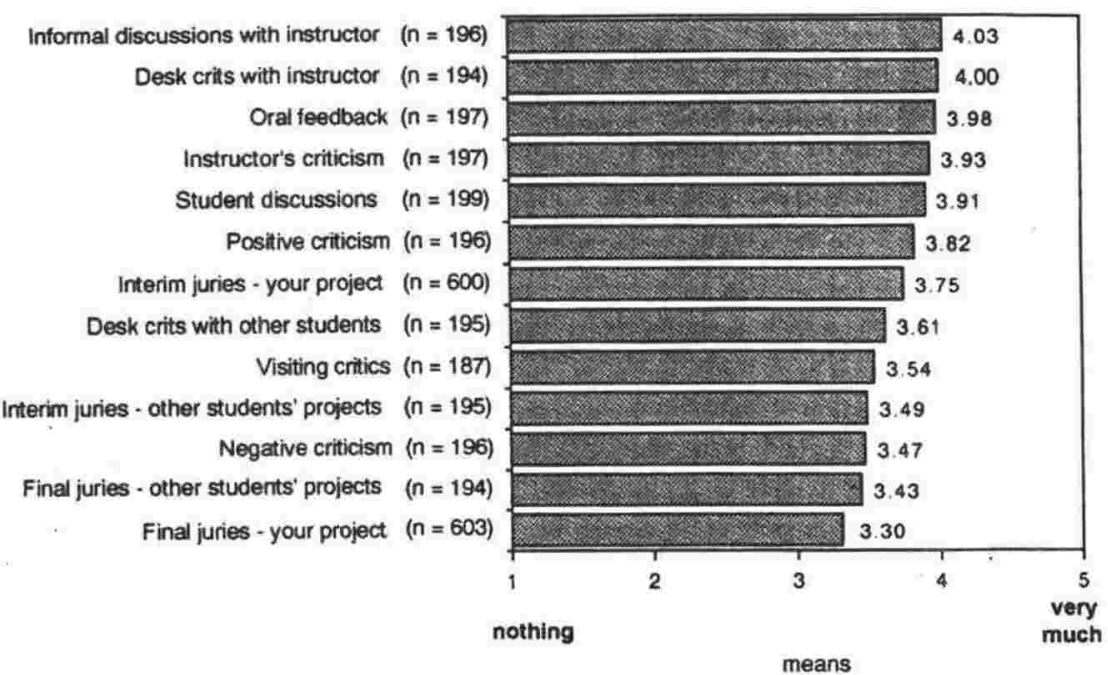

Figure 4.2. K. Anthony confirms the value of the desk crit by reporting that students feel they learn most from informal discussions and desk crits with their instructors and least from final reviews. (Source: Anthony 1991) 
The role the desk crit plays in design education indicates that it holds the key to any process or method aimed at improving the capabilities of graduates upon leaving architecture school. In order to instigate a renewal in education or suggest ways or means towards closing the gap between education and practice, we cannot avoid considering this interaction. In this chapter we will investigate the pedagogical nature of the interaction. Our understanding from this investigation will provide the basis for describing how students can come to an understanding of design and architecture. This will identify the "zone of interaction" which exists in a virtual space and uses drawing as its medium and environment. In the end it will be established that the sketch has to play a key part in preparing design education meet the challenges currently set before it.

\section{The Master and the Student}

The desk critique specifically (also termed the desk crit or individual tutorial depending on which school and in what continent you happen to be located) is, broadly speaking, the only event in architecture school where students and tutors (masters) formally interact one-on-one. It is where the chief educational exchange about design solutions takes place, and the student by means of criticisms, demonstrations, and instruction is taught how to design. This "private" interaction occurs in the public studio space during the allocated period on the school timetable for design studio (and sometimes by appointment in the tutor's office). These sessions will usually last anywhere from 20 to 40 minutes per student. The amount of time spent with each individual student is dependent on various factors: a predetermined allocation of time for each student in the class; the amount of tutors in the class; amount of information presented by the student; the student's progress etc. These sessions provide a regular opportunity for the tutor to provide personal guidance to the student while becoming familiar with the student's personal style of working or designing. This personal guidance includes formulating their design strategy, refining design values as well as discussing general design processes by "reflection-in-action" (Schön 1985). In other words the student learns "how to think like an architect" (Schön 1985) or acquires the "artistry of designing" (Schön 1984). 


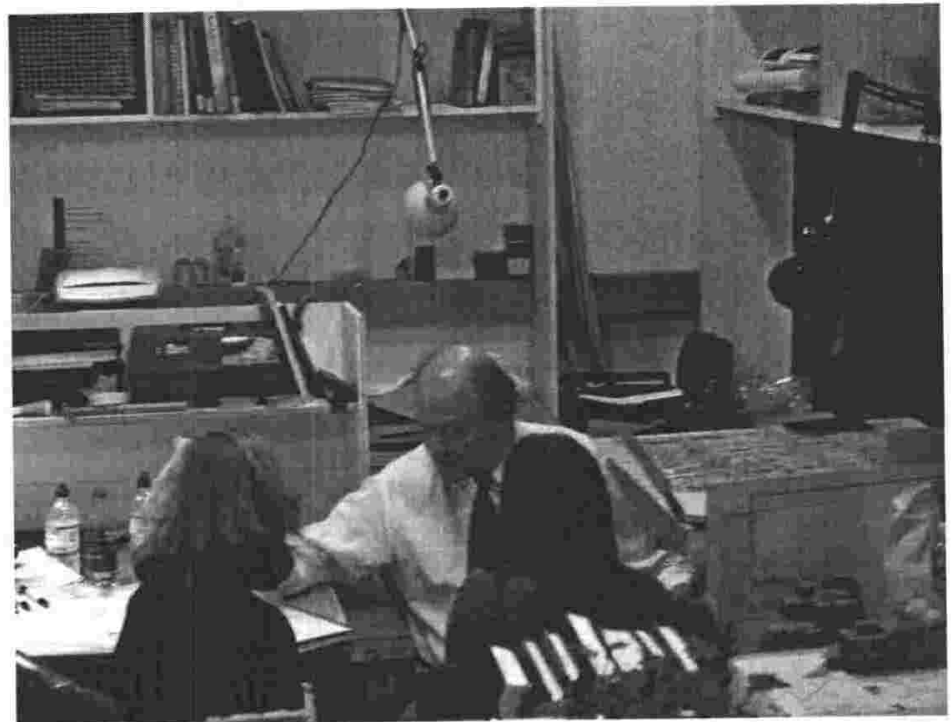

Figure 4.3. A desk crit with two students (Source: http://www.forgemind.net/diary/2002/2002-01/photo/diary-2002-01-photo2002013103.JPG)

The master-student dialogue occurs in the context of reviewing the student's sketches (which consists of two and three dimensional drawings), detail drawings, and/or physical study models. Sometimes the master explicitly demands these exhibits and sometimes the choice of the appropriate representation of the solution is left up to the student depending on their level of skill, knowledge and/or location of their enquiry. The conversation usually commences with the student explaining the current situation. This includes the various moves taken, the positions of difficulty and future directions he/she wants to take. The tutor then analyses the situation (i.e. tries to determine what the student understands, what the student's problems are about, and what the student needs to know (ibid.)). In light of what the student offers (visual and aural) the tutor responds by:

- evaluating the quality of the solution or design strategy;

- restructuring or reinforcing design ideas with the use of analogies and alternate interpretations, demonstrations;

- commenting on the technical aspects of a particular approach; 
- giving suggestions of particular strategies that could provide enlightenment of a particular aspect of the problem.

The master or tutor may seek to clarify by demonstrating what he/she thinks the student should learn. This is done by sketching over or in the vicinity of the student's offering and talking to the student. The good teacher, when sketching, tries to establish clear relationships between what is being said and what is being demonstrated (sketched). The student then attempts to grasp or translate the meanings and instructions received from the master. $\mathrm{He} /$ she takes on board the suggestions or coaching instructions as they appeal to him/her, goes through another design iteration before returning and re-presenting the development to the tutor at the next meeting. The dialogue is then repeated within the framework of the changes and continued discussion from the last session. This cyclical activity (which incidentally resembles the iteration involved in design activity) takes place until the final review.

The preceding is a more or less general description of the activities involved in the master-student interaction. The dialogue however is much more complex than this, with the quality of the learning dependent on various factors e.g. the quality of the master, the environment and the student's willingness to learn. Most importantly though, it is dependent on what the student brings to the dialogue - both abstract (ideas) and concrete (drawings/models). To determine options for a revitalisation we must, however, go deeper and examine the pedagogical foundations that make it such an important and valuable learning tool.

\section{Pedagogy}

The value of design studio instruction cannot be overstated. The studio has the potential to be the interdisciplinary arena for the integration of all aspects of the student's education (Brady 1996). It is in the master-student interaction that the student learns how to assemble the many divergent aspects of architecture, develop a personal attitude towards design process and gain an appreciation for the practical issues that determine architecture. It is here that values can take root and become a part of the individual. These are the values the student will carry with him or her when they graduate and start to practise. In order to 
develop in students an appreciation for environmental issues pertaining to site, climate, wind, light, and other issues that make architecture habitable (in short, a sense of realism), we must examine the pedagogical underpinnings of the master-student interaction.

Literature that outlines the educational base of the communication between student and master is surprisingly scarce. While a lot has been written about the design studio itself (and the events that occur in it), little has been written about the character of the relationship between student and master. At present, apart from a few papers, there exists little established theory about the central interpersonal relationship in architectural education (Ochsner 2000; Webster 2001). Nevertheless, the most comprehensive pedagogical examination of student and master comes from Donald Schön in his publications: The Design Studio (1985), Educating the Reflective Practitioner (1988), and The Reflective Practitioner (1983). Unfortunately this influential study (still cited more than two decades after publication), which covers the design studio in great detail, is not about the merits of the interaction for the benefit of architectural education. Rather it presents the design studio as an exemplar, offering valuable lessons for other professions. Despite criticism of some of Schön's ideas, particularly lack of recognition of the asymmetrical power relationship in desk crits ${ }^{15}$ (Dutton 1991) and "dubious research methodology" (Webster 2002), and its age, Donald Schön's studies still present the clearest picture of what actually happens when the studio master meets the student. It is his analysis and interpretations that we will use to get a pedagogical image and determine a viable solution to our situation.

\section{Paradox and Predicament of learning (or teaching) Design}

Architectural design is subtle, imprecise, culturally rooted and involves synthesising or analysing various parts of the "problem" in order to understand or reveal the overall "essence" or solution. The teaching of it relies on implicit responses to "attempts at solving the so-called "wicked problems"16 that only

\footnotetext{
${ }^{15}$ See "Another Dimension" in this chapter for more discussion of this point.

16 "Wicked problems" is the name given to the kind of multivariable problems that comprise the design of a building. It cannot be solved by a process of logical deduction or by applying a series of formulae. The solution is usually found by trying to understand the problem. For more on "wicked problems" see chapter 11.
} 
define themselves when a solution is sought" (Ochsner 2000). Unlike other courses that usually have predefined answers, in architecture, students are expected to develop a personal attitude towards design. In effect, the student answers the design problem by attempting to create a particular, highly distinctive solution. Because of its personal nature, design teaching is therefore "hands off". Students must find their own way through the problem with periodic intervention from the master. The process, as mentioned, is not predetermined and hence the master cannot tell the student how "best" to design. It is something the student has to find for him or herself by doing it.

For the uninitiated student this can be an experience of uncertainty and ambiguity resulting in a loss of competence and confidence (Schön 1984). The student is unsure what is required and the master cannot explain the process because it can only be understood through the experience of doing it. The master therefore cannot engage with the student until the student has generated an initial response to the design problem, creating a basis for the interaction to exist. Schön (1985) refers to this phenomenon as the "paradox and predicament of learning to design". According to Schön, at the start of learning to design the student does not and cannot understand what designing means. The student finds the artistry of "thinking (and doing) like an architect" to be elusive, obscure, alien and mysterious. Conversely, the studio master is aware that students do not initially understand the essential elements of designing but cannot reveal these things at the onset, because the fundamental concepts of designing cannot be grasped outside the context of doing (Schön 1985). Schön remarks that only as the student "immerses him or herself in the studio experience, the experience of trying to design, can he or she create the conditions in which to begin to understand what the studio master says or does" (Schön 1984). Ochsner (2000) echoes this by saying:

Design education is fundamentally about learning "trust" in a process - a process of discovery, the endpoint of which cannot initially be known or even predicted. (...) a process that involves much psychological risk: it tolerates, even revels in, ambiguity; it offers no guarantees that success will be achieved; it is a gradual process of discovery that is often best approached through wide two and three-dimensional non-linear exploration; and it cannot even be explained to beginners, but still requires a beginning before the instructor can offer assistance (Ochsner 2000). 


\section{Reflection in Action}

Once an initial move is made by the student who is not sure what to do or what to know in order to know what to do, the studio master has the responsibility of "lighting the way". There are two strategies that the master employs showing and telling. The student has the reciprocal responsibility of imitating and listening. In showing the master may demonstrate some aspect of the process that the student should learn or simply imitate. This gives the student something to imitate. In telling the master may "tell" the student something about designing - a general description, specific instruction, suggestions, and questions - in which case the student is expected to listen. Studio masters differ in their preference of strategy.

Whatever the strategy or combination employed, two conditions have to be met if the student-master dialogue is to be successful. One - showing and imitating, telling and listening must take the form of reciprocal reflection - in - action and two - the context must be one where the student is actively engaged in trying to design. (Schön 1984)

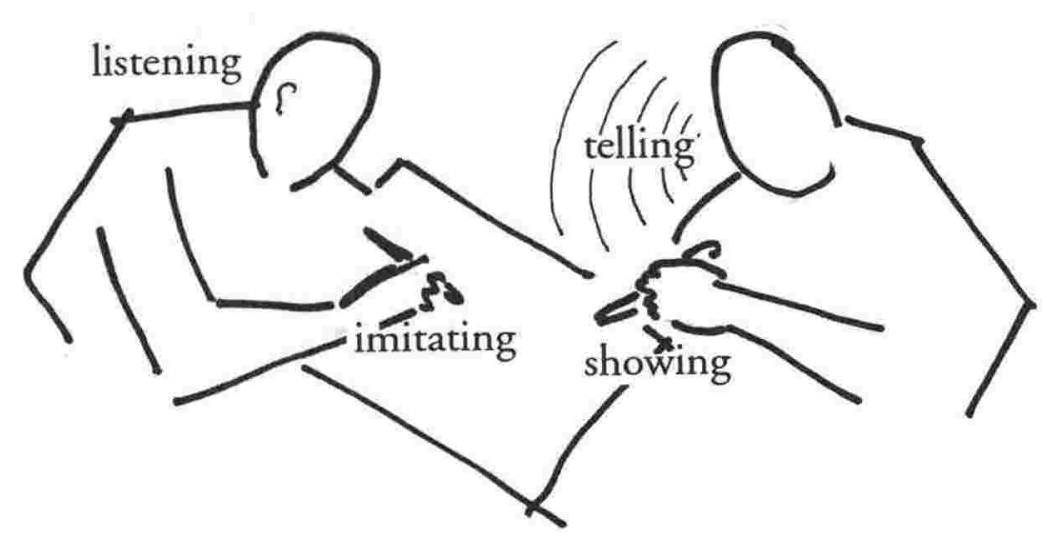

Figure 4.4. Reciprocal reflection-in-action. Student on the left, tutor on the right.

\section{Reciprocal reflection in action}

Schön expands on this notion of reciprocal reflection in action by stating:

The studio master, when he works well, tries to figure out what the student understands, what the problems are about, what he or she needs to know, all of this from the main 
evidence of observation of the student's designing, The studio master's interventions, then, are experiments which test both the studio master's grasp of the student's understanding and the effectiveness of the intervention. In this way, the studio master reflects-in-action.

The student tries to grasp the meaning of the master's showing and telling and seeks to translate what is grasped into his or her own performance. Each such performance is an experiment which expresses the sense the student has made of what has been observed or heard and tests the means by which he or she translates that sense into the task of designing. In this sense, the student reflects-in-action. (Schön 1984)

This process of the student and master performing and responding to that performance continues and is successful when it results in what Schön calls "convergence of meaning" (Schön 1985). As the two persons approach convergence of meaning, their speech becomes more economical, they use shorthand in word and gesture to convey ideas that might seem complex to an outsider; they communicate with greater confidence: they finish one another's sentences, or leave sentences unfinished, confident that the other has grasped their meaning (Schön 1984). Success, then, in the student-master dialogue occurs when they "speak the same language". When this occurs the student's performance and words are recognised by both student and master as thinking and doing "like an architect" (Schön 1985).

\section{Quist, Petra and the Desk Crit}

To better comprehend what happens during the student-master interaction it is practical to observe and analyse an "actual" conversation between a student and a studio master. For this we will use Donald Schön's well-known protocol of a design review of a student's work by the studio master. Schön's protocol takes place in a loft-like design studio where twenty or so students are working on the program for the design of an elementary school. The student in the protocol a first year student named Petra is "stuck" in the early phases of her design. Quist is the studio master and the conversation takes place at Petra's desk where she displays some drawings and a model. Quist examines these while Petra describes her predicament. After a while, Quist places a sheet of tracing paper over her sketches and begins to draw over her drawing. As he draws, he talks. His words do not describe what is already there on paper, but parallels the process by which he constructs what is there. This happens throughout the review. According to Schön this drawing and talking are parallel ways of 
designing, and together make up the "language of designing" (Schön 1985). This language (to Schön) is a meta-language where the master describes some features of the process he or she is demonstrating. The student is then encouraged to reflect on the master's parallel act of designing with the aim of imitating it. In this way the master acts as a "master to apprentices modelling appropriate behaviour, values, design strategies, and thought processes" (Schön, 1983).

The design review described by Schön contains this language and is broken into several phases:

1. Petra presents her preliminary sketches and describes the problems she has encountered.

2. Quist analyses and reframes her presentation in his own terms.

3. Quist demonstrates the working out of a solution to her problem.

4. There is a brief interval of reflection on the demonstration to date.

5. Quist sets out the next steps Petra will have to undertake.

6. Finally, both participants reflect on all that has gone before.
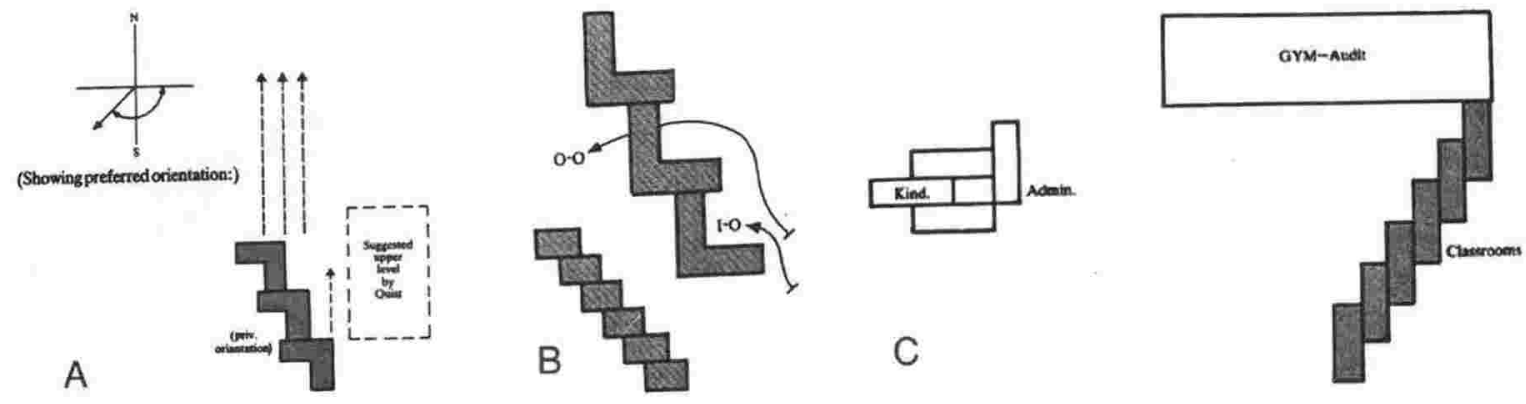

Figure 4.5. Petra's diagrams (Source: Schön 1985)

In phase one Petra shows Quist her drawings, a model with an exaggerated slope and a list of problems. She speaks of trouble getting beyond the diagrammatic phase. Her problems involve the geometry of the building ("shape" according to her), the contours of the site, layout of various rooms, consolidating classrooms to relate to an educational idea and a space that can be outside and inside. During the presentation Quist interrupts her to ask questions about scale, orientation;

Quist: This is to scale?

Petra: Yes. 
Q: Okay, say we have introduced scale. But in the new setup, what about north-south?

(He draws his orientation diagram.)

Phase two sees Quist reframing the problem. From Petra's drawings and the answers about scale and orientation, Quist figures that the problem is not the fitting of the shape of the building to the slope but rather coherence must be given to the site in the form of a geometry - a "discipline" - which can be imposed upon it.

Q: Now this would allow you one private orientation from here and it would generate geometry in this direction. It would be a parallel...

P: Yes, I'd thought of twenty feet...

Q: You should begin with a discipline, even if it is arbitrary, because the site is so screwy - you can always break it open later.
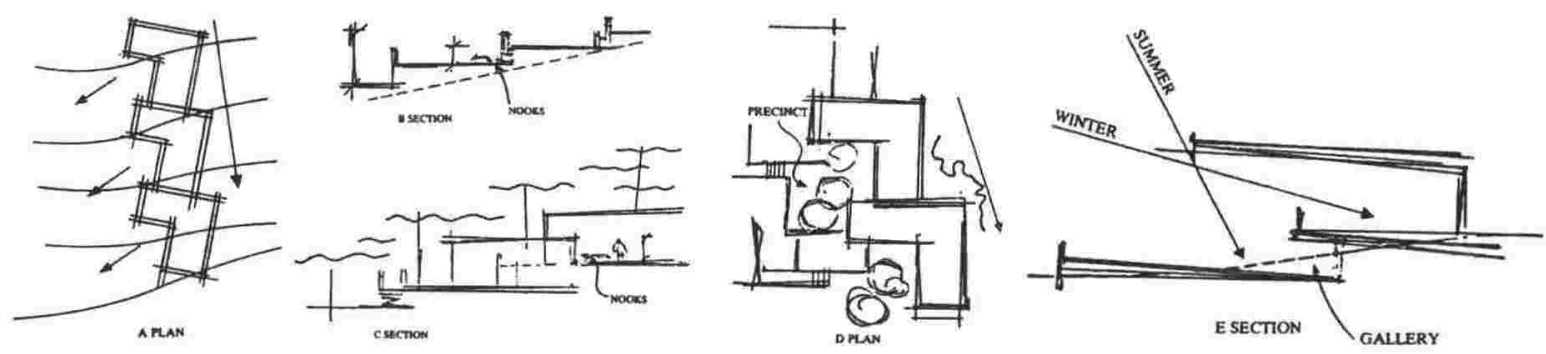

Figure 4.6. Quist's Drawings (Source: Schön 1985)

In his opinion the required design move is to coordinate a constructed geometry with the "screwy" contours of the slope knowing that the geometry can be "broken open" again.

Phase three is the demonstration of this idea. First he draws the imposed geometry on the "screwy" site, the consequence of the move in section showing a step like configuration from the near end of the classroom lying highest on the slope to the far end of the classroom which is lowest on the slope. He then draws another sketch with the resultant "nooks" created by the roofs of adjacent classrooms. Quist continues sketching ending up eventually with a floor plan that takes its cue from the "nooks" leading to "precincts", retaining walls (with multiple functions), gardens and finally a gallery and cafeteria that takes advantage of the north-south orientation, which will cause the sun to fall on the slope at different angles in summer and winter. His demonstration is accompanied by "telling". His telling sounds like this: 
Q: Now you would give preference to that as a precinct which opens out into here and into here and then, of course, we'd have a wall - on the inside there could be a wall or steps to relate in downward. Well, that either happens here or here, and you'll have to investigate which way it should or can go. If it happens this way, the gallery is northwards - but I think the gallery might be a kind of garden - a sort of soft back area to these.

The kindergarten might go over here - which might indicate that the administration over here - just sort of like what you have here - then this works slightly with contours

Q: Then you might carry the gallery level through - and look down into here - which is nice.

Let the land generate some sub-ideas here, which could be very nice. Maybe the cafeteria needn't be such a formal function - maybe it could come into here to get summer sun here and winter here.

The design session partially confirms Quist's reading of the situation (something Petra had not seen perhaps because of her inexperience) and demonstrates the implications and opportunities attached to his design moves. Quist's string of moves ends up in a richer scheme with elements not only fulfilling one domain but also going between several domains.

A period of reflection occurs in the next phase as Quist and Petra discuss the last series of moves with the drawings (Petra's and Quist's) before them as evidence.

P: Where I was hung up was with the original shape; this here makes much more sense.

Q: Much more sense - so that what you have in gross terms is this (he points to his gallery). It is an artifice - the sort of thing Aalto would invent just to give it some order. He's done that on occasion. So in a very minor way, that is the major thing. This repetitive thing is an organized way - there is this which is not repetitive. It is very nice and just the right scale. It also has a sort of verbal order that you can explain to someone.

Schön adds the following commentary:

The gallery, which had begun in Petra's mind as a minor element of the design, a "general pass-through" has now become "in a minor way - the major thing". Quist's reframing and reworking of the problem have led to a reappreciation of the situation, which he now evaluates in terms of norms drawn from several domains - form, scale, and verbal explainability.

Phase five finds Quist giving instructions to Petra about her layout problems with the administration area and the gym. He implies that her ideas about it would not necessarily go with the ideas generated in the previous phases, and implores her to use drawing as the means of looking at the problem from different directions.

Q: Now the calibration of this becomes important. You just have to draw and draw and try out the different grids. 
P: Well, there seemed to be a strange correlation between the two.

Q: No - look at it sideways. It looks much steeper in sections. You see, sections always seem much steeper in reality. Try dividing up a ten degree road - you think you would never make it (draws his slope diagram)

At the end of the session Quist and Petra discuss the design process that has gone before:

P: Yes, this was the main thing to get down - how that basic unit - I was thinking in much closer terms coming through the thing.

Q: (Cuts her off) Yeah, and the other thing is the subjection to a common set of geometry. You'll see that that will be a common problem which will come up with everyone, either too much constraint or not enough. How to do that, that is the problem of this problem.

P: It's amazing - intuitively you look at the shape and you know it's wrong, but it's very hard to get down to the reason

Q: Yeah, well, that is what you are here for. So - I'd worry about the basic geometry of the site. I wouldn't concentrate on the roof.

The principle is that you work simultaneously from the unit and from the total and then go in cycles - back and forth, back and forth - which is what you've done a couple of times stutteringly. You have some ideas of the whole which is the grid thing, but you don't know its dimensions. You've done something about this by eliminating that idea, which I think is a good decision. You keep going on - you are going to make it.

\section{What Petra Learned}

In the review above Petra is relieved of her problem and is armed with ideas to go forward. The solution however is of less importance to the crit than her ability to learn from what Quist has done in the process of arriving at a suitable solution. In the session (according to Schön) Petra learns about designing and learns to design. She also learns about the issues and elements that construct architecture. Petra learns about designing by observing Quist's demonstration. In Quist's demonstration she observes the manipulation of the images, the movement through design domains and a specific approach to design and also the kinds of critical questions (that Quist asks) that she can ask of herself. In addition she learns what to expect from a desk crit, what is expected from her, how she should present her problems to get useful suggestions for the design tutor.

In the same arena Petra learns about design. She observes that designing involves judgements about what is "nice", "good", "interesting", "like what Aalto has done on occasion", or what is "horrible", "spoils the whole idea", "screwy" (Schön 1985). She begins to become aware of her own likes and 
dislikes, values and preferences, by which she judges the results of her design experiments. To these ideas Schön adds the following:

[Petra] learns how the studio master makes his judgements of design quality, and something of what enters into those judgements, and she learns (with greater or lesser independence) to make her own judgements. She also learns to be attentive to certain norms of designing - for example, the norm of fidelity to the implications set up by one's prior moves - and to see the connections of those norms to the qualities she has learned to like in her own and other's work (Schön 1985).

Complementing Schön's two elements of design and designing is the wisdom Petra gains about how architecture is constructed. This wisdom includes aspects of architecture that produces buildings that are fit-for-purpose, cost-effective, environmentally friendly and pleasing to clients and users. She observes how:

- various issues and elements are used, (figure 4.5)

- how the implications of their use produces opportunities, (figure 4.5)

- where examples can be found of their use.

Although this aspect of Petra's learning is downplayed somewhat in Schön's protocol, it is a part of most crits. Even though Quist does not explicitly state the practical implication of his demonstrations this is shown in his drawings (Figure 4.5). More often than not the master points out or develops these elements for the student. Quist also encounters similar problems among the students and expends a lot of time repeating his instruction. He confirms this by making the statement:

"Yeah, and the other thing is the subjection to a common set of geometry. You'll see that that will be a common problem which will come up with everyone, either too much constraint or not enough. How to do that, that is the problem of this problem."

\section{Concrete and Abstract}

This learning happens by the master using singularly or more often than not in combination, the strategies of telling and showing. The master in telling and showing moves from concrete, physical instances related to product, to more abstract notions related to process. Belkis Uluoglu offers his observation of how telling and showing is used in this way:

Whenever the studio master's choice was coaching, the operative knowledge [is] proceeded with associative knowledge. If, instead, his choice [is] demonstration, operative knowledge was preceded with reflective knowledge. In the first case, the studio master helps the student to think about the concrete or the specific, i.e. the 
solution, via examples, analogies, and scenarios, instead of demonstrating one specific solution. In the latter case, the SM demonstrates a solution and helps the ST understand the succession of his actions via interpretations and descriptions, in other words, the mechanisms that lie behind that specific course of action. In short: two kinds of performances were observed while motivating the ST towards a solution; [1.] to show the way and associate it with a concrete situation, [2.] show one specific solution and explain how you perform - interplay of the concrete with the abstract (Uluoglu 2002).

At the end of the desk crit it is hoped that Petra has learned, at least, two things. Abstract ideas about designing, and practical ideas about elements used to create responsible design.

\section{Zone of Interaction}

As stated earlier, the reflective dialogue between master and student can only begin once the student has begun to design. Most of Quist's actions - telling and showing - were made therefore in the context of Petra being in the midst of a task (and perhaps stuck in it). It is in this context of doing that the transference of design knowledge takes on greater meaning. The things the studio master says in these contexts have a potential for communication to the student that they would not have in other contexts. If the tutor talks about issues that consider window size (for instance daylighting) the student will listen in a special way since he/she is engaged in a situation where the window sizes are important. As a result the instruction takes on a special meaning. In Schön's protocol Petra "gets" what Quist says because she has been grappling with the problem of fitting the building to the contours.

It is here in the midst of doing, that the student starts to learn about making architecture (both the act of making and the things that make architecture). The area where this learning takes place is that "space" in the crit that student and teacher engage in a reciprocal reflection-in-action. It is the "space" where convergence of meaning takes place. This "space" influences the knowledge of practical issues by exposing students to the construction of environments whilst engaging with the master. We will call this the "zone of interaction". Because of the importance of the reciprocal reflection-in-action to design learning this "zone of interaction" should be considered central to design teaching and learning. The processes that Schön talks about: showing and telling, imitating and listening exist in the zone. The quality of the educational exchange is therefore directly reflected in the quality and composition of the zone. 


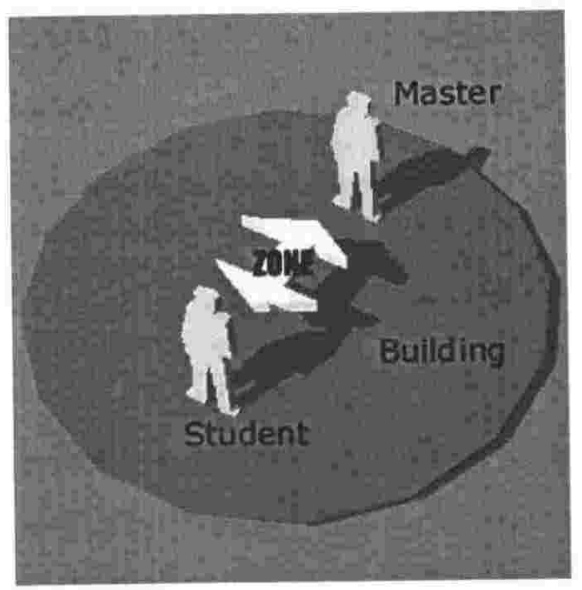

Figure 4.7. The sites of antiquity provided context for the zone of interaction.

The zone of interaction has always been a part of the master/apprentice model of teaching. On the sites of antiquity this zone would have been located on or in the building itself. The apprentice learnt by watching, listening and most importantly participating while having direct exposure to the relationship between design ideas and their built consequences. Because the subject matter (architecture) was not broken up as it is today, into craft, science, and aesthetics, the apprentice learnt all three integrally. These three things could not be separated because the rules of reality dictated their co-existence. The zone, therefore, influenced the knowledge of practical issues by exposing students to the construction of environments whilst engaging with the master.

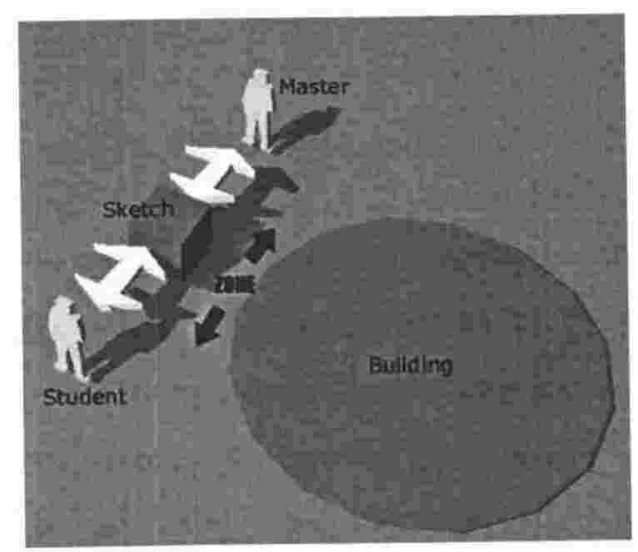

Figure 4.8 Today the zone of interaction exists outside of the reality of the building. 
Today, the zone of interaction is reliant on a virtual environment. When the teacher acts as a "master to apprentices modelling appropriate behaviour, values, design strategies, and thought processes" (Schön, 1983) the zone exists in the realm of a hypothetical project. The "building" does not have to follow any of the rules found in the real making of architecture. Due to the rarity of exposure to the built idea, it is therefore the responsibility of the teacher to make these rules apparent while showing the student how to adhere and creatively operate within the rules. This environment or virtual building that they interface with is, therefore, defined by such representational tools like drawings and models. Drawings and models have an advantage over real sites in that they allow experimentation and focus. The cost, however, is the fact that the student's learning is displaced from the realities of architecture. Drawing (as a broad term) hence becomes the medium for the zone of interaction and the element that controls its success (Figure 4.8).

\section{Another Dimension I}

Before we explore the concept of drawings and models, let us examine other pedagogical dimensions to the zone of interaction. Connected to the idea of the zone of interaction is Vygotsky's idea of the zone of proximal development. This zone of proximal development is the scope of potential each person has for learning, with that learning being determined by the social environment in which it takes place. This potential ability is greater than the actual ability of the individual when the learning is facilitated by someone with greater expertise (Nicholl 1998). Simply put, Vygotsky's theory of learning implies that cognitive development (or learning) occurs through the interaction of the learner with more capable or knowledgeable members of the same culture (in our case the design studio).

Within the design studio support for cognitive development is provided by the studio master and more capable students. Because the studio is comprised of students of various individual strengths and weaknesses, a particular student can theoretically be located in a higher or lower point in the zone (depending on the task at hand) (Conanan and Pinkard 2001). Assuming this, the zones of learning 
potential are not only created by interactions between student and instructor but are dynamically created when students informally interact with each other. This presents us with opportunities for architectural knowledge (or information) that originate from sources other than the studio master.

\section{Another Dimension II}

In Donald Schön's protocol and subsequent promotion of the design studio as an excellent educational model (Schön 1983) there is a noticeable absence of a discussion about the social relationship between his two subjects. Dutton criticises this aspect of Schön's study by indicating that he (Schön) fails to recognise the asymmetrical power relationship in tutorials (Dutton 1991). According to Dutton (1987) the hierarchy of power in the studio between students and teachers ultimately affects dialogue. He claims:

Real dialog (sic) rarely exists across the boundary between teachers and students, even in the design studio. Usually structured in vertical relations, teachers tend to speak in ways (often unconsciously) that legitimize (sic) their power and students orient their speech and work to that which is approved (Dutton 1987).

Learning design is "successful" only to the extent that the student understands and accepts the master's language and frame of reference. As a result the student tries to make connections between his/her issues and the teacher's expectations, reinforcing a dependency on the teacher (Dutton 1991). In this way studio becomes a teacher-centered environment (Dutton 1987; Webster 2002).

This, in fact, runs contrary to modern learning theories and constructivist notions of the personal nature of knowledge and learning where student centered learning is considered ideal (Webster 2002). To Webster, this (tutorcentered desk crit) practice, which is the result of the historical master/pupil lineage, is currently frustrating rather than promoting deep and transformative student learning (Webster 2002). Her research has found that tutors who employ student-centred teaching and learning techniques, provide students with rewarding tutorial experiences and assist them to construct their own learning (Webster 2002). Allowing the student control over his or her learning and providing support to the student's individual development could help students recognize ideas and theories embedded in their work. This would encourage 
reflection, thinking about and comprehension of the "discovery-inventionproduction processes" of design (Dutton 1991) producing a new generation of 'critically' reflective architects (Webster 2002).

\section{The Sketch as Context and Medium.}

In the student-master zone of interaction the student's drawings and models are essential. The student cannot meet the master without first attempting the task. Evidence of this attempt is therefore needed. For the master to grasp the student's understanding of the task there must be something on which the master's observations are based. Drawings and other visual material satisfy both needs. These materials, usually manifested in the form of sketches, determine the outcome of the student master dialogue. It is the basis on which the conversation hinges. A bad sketch or visual information makes for a bad desk crit, since there isn't much the master can work with or interpret in order to give quality feedback. With no visual basis on which to carry out a demonstration, it is sometimes difficult to conduct a productive discussion.

In Schön's desk crit with Petra and Quist, the sketch acts as evidence of Petra's performance, acts as a means for reciprocal reflecting-in-action, becomes a part of the zone of proximal development and legitimises Quist's dominant relationship to Petra. During the protocol the following points are observed:

- Petra's drawings were used as the basis for commencing the discussion.

- Quist demonstrates his design process by drawing.

- Quist's telling occurs in the context of the drawing.

- Quist's sketches illustrate the practical implications of his experiment.

- When Quist and Petra discuss the outcome of his experiment it is to the drawing they refer.

- When Petra reflects on her session after Quist is gone, it is to the sketch that she refers.

With regards to the other dimensions of the zone of interaction the following can be argued:

- Her prior engagement with the sketch helps her to construct and explain her own view of the world. 
- Quist uses the sketch to impose on her his values and frames of reference.

- Quist supports Petra's zone of proximal development through the sketch.

- The sketch facilitates Petra's cognitive development.

From the evidence presented it is clear that design therefore is taught through the sketch by showing, demonstrating and speaking to it. It is in the zone that she learns to manipulate the sketch and reflect on her design activity. She learns that the quality of information contained in the sketch influences the level of interaction and stimulates reflection-in-action. It is through the sketch (directly and indirectly) that Petra learns how to think architecturally. The sketch then becomes an important tool that Petra will use throughout school and when she enters the profession. The quality of the zone and the level of learning are therefore inextricably linked to the sketch.

\section{Influence of the Quality of the Zone}

Teaching and learning in the design studio occurs in the zone of interaction between student and master. The quality of such teaching and learning is dependent on the quality of the zone of interaction. The quality of the zone is dependent primarily on the information wealth of the medium of the zone - the sketch. What the sketch contains or offers, determines the basis for quality and effectiveness of the zone. It follows therefore that for the quality and effect of the zone to meet the challenges facing architectural education the role the sketch plays in the encounter has to be reconsidered.

The opportunity for the sketch to influence learning occurs before and during the period of interaction:

Before - Productivity in the zone of interaction is dependent on the first move by the student. The initial move and its representation have to be of such quality that it generates the required feedback from the tutor and directs the nature of the encounter and its success. A high quality "informed" move provides the tutor with more material to critique and allows the master more time to teach the student how to properly synthesise and manipulate the 
disparate parts of the problem/solution. It also allows the student more time for reflection on the design process. The resulting informed move allows the student more room to define an individual view of the world, and gives tutors less opportunity to impose their values and frames of reference.

During - The sketch plays an important role during the master/student dialogue. If Petra "knew" of the moves that were available beforehand, she would then be better able to value and appreciate Quist's moves. Her understanding or interpretation of Quist's moves would also be easier if she could see the connections or possibilities involved in his decisions while he was demonstrating. Her acceptance of his criticisms and judgement would not be attributed to mystery and suspense in belief (Schön 1985) but rather from an informed position. The conversation would be elevated to a higher level facilitating an earlier convergence of meaning.

\section{Conclusion}

For Donald Schön, the design studio (as a metaphor for design education) is where students learn to be aware and critical, by questioning and challenging personal assumptions, and where they learn to be innovative, by experimenting and exploring new phenomena (Schön 1985). The informal reviews or desk crits that take place between individual students and instructors occur within a zone of interaction. In this space the student performs, the master interprets, demonstrates and tells the student about the process in action. The student then tests his/her understanding of the demonstration and instruction and generates a new performance. The activity that occurs in the zone interestingly closely resembles the activity of sketching where the designer makes a move, evaluates the move, decides on a forward strategy or corrections and then makes another move (influenced by the evaluation). Schön refers to both participants' activities as reflection-in-action. This reciprocal reflection-in-action in located in the context of the sketch. Therefore, the quality of the reflection-in-action and subsequently the zone of interaction is determined by the sketch.

We have arrived at last, at the nucleus of design education - the sketch. This is the element in design education (it would seem) that controls how the student views the "world". The sketch to the student becomes a virtual world where 
design is conducted. Practical knowledge is gained if interaction happens in the context of reality (or the rules of such reality). If this world does not follow rules (or at least refer to them) of the real world the student has difficulty adjusting to "real" problems and has to "relearn" these rules much to the annoyance of his/her new employer. If the sketch controls the outcome of design learning then it has to be reconsidered for education to meet the challenges of the 21 st century.

One of the issues facing teachers of design in today's fast moving society is keeping pace with information and architectural ideas, and transferring these to their students while at the same time teaching them basic fundamental principles about making architecture. The rules of the current world are too much for the teacher of design to inform the student of while teaching the student how to design. Some educators (a few in reaction to this) teach the academic and cognitive sides of education leaving practitioners with the responsibility of teaching graduates the realities of architecture. Practitioners, however, have little time to give the students the structured education required to adequately teach them. Other teachers try to instruct students about the practical aspects of architecture. This however deprives the student of adequate critical thinking and problem-solving skills. The answer lies in a balanced approach to imparting rules and techniques.

It may be necessary to separate both approaches by delegating each activity to separate yet concurrent activities within the zone. One action is the demonstration and instruction of the student about design. The student learns about designing and learns to design. The other action instructs the student about the aspects of architecture that produces buildings that are fit-forpurpose, cost-effective, environmentally friendly and pleasing to clients and users. The student understands how elements fit together and how subsequent implications affect the design. The tutor could play the first role, since this role is dependent on judgement, exposure and a particular way of viewing the world; while the other role could be a part of the sketch the student interacts with before and during the desk crit, allowing a student centred learning. The final solution therefore is to embed the rules of reality in the sketch or empower the sketch to reveal the rules of reality. This involves understanding how the sketch 
works, how the student of architecture uses the sketch, and how the sketch can be modified to play this new role; subjects of Part Two.

\section{References}

Anthony, Kathryn H. 1991. Design Juries on Trial: The Renaissance of the design studio. New York: Van Nostrand Reinhold.

Brady, Darlene A. 1996. The Education of an Architect: Continuity and Change. Journal of Architectural Education 50, no. 1: 32-49.

Conanan, D., and N. Pinkard. 2001. Students' Perceptions of Giving and Receiving Design Critiques in an Online Learning Environment. In European Perspectives on Computer-Supported Collaborative Learning, edited by P. Dillenbourg, A. Eurelings, and K. Hakkarainen, 165-72. Maastricht, The Netherlands: Universiteit Maastricht.

Cuff, Dana. 1991. Architecture: The Story of Practice. Cambridge, MA: MIT Press.

Dutton, Thomas A. 1987. Design and Studio Pedagogy. Journal of Architectural Education 41, no. 1: 1625.

Dutton, Thomas A. 1991. The Hidden Curriculum and the Design Studio. In Voices in Architectural Education: Cultural Politics and Pedagogy, edited \& compiled by Thomas A. Dutton, 165-94. New York: Bergin and Garvey.

Nicholl, Trish. 1998. "Vygotsky,Vygotsky Centennial Project: Massey University's Virtual Faculty.". [cited 3 Jan 2003]. Available from < http://www.massey.ac.nz/ ALock/virtual/trishvyg.htm>.

Ochsner, Jeffrey K. 2000. Behind the mask: A psychoanalytic perspective on Interaction in the Design Studio. Journal of Architectural Education 53, no. 4: 194-206.

Schön, Donald A. 1983. The Reflective Practitioner. New York: Basic Books.

Schön, Donald A. 1984. The Architecture Studio as an Exemplar of Education for Reflection-inAction. Journal of Architectural Education 38, no. 1: 2-9.

Schön, Donald A. 1985. The Design Studio: An exploration of its traditions and potential. London: RIBA Publications Ltd.

Schön, Donald A. 1988. Educating the Reflective Practitioner - Toward a New Design for Teaching and Learning in the professions. San Francisco: Jossey - Bass Inc., Publishers.

Uluoglu, Belkis.2002. Email message to R Bailey, uluoglub@itu.edu.tr. 10 Oct 2002.

Webster, Helena. 2001. The Design Diary: Promoting Reflective Practice in the Design Studio. presented at Architectural Education Exchange 2001 - Architectural Educators: Responding to Change, Cardiff, Wales, 11th -12th September 2001. 
Webster, Helena. 2002. Facilitating Critically Reflective Learning: Excavating the role of the design tutor in architectural education. presented at Shared Visions incorporating Architectural Education Exchange 2002, Brighton, UK, 1 - 3 September 2002. 3 Jan 2003. 


\section{Part 02 Sketching}




\title{
5. Sketching
}

\author{
"The sketch is communication \\ - between 'me' and 'i' \\ - between me and you \\ - between student and teacher \\ - between architect and client"
}

(Cold 1995:60)

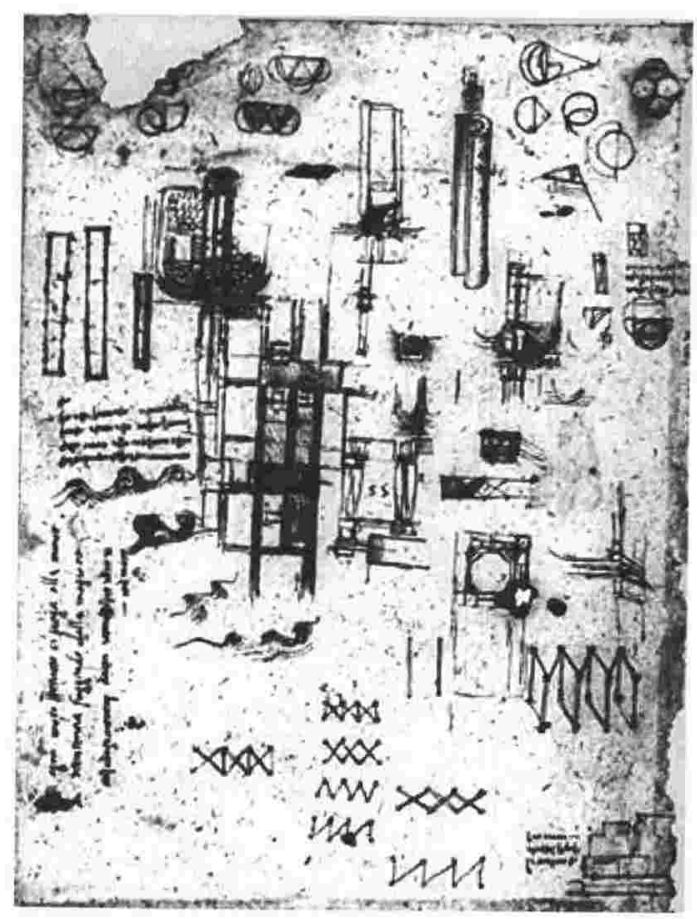

Figure 5.1. Leonardo da Vinci, study sketches for a new Palazzo Medici in Florence, c. 1515.

Source: http://www.lboro.ac.uk/departments/ac/tracey/somag/gabi.html]
$\mathrm{T}$
he sketch ${ }^{17}$, a special form of drawing used by artists and designers to investigate ideas, originated during the Renaissance when the "fundamental codes for design drawings and construction drawing no longer coincided" (Herbert 1993). It was used formally at the Ecole des Beaux-

\footnotetext{
17 It should be noted that while this chapter refers primarily to the marks made on paper, by the designer, in a "two dimensional" way, there are other equally valid and significant means of "sketching". One such "thinking" can include the use of rough three dimensional study models.
} 
Arts as a means of capturing and documenting the primary conceptual parti during the en loge portion of the concours. Its importance then was eclipsed only by the elaborate presentation drawings produced as finished products to be considered by the competition jury. In the recent past (1960s) the sketch (or as J. Christopher Jones (1992) labels it - design by drawing) was further devalued by the design methodologists, who mistrusted "drawing as some sort of irrational ritual..." (Lockard 1982). Drawings, for them, were considered to be misleading, less dependable than models, less informative than quantitative analytical information and "the neutral printing-out of decisions arrived at previously in the clear light of logical 'problem solving" (Lockard 1982). The design method movement then went on to promote the introduction of the computer into the field of architecture as a "superior" tool. It is therefore ironic that during the age of the computer and the pervasiveness of digital tools that an awareness of the sketch as an aid to architects' thinking and creating is being revived.

Evidence of this "revival" is seen in the increase in volume of research about sketching. Conferences and literature over the last decade and a half have testified to this (Goldschmidt 1994; Tang and Gero 2001; Gruzdys 2002; Tversky 2002). A recent symposium hosted by the American Association for Artificial Intelligence (AAAI) acknowledged sketch understanding as an emerging research field and confirmed the fact that researchers are increasingly investigating the phenomenon of the sketch (Stahovich, Landay, and Davis 2002). Books have been written solely on the theoretical basis of drawing (Laseau 1989; Herbert 1993; Robbins 1994; Fraser and Henmi 1994; Lockard 1982) and Bryan Lawson has even added a completely new chapter, dedicated to design by drawing, to the third edition of his valuable book, How Designers Think (Lawson 1997). In the book Architectural Grapbics, Francis Ching justifies the currency of a book on graphic techniques today by claiming that:

While digital technology continues to augment and enhance (the) traditional drawing toolkit, hand drawing with a pen or pencil remains the most direct and versatile means of learning the language of architectural graphics (Ching 2002).

The abundance of such works has established the importance and validity of sketching as a field of study and by extension an essential part of the designer. 


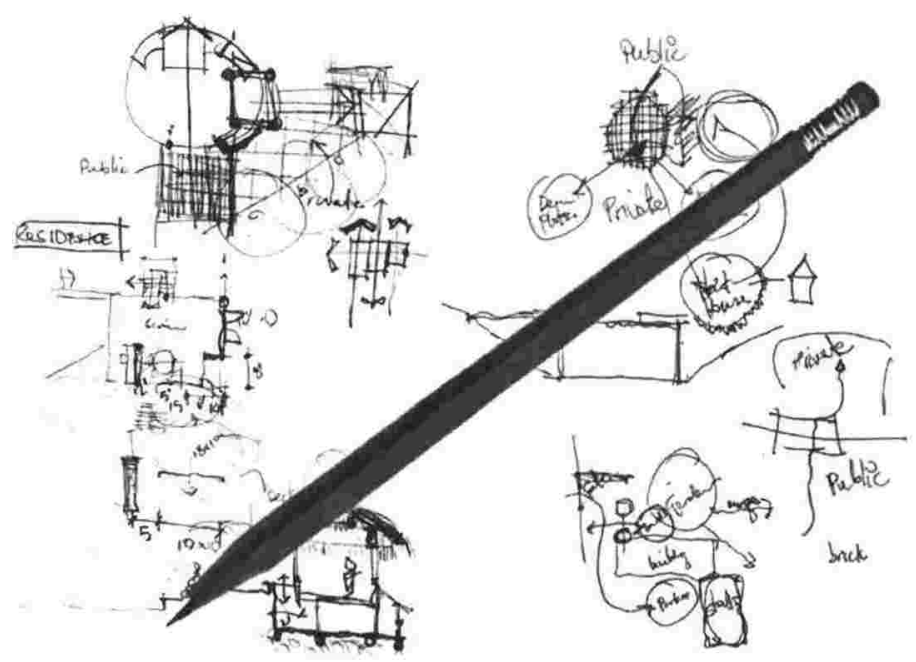

Figure 5.2. There is nothing as simple, loose and disposable as a traditional hand sketch.

It is widely recognised that the most important tool the architect has in the design process is the hand sketch (Lockard 1982; Herbert 199; Do 1997; Lawson 1997; Do 2002; Goldschmidt 2002). This iterative way of testing ideas and informing the design process with images fundamentally directs and aids the architect's decision making. Because the sketch is such a crucial part of the designer's activity it also exists at the centre of the zone of interaction between student and teacher during the deskcrit. It provides the student and master with visual evidence of design thinking and provides the instructor with a means of showing the student how to design. As a result of this dependence, the burden therefore rests on the sketch to assist architectural education in facing the challenges outlined in chapter 2 .

Part 2 of this thesis is about the sketch and its potential as a part of the revitalisation of education. In this first chapter, we will demonstrate the value of the sketch as a means of thinking, understanding and, most importantly, learning. We will explore the dialogue that designers engage in with the media they use and through analysis indicate that sketching is a conversation involving two components - the head and the hand. We will conclude by placing the sketch in the context of design education. In the next chapter, empirical data will be presented from a unique protocol analysis that investigates the two roles (head and hand) being played by human subjects. A related design studio 
conducted in New Zealand and Jamaica is also presented. The conclusion in chapter 6 will discuss the necessity of making the sketch an essential part of any tool or method that is used to aid design teaching. It will also speculate on the form of such tool which can only (it will be argued) exist in the digital realm. The final chapter of the section examines experts and novices and their relation to the existence of an empowered sketch.
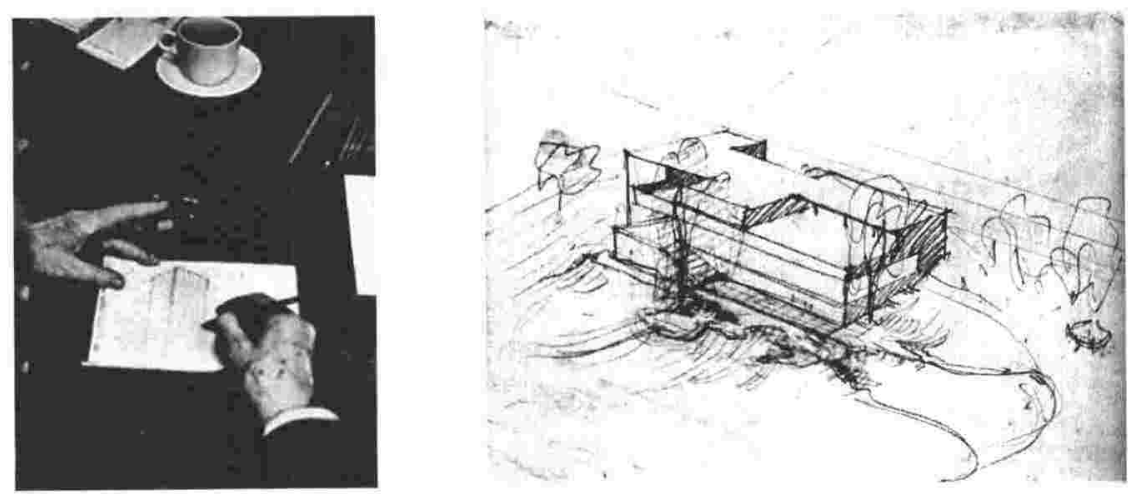

Figure 5.3. Mies van der Rohe sketching (Source: www.designboom.com/portrait/mies/bg.html)

Figure 5.4 Design sketch of Tugenhadt House by Mies van der Rohe.

\section{Images and the Design Process}

\section{Design}

The activity that separates architects from other members of the building team is the predisposition to a certain kind of designing. Design process is seen largely as the activity of organising ideas and issues in order to produce a desired result. It involves analysing or synthesising various parts of the design/problem in order to understand or reveal the overall "essence" or solution. The information that the designer receives when analysing these parts is important in revealing more about the problem. As the designer proceeds through the process, different ideas or pieces of information are revealed. The designer "sees" patterns and possible solutions based on the information revealed. This information when put in the right places or turned the right way helps to reveal still more information. One of the most challenging aspects of designing therefore is the need to keep in mind and consider the many disparate 
factors of architecture. The architect is therefore trained to take available information and filter, store, retrieve and manipulate relevant parts to generate an appropriate result.

For the architect to make judgements about the kinds of information that needs filtering there must be adequate feedback from the situation. Feedback is therefore necessary to make decisions towards a workable solution. Designers get feedback by communicating intentions and testing them. The architect has to communicate intent to him or herself, the client, consultants and the public at large in order evaluate the validity of a solution. In design, this communication is done with the use of images. Decision-making in the design process is therefore highly visual.

\section{Images}

Human beings have always been visual creatures. Idioms like "seeing is believing" and a "picture is worth a thousand words" are testimony to the value we place on visual imagery. Researchers generally agree that between 70 to 80 percent of what we learn is facilitated by our eyes. The means by which our environment is experienced through the use of our senses is called perception. Through our eyes perception is influenced and codified by the images we store. A detailed discussion on the effects and psychology of perception is beyond the scope of this work, however, we can conclude that visual perception is critical for our understanding of the world around us. The proliferation of computers, television and film is sufficient evidence to indicate that visual communication is increasingly becoming an important force in today's society. Images are, therefore, an important means of experiencing and learning about the world in which we live.

In architecture, images are the primary means by which ideas and perceptions are communicated. Unlike spoken and written forms of communication, images have the advantage of "conveying visuospatial ideas directly (...) to convey elements and spatial relations in the world" (Tversky 2002). Comprehension and inference using images is much easier than in a more abstract medium such as language (ibid.). With the use of images the architect communicates spatial ideas and intentions to him or herself, clients and any consultants involved in 
the process. Since architecture is "shared" by clients, users, consultants etc. the nature of the image is determined by the context it finds itself in. The images shared on the wider level therefore have to be fairly conventional as against the personal images used by the designer to communicate with him or herself.
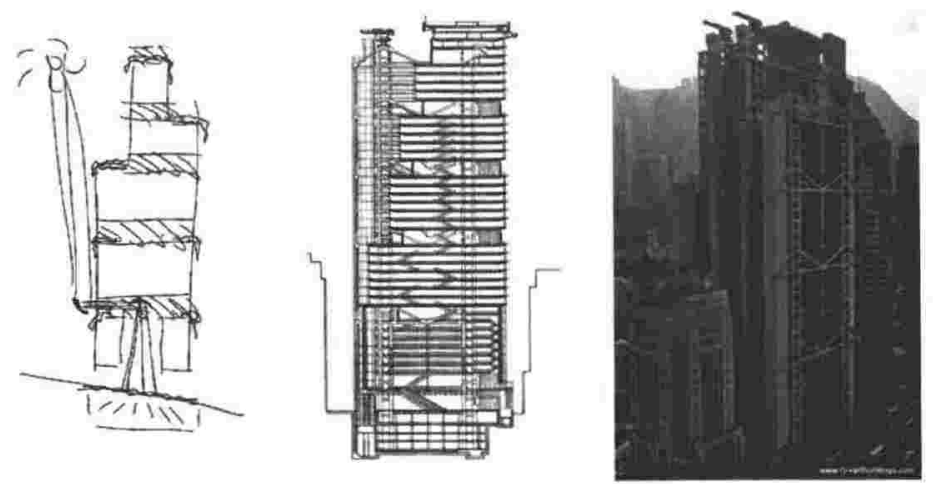

Figure 5.5. Three images of Foster's bank in Hong Kong illustrating the levels of image "sharing" - the private schematic, the drawing for the client and the building for the public. (Source: www.greatbuildings.com)

Images therefore exert tremendous influence on design operations. This influence is related to the amount and type of information embedded in the image. It dictates the flexibility for decision-making and the viewer's perception of the situation. For example: images that lack enough information for an effective decision usually restricts the designer's options. As decisions are based on image, the level and types of information in an image have to be appropriate to the amount of information required by the situation. This level and type of information is usually controlled and manipulated at the discretion of designer.

\section{Drawing}

It must be clear by now that the most important and common use of image in architecture is the drawing. Ever since paper became a ubiquitous part of society, drawings have been similarly ubiquitous and necessary tools in the field of architecture. Drawing is such an important part of architecture that schools of design will go to considerable lengths to teach and develop drawing skills in their students (Lawson 1997), despite the growing use of computers in the profession. At Harvard's Graduate School of Design for instance, students are 
taught both perceptual freehand drawing and rigorous, hard lined descriptive geometry (Gruzdys 2002). At the Columbia University where the "paperless studio" is a fact of life, students are taught drawing in order to understand and follow more closely the functions of the computer (Gruzdys 2002).

As explained earlier the information conveyed by an image is directly related its use. This is reflected in the drawing. In their book Envisioning Architecture - An Analysis of Drawing, Fraser and Henmi (1994) have suggested a classification system for drawings based on their uses. The categories are as follows:

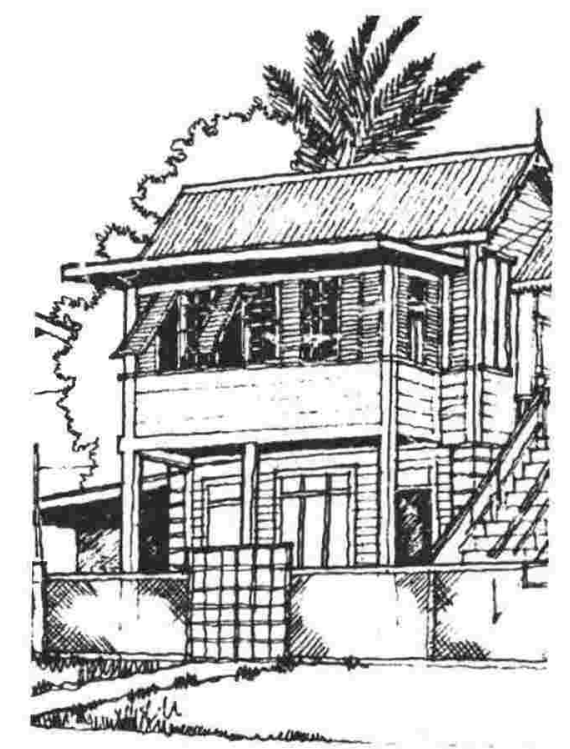

Figure 5.6 Example of a referral drawing. A House in Georgetown, Guyana. (Source: Patrick Forbes)

- Referential drawings are drawings used by the designer to record other designs and the world around them (fig 5.6). These are kept in the form of sketchbooks and help the designer attain a knowledge base not easily gained by simply looking at or photographing an object or place. Referential drawings also expose the prejudices of their author by offering clues to the perceptions and nuances of the maker. In this way they are as particular and revealing as a signature (Fraser and Henmi 1994).

- Diagrams are drawings that use abstract representation to indicate relationships and other phenomena through the use of symbols. 
Diagrams usually do this without giving "detailed descriptions of scale (...) or realistic pictorial representations" (Do and Gross 2001) or space. A very good example of this is the London Underground map (fig 5.7).

- Drawings used by the designer to think about and develop ideas are called design drawings (fig. 5.9) or study drawings (Herbert 1993). Images used in study drawings are akin to personal shortcuts and are necessarily private. Elements from other categories (diagrams especially) are sometimes used and incorporated in design drawings.

- Presentation drawings (fig. 5.8) are the devices that architects use to communicate design ideas to third parties. Using more conventional means to convey information they determine the third party's perception of the design and consequent reaction to it. Compared to design drawings, presentation drawings are more closed, premeditated and deliberately composed. The information contained and its format plays a great role in its effectiveness. As it is presentation drawings are usually reliant on feedback and assessment (from client, developer, and teacher). Also included in this category are working drawings that describe how the design will be constructed.

- Visionary drawings (fig. 5.10) are intended to communicate general indications of some of the intended qualities of the proposed design. They are primarily intended to give the viewer an idea of how the design might feel or look. They usually break drafting conventions in their concern "with the what of design rather than the how, and there is little if any technical accuracy" (Lawson 1997). 


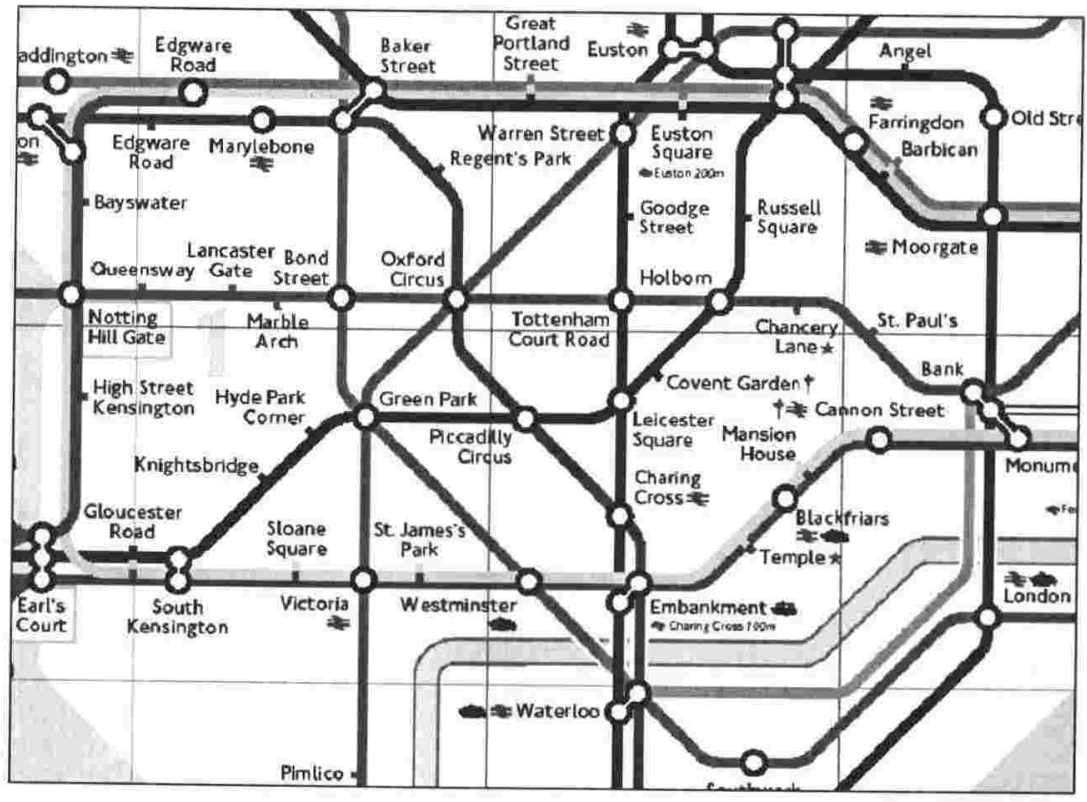

Figure 5.7 Part of the London Underground Map - a diagram (Source: www.thetube.com)

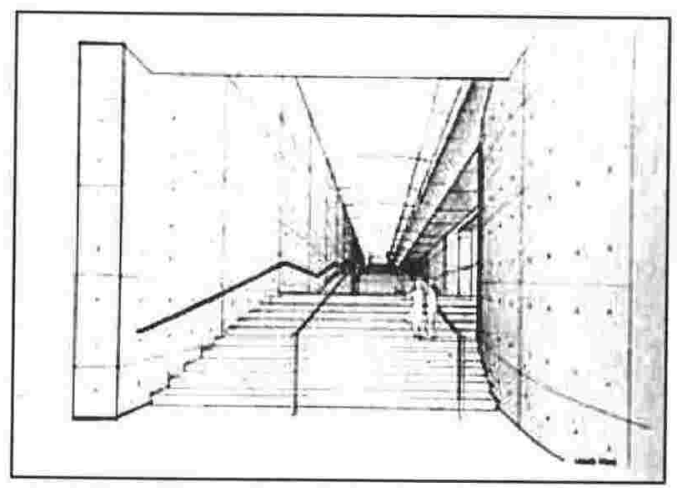

Figure 5.8 Presentation Drawing, Modern Art Museum, Tadao Ando (Source: www.arcspace.com/architects/ando/modern_art_museum/test.htm) 

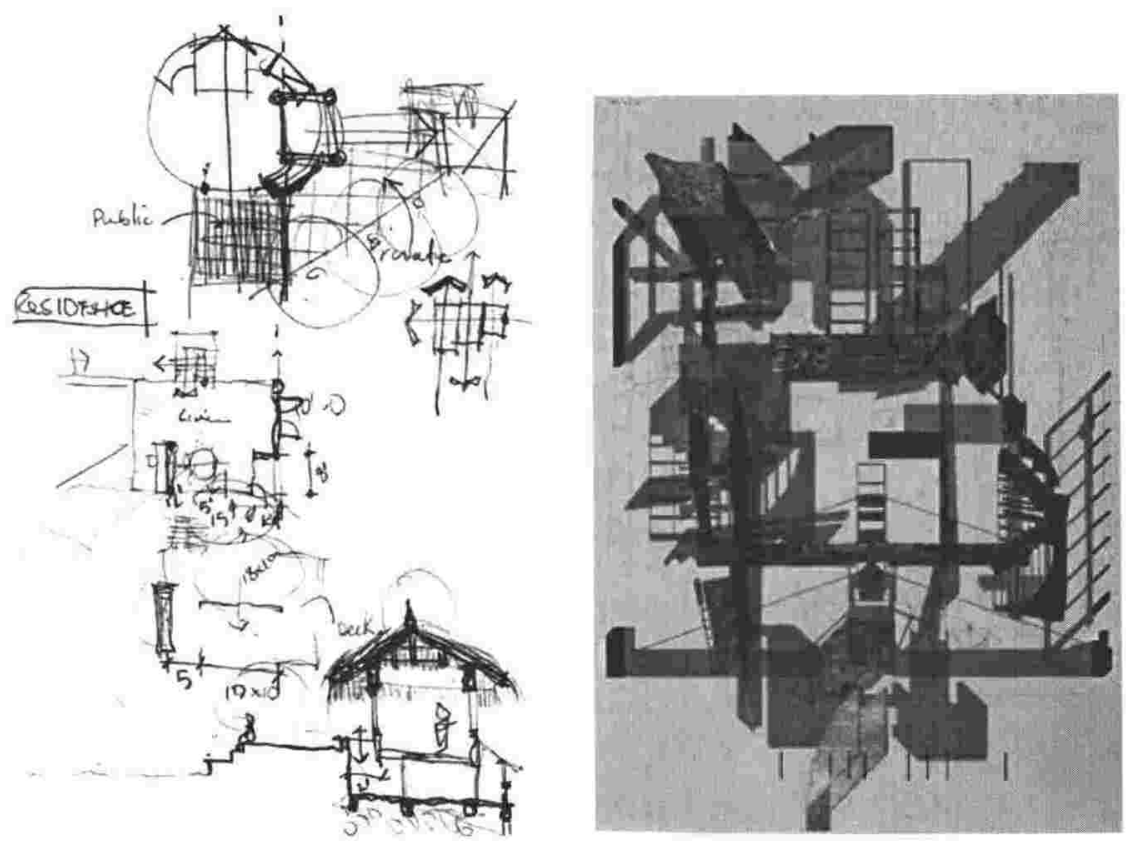

Figure 5.9. A design study drawing

Figure 5.10 Thomas Mayne, Sixth Street Residence, Ocean Park, California, screenprint after composite drawing, 1988 (source www.wesleyan.edu/dac/ exhb/past/2001d.html)

Although all the categories described have varying degrees of impact on the design process, design drawings or study drawings are the focus of our investigations. According to Fraser and Henmi:

Design drawings (...) are done primarily as a way to study architecture, to find and test ideas, to enter and develop the process of inspiration, invention and exploration (Fraser and Henmi 1994).

Design drawings are regarded by Lawson as an attempt to "freeze" and hold constant some limited aspects of the design so that other design issues can be thought about (Lawson 1997). The drawing is made when the designer understands and makes a decision about an idea by putting it down on paper "to see if it works". Thus design drawing represents a sort of hypothesis or "what if" tool. For design drawings to be effective in this sense, Lawson suggests that they display two important characteristics:

First, it is usually helpful if the drawing does not show or suggest answers to questions which are not being asked at the time. Second, it seems helpful if the drawing suggests only a level of precision which corresponds to the level of certainty in the designer's mind at the time (Lawson 1997). 
The process by which drawings and images are used as fundamental objects for design decision-making can be called design drawing (Lockard 1982), graphical thinking (Laseau 1989), or simply sketching ${ }^{18}$.

\section{The Sketch}

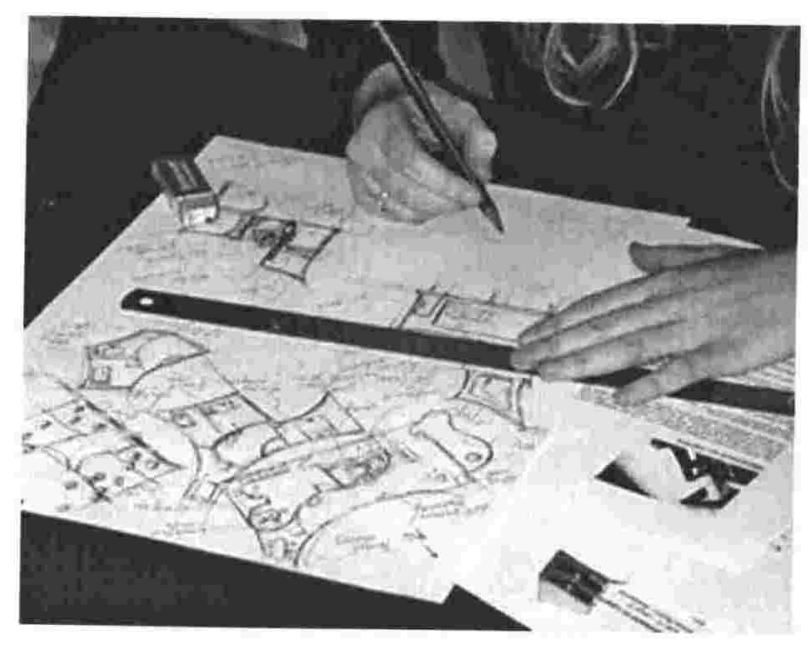

\section{Figure 5.11. Sketching}

Even though the designer uses other tools when designing e.g. rough physical models, the central instrument of graphical thinking is the sketch. The sketch is such a natural part of the designer (many designers are "unable to think without a pencil in their hand" (Lawson 1997)) that it is used without question, relegated to the background, and not given much thought. Sketches are taken for granted probably because they are easily made and just as easily discarded. Despite its apparent simplicity the sketch is actually a complex phenomenon. Rather than simply being a method to record ideas, the designer uses the sketch as a means to reason with (Goldschmidt 1999) or think (Lawson 1997). It is powerful enough to control the information transaction involved in designing ultimately controlling the design process itself. According to Herbert:

... the origin, nature, and methods of obtaining knowledge in architectural design can be explained largely in terms of the properties and working processes of the [sketch] in which design problems are formulated (Herbert 1988).

Several writers have added weight to the theoretical argument that sketches are the "principal graphic instruments of thought in architectural design" (Herbert

\footnotetext{
${ }^{18}$ The words sketching and drawing will be used interchangeably throughout this work to mean those drawings that
designers use in the early stages of the design process.
} 
1993) giving credibility to the effort of understanding it. Other writers have gone beyond considering the sketch as a tool to looking at it as a partner in the design process. Birgit Cold underlines this:

A tool becomes a medium as it is used for things that were not its original intention. When a tool becomes a medium, it gains immeasurably in potency and in its ability to help for our thinking - and thus to take a role as a partner in enhancing our creativity (Cold 1995).

\section{Drawbacks of Sketching}

Despite being an important tool for design, there are some limitations in the activity of sketching. The sketch is a passive partner and relies on initiative from the designer. Skill in controlling the sketch can deliberately provoke specific thoughts and direct thinking to promote imagination and innovation (Laseau 1991). The effectiveness of the sketch is therefore dependent on the designer's assertiveness. The sketch is also labour intensive. Ideas usually require lots of reworking or redrawing to achieve an interesting result. This usually results in information loss with each iteration (Herbert 1993). The extent of the information loss is dependent on the designer. Only the designer can determine what elements of the iteration to keep for a successful process. The designer, therefore, has to be experienced in order to identify and react effectively to some of the multiple design issues embedded in a sketch.

\section{Conversations}

The manner in which information is processed by the designer during the activity of sketching is both interesting and complex. It will go through numerous forms when moving from concept to reality indicating that the sketch means a lot more to the designer than just imagery. It is seen as generative and evaluative, the manipulation of an idea that needs further development towards certainty. The consequence of this is a process in which designers make a mark, respond by examining and criticising the mark, make a decision based on this criticism (with a desired result in mind), makes further marks and so progress in design. To the designer the sketch is not simply a representation on paper of the images held in the mind but rather it is a dialectic process (Goldschmidt 1992). As Goldschmidt puts it: 
[It is] the oscillation of arguments which brings about [a] gradual transformation of images ending when the designer judges that sufficient coherence has been achieved (Goldschmidt 1992).

Goldschmidt goes further to state that the design process is an interaction of arguments and moves. "Arguments" are explorations of the task and the reasoning about it while "moves" are the physical motions brought about by the arguments. The drawings of the designer that are essentially produced by moves supply new food for the arguments (Arnheim 1995). In other words architects often engage in sketches not to record an idea (that does not yet exist) but rather to help generate one (Goldschmidt 1994). Researchers have defined this activity as conversations being held with the materials of a design (Schön and Wiggins 1992) and have given value to the idea of "back-talk" (Goldschmidt 1999) in which the drawing itself acts as a catalyst to propel the design process forward. It can be further suggested that the designer explores the drawing looking for clues as to the way forward. In this way, the sketch is responsible for the architect's decision making.

The sketch can also be a tool for reflection. In his book The Design Studio, Schön (1985) speaks of the act of sketching as a kind of reflection-in-action where the designer shifts stance from exploratory what-ifs (the first mark) to recognition of implications and eventual commitment to a way forward (Schön 1985). The sketch records this shift offering the designer more material to reflect on. By observing and critically assessing previous moves designers are best able to comprehend and be conscious about their own design process. Birgit Cold puts it like this:

\footnotetext{
Reading and interpreting sketches make you recognize what you have 'chosen to emphasise': the features, the space, and the light. To open up to the phenomena and to make 'the unconscious' stream' flow between the senses, the mind, the hand, pen and paper, a deep concentration and a conscious attitude towards the power of this unconscious cooperation is necessary. Exercising this 'internal cooperation' is crucial in the design process (Cold 1995).
}

By being aware of the sketches designers make and having the opportunity to reflect on them, the aware designer can make designing a conscious activity this is achieved by teaching design as a process that requires "thinking" and reflecting through images and visualisation. 
The main reason for encouraging hand sketching [in education] is the importance of learning and knowing how 'to catch, keep and create' environmental impressions and conceptions directly in time and on the spot (Cold 1995).

It is partly through the sketch that the master produces behaviour that the student mirrors in reflection-in-action.

Sketching therefore can be referred to as a reflective conversation with images and ideas conveyed by the act of drawing. In his book Graphic Thinking for Architects and Designers, Paul Laseau (1989) agrees with this premise by claiming that the process of graphic thinking can be seen as conversations with ourselves in which we communicate with the use of sketches. Sketching can then be seen as a personal "conversation" that the designer engages in with the use of images (and related information).

Eye + Mind + Hand $=$ Sketch

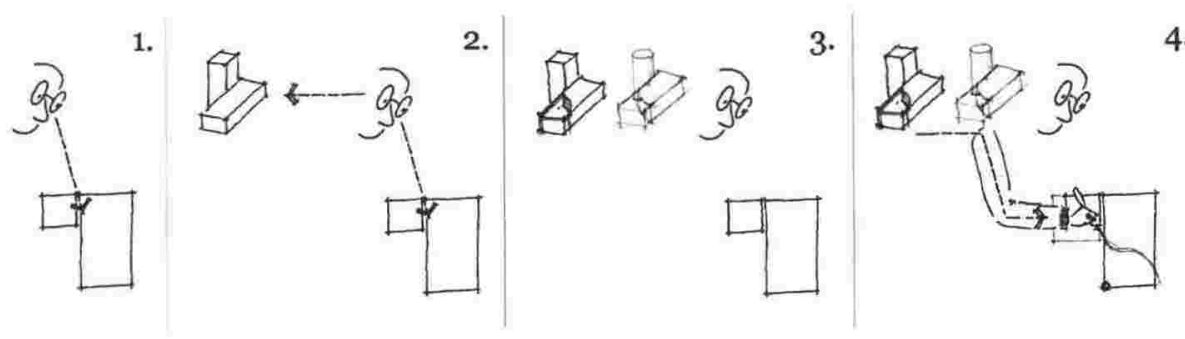

Figure 5.12. Having a design conversation. 1) Seeing the image with the eye. 2) Creating an image in the mind. 3) Generating a modified condition. 4) Drawing in relation to the modified vision with the hand. Number five (not shown) would be the action of "seeing" the modified image and starting the cycle again.

The value of the sketching conversation lies in the cycle of information from paper to eye to mind/brain to hand and back to paper. Consequently the more information involved in these "transactions", the more opportunities there are for change, which will result in a richer output. In the illustration above, Jack our designer starts by sketching two rectangles to represent the parti of a house as yet to be designed. Jack looks at the sketch [1] and translates this into forms in his mind [2]. The ease of the translation is dependent on such factors as his experience, particular interests and ultimate aim. The translation is essentially a filtering of the image with Jack choosing to see certain aspects or implications 
and ignoring others. Jack takes the translated forms and based on what he knows of the context considers manipulating the corner of one of the solids [3]. He then transfers this "what if" to paper [4] where he considers the new image and the cycle begins again.

This is of course simplifying what can be regarded as a complex cognitive process that can take place in less than a second and as the hand is drawing. Using Schön's argument that design is a reflective conversation (Schön and Wiggins 1992), we can infer that a reflective conversation is about the designer seeing what is there, drawing in relation to it, seeing what is drawn and so further informing the design. To put it simply, Jack makes a mark, criticises, analyses and makes a decision based on that mark. He then makes a new mark influenced by this decision and the process is repeated. This operation is possible only with the use of the eye, brain and hand and manifested in the sketch (Laseau 1989). The importance of this combination cannot be overstated.

If we consider the role each entity plays in the conversation it can be argued that the eye and mind works as one unit since the mind relies on what the eyes see in order to filter, translate, and make decisions. The hand does not necessarily rely on the eye, more than as a device that relays what it is doing to the mind (brain). It however works with the brain to translate the images for examination. We can in essence distil the conversation from three parties to two: the head, comprising eye and mind and the hand, comprising hand and mind.

\section{Conversation Dimensions}

The dialogue between head and hand can best be managed by a definitive understanding of their interaction. Four interrelated characteristics of particular interest to this thesis define the conversation between head and hand. They are (in no particular order):

1. The domains of language in which the designer describes and appreciates the consequences of his/her moves. Domains are contexts 
that determine the choice of the representation, for example, drawing of a cross-section for considering ceiling heights.

2. The implications the designer discovers and pursues determines whether a new image is produced or the same image is marked.

3. The implications discovered might also change the designer's stance toward the situation with which he/she converses.

4. The search for clues through which the problem can be understood and a suitable approach developed.

These characteristics will be explored fully in the next chapter where these dimensions will be used to analyse empirical data. Before we do this however it is appropriate now to locate the sketch within the context of the issues we are trying to address in this work.

\section{The Sketch and the Student}

Drawing as a legitimate tool for thinking has been largely neglected by design schools (Lockard 2000). Even though some schools actively encourage the teaching of drawing, the drawing is usually seen as a means of communication e.g. presentation drawings, as a means of projecting an idea e.g. visionary drawings or in most cases as an end in and of itself. If tutors do in fact encourage the use of drawing as a thinking tool, it is often overlooked when students present designs for criticism. This view or consideration of drawing reinforces and influences the many challenges facing architectural education today. It also affects to large degree the interaction between student and teacher.

\section{Product or Process?}

One of the many challenges facing education - product valued above process (Chapter 2) - greatly influences the student's approach to drawing or sketching. The lack of emphasis on process hinders the student's productive use of sketching. This is reflected in the inability, or lack of confidence in the ability, to externalise ideas in an acceptable graphic form (Lockard 1982). Even though the student may feel that his/her ideas are comparable to those of fellow 
students, he/she may be intimidated by the graphic quality seen in other students' sketches. Because the student does not view the sketch as part of a process, but rather as an object that reflects his/her ability, he/she is afraid to sketch. This affects students' ability express their thoughts and ideas through drawing as they feel that the sketch has to be somehow "beautiful". This attitude which results in students feeling 'stuck', denies students the ability to freely and actively manipulate their concepts and ideas. Without control of the changes and refinements that are part of sketching, students have a limited range of options from which to select their path.

\section{High Art}

Considering architecture as "high art" affects the perception of sketching in schools. There exists within schools the myth that creativity is about that "one big idea" or full-blown concept. The emphasis placed on theories and concepts (in lieu of process and pragmatism) sometimes hinders the student's exploration through sketching. Students sometimes wait until there is "something to draw" not trusting the potential of the sketch to suggest or initiate a way forward.

\section{The Zone of Interaction}

The sketch makes the workings of the creative mind visible. According to Arnheim:

They not only supply the designer with tangible images of what his or her mind is trying out... but they also permit the observer or theorist to catch a few stop-motion glimpses of the flow of creation (Arnheim 1995).

Because design teaching depends on "the externalised printout of the conceptual process" teaching cannot begin until the student offers a common referent for discussion (Lockard 1982, Schon 1985). As teachers and peers react to the drawings they sometimes expose issues that the student had not seen before. As a result, students who are good at externalising their thought processes through sketching tend to get more teacher/peer attention. Others unfortunately get proportionally less feedback. The challenges described therefore inhibit the open communicable process that benefits the zone of interaction with peers and teachers (Lockard 1982). 


\section{Virtual World}

Another educational challenge that is reinforced by the student's use of sketching is the notion that architectural education exists within a virtual environment (Chapter 4). Because the contemporary studio cannot provide students with an actual building to test and experience first hand; the testing is performed in the virtual world of the sketch. The study drawing or sketch embodies a virtual world that represents something that is not yet constructed and, in the case of design studio, something that may never exist or be constructed. When immersed in the virtual world of the sketch the student (who has little experience of the "real" world) struggles to define an accurate model of the problem or come to terms with the rules embedded within it. $\mathrm{He} /$ she has no idea how the design will perform in the physical world and so is more willing to suspend "physical rules" and ignore limitations. This is replaced by aesthetic rules, which require no testing. Consequently the student designer has no appreciation of the issues concerned in making the environment cost effective and responsive to the user. It is therefore the teacher's responsibility to reproduce real project conditions lacking in the students' sketches. This subsequently reduces the time afforded to other aspects of teaching design.

\section{Lack of information}

An additional challenge involves the quality of information embedded within the student's sketch. Because students often fail to see a connection between lecture courses and design studio, the sketches executed in studio are usually devoid of information learnt elsewhere. This lack of information restricts the options afforded to the designer. For the sketch to be effective it has to "contain" adequate and relevant information that gives the student enough scope for designing or decision-making. Again, it is the teacher who provides this information, usually during the deskcrit. Unfortunately the student needs this information during the process of design when he/she would benefit from it most. This would allow more time for a quality deskcrit. 


\section{Challenges for educators in relation to the sketch}

It is clear that the sketch has to play an important role in the revitalisation of architectural education. If the challenges facing architectural education are to be met then there are prerequisites that have to be addressed for the sketch to play its part. One of the most important is the recognition of the sketch by the student as an essential part of the design process. It must be emphasised that concepts can only be developed and evolve by using the sketch as an incubator. It is also important for the student to remember that it is not the quality of the sketch, but what it imparts to the designer that is crucial. For this to occur the value of the sketch must be explicit. Another challenge involves providing adequate connection with the realities of architecture. The sketch in this case has to contain or project some elements of reality for the student to get a solid understanding of how architecture works.

\section{Conclusion}

Successful design relies on the designer's ability to peel away, analyse and synthesis design issues. Drawing in architecture is the fundamental activity that facilitates this process. The drawing as an object is one of architects' most powerful tools of thought and communication. As a tool of thought, the drawing in the form of the sketch seems to be essential to many designers. It is not simply used as an appendage but rather is an integral part of the designer. Not only is it a way of "externalizing ideas, of turning internal thoughts public, of making fleeting thoughts more permanent" (Tversky 2002) but it mediates creative thought processes. It facilitates the design process. It is the "conversation" that the designer engages in with the use of images (and related information).

This conversation (or interactivity) involves chiefly two thought processes - the production of ideas and the interpretations of those ideas and representing them in a physical sense and spatial sense. These interpretations then facilitate the production of more ideas. The brain through the eye reacts to the sketch the hand has drawn. This has been translated into two players - the head and the hand. 
In design education students have trouble coordinating these elements and realising the potential of the sketch. Valuing product over process, their consideration of the sketch as an end in itself prevents deliberate exploration. Students think that somehow their sketches have to be beautiful or have a "big concept" in it. As a result, students are hesitant to utilise the sketch as a thinking tool. Even when the sketch is used for thinking, the students' unfamiliarity with the real world and lack of experience in interpreting and seeing ideas prevents positive use of the medium.

This negative situation has serious implications for design education. We have seen (Chapters 3,4) how, in the ideal and real interactions that occur in design education, students are encouraged to develop critical observation skills, to be flexible, and to develop self-knowledge. Perhaps the most influential of these interactions is the student-master dialogue that embodies the desk crit. At the centre of this zone of interaction is the sketch. The sketch and the zone of interaction are therefore inexplicably linked. Unless the sketch is used by the student to its full potential, the effectiveness of any changes or strategies for enhancing the zone will be diminished. By improving the capabilities of the sketch we can consequently improve the nature of the zone of interaction. By enhancing and enriching the zone of interaction we can effectively improve on the student-teacher dialogue allowing higher quality learning and a greater response to the challenge of education.

Understanding the act of sketching, therefore, is crucial to understanding how we might use it to enhance the student's ability to capture, manipulate and reflect on ideas during conceptual design. Understanding the contributions of the head and the hand might enable us to define a means through which sketching might be used to help students gain practical knowledge that would otherwise be denied. The means to achieve this would be through the provision of an environment rooted in the interaction of designer and media; head and hand.

Lockard in his book Design Drawing presents leads to this environment. In it he describes what he observes when helping design students in the early phases of the design process. Using an "eyemindhand" wheel as a metaphor, Lockard claims that the design process may be triggered by any of the three components 


\section{References}

Arnheim, Rudolph. 1995. Sketching and the Psychology of Design. In The Idea of Design, A Design Issues Reader, edited by Victor Margolin and Richard Buchanan, 70-74. Cambridge, Mass.: MIT Press,

Ching, Francis. 2002. Architectural Grapbics. 4th ed. New York: John Wiley and Sons.

Cold, Birgit. 1995. Tree of the sketch. In Educating Arcbitects, edited by Martin Pearce and Maggie Toy, 60-63. London: Academy Editions.

Do, Ellen Y.-L. 1997. Computability of design diagrams : an empirical study of diagram conventions in design. In CAAD Futures 97, edited by R. Jungs, 171-76. Munich: Kluwer.

Do, Ellen Yi-Luen. 2002. Functional and Formal Reasoning in Architectural Sketches. In American Assocation for Artificial Intelligence, AAAI Spring Symposium SSSO2, 25 - 27 March 2002, edited by Tom Stahovich, James A. Landay, and Randy Davis, 37-44. California: Stanford University.

Do, Ellen Yi-Luen, and Mark D. Gross. 2001. Thinking with Diagrams in Architectural Design. Artificial Intelligence Review 15, no. 1/2 (Mar): 135-49.

Fraser, Iain, and Rod Henmi. 1994. Envisioning Architecture - An analysis of Drawing. New York: Van Nostrand Reinhold.

Goldschmidt, Gabriela. 1992. Serial Sketching: Visual Problem Solving in Designing. Cybernetics and Systems: An International Journal 23: 191-219.

Goldschmidt, Gabriela. 1994. On visual design thinking: the vis kids of architecture. Design Studies 15, no. 2: $158-74$.

Goldschmidt, Gabriela. 1999. "The Backtalk of Self-Generated Sketches.". [cited 10 Jan 2001]. Available from <http://www.arch.su.edu.au/kcdc/books/VR99/gold.html>.

Goldschmidt, Gabriela. 2002. "Read-write acts of drawing, or the economy of treasure hunting." [cited 3 Oct 2002]. Available from

<http://www.lboro.ac.uk/departments/ac/tracey/somag/gabi.html >.

Gruzdys, Sophia A. 2002. Drawing: the creative link. Architectural Record (Jan): 65-67.

Herbert, Daniel M. 1988. Study Drawings in Architectural Design: Their Properties as a Graphic Medium. Journal of Architectural Education 41, no. 2: 26-38.

Herbert, Daniel M. 1988. 1993. Architectural Study Drawings. New York: Van Nostrand Reinhold.

Jones, John Christopher. 1992. Design Methods. New York: Van Nostrand Reinhold.

Laseau, Paul. 1989. Graphic Thinking for Architects and Designers. 2nd ed. New York: Van Nostrand Reinhold Company Inc.

Lawson, Bryan. 1997. How Designers Think: The Design Process Demystified. Third ed. Oxford: Architectural Press.

Lockard, William K. 1982. Design Drawing. Tucson, AZ: Pepper Publishing. 
Lockard, William K. 2000. Design Drawing Experiences, 2000 Edition. W.W. Norton \& Company.

Robbins, E. 1994. Wby Architects Draw. Cambridge, Mass: MIT.

Schön, Donald A. 1985. The Design Studio: An exploration of its traditions and potential. London: RIBA Publications Ltd.

Schön, Donald A., and Glenn Wiggins. 1992. Kinds of seeing and their functions in designing. Design Studies 13, no. 2: 135-56.

Stahovich, Tom, James A. Landay, and Randy Davis. 2002. "AAAI 2002 Spring Symposium: Sketch Understanding." 11 Jun 2002. [cited 23 Nov 2002]. Available from <http://www.me.cmu.edu/faculty1/stahovich/sketchsymposium.htm>.

Tang, H., and John S. Gero. 2001. Cognition-based CAAD: How CAAD systems can support conceptual design. In Computer Aided Architectural Design Futures 2001, edited by Bauke de Vries, Jos van Leeuwen, and Henri Achten, 521-31. Eindhoven, The Netherlands: Kluwer Academic Publishers.

Tversky, Barbara. 2002. What do sketches say about thinking? In Proceedings of AAAI spring symposium on sketch understanding, T. Stahovic, J. Landay, and R. Davis (Editors). Pp. 148- Menlo Park, CA: AAAI Press. 


\section{Heads and Hands}

Do we think while we draw or draw while we think? Does the hand guide the head or head the hand? Was there an idea before we began designing or did the idea arise during the design process? (Hertzberger 2000)

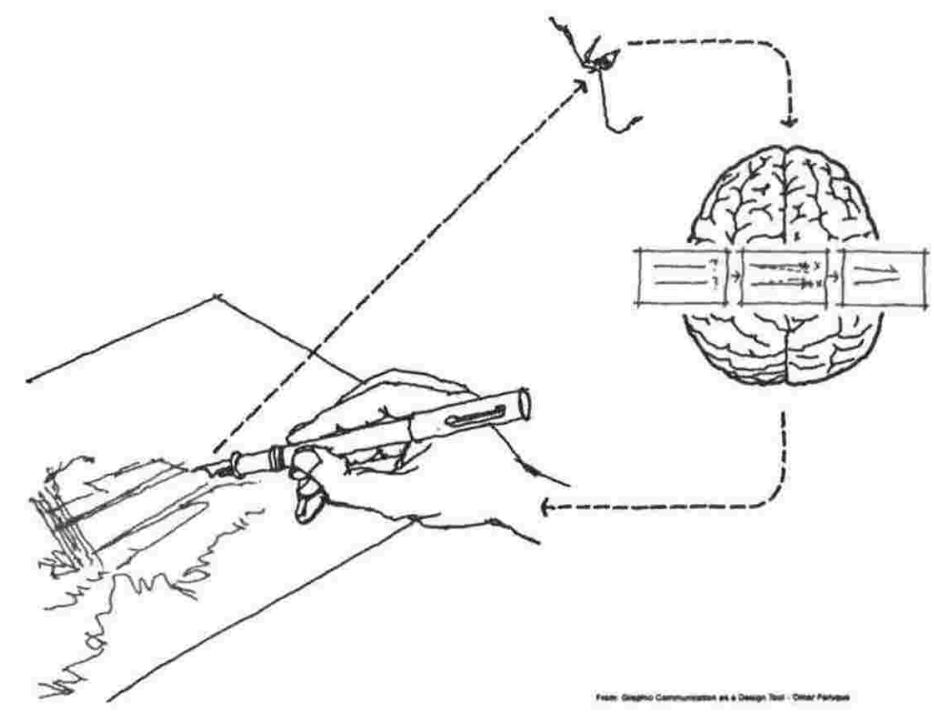

Figure 6.1. The eye and brain, hand and sketch. (Source: Faruque 1984)

$\mathrm{S}$ ketching is a conversation with the materials of a situation (Schön and Wiggins 1992). Like a conversation, the activity of sketching is interactive and highly dependent on feedback. This interactivity involves chiefly two thought processes - the creation and manipulation of ideas and the representation of those ideas for criticism and further manipulation. Writers on graphic thinking define this another way: the brain through the eye reacts to the sketch the hand has drawn (Figure 6.1) (Laseau 1989; Faruque 1984). This thesis distils this to an interaction between two elements - the head and the hand.

To move beyond this definition and begin to develop strategies to enhance the zone of interaction through the sketch, it is important to ask the following questions: What does the "head" do? What does the "hand" do? What is the interaction between the two? What is it the "hand" should know to represent 
the ideas of the "head"? Finally, how can knowledge of this relationship assist sketching and by extension architectural education?

The description of a series of experiments employing human subjects in these two roles, is the central theme of this chapter. It starts with a design studio that attempts to teach students about the potential of the hand sketch. Next, a subsequent exercise in Jamaica, reveals an interesting development: students tended to design with more intensity and with more confidence when paired with a senior colleague. This idea was further investigated, employing a practitioner and a student.

To aid in these investigations a quasi-experiment (a modified protocol study) was designed to determine the relationship between the head and the hand in the conversations that define sketching. It was discovered from this experiment that the head indeed benefited from having a senior hand in the conversation. The question then became - How can the "expert hand" better inform and assist the "novice head"?

\section{Head and Hand Studio at Victoria University of Wellington}

What is the nature of the interaction between the head and the hand in sketching? In response to this question, an exercise about sketching and design thinking was designed as a project for design studio. The studio had two purposes - one experimental and the other educational. The purpose of the studio, therefore, was to:

1. Investigate the interaction between head and hand;

2. Illustrate to students the likeness of marks on a page to conversations whilst demonstrating other approaches (courtesy of their peers) to design;

\section{The Studio Project}

The project was introduced at the start of the second semester in an architectural design course at Victoria University of Wellington. ARCH 212 comprised of 60 second year students enrolled in the 5-year Bachelor of 
Architecture program. The project took place over a period of 5 teaching days ${ }^{19}$ for a total of approximately 18 hours (including initial lecture and review sessions). On the first day of the project a lecture on design process and sketching was presented to the students. This served as the theoretical underpinning of the exercise. A demonstration of the proposed activity was then performed and students received the rules of engagement for the exercise (see Table 6.1). During the next two days, the design activity took place in four sessions. In each session each student acted as either head or hand in the design of an "inner city studio" and as either head or hand in the design of a "rural house". Students, who designed or played the role of the head, told the "hand" what to do. The hand then had the responsibility for sketching images to assist the head in grasping the problem and progressing towards a satisfactory design outcome.

\begin{tabular}{|l|l|}
\hline $\begin{array}{l}\text { Hand } \\
\text { Follow instructions of the head; only asking } \\
\text { questions as they relate to the image. }\end{array}$ & $\begin{array}{l}\text { Head } \\
\text { Design a response to the design problem } \\
\text { relying on images and information presented } \\
\text { by the hand. }\end{array}$ \\
$\begin{array}{l}\text { Draw or illustrate concepts that the hand } \\
\text { thought would enhance the understanding of } \\
\text { the head. }\end{array}$ & $\begin{array}{l}\text { Ask specifically for the image/information } \\
\text { needed to make decisions. }\end{array}$ \\
$\begin{array}{l}\text { Advise on the consequences to other design } \\
\text { domains that were not being investigated. }\end{array}$ & $\begin{array}{l}\text { Set out and specify the kinds of questions the } \\
\text { head wanted the hand to ask. }\end{array}$ \\
& $\begin{array}{l}\text { Request any "non-visual" information from the } \\
\text { hand i.e. ergonomic distances, max. room } \\
\text { widths, stair configurations etc. }\end{array}$ \\
\hline
\end{tabular}

Table 6.1 Rules of engagement for the head and hand studios.

Students were divided into four tutorial groups - A, B, C, and D. In the first session (see table below), those students in the first group mentioned (A \& B) acted as the head while those in the second group (C \& D) were hands.

\begin{tabular}{|l|l|l|l|l|}
\hline Project & Session 1 & Session 2 & Session 3 & Session 4 \\
\hline Studio - inner city & A/C & D/B & C/A & B/D \\
\hline House - rural & B/D & C/A & D/B & A/C \\
\hline
\end{tabular}

Table 6.2 Heads and Hands session configurations

\footnotetext{
${ }^{19}$ Teaching days mentioned are the scheduled studio sessions for ARCH $212-4$ hours Mondays and Wednesdays.

${ }^{20}$ The hand had a right to ask what projection/representation to illustrate (plan/elevation/section/3D) and what scale if any.

${ }^{21}$ The hand had a right to point out potential problems and discrepancies overlooked that had to do with the objective (practical) side of the design.

${ }^{22}$ The head had a right to tell the hand exactly what was necessary in the image and what was redundant.
} 
For example, suppose a student (Pedro) in group A, begun in Session 1 as a head for the design of an "inner city studio" and worked with a hand (Fiona) from group C. In Session 2, Pedro acted as the hand for a student (Saul) in group $\mathrm{C}$ who was the head designing a "rural home". In Session 3, fuelled with the experiences of Sessions 1 and 2, Pedro was the hand in the design of the studio and in Session 4, the head for the rural home. In the end Pedro was head and hand in the rural home and head and hand in the inner city studio. The result was an experience in both aspects of the two problems. This setup was done to negate any preconceived bias or preferences to any particular project permitting the student to experience both projects in different capacities (as heads and hands).

All sessions were approximately 1 hour long. Students were allowed to use their preferred "design tools" (marker, pencil, scale rule etc.) and faculty supplied them with $\mathrm{A} 3$ bond paper. In addition to the design problem and paper for drawing, the hands were given some basic reference information in the form of an "info booklet". This booklet contained information about planning rules, anthropometric data, ergonomics, excerpts from Christopher Alexander's Pattern Language and space use data. The idea behind the booklet was to provide students with adequate on the spot reference material for the task. It was thought that this would save time (spent looking up information) for the participants. During the sessions, tutors went around observing the process and giving advice where needed. At the end of each session day, students met with their group tutors as two large groups - $(A+B)$ and $(C+D)$ - to discuss the sessions.

At the conclusion of the final session, students had to choose the design solution (either a studio or rural home design) of one of the heads for which they acted as hand. The student would then work with the chosen strategy/proposal, criticising it and taking it to a further level of development. In other words, create a product consistent with the design strategy employed. On the fifth and last contact day, students met individually with tutors to talk about progress and ways of presenting their information. The computer was used to create presentation drawings (Figure 6.2) that showed the process and outcome (with commentary) of the interaction experienced, and the process 
used and outcome achieved as a result of developing the design strategy of their peer. The review of the work took the form of an informal crit or discussion. From casual observation it was evident that students demonstrated a willingness to criticise and engage with the ideas generated by their peers. Overall, students responded positively to the review, and some lively discussions took place. Evaluation of the experimental component of the exercise was done by questionnaires and casual conversations with the students.

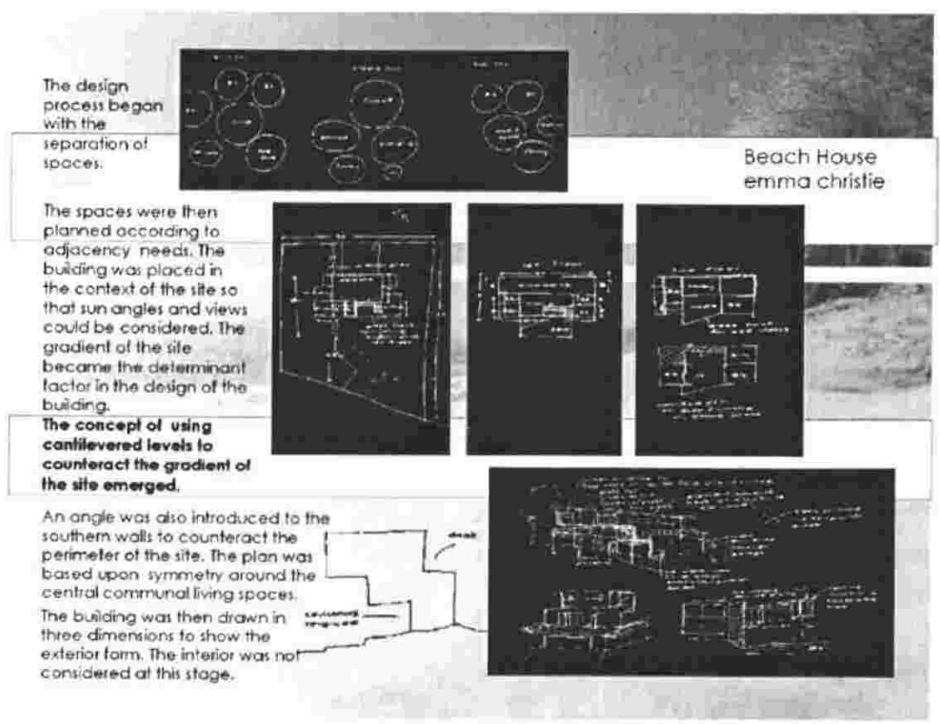

Figure 6.2. Presentation of one of the "results" of the exercise.

\section{Informal Observations}

A number of interesting observations arose from the exercise:

- Some students tended to treat the project as a function planning exercise. More effort was placed in "getting the plan right" and not on the "architectural" concepts or issues involved. This could have been attributed to the limitation on time and the very prescriptive nature of the design brief.

- Stronger students (students with some experience in the field and students who usually get the best grades) as the "hand" attempted to control and lead the outcome of the scheme (usually out of impatience with their partner). The partners or heads in these circumstances 
responded either by accepting or resisting the attempt at control sometimes at the detriment of the scheme. This revealed the strong influence the hand had over the head.

- As the head, some stronger students expressed frustration with their partner not "delivering" suitable images. These students were forced to be explicit with their wishes/ideas or to wait (a few seconds) while their partner generated the required information. This also emphasised the influence the hand has with the head.

- The use of two sites, which each student "visited twice", meant some strong thematic repetition of ideas. As some students became familiar with the issues involved they were directed, or rather consented, to enter into scenarios that they had already worked through. Schemes that reworked previous ideas tended to reach further in the process.

- Students who were heads for some projects still felt "ownership" of the schemes during the review and were in most cases in agreement of the projected outcome. This indicated a strong connection between the head and ideas generated.

\section{Formal Responses}

A week after the project students were given a questionnaire to answer. The questionnaire comprised of 33 questions; 22 of which were fixed response using a 5 -point scale. The first 12 questions on the questionnaire were about the students' "design habits" while the rest were about their appraisal of the activity. Of the sixty students, fifty returned the questionnaire for evaluation.

When asked how they found the activity, most of the students found the process frustrating. Despite this, they were mostly positive. According to one student it was "interesting and frustrating at the same time." Other students indicated that it was an interesting way of communicating design ideas while a few expressed surprise that they actually enjoyed the activity. Among the aspects students found particularly interesting were: 
- It was useful to experience how "another's brain works". Students were enlightened to see and experience the way other students viewed and approached design.

- Through verbalising their ideas and seeing someone's interpretation of it, they learnt a lot about their own limitations.

- It highlighted the design process and how important the sketch was.

- It was a good way of learning to communicate

Interestingly, when asked how often they referred to the info booklet on behalf of the head only two answered a lot or less than a lot (scale: one and two) while 19 were neutral (scale: three), 21 answered very little (scale: four) and eight did not refer to the booklet at anytime. This indicated what educators have suspected: students are reluctant to check reference materials when designing.

Of significance was the discovery that the projects using the stronger students as hands tended to be more resolved. This evidence was purposefully checked if this was the case in a similar experiment in Jamaica.

\section{Head and Hand Workshop at Caribbean School of Architecture}

At the Caribbean School of Architecture in Jamaica a similar exercise was undertaken. The differences, however, were the duration of the exercise -2 days (of 8 hours each) and the nature of the subjects. To test the notion of the more experienced hand, third year students are partnered with students from the postgraduate years ${ }^{23}$ instead of using subjects from the same design year.

${ }^{23}$ The Caribbean School of Architecture uses a 4+2 education structure. Four years are used to attain a Bachelors of Architectural Studies and after a "year out", the final 2 years (of design and research) is used to attain a Masters of Architecture. 


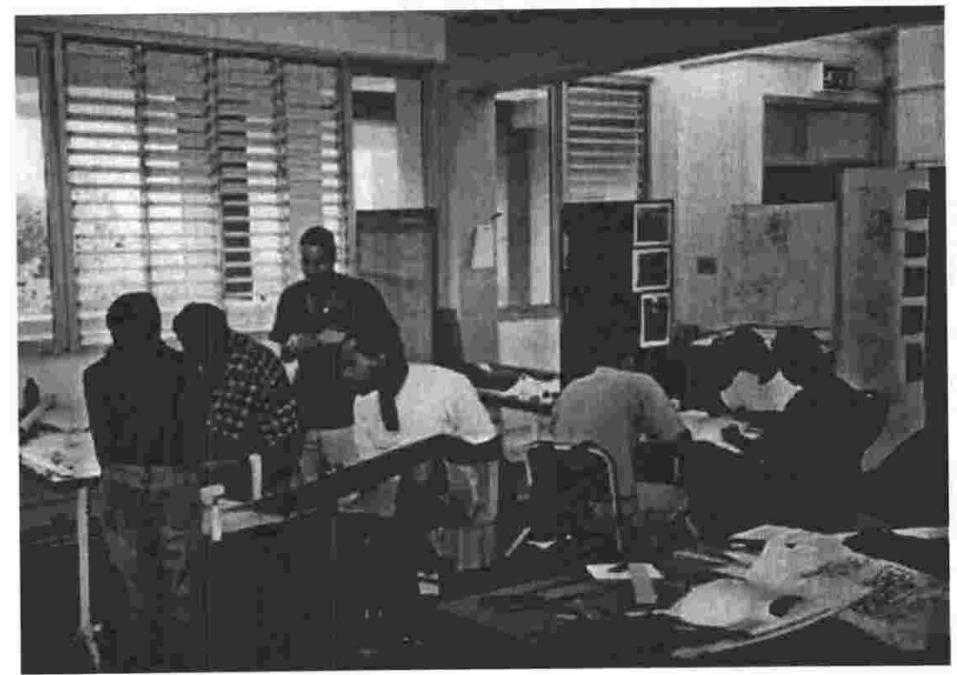

Figure 6.4. Students of the Caribbean School of Architecture taking part in workshop.

\section{The Sessions}

On day one, the first two hours of the exercises were spent introducing the students to the workshop. This included a lecture on design processes, and a demonstration of the head and hand exercise. Junior students were then paired with senior students and vice versa for two design sessions. Each student was the hand for one project and the head for the next. Both sessions were approximately sixty minutes long. Students were allowed to use any drawing tools (paper and drawing instruments) they desired. No info booklet was distributed.

On the second day the sketches from the sessions the day before were pinned up and the hands took turns to describe the ideas and direction their partner took. The schemes were voted on and the 4 schemes that were deemed most "workable", most interesting and most clear were used for the next phase of the workshop. Students were invited to arrange themselves in four groups to develop the design work further on these four projects. The hands on the particular schemes that were selected became the group leader by default. Interesting groups were formed - in the lone scheme done by a junior head, her group comprised of masters students. In another group, a senior student ended up in the group for a project for which she was the head. The workshop ended with a review and a quite spirited discussion. 


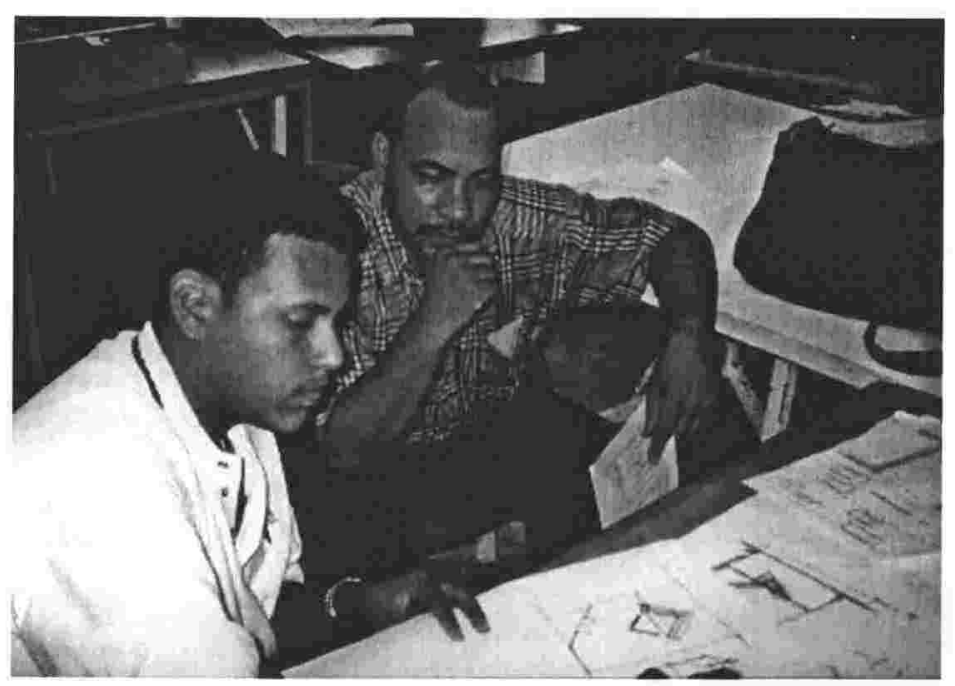

Figure 6.5. Heads and hands during the CSA workshop.

\section{Observations}

During the sessions the following were observed:

- Junior students partnered with a senior colleague for hand generally presented "refined" schemes that were comparable to schemes with senior students as heads.

- Sketches done by junior students as "hands" lacked the refinement and richness of similar sketches by senior "hands".

- Students, particularly junior students, admitted to an appreciation of the design process and in particular the nuances of sketching. The claim was made that "they had never thought about" the conversations with themselves that "exist" when sketching.

- Senior students as heads expressed frustration in getting their ideas across and on the paper of their junior colleagues. Junior students, however, were amazed by the intensity of the task. They claimed that they were able to think "straight" because they "(had) someone prompting (them) and requiring input to go on". These students also had the perception of designing faster, illustrating the old adage that two heads are better than one. 
- One senior student who had seen the issues involved in the design earlier as a hand finished well before the prescribed time as head since he made it a point to address the same issues his junior partner (as head) had encountered and struggled with before.

\section{Conclusions of the Head and Hand Studios}

Some common themes and interesting differences emerged from the two studios. In New Zealand where students were of equal (more or less) capabilities the output was no different from a regular design studio at that level. Students were frustrated with their colleagues but appreciated the exposure to the nuances of sketching. In Jamaica, the reaction of the students to a more "educated" hand was worthy of note as it was discovered that junior students:

- had the perception of designing faster,

- perceived that their design activity was more "intensive" than normal,

- considered questions that wouldn't normally be considered,

- perceived a rise in the level of their design proposal.

The ideas of the "more capable" hand appeared to help tremendously in making the "less capable" head aware of some of the issues involved in design. Despite this support, the head retained the perception that it was in control of the design. These observations indicate a relationship between the relative education of the two parties and the "success" of the activity.

\section{The Double H Experiment}

The relationship of the head to an "educated" hand is an interesting premise. It relates to the discussion in Chapter 4 about the zone of interaction and the relationship between student and master. It demands the questions: to what extent is the master the hand, to what extent is the hand's role in the zone and what is the nature of the information that is communicated between the parties. To examine this relationship in the context of the sketch and designing, a unique experiment employing protocol analysis was designed to understand the 
conversation that characterises sketching and determine the nature of an "educated" hand and its effect on the process.

\section{Protocol Analysis}

Protocol analysis is a research methodology used in the field of psychology to study human problem solving and information processing techniques. It has been used extensively, since the 1970 s, by design researchers as a method to elicit design thinking (See Akin 1986; Eastman 1970; Anders and Simon 1993). Since then, it has become the prevailing experimental technique for exploring and comprehending aspects of designing.

Protocol analysis offers design researchers a potentially effective (and debatable) method for observing and analysing design problem-solving behaviour. While this research method usually involves sole designers verbalising their thoughts while they sketch and tackle the design problem, since the 1980s, single person study has crossed over into team design activity (Lawson 1997). Protocol analysis has also recently been used to investigate techniques in computer-mediated collaboration (Gabriel and Maher 1999).

A protocol is the recorded behaviour of the problem solver or (in this case) the designer under controlled conditions. This usually takes the form of "sketches, notes, video or audio recordings" (Akin 1986). According to current literature, there are two ways of obtaining design protocols: concurrent (or introspective) and retrospective (Dorst and Dijkhuis 1995; Gero \& Tang 2001). In the concurrent protocol, subjects are required to design while verbalising their thoughts. In contrast, subjects are asked to design first and then retrospectively report the design processes in retrospective protocols. This is usually done with or without the visual aids provided by the video and audiotapes documenting their design processes (Gero and Tang 2001). Portions of the recorded verbal protocol (in both cases) are then assigned, or encoded, to "previously defined categories in a model based theory of cognition" (Eckersly 1988). Recent research has shown that both produce similar results in terms of exploring the process oriented aspects of designing (Gero and Tang 2001). 


\section{Criticisms of Classical Protocol Analysis}

Despite its popularity in eliciting understandings of "design thinking" classical protocol analysis has been criticised by some researchers. Critics usually say that:

The small sample does not produce enough data. Critics argue that protocol analysis techniques lack sufficient subjects to get a large enough sampling in which to make generalisations. Arguments to the contrary suggest that the dozens of observations found in the protocols of subjects offset the small size of the sample (Akin 1986).

Concurrent verbalisation alters subjects' behaviour. Again, it is argued that being placed under a "microscope" in this way makes designers conscious of their actions and so tend to engage in activity they think the researcher wants to see (rather than action they normally engage in). This criticism isn't easily refuted and can only be minimised if special care is taken to avoid this. This is helped if the observer is as unobtrusive as possible. This can also be regarded as a limitation of the experiment since it is the only way to "capture" designers' thoughts.

Experiments are not reflective of real design episodes. Supporters of this view point to the fact that there is no negotiation with clients, no discussion of ideas with peers and no opportunity for reflection (away from the task) (Lloyd, Lawson, and Scott 1995). This view while being valid doesn't take into consideration that only the period of specific activity is under investigation and not the factors that indirectly influence design process.

The data obtained is unreliable. Some critics argue that because thought is not a directly observable activity, concurrent and retrospective accounts of human thought can be regarded as unreliable data for scientific enquiry. They claim that subjects - tend to forget (in retrospective protocols); tend to qualify their thoughts (in relation to what they think the researcher wants); and apply reasoning (to the thoughts) in some instances. However, it has been proposed that under controlled conditions, individuals (when trained to concurrently verbalize their thoughts) can reveal a remarkably accurate picture of their cognitive processes while engaged in problem solving (Eckersly 1988). 


\section{A different approach to protocol analysis}

Considering these criticisms and pursuing the aim of getting a clearer picture of the head's expectations of the hand, an unexampled variation of the protocol analysis method was developed to determine the interaction between hand and head in design activity. This variation, which integrates classical analysis with that of collaborative environments, sets out to discover how "intelligent" the hand should be to enhance design by reflection. In the protocol study described in this research, two subjects are used. Like previous studios - one plays the role of the "hand" while the other is the "head"- two elements that are involved in the design "conversation". The designer or head tells the hand what to do. The hand then has the responsibility of coming up with images that would greatly assist the head to grasp the problem and progress towards the design solution. In other words - provide "food" for the arguments of the head.

The goals of this modification, which we will call double h, are as follows:

1. To verify the importance of hand sketching to the designer.

2. To examine the role images/sketches play in design activity.

3. To validate the purpose of an expert "design partner/assistant" in the design process.

4. To determine if there is a difference between what experts look for and what novices seek.

5. To find what is the nature of the knowledge base that helps the designer "sketch".

\section{Advantages of this method}

Concentrating on the contents of the head and hand interaction was considered more important than solely concentrating on the design strategy employed by the designer. This approach was expected to easily identify the nature of the images and information requested by the designer, to inform the process (and enhance the designer's strategy). Approaching the investigation in this manner, has its advantages. By allowing free dialogue between the subjects and looking at the questions the subjects ask each other, one can begin to speculate on the 
sort of dialogue that occurs when the designer is alone. In addition, by using this technique one subject has the benefit of sketching without the added distraction of verbalisation (except to ask for clarification which itself can indicate importance of elements to represent data). The other subject verbalises without worrying about sketching. It can also be argued that the behaviour of the subject is less affected by this arrangement. Data collected would illustrate two different approaches to design instead of one, providing more data for analysis.

\section{The Experiment}

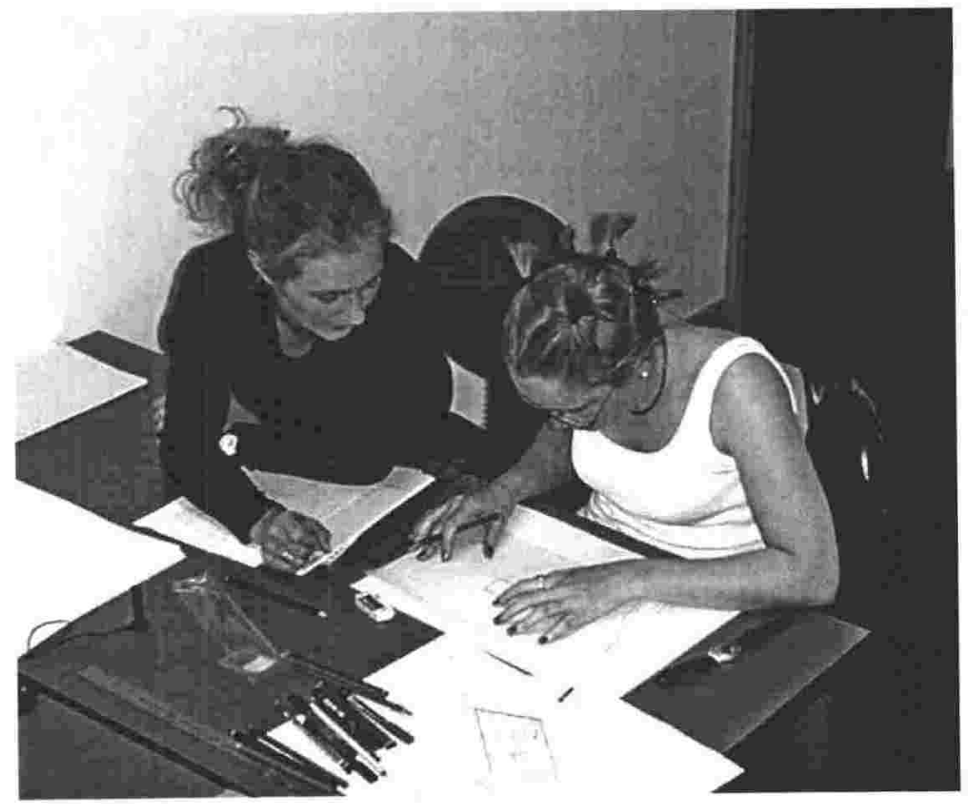

Figure 6.6. Double $\mathrm{h}$ experiment in session: Practitioner Amanda (head) and Student Amy (hand) engaged in design.

Two subjects - one, a practitioner (Amanda) with over four years practice experience and the other, a third year architecture student (Amy) - participated in the experiment (Figure 6.6). As stated before, the decision to use a practitioner and a student, stemmed from a desire to closer witness what effect experience (or the educated hand) had on the activity.

The experiment consequently was done in two design sessions. In the first session, the practitioner was given the role of "hand". The student as the "head" was given a design program for an architect/artist's studio and gallery 
on an inner-city site. In the second design session the roles were reversed and the practitioner as the "head" was asked to design a 4-bedroom residence on a beach site. The choice of the task, in addition to being similar to actual design studio projects, was based on the kinds of tasks given to students on the same design level as the junior participant.

The experiment is similar to the head and hand studios. The subjects were given various sizes of paper (bond and tracing) as well as a wide assortment of pencils and pens. In addition they were furnished with a scale rule and a $30 \mathrm{~cm}$ ruler. On average, each session took one hour (this was the time specified by the researcher; however, this was not strictly enforced). On both occasions a video camera was used to record marks on paper (by the "hand") as well as any gestures by the "head" in directing the sketching operations. The sessions were also recorded on audiotape, while the observer took notes of the activity and the sketches made by subjects were retained. Prior to the experiment the participants were given a short questionnaire (that covered personal information about design experience and their drawing preferences). After returning the questionnaire, the subjects were allowed to read the design brief for about five minutes before beginning the design task. During the session, the subjects were asked to adhere to the "rules of engagement" used in the head and hand studios. The subjects were also asked to ignore the observer (and recording apparatus) as much as possible, yet not hesitating to ask questions about issues that posed a problem in achieving the stated objectives of the exercise.

The head was instructed to take the design to as far as the end of the schematic design stage i.e. when the scheme was considered ready for "drawing up" (i.e. ready for technical drawing/entering on the computer). The following minimum, however, was required: floor plans, site section, and elevations and/or another section (to some scale) and 3D sketches (which were optional). The "finished" product was intended to reflect the level of design usually presented in a design studio. At the end of the session the subjects were given a questionnaire and spent a further fifteen minutes discussing the activity with the researcher. 


\begin{tabular}{|c|c|c|}
\hline & Amanda & Amy \\
\hline Occupation & Practitioner & Student \\
\hline Education (years) & 7 & 2 \\
\hline Practice (years) & 4 & 0 \\
\hline $\begin{array}{l}\text { What do you understand } \\
\text { by the word Sketch }\end{array}$ & $\begin{array}{l}\text { Draw experimentally, } \\
\text { thoughtfully to test and } \\
\text { plan }\end{array}$ & $\begin{array}{l}\text { Hand drawn, fairly } \\
\text { rough, not necessarily } \\
\text { measured }\end{array}$ \\
\hline $\begin{array}{l}\text { How often do you sketch } \\
\text { when designing }\end{array}$ & 1 & 1 \\
\hline $\begin{array}{l}\text { How often do you sketch } \\
\text { when communicating }\end{array}$ & 3 & 3 \\
\hline $\begin{array}{l}\text { Representation use } \\
\text { most when designing }\end{array}$ & $\begin{array}{l}\text { Plan - 20\% } \\
\text { Section - } 20 \% \\
\text { Elevation - } 20 \% \\
\text { Perspective }-20 \% \\
\text { Other - axo-20\% }\end{array}$ & $\begin{array}{l}\text { Plan }-20 \% \\
\text { Section }-20 \% \\
\text { Elevation - } 0 \% \\
\text { Perspective }-60 \% \\
\text { Other - } 0 \%\end{array}$ \\
\hline $\begin{array}{l}\text { How much time in one } \\
\text { sitting do you spend on } \\
\text { design activity }\end{array}$ & $2-3 \mathrm{hrs}$ & $1.5-2 \mathrm{hrs}$ \\
\hline $\begin{array}{l}\text { How often do you } \\
\text { consult outside sources } \\
\text { when designing }\end{array}$ & 2 - less than all the time & 2 -less than all the time \\
\hline $\begin{array}{l}\text { How early do you use } \\
\text { reference material at } \\
\text { start of process }\end{array}$ & 1 - very early & 1 - very early \\
\hline $\begin{array}{l}\text { How early do you use } \\
\text { the scale rule }\end{array}$ & 1 - very early & $3-$ \\
\hline $\begin{array}{l}\text { What scale do you start } \\
\text { design at }\end{array}$ & Other & $1: 100$ \\
\hline
\end{tabular}

(A $1-5$ scale. $1=$ all the time and $5=$ never $)$

Table 6.3. Profiles of subjects used in experiment taken from answered questionnaires.

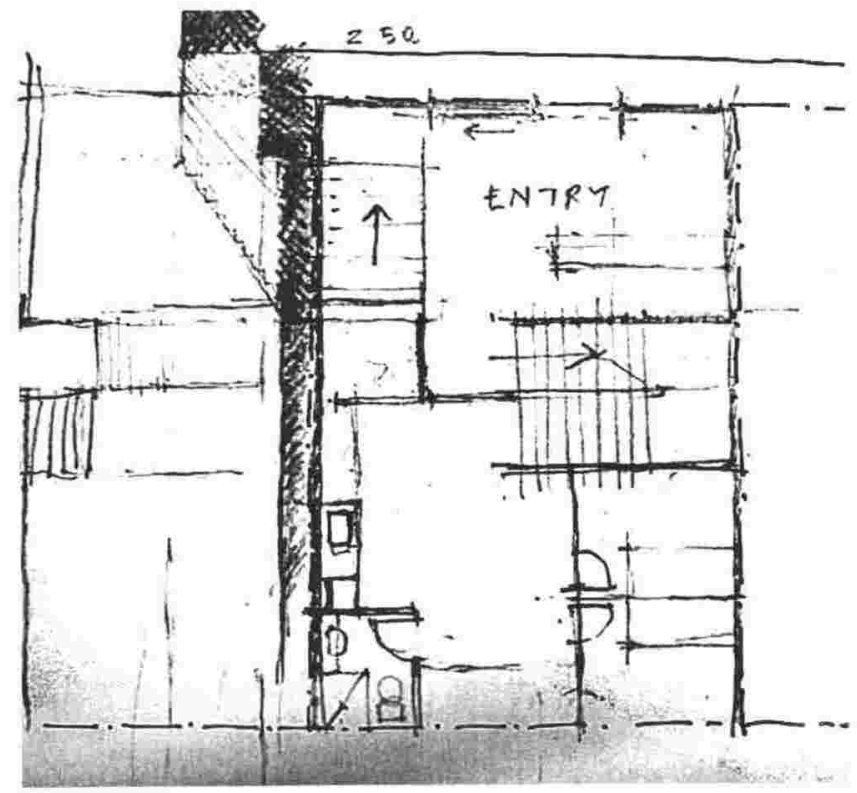

Figure 6.7. An example of the sketches produced during the experiment 


\section{Student as Head}

Even though there were two sessions in the experiment the student's session as head was the focus of the exercise. The session using the practitioner as head was considered a control experiment to check for similarities and differences. Below is a short summary of the student's activity as head.

The session for which the student was head can be divided into three phases. Phase one, the longest, involved locating and resolving the issues of entry, vertical circulation and the $1.5 \mathrm{~m}$ change in level. Phase two involved locating the other spaces in the proposal. In phase three, the development of an elevation for the design was the focus.

The design session began with the "head" establishing an entry to the building. The first moves involved setting up a reception on the minor of the two streets, establishing a stair that goes "underground", recognising that there is a $1.5 \mathrm{~m}$ difference between both streets. A stair to compensate for the level difference $(1.5 \mathrm{~m})$ was put in with its dimensions determined by the use of the building. The first question for the head pertained to the width of the stairs. The student started with a straight flight but with the help of the hand soon "discovered" that a "U" stair was more appropriate given the space the straight flight would have required. Once the stair was established (or satisfactory) the head moved on to developing other spaces that were determined by and arranged around the stair. The domestic functions came first and were subsequently followed by the public spaces. On the next floor, the orientation of the site determined the location of gallery, workshops and studio with a balcony. The head spent some time before deciding that more light was needed in the gallery and so added a skylight. The final moves of the session involved designing the elevations. Time was spent here considering the character of the adjacent structures as well as materiality of the surfaces.

\section{Observations}

After the experiment the participants discussed the previous activity with the researcher. Both participants expressed delight in the exercise and thought it was a novel way to look at design. They were surprised at their ability to 
verbally communicate design ideas well enough to get the needed feedback for further development of the design. Both in the role of "head" claimed full authorship of their respective schemes despite having no physical connection to it; meanwhile the "hands" claimed to have felt no stake in or connection to the design despite having produced the images. Interestingly the hands (who sketched) asserted that there was no "thinking" involved in their activity. They admitted difficulty in keeping track of spaces and elements despite physically interacting with drawings. It can be implied that to the "hand", events in the design task held no meaning and so were not retained in memory or "owned". It can also be assumed that the hand only considered the task on an event by event basis.

The subjects also saw the task as an exercise in planning with no architectural concepts involved. It was mentioned that they usually spent more time doodling (sometimes not "building things") before starting to design at which point codes and ergonomic issues "take over". This attitude could have been attributed to the time limit imposed on the sessions ${ }^{24}$. Although a financial cost was attached to the projects both the practitioner and the student largely ignored it.

Participants felt their usual process (whether sketching or designing) had to be modified in order for the other person to understand intentions but not to the detriment of the design. The student as "head" expressed appreciation and benefit from having the answers "spat at me", in that it "made it easier to get your head around the problem". A further claim was made that the design was more "purposeful" when questioned (by the practitioner) as to spatial and physical aspects of elements. On the other hand, the practitioner found it frustrating having to specify precisely what image was needed. Both subjects reported the now confirmed frustration at not using their hands to draw.

\section{Analysing the Data}

The protocols of the subjects were transcribed and examined in conjunction with the video evidence by the researcher. Usually the techniques of recording

${ }^{24}$ This was a common complaint in the studios and became a common complaint in subsequent experiments. This finding can be seen as a limitation of the experiments. 
protocols generate a great amount of raw data as confirmed by this experiment. This is usually too much data to deal with and so has to be broken into smaller manageable units. These units or "chunks" or "segments" (Gero and Tang 2001) are usually divided along the lines of the designer's intentions and actions instead of verbalization events or syntactic markers. The method of segmentation employed in this analysis was to divide the protocol based on episodes between points where the hand "fixed" and embellished elements on the sketch. This indicated where a decision had been made and a deliberate direction taken. In order for segments to be properly scrutinised to determine a suitable model of the activity, it is usual for a coding scheme to be developed. This influences how information derived from the experiment is examined and described. The development of the code is usually dependent on the researcher's view on design methodology. According to Dorst and Dijkhuis, there are two different paradigms for looking at design methodology (Dorst and Dijkhuis 1995). One paradigm sees design as a rational problem solving process and so is more interested in describing the process and examining concepts like acts, goals, contexts etc. The other viewpoint takes a constructionist approach and is influenced by Donald Schön's theories of design as a process of reflection-in-action. This takes a more content orientated approach while maintaining some link to process. Since we have aligned our theoretical stance with that of Schön (Chapter Four) our approach to analysing the data, while being interested with the design process, was more interested in the interaction between the two subjects and how they interacted with the images and information traded between them.

In the protocol generated by Amanda and Amy, the segment of interest to us is what we will refer to as the "stair sequence". The observations and results presented below, are based on this sequence as a sample of the data from the whole session. This sequence, which starts at 1:02 minutes in the protocol and ends 12 minutes later, (while not containing all the examples discussed) is used because it contains the richest source of a problem being identified and dealt with. Other sequences, while sources of design behaviour, were as a result of moves made during the stair sequence. Due to the nature of the investigation, analysis is limited to a general observation of the whole data by a relation of the 
selected sample to Schön's theories. Other sections of the transcript will be referred to as the need arises.

\section{Observations of Activity during the Protocols}

The physical interaction of the subjects during the exercise was indicative of the activities involved in sketching. The content for analysis was generated by the physical interaction of the subjects demonstrating the close link between the activity and the content generated. In the experiment, the subjects looked, pointed, labelled, asked questions and gave advice, in addition to drawing. This activity can be grouped into two main categories - communicating and searching. The interaction and subsequent dialogue were as follows:

Searching

Head
Looking and examining
This included watching the hand's sketching
activity, and the comparison of images.
Information gathered from examining was
seen as cues that trigger decisions or further
moves. It was also noted that subjects
tended to examine images side by side.
Looking and examining usually resulted in
requests.

\section{Requests}

This action on the part of the head included requests for information as well as requests to see particular drawings (or marks on a particular drawing). Requests usually entailed asking for distances and heights and requests occurred more frequently in session one where the student was head. Information gained from requests was used to make design decisions that related to "existing" elements. Gesturing and pointing usually accompanied requests.

\section{Hand \\ Advice}

Requests and examination usually resulted in advice. The hand for the most part advised or questioned the head as to aspects of the design (especially when the practitioner was hand) that might not work. This usually included information that could only be known when measuring and drawing.

Communicating

Head
Gesturing, Pointing or touching image with
hands
Pointing at the image and moving the hand
over it to indicate spatial and directional
movement (like movement through a door)
usually occurred when participants referred to
a physical element.

\section{Hand \\ Clarification}

During the experiment, the hand would repeat pieces of information uttered by the head. This usually occurred when placing elements for the first time.

\section{Labelling}

The hand would use labelling (text or otherwise) to identify elements e.g. stair, void, studio or drew furniture. This provided context for the head. Concrete decisions by the head were "darkened in" i.e. made 
bolder, to depict and emphasise that a decision or commitment had been made.

Gesturing (as per the head)

Table 6.4 displays an excerpt from the transcripts that illustrate some of these actions.

\begin{tabular}{|c|c|c|c|}
\hline Person & Transcription (speaking) & Action & Observations \\
\hline Amy & $\begin{array}{l}\text { Storage space is going to be under there so entrance is } \\
\text { from this side, so coming in there at the back of this } \\
\text { space, we are going to have another staircase which } \\
\text { will lead upstairs. }\end{array}$ & & \\
\hline Amanda & $\begin{array}{l}\text { Is it going to be running this way or is it going to be } \\
\text { that way. }\end{array}$ & Gestures in direction & \\
\hline Amy & Yeah running this way. & Gestures in direction & Spatial Gesture \\
\hline Amanda & That way. & Repeats gesture & Clarification \\
\hline Amy & Towards us yeah. & & \\
\hline Amanda & $\begin{array}{l}\text { Okay so how high do you want your floor to ceiling in } \\
\text { the ... }\end{array}$ & $\begin{array}{l}\text { Amanda draws stair } \\
\text { and calculates treads }\end{array}$ & $\begin{array}{l}\text { Info for stair } \\
\text { representation based } \\
\text { on height }\end{array}$ \\
\hline Amy & $\begin{array}{l}\text { In the reception area um lets call it } 3 \text { meters which is } \\
\text { the height of the ... }\end{array}$ & Looks around room & $\begin{array}{l}\text { Seeks relationship } \\
\text { for dimensions }\end{array}$ \\
\hline Amanda & How wide do you want this staircase? & & $\begin{array}{l}\text { Info for stair } \\
\text { representation }\end{array}$ \\
\hline Amy & $\begin{array}{l}\text { The staircase is going to be } 3 \text { meters wide. No... it has } \\
\text { got to be in the middle of the.... }\end{array}$ & $\begin{array}{l}\text { Points to halfway } \\
\text { line on drawing }\end{array}$ & Corrects hand \\
\hline $\begin{array}{r}\text { Amanda } \\
\text { Amy }\end{array}$ & $\begin{array}{l}\text { In the middle of here? } \\
\text { Yep. }\end{array}$ & & Clarification \\
\hline Amanda & Okay, 3 meters wide. & Starts to draw stair & \\
\hline Amanda & All in one direction? It's not wrapping around? & & Expert Advice \\
\hline Amy & How much space does that give us? & & $\begin{array}{l}\text { Request for } \\
\text { information }\end{array}$ \\
\hline Amanda & $\begin{array}{l}\text { Ahhhh, if you have got to go up } 3 \text { meters, that is, how } \\
\text { many? } 15 \ldots \text { about } 18 \text { steps generally. }\end{array}$ & & Expert Advice \\
\hline Amy & Okay & & Confirmation \\
\hline Amanda & 17.5 so $1,2,3,4,5,6,7,8,9$. & Measures and counts & \\
\hline Amy & Oh... good God no & & $\begin{array}{l}\text { Responds to } \\
\text { information and } \\
\text { counting on image }\end{array}$ \\
\hline Amanda & You could wrap it & & Expert Opinion \\
\hline $\begin{array}{r}\text { Amy } \\
\text { Amanda }\end{array}$ & $\begin{array}{l}\text { Yeah we are going to have to wrap it. } \\
\text { Okay }\end{array}$ & & Confirmation \\
\hline \multirow[t]{2}{*}{ Amy } & $\begin{array}{l}\text { Which way though? It is going to have to be in so } \\
\text { maybe we should bring it around this way. Which way } \\
\text { is this, that is the little building so,... but that is not up } \\
\text { there. }\end{array}$ & $\begin{array}{l}\text { Indicates/gestures } \\
\text { turning stair around }\end{array}$ & Spatial Gestures \\
\hline & See, I want the gallery space to he south lit coum & $\begin{array}{l}\text { Amanda darkens } \\
\text { stair, Amy thinking } \\
\text { by looking at } \\
\text { drawing. }\end{array}$ & Examining \\
\hline Amy & See, I want the gallery space to be south lit so um. & & \\
\hline
\end{tabular}

Table 6.4 Transcript excerpt from design session 1. $\mathrm{M}=\mathrm{Head}$ and $\mathrm{H}=\mathrm{Hand}$ 


\section{Four Dimensions: a detailed analysis of a Double $\mathrm{H}$ protocol}

Using Schön's constructivism theories we will attempt to breakdown and analyse the protocol. This analysis will be given four dimensions: domains, implications, shifts in stance and the search for clues. Most of the terms we will use are Schön's terms. These dimensions, however, are not exclusive to the sketch but rather are a part of the general design process.

\section{Domains}

The designer combines drawing and speaking into what Schön terms "a language of designing" (Schön 1983). In this language, words have different roles. In Schön's protocol, Quist (the master) speaks of a cafeteria that could "come down into here to get summer sun here" and "steps to relate in downward". In the double h protocol, Amanda asks Amy about the stair, "Is it going to be running this way or is it going to be that way?"

Amy: Storage space is going to be under there, so entrance is from this side so coming in there at the back of this space, we are going to have another staircase which will lead upstairs.

Amanda: Is it going to be running this way or is it going to be that way.

Amy: Yeah running this way (Gestures in direction)

Amanda: That way (Repeats gesture)

Amy: Towards us yeah.

In both cases "spatial action language" is used. Actions are attributed to elements of the design as though they were "creating form and organizing space". Simultaneously, Amanda's question seeks to determine the path of the user of the building and their interaction with the stair. Words are also used to label elements of the design ('staircase', 'reception area') to describe the consequences and implications of moves and to re-appreciate the situation.

In his book Design Studio and other publications Donald Schön has identified twelve groups or domains into which he grouped elements of the language of designing (Schön and Wiggins 1992). These design domains for Schön contain the names of elements, features, relations, and actions, and of norms used to evaluate problems, consequences and implications. We will use these domains to help us in analysing the double $\mathrm{H}$ protocol. 
As Amy and Amanda interact over the design, they draw on a repertoire of design domains to fulfil a variety of constructive, descriptive and normative functions. In the program domain they consider spaces according to their use and role in the program. e.g. "storage space", "reception area" and "gallery". They also consider "right sizes" for elements based on their predicted experience. For example, "the staircase is going to be 3 meters wide". Table 6.7 illustrates some domains.

\begin{tabular}{|c|c|c|}
\hline \multicolumn{3}{|c|}{$\begin{array}{l}\text { Normative Design Domains } \\
\text { Domains }\end{array}$} \\
\hline Domains & Definitions & Examples from Protocol \\
\hline Program/Use & $\begin{array}{l}\text { Functions of building or building } \\
\text { components, uses of building or site; } \\
\text { specification for use }\end{array}$ & Gallery, studio, reception \\
\hline Siting & $\begin{array}{l}\text { Features, elements relations to } \\
\text { building site }\end{array}$ & $\begin{array}{l}\text { "Main entrance will be from Johns } \\
\text { Lane." }\end{array}$ \\
\hline Building Elements & Building or components of buildings & Stair, roof skylight, wall \\
\hline Organisation of space & $\begin{array}{l}\text { Kinds of spaces and relations of } \\
\text { spaces to one another }\end{array}$ & "some kind of walkway" \\
\hline Form & $\begin{array}{l}\text { (1) Shape of building or component } \\
\text { (2) Geometry (3) Markings of } \\
\text { organisation of space (4) Experienced } \\
\text { felt-path of movement through spaces }\end{array}$ & \\
\hline Structure/Technology & $\begin{array}{l}\text { Structures, technologies and } \\
\text { processes used in building }\end{array}$ & $\begin{array}{l}\text { "south lighting won't ruin computer } \\
\text { screen", "curtain wall system" }\end{array}$ \\
\hline Scale & $\begin{array}{l}\text { Magnitudes of building and elements } \\
\text { in relation to one another }\end{array}$ & "kitchen will be small" \\
\hline Cost & Dollar cost of construction & "tight budget" \\
\hline Building Character & $\begin{array}{l}\text { Kind of building as a sign of style or } \\
\text { mode of building }\end{array}$ & $\begin{array}{l}\text { "we are looking at glass and concrete } \\
\text { (as a type of building)" }\end{array}$ \\
\hline Precedent & $\begin{array}{l}\text { Reference to other kinds of buildings, } \\
\text { styles or architectural modes }\end{array}$ & \\
\hline Representation & $\begin{array}{l}\text { Languages and notations by which } \\
\text { elements of other domains are } \\
\text { represented. }\end{array}$ & $\begin{array}{l}\text { Section, elevation, "Where is our floor } \\
\text { plan" }\end{array}$ \\
\hline Explanation & $\begin{array}{l}\text { Context of interaction between } \\
\text { designer and others }\end{array}$ & \\
\hline
\end{tabular}
Table 6.5 Design Domains (Source: terms - Schön 1985, examples - double h
protocols)

Often moves can have consequence and implications that transcend design domains. For example, the stair at the front is a function of the program - a means of getting from ground to second floor. It then develops, by the end of the sequence, as a means of organising the space. The use of the word "stair" subsequently refers to a particular building element, a functional part of the program and a means of organising the spaces. Students of design learn to detect multiple references, distinguish particular meaning in context and use these as an aid to understand and transcend design domains. The use of specific 
domains indicates a structure of priorities for addressing design situations. The relative frequency of reference to design domains, reveals the designers priorities for attention at this early stage of process. In our protocol, Amy seems intent from the start to allow users to interact with the stair. This is seen where most domains in the exchange focus on moving through the space and the organisation of other spaces to accommodate this. Domains, therefore, represent contexts for the designer to locate his/her "conversation". These contexts define the particular priorities, meanings of multiple references and space for arguments to develop and be appreciated. The interaction between head and hand therefore exists within domains or contexts.

\section{Implications}

Amanda: Do you want me to leave that much for your landing?

Amy: Yep, Yep. We could go that way

Amanda: Or we could wind up further

Amy: Wind up further, yeah

Amanda: And then just come back a little way this side which means people could walk.

Amy: I think yeah we will go like that. Keep the walkway though because I want to be able to get around the other side.

Amanda: Around there? No.

Amy: Um.

Amanda: Because you can walk ....

Amy: This will be floored over so that is all right.

Amanda: That is actually only going to be able to be floored over from about there.

Amy: Yeah.

Amanda: So do you want to move that that way so that is going down here we are on that level.

Amy: Okay because we are still on the basement plan, um we need to be able to get from this front lobby space through to the back so there is going to have to be some kind of walkway.

Amanda: Are you are going to need to get to the stair so you could ....

Amy: How can you get to the stair?

Amanda: So you could ....

Amy: The stair is going down this way, Yep.

Amanda: So if you want to go up this stair you probably don't want to walk right around it.

Amy: Yep okay so what we need is actually a wee area here to start going up the stairs. 
The sketch acts as a "what if" tool for the designer and involved in that "what if" is the subsequent activity of "then". The implications for later moves are influenced by the moves done presently. When Amanda says, "Do you want me to leave that much for your landing?" and Amy says, "Okay because we are still on the base plan, um, we need to be able to get from this front lobby space through to the back, so there is going to have to be some kind of walkway"; they are "noting the implications of earlier moves for later ones" (Schön 1985). This indicates that a pattern of "if...then" connections exist which "relates the cumulative sequence of prior moves to the choices now confronting the designer" (ibid.). The web of moves has many offshoots as witnessed by Amy. She sees that the move of the landing has implications on the space for persons to walk, the flooring of the landing, access from the lobby space, and access to the stair. There are decision-points which the hand (Amanda) makes easier by pointing them out and inviting a discussion about the implications of the decision. Hidden in some of the questions asked by Amanda is the tree of further choices to which a particular decision leads. Amanda's question about the landing indicates that somehow the width of the landing is important enough to be considered, hinting that there are implications in such a move and subsequent consequences for Amy's decision.

At some point the designer has to make a decision and move forward. The acceptance of this decision is based on three things:

1. the desirability of their consequences judged in categories drawn from the normative design domains,

Amy: Wind up further, yeah

Amanda: And then just come back a little way this side which means people could walk.

Amy: I think yeah we will go like that. Keep the walkway though because I want to be able to get around the other side.

2. Their conformity to or violation of implications set up by earlier moves,

Amanda: So do you want to move that that way so that is going down here? We are on that level.

Amy: Okay because we are still on the base plan, um we need to be able to get from this front lobby space through to the back so there is going to have to be some kind of walkway.

Amanda: Are you are going to need to get to the stair so you could ... 
3. The designer's appreciation of the new problems or potentials they have created.

Amy: Yep okay so what we need is actually a wee area here to start going up the stairs.

In the first example, the head (Amy) accepts Amanda's suggestion to "wind the stair further" because she finds that it has produced the desirable implications in the domain connecting spaces through user access. In the second, the head finds that the earlier move of the lobby has a bearing on the configuration of the stair. Finally the designer accepts a new situation presented to her (as a consequence of the earlier move) in the form of a "wee [small] area" to start going up the stairs (or when one comes down). Schön (1983) expands this notion by saying:

\footnotetext{
In the designer's conversation with the materials of his design, he can never make a move which has only the effects intended for it. His materials are continually talking back to him, causing him to apprehend unanticipated problems and potentials. As he appreciates such new and unexpected phenomena, he also evaluates the moves that have created them (Schön 1983).
}

At the end of the sequence the hand embellishes and darkens the stair. She uses the convention for stair (lines and arrows) "freezing" the element. This then becomes the context for the next sequence. The decision then becomes according to Schön "a design node with binding implications for further moves." The stair in the case of our protocol goes on to define the organisation of the subsequent spaces as well as organise the building vertically. Thus during the design process there are a series of decision points with implications that the designer considers and values continually evolving into a suitable solution. The hand in the protocol assists in making the head aware of them.

\section{Shifts in stance.}

As the designer moves through the web of domains and implications, his or her stance to the design situation goes through a series of changes. Schön speaks of three such shifts:

- The designer "shifts from a recognition of possibility and freedom of choice to an acceptance of the imperatives which follow from choice" (Schön 1985). In our protocol the designers speak of placing the stair in relation to the reception, and then discover that a straight flight would 
not work. She then accepts that the stair would have to be "wrapped" and begins to reconsider the direction of the stair, later accepting it as inevitable.

- The designer shifts between the unit and the whole. He or she oscillates between inciting local moves and viewing how those moves fit within and affect the whole idea. This is seen in the protocol when Amy leaves the stair to consider the whole building.

Amy: Okay, alright, we will worry about the staircase in a second.

- Finally, the designer "shifts from tentative adoption of a strategy to eventual commitment." The tentative adoption is supported by the perception of the designer, in that his/her steps can be retraced which is a separate stance from a position of no return (the designer "owns" the move or decision.). Amy does this when she states "Okay, alright we will worry about the staircase in a second". She then looks at other issues before coming back to the situation and committing to it.

Changes in stance have the advantage of providing the designer with a fresh perspective or a different domain to consider the situation. Changes in perspective prevent the designer from being "bogged" down and initiates multidimensional investigation. In the protocol, the hand created instances for a shift in stance, by highlighting difficulties or situations that required special attention. The hand also took the initiative to draw a section for an alternate view of the stair.

\section{Clues}

Clues are important in the solution of problems. Where would a crossword puzzle be without them? Clues are useful only if they are associated with something that is relevant to the problem under consideration. The clue must trigger some pertinent information stored in memory that is difficult to get at. Gabriela Goldschmidt uses the recall of a name as example of this:

If you are thinking of someone's name, it may help if you are told that the name starts with an A, but this clue is useless if you never knew the name in the first place
(Goldschmidt 1994). 
Unlike the crossword puzzle and the problem with names which are "well defined" (i.e. has a predetermined outcome or solution), design problems are "ill-defined" or "wicked" (Rowe 1987)25. In this case, the design problem is defined through the process of solving it. As a result of this, the designer in the early phases of problem solving resorts to generating images from which aspects of the problem is gleaned in a search to form an impression of the problem. Goldschmidt believes that the purpose of this gleaning (early sketching activity) is primarily to provide the designer with "potentially meaningful clues". She further claims that if detected, these clues can be used to form and to inform emerging design concepts (Goldschmidt 1994).

During our protocol, the practitioner as "hand" asked questions in such a way as to give the student clues to direct her thoughts.

Amanda: Do you want me to leave that much for your landing?

The student responded to these "clues" or hints enthusiastically. She mentioned afterwards that it was

"...good to have another opinion. ...(She) would have thought about it (herself) (but)

the hand was quicker - more expert".

While this was encouraging, it was viewed with some caution since there was a danger of the student being too accepting of the practitioner's information.

When it was the student's turn to be the hand, her questions tended to refer to the representation rather than the design situation and the ideas involved, e.g. "Put the door here?" - a question of confirmation, when asked by the head to define a specific opening in a wall. In contrast, the practitioner's question was "Do you want the door here or here?" when asked to define a particular space. In the first instance the student responds to a specific request and goes no further. In the second, the practitioner addresses the design situation by suggesting (through a question) that the position of the door (something that was never requested) was important to the act of defining the space.

${ }^{25}$ For a detailed discussion of the nature of design problems see Chapter 11 


\section{Additional Double H Experiments}

The Double $\mathrm{H}$ exercise was subsequently repeated successfully four times. These exercises were part of a wider experiment that required students to design in a variety of situations. The opportunity was taken to capture the data gleaned in the wider experiment for comparison to the original head and hand sessions. Twenty-three students out of over seventy were selected from the second year design studio course (ARCH 211) at the School of Architecture at Victoria University of Wellington. Of the twenty-three, twelve took part in the experiment and of the twelve; four took part in the double $\mathrm{h}$ sessions (two male and two female). Design experience of the twelve ranged from only first year design (which comprised of a basic course not unlike the Vorkurs - little if any building design took place) to two years in polytechnic (doing architectural drafting). In most cases students were designing a full building for the first time. In addition to the students, a practitioner with thirty-three years experience in practice was chosen to act as hand during the four double $\mathrm{h}$ sessions of the experiment.

\section{The Double H Sessions}

The design task - a studio in the city - was the same project (with little change) used in the original double h experiment. The set-up was the same. All sessions lasted approximately sixty minutes, excluding time used to read the brief and answer the questionnaires given at the end of the session. The protocols were recorded on audiotape and video with additional notes taken by the researcher. It should be noted that the main difference was that all the students played the role of head only. 

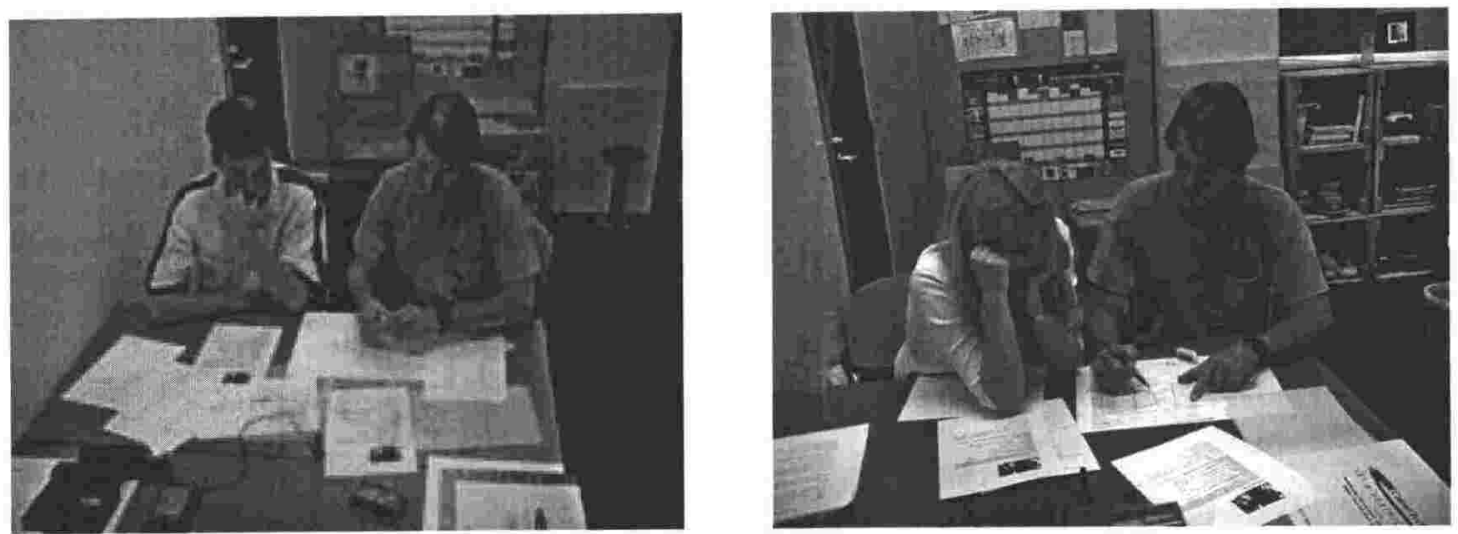

Figure 6.8. Keith (the practitioner) with Steven and Ellen in double $h$ sessions

The students' sessions compared well to the original double $\mathrm{h}$ session and differed in some aspects. Before we note the similarities and difference, it is perhaps important to note particular differences between the subjects. These could have a bearing on some of the inconsistencies between the first session and the four that followed. The two practitioners had vastly different experiences in practice. Amanda had only been practicing for four years versus Keith who had been in practice for as long as Amanda had been alive! Of the students, Amy was a third year student exposed to two years of design, while the students used in the second experiment, were just starting to design.

\section{Observations}

The actions of the parties during the experiments echoed the original in some respects (subjects searched for clues, changed stance etc.) and differed in others with the differences seemingly related to the personalities involved.

Some observations of the second experiments were as follows:

1. All students were a little intimidated by the practitioner, and so, in the case of being the head, did not totally control the situation. Students appeared hesitant and unsure; and two admitted to feeling intimidated. This could have been attributed to the video camera or the personality of the practitioner, who tended to be a bit matter of fact. Students also hesitated to make many changes that required a lot of redrawing and erasing. When the practitioner designed and the student sketched in the original protocols, there was no hesitation to try ideas. 
2. Some students were more willing to regard something as unimportant, in order to pursue a preferred direction. In one case, a student had the tendency to put off issues that did not conform to directions she wanted to push the design. Every time the hand pointed out implications that resulted in a different outcome than what she wanted she would immediately change stance. Other subjects shifted stance, (although for other reasons) several times between activities. They chose to assail the situation from different angles without a particular focus. This could be attributed to the student's inexperience with the design process.

All the protocols (including the first one) confirmed similar observations about sketching from previous experiments (Suwa, Gero, and Purcell 1998; Do 1997). These observations found that designers:

Layered information on their sketches. They labelled spaces and used graphic symbols to illustrate or determine design context. Designers wanted as much information as possible put on individual drawings. The practitioner placed more information on his/her drawings. As a result, the information quality of the practitioner's sketches tended to be a lot richer than that of the student.

Drawings were deliberately used to make decisions. Sketches served as external memory that were revisited and provided visio-spatial cues for thinking about functional issues. How they were manipulated and placed was important to decision making. For instance, subjects preferred seeing drawings side by side. This was important (especially between floor plans) although some overlaying of information took place (more a shortcut than anything else).

Designers related their drawings to the world around them. It was observed on several occasions that some subjects used the experiment room (by looking around) as reference to gauge scale. They then related these sizes and dimensions of immediate surroundings to existing elements in drawing.

\section{Limitations of Method}

Even though valuable data was gleaned from the experiments there are a few concerns that could be addressed in future experiments. Little concurrent 
verbalisation took place by the head while waiting on the other subject to draw. It was observed, though, that the subject was still thinking by looking at what the hand was doing. Whether or not this (the actual activity of drawing) helped the designer's thinking is an area that needs to be explored. It was also observed that the design process was not concentrated or focused enough to reveal more of the kinds of information traded. This could have been a result of the scope of task which could be considered too broad. Assigning smaller specific tasks (for instance - the design of two adjacent spaces to face a particular view) could be a possible solution to this. Related to this concern is the rigid planning approach taken by a majority of the subjects. The correlation of the task and the time permitted could be revised. Finally, experiments did not specifically look at coaching. In fact coaching (telling the student what to do) of the student was discouraged. The response of the student to active coaching could be a specific issue examined in future experiments. While these unanswered questions are important, they did not prevent the conclusion that the relationship between head and hand is dependent on the relative "abilities" of the two entities.

\section{Conclusions}

We have stated that there are two players in the activity of sketching - the hand and the head. By literally employing two separate individuals in this conversation, we were able to take a closer look at the communication between these two players in sketching. Design studios that used students in these roles revealed an interesting premise: the more capable the hand the more intense and enlightening the head felt about the process. This required a closer look. A close dissection employed the use of a unique experiment - the double $\mathrm{h}$ where a practitioner played the role of hand and a student played the part of head. Our empirical studies while confirming similar research (Do 1997; Suwa, Gero, and Purcell 1998) has also shown that there is a certain give and take that is necessary when sketching. Designers engage in a language of domains that situate and give meaning to this dialogue. It also showed that designers spend time during the process questioning and interpreting the functional implications of their ideas in broad terms. As a result of the questioning and constant reinterpreting, the designer shifted stance or changed viewpoints accordingly. 
Finally, the sessions revealed that designers rely on dialogue and interaction with images to produce clues for development of the solution.

Most importantly to this thesis, however, was the reaction of the designer to the "smarter" hand. If there was a single concept that emerged from the double $\mathrm{H}$ experiences, it was the vast difference between the expert or experienced designer and the student or novice in the "conversations". In all cases the expert (practitioners and senior students) as head, exhibited impatience with their junior hands. They realised they had to be explicit and halting, because their partner was struggling to make sense of a design situation they had figured out two moves back. In the contrasting position, when playing the role of the hand, the experts were able to push the design activity along because they asked questions ahead of the novice's acknowledgement of the situation. The expert, with the ability to see more options, was in the position to prompt the novice and reveal directions the novice wouldn't otherwise think of. This was well appreciated by the novice and gave him/her the perception of an intense design session. The experiments demonstrated distinctly that the experience of the conversation was elevated when the hand was more experienced than the head. The hand by virtue of this experience was able to present clues, cross and integrate domains, trigger shifts in stance and reveal implications. It is therefore evident that the key to using the sketch to enhance the student's grasp of a design situation is the employment of an expert "hand". This implicates the development of design aids for sketching that constantly question the emerging design providing hints or clues along the way. To take advantage of this notion, it becomes important to understand from literature the differences between what the experienced or "expert" hand knows and what the "novice" hand knows (or doesn't know). How do they individually see the design situation?

Aside from this issue of novices and experts, is the knowledge that this discovery forces a reconsideration of the student/master relationship. In the zone of interaction the tutor or master takes on the role of the expert. The expert, in the case of the student/master dialogue, comes to the relationship after the design act. This differs from the expert hand in the case of the double $\mathrm{h}$ experiment, which was involved in the act itself. As pointed out earlier, using Vygotsky's theories, the potential ability for learning in a particular social 
situation is greater when the learning is facilitated by someone (or something) with greater expertise. It follows that this learning is a lot stronger when the support occurs while the task is being attempted, rather than after the attempt. Unfortunately it would be expensive and impractical to have the design tutor being the hand and available at all times while the student is designing. In any case, we have already established that telling and showing are also important in the dialogue after the student has started to design. The solution therefore lies in a combination of the ever-present expert hand and the master who takes a critical approach to the design attempt. In this way, the expert hand enhances the relationship of student and master/tutor, raising the level of dialogue and making the zone of interaction richer. The student as a result receives two experts, each with a distinct and separate role. In order to facilitate a clear and unambiguous learning process, it is important to clearly define these roles.

\section{References}

Akin, Ömer. 1986. Psychology of architectural design. London: Pion Ltd.

Anders, Ericsson K., and Herbert A. Simon. 1993. Protocol Analysis: Verbal Reports as Data. Cambridge, Massachusetts: MIT Press.

Do, Ellen Y.-L. 1997. Computability of design diagrams : an empirical study of diagram conventions in design. In $C A A D$ Futures 97, edited by R. Jungs, 171-76. Munich: Kluwer.

Dorst, K., and J. Dijkhuis. 1995. Comparing paradigms for describing design activity. Design Studies 16, no. 2: 261-74.

Eastman, C. M. 1970. On the analysis of intuitive design processes. In Emerging methods in environmental design and planning, edited by G. Moore, 21-37. Cambridge Mass.: MIT Press.

Eckersly, Michael. 1988. The form of design processes: a protocol analysis study. Design Studies 9, no. 2: 86-94.

Faruque, Omar. 1984. Graphic Communication as a Design Tool. New York: Van Nostrand Reinhold Company Inc.

Gabriel, G., and M. Maher. 1999. Coding and modelling communication in architectural collaborative design. In Media and design process, edited by O. Ataman and J. Bermúdez, 152-66. Salt Lake City: ACADIA ' 99.

Gero, John S., and M. Tang. 2001. Differences between retrospective and concurrent protocols in revealing the process oriented aspects of the design process. Design Studies 21. 
Goldschmidt, Gabriela. 1994. On visual design thinking: the vis kids of architecture. Design Studies 15, no. 2: 158-74.

Hertzberger, Herman. 2000. Space and the Architect: Lessons in Architecture 2. 010 Publishers.

Laseau, Paul. 1989. Graphic Thinking for Architects and Designers. 2nd ed. New York: Van Nostrand Reinhold Company Inc.

Lawson, Bryan. 1997. How Designers Think: The Design Process Demystified. Third ed. Oxford: Architectural Press.

Lloyd, P., Bryan Lawson, and P. Scott. 1995. Can concurrent verbalisation reveal design cognition? Design Studies 16, no. 2: 237-59.

Rowe, Peter G. 1987. Design Thinking. Cambridge, Mass.: MIT Press.

Schön, Donald A. 1983. The Reflective Practitioner. New York: Basic Books.

Schön, Donald A. 1985. The Design Studio: An exploration of its traditions and potential. London: RIBA Publications Ltd.

Schön, Donald A., and Glenn Wiggins. 1992. Kinds of seeing and their functions in designing. Design Studies 13, no. 2: 135-56.

Suwa, M., John S. Gero, and T. A. Purcell. 1998. The roles of sketches in the early conceptual design processes. In Proceedings of twentieth annual meeting of the Cognition Science Society, edited by L. Erlbaum, 1043-1048. . 


\section{Novice and Experts}

Novice - somebody who has just started learning or doing something new and has no previous experience in the skill or activity

Expert - somebody with a great deal of knowledge about, or skill, training, or experience in, a particular field or activity

(Encarta World English Dictionary 1999)

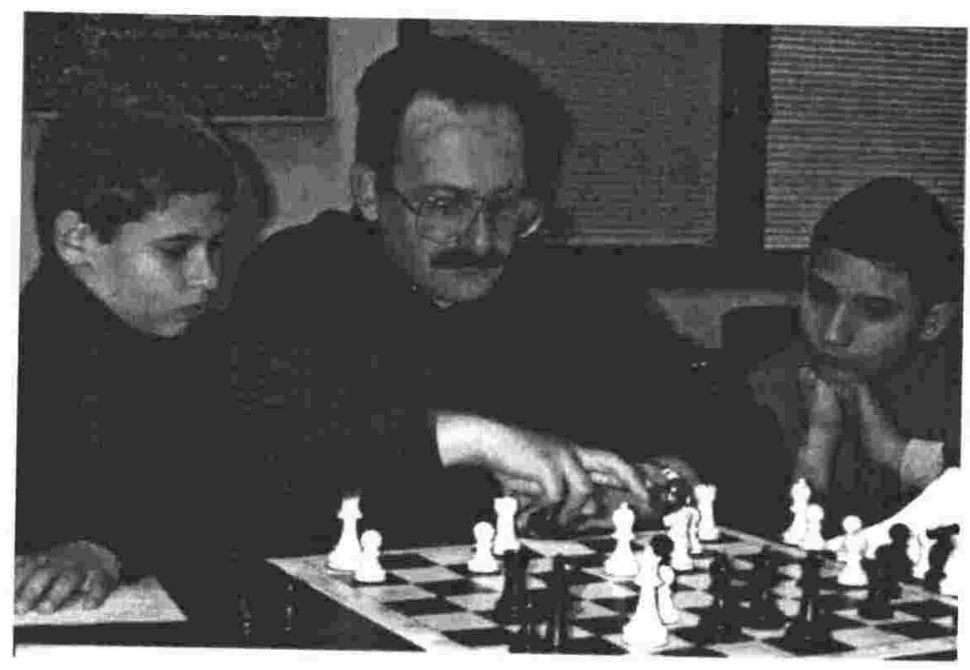

\section{Figure 7.1. A master and his novices (Source: Unknown)}

I

$\mathrm{t}$ is reasonable to say that due to their superior knowledge and experience, expert designers or masters are more capable of solving design problems than beginners. With knowledge and informed insight/experience, the designer is able to see more creative opportunities in a design situation. Success in design is directly related to the level of information the designer has access to. The greater the knowledge and experience, the greater the creative leap. If we relate the existence of creative opportunities to the context of the sketch as described in Chapter 5, then, the more experienced the designer is, the easier it is for the sketch to inform or clue him or her about the vital aspects of the problem. This also means that the same sketch means more to the expert than the novice. It is therefore perceived and utilised in a different way. A fluid, 
informed and creative design process is therefore largely the result of an expert hand.

Novice and expert cannot see eye to eye because they "see" differently. As seen in the double h experiment, there was a noticeable frustration on the part of the expert, as both participants engaged over the same design task. This also affects the desk crit. When the novice (student) meets the expert (master) the expert has to spend time bringing the novice up to his/her level, in order to achieve a convergence of meaning. It would help the situation if the novice were at that level, or at least close to it, prior to meeting the expert. This calls for a mediating factor that supports and adds value to the novice's contribution in the relationship.

This chapter is entitled Novice and Experts, implying more than two participants - the student (novice), the expert sketch/hand (the mediator) and the expert tutor. After highlighting and defining the differences between experts and novice, we search for roles each can play in the zone of interaction. Finally, it becomes clear that what is required is the sketch becoming a ladder or scaffold that supports the student and allows meaningful critical dialogue between student and master, novice and expert, about the design process.

\section{Novices and Experts}

Images again

The representation of a design idea at any one point in time is discernible in images. Images affect how the design idea is understood and how subsequent operations are carried out. The success of these operations is based on or feedback allowed by the image. The idea therefore must be represented and manipulated for the level of intent or information needed to communicate, inform and direct the design process. We have already concluded that the process of representing, manipulating, directing, controlling, testing and informing a design idea through image, is called sketching or graphic thinking. The influence exerted by images on decisions in the process is related to the crucial link between the sketch and any limitations of the designer. 
Ease of design is related to the ability to interpret and manipulate the sketch. Most design decisions are generally founded on the ability of designers to use their powers of visualisation to read and manipulate the sketch. Ease of use and extreme familiarity with manipulating the sketch, allows the designer freedom to explore design ideas, makes the designer's chore lighter, and accelerates the design process. Manipulating the sketch is facilitated by the amount and quality of information interpreted and gleaned from the sketch. How the sketch is used - the amount of information perceived and how confident and conscious the designer is of its use - is measure of the designer's competence.

\section{Climbing Rocks and Playing Chess}

To explore this concept further let us use the analogy of the rock climber. When a climber approaches the rock face at first it is a jumble of cracks, protrusions, and holes. To the inexperienced (who knows nothing about rock climbing) it is simply an uneven surface. To the climber there are possibilities that manifest themselves in the confusing jumble of "finger holds" on a rock face. The novice sees the rock face one or two finger holds at a time, and spends each step searching for the next finger hold, not caring (or unable to care) where the route will end up. Sometimes the climber gets stuck (sees no more suitable holds) and has to go back a couple of steps. The expert, however, sees five possible finger holds at any one time and evaluates each on the range of possibilities they hold for the next step or intended direction. Both climbers see the same surface, however the expert is able to see a wider field or group from which to choose from. The sketch is another form of "clue" or "finger hold" searching. Good finger holds lead the climber into a better position from which to make the next set of choices. The difference between the expert and novice is expressed in the amount and quality of "clues" or "finger holds" they see in each manipulation of the sketch. 

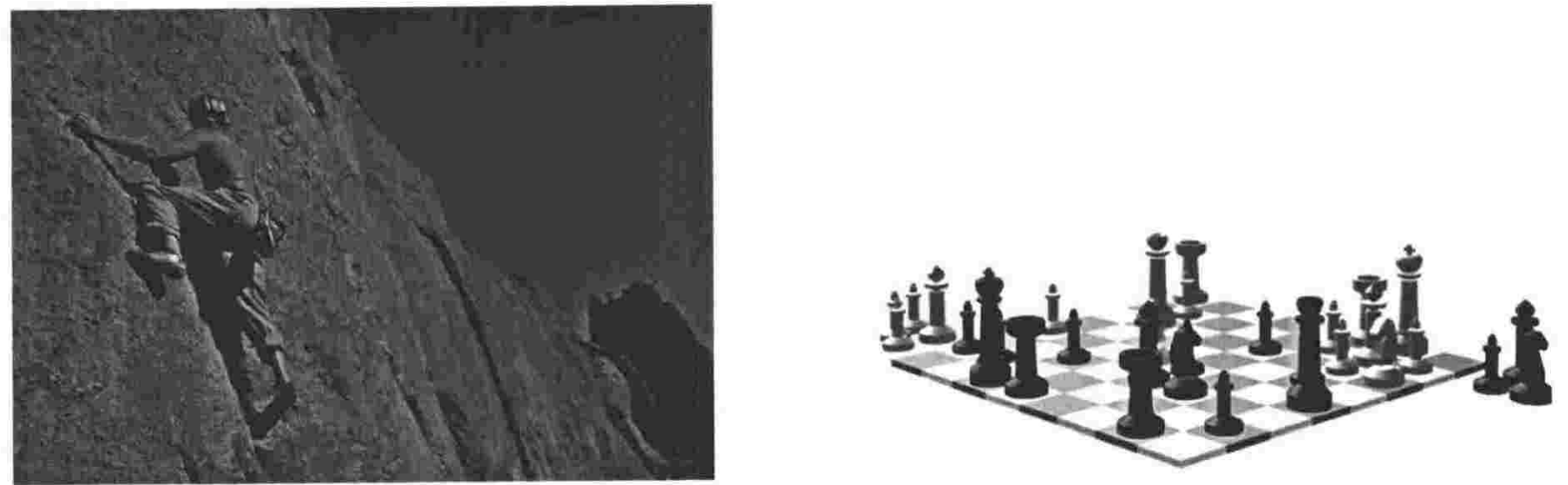

Figure 7.2. Rock climbing and Chess are similar.

An analogy of this searching process is that of the chess player. In his book Gödel, Escher, Bach: an eternal golden braid, Douglas Hofstadter (1983) writes about how chess novices and chess masters perceive a chess situation:

.... in normal chess play, certain types of situation recur - certain patterns - and it is to those high-level patterns that the master is sensitive. He thinks on a different level from the novice; his set of concepts is different. Nearly everyone is surprised to find out that in actual play, a master rarely looks ahead any further than a novice does - and moreover, a master usually examines only a handful of possible moves! The trick is that his mode of perceiving the board is like a filter: he literally does not see bad moves when he looks at a chess situation - no more than chess amateurs see illegal moves when they look at a chess situation. Anyone who has played even a little chess has organized his perception so that diagonal rook-moves, forward captures by pawns, and so forth, are never brought to mind. Similarly, master-level players have built up higher levels of organization in the way they see the board; consequently, to them, bad moves are as unlikely to come to mind as illegal moves are, to most people (Hofstadter 1983, pp. 286).

If we relate this to the sketch, these high level patterns or "chunks" are embedded in the images that the expert draws and these "chunks" contain smaller subgroups of information. The expert therefore sees the sketch not as individual elements, but rather as interconnected groups of information from which an evaluation is done and decisions made. Efficiency is achieved because the smaller groups of information contained in the larger groups require no further thought. In the final analysis, design experts (experienced designers) are more able to see or "read" the information contained in sketches, because they have larger "inventories of usable forms, combinational rules, and other organizational 'schemata"' than novices (Casakin and Goldschmidt 1999). In other words, the ability to "read" the information embedded in the sketch, separates the novice from expert. 


\section{The Expert and the Sketch}

According to Goldschmidt; in the search for clues, the designer "reads off the sketch more information than was invested in its making" (Goldschmidt 1994) and "success in [serial sketching] depends on the ability to "read" sufficient relevant information off each newly created image to instruct the next move" (Goldschmidt 1992). The key, therefore, to the design expert's effective use of the sketch lies in the ability to "read". The expert reads or takes more information from the sketch in relation to amount of clues detected by the novice. As a result, the expert is able to see and bridge domains easier, visualise elements in terms of moves and implications and be able to alter positions (change stance) easily throughout the design process.

Researchers have claimed that the expert is more active and productive than the novice in the conceptual design process (Kavakli et al. 1999; Kavakli and Gero 2002; Suwa and Tversky 1996). Their empirical studies have demonstrated that:

The expert engages in much more cognitive activity while sketching, that is visual reasoning, than the novice...

The expert modifies existing depictions by revising and manipulating them while the novice draws more new depictions in the form of symbols such as arrows and lines or symbols with special meaning...

The expert discovers new or revisits old spatial or organisational relations while the novice discovers more implicit spaces... (Kavakli et al. 1999).

They have also stated that the expert engages in more focussed and progressive visual reasoning (Kavakli et al. 1999) and the "expert's cognitive activity and productivity (in terms of image generation) were three times as high as the novice's in the overall design process" (Kavakli \& Gero 2002). This indicates that a highly organised and focussed visual reasoning process is associated with the sketching activity of an expert architectural designer.

To relate this information to the discussions of Part One; Casakin and Goldschmidt (1999) determined from an experiment involving architects, beginning students and advanced students that while there was marked difference between design ideas and solutions generated by the architects and beginning students, there was no significant difference between the advanced students and the other 2 groups. From this, Casakin and Goldschmidt 
conjectured that a considerable amount of information was required before a designer was able to design economically (i.e. with the shortest possible searchcycle) (Casakin and Goldschmidt 1999). The content of this information is provided by Lockard (1977), who proposes that the ability to "diagram" or represent a context in a sketch, depends largely on the designer's knowledge of related issues in a setting, such as climate, environment, topography or ergonomics (Lockard 2000). A more experienced designer, knows the issues involved in the design situation, and reads the sketch to discover the "truths" hidden within the problem. The student/novice is unable to do this effectively, because the sketch contains information that the student 1) isn't aware of, 2) doesn't know how to manipulate, and 3) doesn't understand. The aim therefore is to improve the "literacy" of the novice/student.

It can be acknowledged that the length of the search cycle and success in design depends on more than the literacy - experience and informed insight - of the designer. Other factors like the nature of the problem and the intrinsic characteristics of the designer (thinking style, talent etc.), while important, are beyond the control of design education. However, design education controls the way in which literacy is gained.

\section{The Expert Hand in Design Education}

We have already concluded that the transference of the skills the novice needs to develop in architectural education is embodied in the zone of interaction. Let us go back to the chess game. A novice is trying to learn how to play and as yet does not see the chunks of information the expert perceives. In an attempt to teach the novice the expert does two things: 1) shows the novice the moves that are available, sometimes reminding the novice about legal moves; 2) instructs the novice as to the quality of each move as it relates to the game situation. Similarly, in the zone of interaction, the master shows the student the issues available in the design situation, and simultaneously criticises and qualifies the issues embedded in the student's attempt.

The medium for the zone is the sketch. Designers use the sketch by representing concepts and examining them by reading the information (or clues) embedded within. In other words, the designer uses the sketch as a 
means of understanding the implications of a design decision. As argued extensively, the same sketch therefore means more to the master than to the student as the master sees more into the sketch. As demonstrated by Schön using Quist and Petra and observations from the double h experiment, the teacher (hand) uses prompts (questions, comments) to guide the student. These prompts become clues that point to the next step or at to least create a favourable environment for the next step. This guidance allows for greater readability of the sketch. The value of the clues to the student's literacy and understanding of the design situation is dependent on the timing of the offer. Clues at the moment of conception allow for greater understanding than clues that occur after the design activity.

This dichotomy is acute when referring to the evolution of design teaching. In the contemporary desk crit, any advice or prompts that are given occur after the act of the designing and outside of the realities of building. This compares with the relationship of student and master on the sites of antiquity. There, the master gave prompts and advice in the context of the building whilst the student or apprentice was engaged in activity. Therefore, for the novice to read the inherent possibilities embedded in the sketch, and effectively learn about the issues involved, this information has to be revealed to the novice within the virtual world of the sketch.

\section{One Novice, Two Experts}

The student in design education is at present being served by one expert - the design tutor. This tutor sees the student after the design attempt and uses the session to instruct the student about designing, how to design and about the aspects of architecture that produces buildings that are fit-for-purpose, costeffective, environmentally friendly and pleasing to clients and users. It has been demonstrated (Chapter 4) that integrative knowledge cannot be adequately achieved without depriving the student of adequate critical thinking and problem-solving skills or knowledge of the realities of architecture. To achieve a balanced approach to design teaching it may become necessary to separate the function and timing of the activities involved in the zone. 
As verified by the double $\mathrm{h}$ experiment, this implies two experts alongside the novice. All three parties would exist within the zone of interaction. The student engages with one expert during the design, concentrating on the specifics relevant to the "virtual building" and engages with the other after the design attempt, accepting criticism where relevant. The roles would be specifically:

Expert one: demonstrate and instruct the student on the means and methods of design. This involves showing and mostly telling the student about the value or quality of the student's design effort. Expert one would reveal to the student the best approach, or general principles involved in tackling the task, criticise the reconciliation of the specifics and direction the solution is going while demonstrating how to judge and criticise the attempt without dwelling on the specifics. In other words, expert one is responsible for the intellectual worth of the work.

Expert two: demonstrate and instruct the student on how architectural issues fit together, and the subsequent implications of their connections. Without judgement, expert two should be able to, through prompting and hinting, show and tell the novice information about the task being grappled with. This information can be particular to that task or (the better option) be common to several tasks. E.g. the notion that windows admit daylighting is common to most tasks from classrooms to laboratories and offices (an infinite set). The idea that aluminium (as suitable material for a window) does not rust is specific to seaside buildings (a finite set). Expert two would be responsible for the practical worth of the design.

In the end, two experts with vastly different roles support the student. Not only is the difference in the roles characterised by function but they also differ in terms of timing. One would occur during the act of design and the other would occur after in a critical position.

It has already been argued in Chapter 4 that the design tutor is best able to play the role of expert one, since this is dependent on judgement, exposure and a particular way of viewing the world. This expert would support the student after the design has been attempted. Expert two would therefore support the act of 
designing providing information while the designer is immersed in the act. This is not unlike the sites of antiquity.

The sketch was deemed important in Chapter 4 since the student interacted with it during and after design (in the desk crit). For the sketch to fit in the role of expert two it has to be so empowered, that, like the practitioner in the double $\mathrm{h}$ experiments, it becomes an "expert" hand (Table 7.1).

Traditional Sketch

- Passive: waits for participant to reveal situation

- All domains equal

- Clues have to be searched for. Ability to find based on expertise

- Implications are discovered

- Lateral thinking is the domain of the participant

\section{Empowered Sketch}

- Informs participant what image could be about

- Reveals and concentrates only domains relevant to objectives of lesson

- Various clues are offered for choosing

- Implications are revealed

- Encourages lateral thinking

\section{Table 7.1. Traditional vs. the empowered sketch}

\section{The Empowered Sketch}

The value of the empowered sketch does not simply rest at the level of assisting the novice to perceive the issues involved in the sketch. By increasing the novice's awareness in the situation, the empowered sketch also sets the stage for the zone of interaction. The novice has the opportunity to meet the expert on terms rarely existing in the present desk crit. With the context of the discussion already established prior to the meeting, the novice is cognisant of the issues involved, asks the "right" questions and understands the criticism and advice on the issues. The empowered sketch therefore acts as a mediator in the relationship.

The empowered sketch also plays an important educational role. This assistance where tutors or more capable peers provide information and support necessary for the student to grow intellectually is usually termed scaffolding when referring to Vygotsky's theory of learning. However, in many cases, scaffolds are also used to refer to support materials and support processes (Open Learning Technology Corporation 1996). In this case the empowered sketch also becomes a scaffold for learning. 


\section{Conclusion}

The sketch is the most important tool used by designers in the design process. When sketching, the designer interactively tests ideas through the use of images, symbols, lines and words. The sketch is not only important to the individual designer, but also is an important part of the zone of interaction between student and teacher during the desk crit. It provides the student and master with visual evidence of design thinking, and provides the instructor with material for criticism. The sketch's role in the zone places a burden on the sketch to assist in making young designers aware of the kinds of issues that determine an architecture that is cost effective, sustainable and accommodating to users. The sketch is therefore essential as a means of thinking, understanding and especially learning.

Schön and Wiggins (1992) see sketching as a conversation with the materials of a situation. Like a conversation, it is dependent on feedback and interactivity. This requires the existence of "separate" entities that interact and communicate with each other. We have identified these entities as the eye, brain, hand and most importantly, the sketch (Chapter Five). We have distilled these entities to two: the head - which produces ideas and the hand - which interprets and represents the ideas in a spatial and physical sense.

Through empirical evidence (Chapter Six), we have subsequently determined that the more expert the hand is, the more able it is at assisting the head in addressing the design task. As revealed in the double $\mathrm{h}$ experiments, students responded well to this kind of intervention. While being a little intimidated by the other person (the practitioner) the student was able to design in a focused and satisfactory manner. This intervention, however, requires having "someone" who rationally deduces the design problem/situation make-up, asks the right questions or provides the right clues that enable the student to tackle the problem. Since it would be expensive and time consuming to provide such a person for every student while they were engaged (at all times) with a design problem, it would be prudent for this ability to be embedded in the design tools of the student. An option may be to empower the sketch, the main tool used by students to explore the notion of architecture. 
This gives some value to advocating a reconsideration of the sketch from being less passive in design to an interactive position where it prompts and cues the novice designer about aspects of the design situation. Prompting would make the sketch more legible to the novice designer. This would help students of architecture read the issues and elements of architecture existing in the sketch and determine how they can best be put together. For this to happen the sketch must be placed in such a position to best serve the novice designer. The sketch would not be seen as a mere tool but rather as a part of the zone of interaction through partnering with the novice. By emulating the expert hand and encouraging literacy, the empowered sketch would assist in transcending the novice's limitations. The value in empowering the symbiotic relationship between the two, lies in the benefits to the relationship between master and student.

Pursuing this direction necessitates the development of teaching aids, in which students (who have limited design vocabularies) are exposed to the myriad of issues involved in design. These teaching tools would exist in the empowered sketch. Empowerment is possible through the use of digital technology. With the current information explosion and the complexity of today's buildings, the computer is a precondition for the design process. The ability to provide and capture lots of information, and present faster ways of evaluating that information, attests to this. Because of this computers have the ability to provide us with clues other than just represent, analyse and/or test what we have done. The computer is therefore an important component when teaching young designers essential design skills. Having examined the problems in education and determined the value of the empowered sketch as an expert hand, we have now arrived at the third element in our trinity - the computer. What will be the computer's contribution to the trinity? 


\section{References}

Casakin, H., and Gabriela Goldschmidt. 1999. Expertise and the use of visual analogy: implications for design education. Design Studies 20, no. 2: 153-75.

Goldschmidt, Gabriela. 1992. Serial Sketching: Visual Problem Solving in Designing. Cybernetics and Systems: An International Journal 23: 191-219.

Goldschmidt, Gabriela. 1994. On visual design thinking: the vis kids of architecture. Design Studies 15, no. 2: $158-74$.

Hofstadter, Douglas. 1983. Gödel, Escher, Bach: An eternal golden braid. London: Penguin Books.

Kavakli, M., and J. S. Gero. 2002. The structure of concurrent cognitive actions: A case study of novice and expert designers. Design Studies 23, no. 1: 25-40.

Kavakli, M., M. Suwa, J. S. Gero, and T. A. Purcell. 1999. Sketching interpretation in novice and expert designers. In Visual and Spatial Reasoning in Design, edited by John S. Gero and Barbara Tversky, 209-20. Sydney, Australia: Key Centre of Design Computing and Cognition, University of Sydney.

Lockard, William K. 2000. Design Drawing Experiences, 2000 Edition. W.W. Norton \& Company.

Open Learning Technology Corporation. 1996. "Learning with Software: pedagogies and practice Learning Concepts.”. [cited 3 Jan 2002]. Available from

<http://www.curtin.edu.au/learn/unit/05474/lconcepts.htm>.

Suwa, M. and B. Tversky. 1996. What Architects and Students See in Architectural Design Sketches: A Protocol Analysis . 1st International Symposium on Descriptive Models of Design, 1996. Istanbul, Turkey. 
Part 03

Computers 


\section{Computers and Architectural Designing}

Does anybody remember that before CAD, architectural design also required aid? $J$. Frazer quoted in Asanowicz 1999:94)
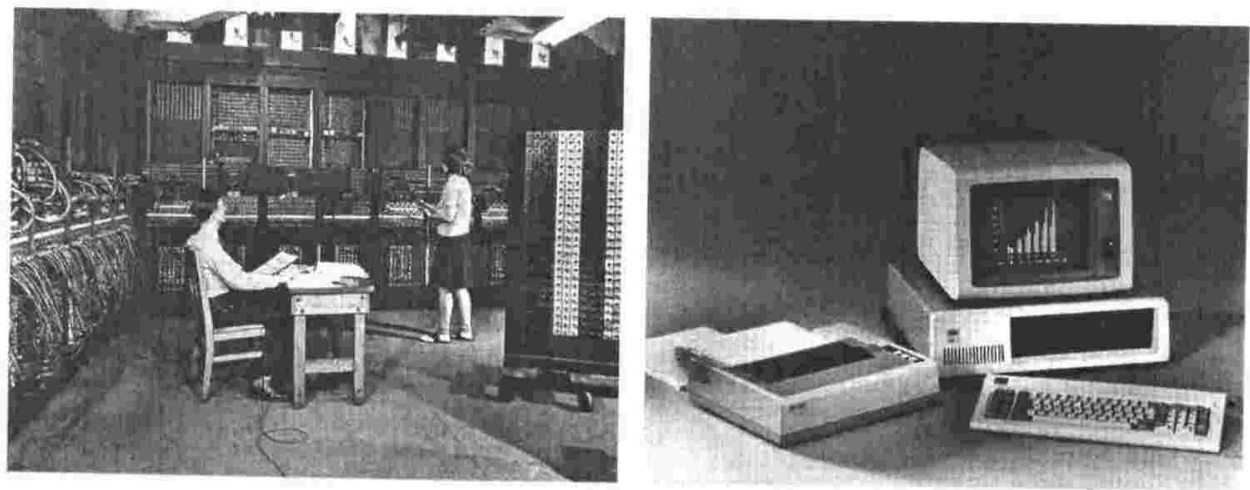

Figure 8.1 The ENIAC of 1946 (left) and the IBM PC (right). Notice the size of each computer. The PC was many times faster and powerful than the ENIAC a machine several times larger (Source: Fallon 1997:136 \& 159).

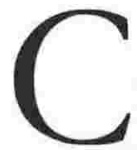

omputers are now a ubiquitous part of our lives. It has been over fifty years since the ENIAC appeared in 1946 and over twenty years since the advent of the personal computer. Since then, digital technologies (computers and supporting technologies such as miniaturised digital electronics and communications) have radically transformed most areas of life - media, commerce, education, entertainment, and simple day-to-day living. It is everywhere; the telephone, car, television and most objects we interact with in the physical world. How we live our lives, how we interact with each other and the value we attribute to information is vastly different from as little as twenty years ago. There is little doubt that the computer is the primary technological instrument at the turn of the $21^{\text {st }}$ century.

The computer has been (to one degree or another) a part of architecture for over forty years. During the last decade or so, it has also been a catalyst for change in the field. It has created new ways of realising and communicating our ideas significantly redefining the product and process of architecture. Evidence of this is present in visualisation techniques, form making, construction, 
building technology, and the current enthralment with virtual places. Interestingly, despite the overwhelming impact of technology on architecture, the design process has for the most part remained the same. Architects still use pen and paper to sketch and develop ideas in the early stages of designing.

Part three of this thesis is concerned with the issues that affect the use of computers in architecture generally and in architectural education specifically. It also completes the trinity (education, sketching, computers), which is inextricably at the root of this research. It aims to define, like the previous two sections, a recommendation that would allow an effective resolution to the issues that challenge architectural education.

This chapter - Computers and Architectural Designing - argues that while the development of digital representational tools (modelling, drafting) have achieved a considerable level of sophistication, the use of the computer as design support for the early stages of the design process has not been as advanced $^{26}$. It presents this argument by tracing the development of the computers in the field of architecture. Connections are established with such subjects as the design methods movement, computers for automated design support, the proliferation of the PC, computer aided drafting and the Internet. These are discussed within the context of the capabilities of technology, the relationship between man and machine, and the absence of the computer during the early stages of design.

These connections will be shown as important in defining a new paradigm for integrating the computer into the process. It will be argued that owing to the complexity of architecture today, there is a need to use digital technology to actively support the designer. This need will define the man-machine liaison, which, in turn, is directly analogous to the need for the hand to actively support the head for successful design. A link is made between the conversations the computer would have with the designer and a relationship between head and expert hand. The chapter concludes with suggestions for using the computer to more adequately support design decision-making especially in architectural education.

\footnotetext{
${ }^{26}$ This argument has gained some currency lately. It was the theme of the recently concluded ECAADE conference (Digital Design) in Graz, Austria held September 2003.
} 


\section{Computers: Architecture}

Like society, the computer has had a tremendous effect on the field of architecture. Computers exist in and influence all aspects of practice. Over the past few years, digital pioneers have demonstrated innovative uses for the computer in practice by developing buildings that embody in one way or another technology's effect on architecture.

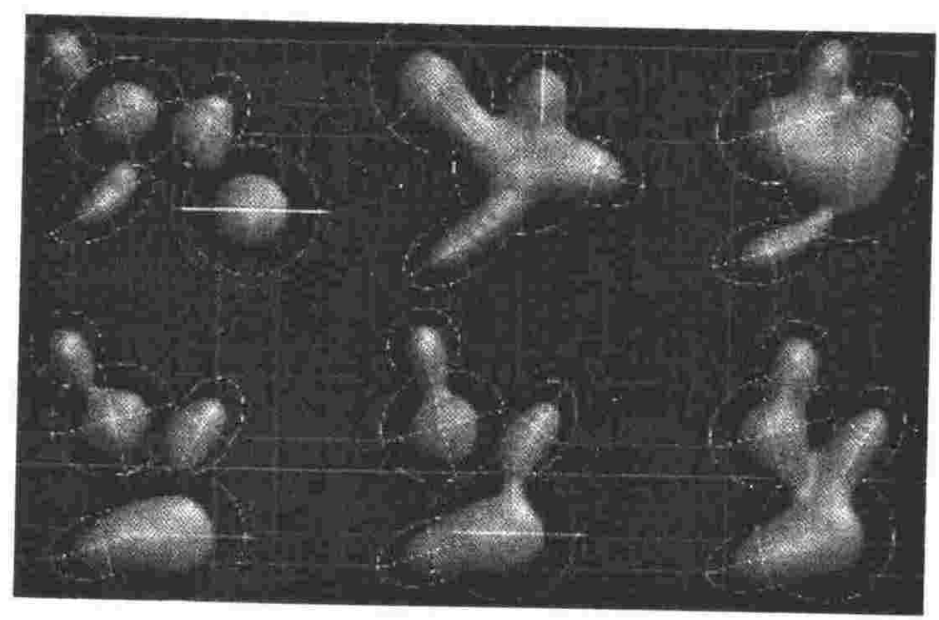

Figure 8.2 This image attempts to explain the use of the computer to generate forms through algorithms. Nodes within a field interact with each other as the computer calculates conditions of balance between the nodes. A state of equilibrium is achieved as the nodes (rooms) combine into a single surface incorporating the entire program. (Source: Pontgratz and Perbellini 2000)

New forms generated using computer algorithms and linked to the fields of morphology, metaphysics, ontology, cellular automata, and genetic algorithms are now emerging in the field (Figure 8.2). The process of architecture is changing also as the computer helps to document, organise, and store information; to visualize design alternatives and produce working drawings or models for construction in new effective and economical ways. The integration of CAD (computer aided design) and CAM (computer aided manufacturing) enables the rapid prototyping and flexible production of building components enabling mass customisation. Frank Gehry's museum in Bilbao, Spain is a welldocumented illustration of this (Figure 8.3). New building types influenced by digital technologies have also appeared along with the reconsideration of existing building types. Among the new building types are cyber cafés while around the world libraries are being redefined to facilitate digital media and other new forms of information sharing. A celebrated example of a 
reconsidered and new building type given form is Toyo Ito's Sendai Mediatheque (Figure 8.3).
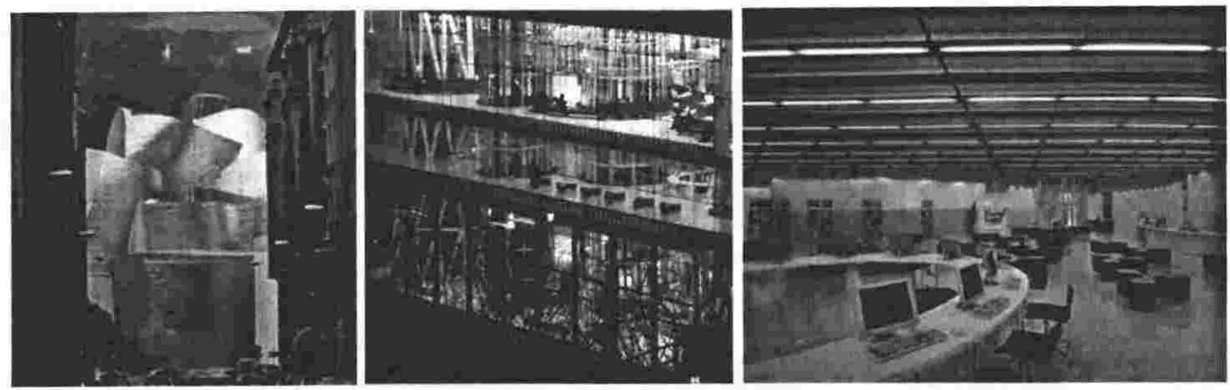

Figure 8.3 From left: The Guggenheim Museum in Bilbao, Toyo Ito's Mediatheque exterior and interior of information floor. (Source: Chollet 2001 and Barrie 2001)

Early in the 20th century, Le Corbusier proclaimed the house as "a machine for living"; today we inhabit "intelligent" buildings - spaces and places that have considerable computational power. The architect's palette now consists of smart materials, responsive building components, intelligent controls and networks. Throughout the life of the building the computer is used to support maintenance, monitor security and calculate energy consumption, while keeping track of building parts for possible re-use.

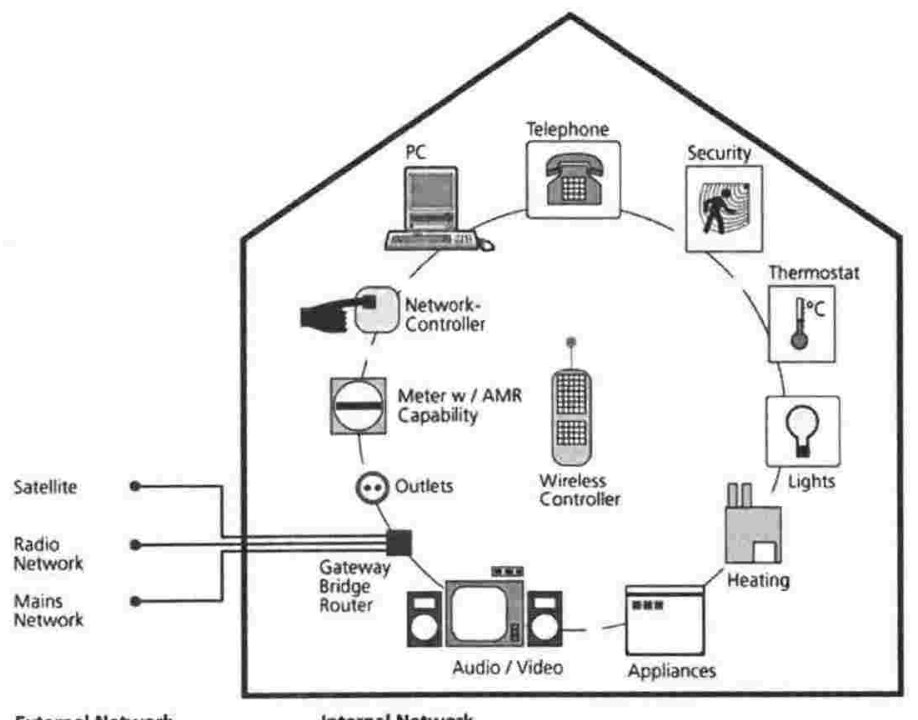

External Network

Internal Network

Figure 8.4. The intelligent house. (Source: unknown) 

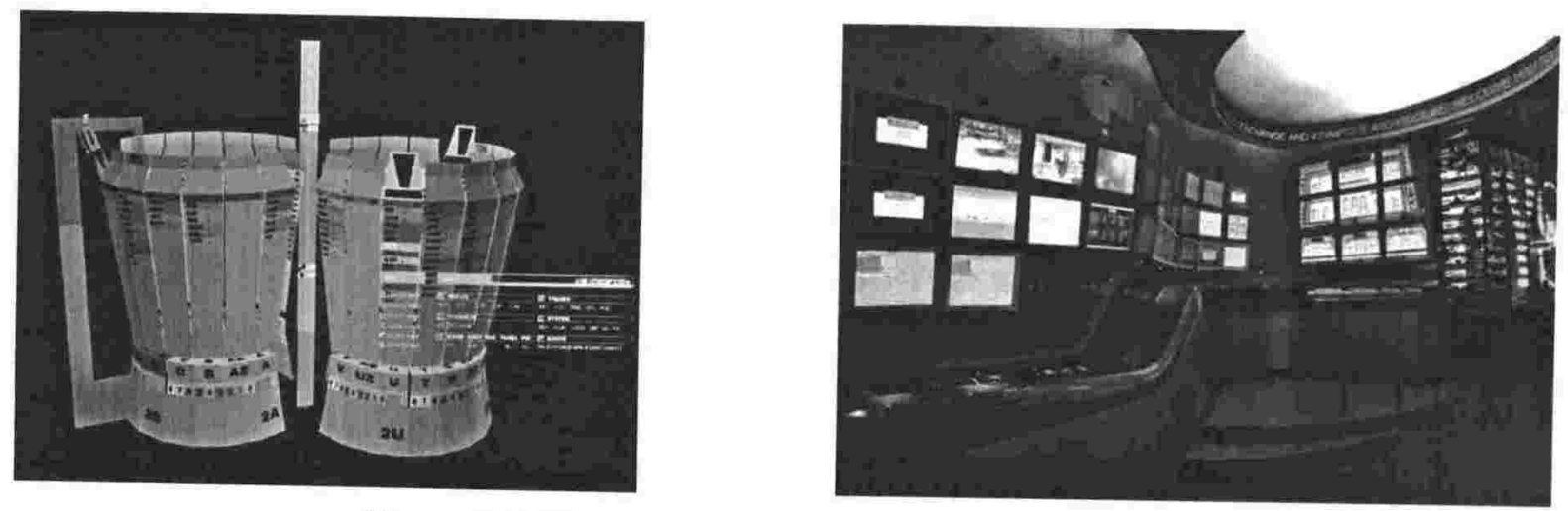

Figure 8.5. The Virtual and Physical Floors of the NYSE (Source: (online www.architect.org/features/nysecc/nysecc3.html and www.architect.org/features/nyse/nyse2.html)

The computer has enabled architectural debate to go beyond the physical. Architects are now exploring cyberspace as a design problem and integrating it with physical spaces to make "cybrids". A well-known example of this is the New York Stock Exchange (NYSE) where American design firm Asymptote designed the Virtual Trading Floor - an interactive architectural environment accessed on the computer. Asymptote also designed an Advanced Command Centre for the actual NYSE floor integrating its functionality with the virtual trading floor. These contemporary examples are clear indicators that the computer and related digital technologies have brought about a significant shift in how architectural practice is carried out and considered in the late 20th century.

Technology's influence is reflected in the computer's value to the designer's personal design process. Increasingly, traditional tools and design media (e.g. physical models, drawing, and photography) are being superseded by the computer. One reason for this condition is its efficiency in the architects practice. It is perceived as a tool that replaces existing tools and processes that are difficult, boring, tedious or expensive (Schmitt 1999). With it, tool and media are more integrated and interdependent than in a traditional drawing. The ability of the computer to both create and communicate causes a blurring between its use as tool and media. This interdependence is another of the reasons why designers consider the computer valuable.

Enabling informed decisions by allowing easy access to information is another advantage when compared to "existing traditional" tools. Design is an 
information rich activity. In it there is an inherent need to reconcile various bits of information and viewpoints. The ability of the computer to capture and communicate lots of information, present faster ways of evaluating that information, allowing more informed decisions makes it valuable for the design process. The computer, however, tends to be more effective at the design development stage where more "precise" information is required to make them truly effective.

Despite its influence and in spite of its advantages the computer is increasingly being associated with and focused on architectural representations and the manipulation of those representations (Tang and Gero 2001). This focus unfortunately does not include a perception of the computer as an able design support/aid resulting in the continued use of traditional media (pen and paper) to realise the first organisational notions of design.

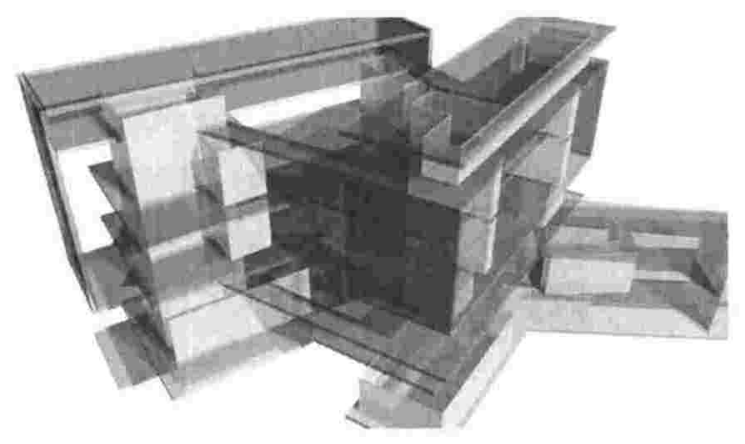

Figure 8.6 Digital Image created in design studio by a student (Source: Chris Hay, Victoria University)

\section{CAAD, CAD or CADD?}

When someone discusses computers in architecture inevitably the acronyms CAAD (Computer Aided Architectural Design) and the better-known generic term CAD (Computer-Aided Design or Computer-Aided Drafting) or CADD (Computer-Aided Design and Drafting) confuses the discussion. Before we discuss the use of computers in architecture it is important to give definitions for $\mathrm{CAAD}$ and $\mathrm{CAD}$ in relation to this thesis.

Research into the use of computers in the field of architecture is quite young having been around for less than 40 years. The original idea behind using computers in architecture (termed CAAD) was to enhance the built, physical environment by "providing the best instruments and methods for the creators 
of architecture" (Schmitt 1999). Since the 1970s and 1980s CAAD went on to become associated with productivity, communication and representation. When one spoke of computers in the office then they were referring to computer aided drafting (CAD, CADD). The power, speed and versatility of the computer (hardware and software) has moved it from being a rather expensive drafting tool to the position today in architecture where it is sometimes considered by some as a medium (Schmitt 1999; McCullough 1996). Today the meaning of the "word" CAAD is still relevant even though the role of the computer in architecture is constantly changing.

In this thesis, the acronym CAAD will be taken as a synonym for the use of computer resources in the architectural design process generally. Computer applications that act specifically as tools for the designers will be referred to as CAD software. This includes applications for representation (drafting, 3Dmodeling, rendering, rapid prototyping, animation, etc.) while applications for simulation and analysis will be referred specifically as evaluation software.

\section{A Concise History of Computers in Architecture}

The previously mentioned confusion between CAD and CAAD is rooted in the dual histories of the computer in architecture. This duality is based on two different attitudes to research in the field of architectural computing. One attitude is based on design thinking and views the computer as a potential thinking design machine while the other is based on the visual nature of architecture and views the computer as a representation tool. Hwa-Ryong Lee elaborates:

...the first direction has tried to solve design problems by representing design knowledge, rules or principles in computers, the second direction has aimed to help designer (sic) to draw faster, or produce photo-realistic renderings and animation in real
time (Lee 1999).

In the context of this thesis it can be suggested that the first attitude is related to the role of "head" in the design process whilst the role of "hand" is embodied in the second approach. The two approaches have emerged parallel to each other with one or the other dominating the attention of researchers from one decade to another. 


\section{The Early Years}

Writers and commentators on the visual use of computers in architecture consider Ivan Sutherland's doctoral thesis at the Massachusetts Institute of Technology (MIT) in 1963 as one of the primary starting points for CAD (Schmitt 1999; Lee 1999; Fallon 1997). In his thesis Sutherland suggested several areas where computer graphics could be useful (Fallon 1997) namely:

- Creating highly repetitive drawings

- Making changes to existing drawings

- Gaining scientific or engineering understanding of operations that can be described graphically

- As graphical input to computational programs requiring topological data, e.g. structural analysis programs.

The work was seminal and far reaching as concepts like interactivity, modular design, and object-oriented modelling that Sutherland presented in his thesis are still valid today (Schmitt 1999).

Sutherland's ideas contributed to the first computer graphics program SKETCHPAD, which was developed at MIT on a TX-2 computer (Fallon 1997). "Drawing" was done on the display with the use of a light pen and commands were entered using push-button controls - there was no keyboard or mouse. SKETCHPAD was used to create a wide variety of drawing types: electrical, mechanical, scientific, mathematical and animation, and while it supported only lines and arcs it had some of the capabilities and indeed requirements of modern day CAD programs, for instance - groups, symbols, copy, rubber banding, and snapping (Fallon 1997). 


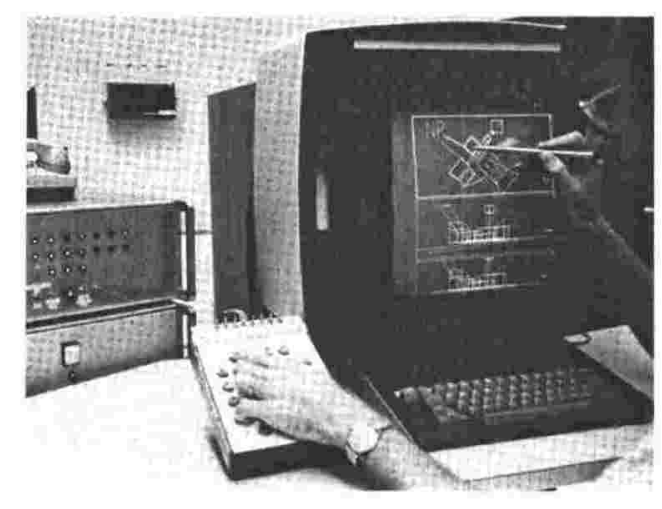

\section{Figure 8.7 A similar system to Sketchpad (Fallon 1997)}

The application of SKETCHPAD as a "drawing tool" was hindered, however, by the lack of speed and power needed for the graphic capabilities of the computer. Graphical capabilities would have made such a tool desirable and widely used. The lack of speed and power was eclipsed however, by its number crunching capabilities. This was evident from as early as 1958 when the computer was used in tasks that fully exploited the calculation power of the machine. These included such tasks as accounting; space programming and inventory analysis; project management and scheduling; cost estimating; energy analysis; specifications and plan optimisation.

\section{Design Methods Movement}

Parallel to these developments, was an increased interest by researchers in the possibilities of systematic design methods. The rapid advance of technology and consequential complexity of the design task in the late fifties and early sixties increasingly rendered the traditional process of design unable to cope. New and larger scale design tasks, new building types and new materials for which there was no precedent demanded a means of design appropriate in application to these new design tasks. Christopher Alexander outlined the problems facing designers in the introduction to his book Notes on the Synthesis of Form written in 1964:

Today more and more design problems are reaching insoluble levels of complexity. This is true not only of moon bases, factories, and radio receivers, whose complexity is internal, but even of villages and teakettles. In spite of their superficial simplicity, even these problems have a background of needs and activities which is becoming too complex to grasp intuitively. 
...the problems increase in quantity, complexity, and difficulty; they also change faster than before. New materials are developed all the time, social patterns alter quickly, the culture itself is changing faster than it has ever changed before.

The intuitive resolution of contemporary design problems simply lies beyond a single individual's integrative grasp (Alexander 1964).

He went on to claim that this confusing array of information had an effect on the forms produced at the time:

To match the growing complexity of problems, there is a growing body of information and specialist experience. This information is hard to handle; it is widespread, diffuse, unorganized. Moreover, not only is the quantity of information itself by now beyond the reach of single designers, but the various specialists who retail it are narrow and unfamiliar with the form-makers' peculiar problems, so that it is never clear quite how the designer should best consult them. As a result, although ideally a form should reflect all the known facts relevant to its design, in-fact the average designer scans whatever information he happens on, consults a consultant now and then when faced by extraspecial difficulties, and introduces this randomly selected information into forms otherwise dreamt up in the artist's studio of his mind. The technical difficulties of grasping all the information needed for the construction of such a form are out of hand - and well beyond the fingers of a single individual.

... if we look at the lack of organization and lack of clarity of the forms around us, it is plain that their design has often taxed their designer's cognitive capacity well beyond the limit (Alexander 1964).

To deal with the increased complexity in design, researchers made a determined attempt to develop processes that were relevant to these new tasks and that went beyond the limitations of the traditional design process. Through their research they sought ways and methods of enabling architects to deal with the amount of information and processes in efficient and rational ways. In the search for more explicit and rational processes of decision making design researchers discovered the systems or mission oriented approach.

Systems research or systems analysis was basically about developing techniques for examining existing systems as well as the designing of new ones (Cherry 1998). It emerged from the increased scientific activity of the "space race" as a means of flawlessly coordinating the various technological systems required for space travel (Cherry 1998). According to Rittel:

It was the outsiders who had heard about this and read about this in the emerging literature. I think that in the beginning, outsiders from architecture, engineering and business heard about the methods of the systems approach and thought that if it were possible to deal with such complicated things as the NASA programmes then why couldn't we deal with a simple thing like a house in the same way? Shouldn't we actually look at every building as a mission-oriented design object? (Rittel 1972). 
The resulting research which responded to the question of how designers (should) design and related it to systems analysis was called design methods research or design methodology. Some of the earliest work in the field took place in Europe (Britain and West Germany in particular). In West Germany work was done at the Hochschule fur Gestaltung (HfG) Ulm, under Horst Rittel, who later moved to Berkeley in the 1960s. In Britain, research was documented through the work of Bruce Archer, John Christopher Jones, Christopher Alexander, Geoffrey Broadbent, and others. Of the Britons, the two most significant figures of the movement were Jones and Alexander (though their work developed independently). Jones co-organised the first conference on design methods in London in 1962 and in 1970 published the first edition of Design Methods, a compendium of thirty-five different design methods that was to become the standard textbook on the subject (Cherry 1998). Alexander attended Jones's conference and two years later published his own book Notes on the Synthesis of Form, which was influential to the ongoing debate of the design methods movement.

\section{Aims of the Movement}

Although the main players had different ideas about defining design methods there were common intentions. Among these intentions:

- They intended to design better by understanding the design process.

- They hoped by understanding the process they could externalise it enough to allow large teams to collaborate from the conceptual phase allowing more complex designs.

- They also focussed research on the teaching of design. It was assumed that:

...clear descriptions of the process of design decision making could be communicated to design students. The learning of process in lieu of the learning of a designer's style was seen as healthy and applicable to more situations. A student who was exposed to a variety of design methods could select the process most suited to his or her personal characteristics (Cherry 1998).

To achieve these goals researchers attempted to alter

..the nature of the design process itself by replacing the principal design technique of the industrial era - 'design-by-drawing' - with other, more abstract, methods that 
permitted a greater "perceptual span" than was possible with traditional design methods (Mitchell 1993).

One of these abstract methods implicated the use of computers to automate the repetitive parts of the design process as well as develop new strategies.

\section{CAAD and the Design Methods Movement}

The application of computers to the design process was partially a consequence of the design methods movement. While CAAD was not the main concern of the movement a few researchers theorised that the chaos at the start of the design process was the natural consequence of information overload, in which case the power of information processing machines might prove useful (Milne 1975). They believed that the computer provided the means of significantly changing the way design was carried out. The real potential of the computer in architecture was not made clear until Christopher Alexander in 1963 presented his paper on the design of an Indian village in which he illustrated how complex design problems could be broken into simpler component sub problems. In his paper he made specific reference to his use of an IBM 7090 computer in calculating the breakdown of his components (Alexander 1963). Combining systemic design methods with computer technology revealed the possibility of the computer radically transforming the design process. As a result of this, the goal of automated design was actively pursued.

\section{The Design Machine}

By the end of the $1960 \mathrm{~s}$, research into architectural computing went in the direction of intelligent environments that tried to solve design problems by representing design knowledge, rules or principles in the computer (Lee 1999). The model of designing used by these groups focussed on an understanding of design as postured by J.C. Jones and others in the design methods movement. In addition to this "understanding", CAAD research utilised ideas from other fields - such as artificial intelligence - and energy was spent developing algorithms that "automated design". A well-known example of this approach was the Architecture Macbine by Negroponte and others at MIT. Taking the 
position that "a machine could do anything better than an architect could do it" (Negroponte 1970), the purpose of the group was to:

....achieve intimate machine - environment interaction (where environment could be buildings as well as people) such that a machine could enjoy, or at least understand, some of the meanings we as people and users of architecture (attach) to our built environment (Negroponte 1975).

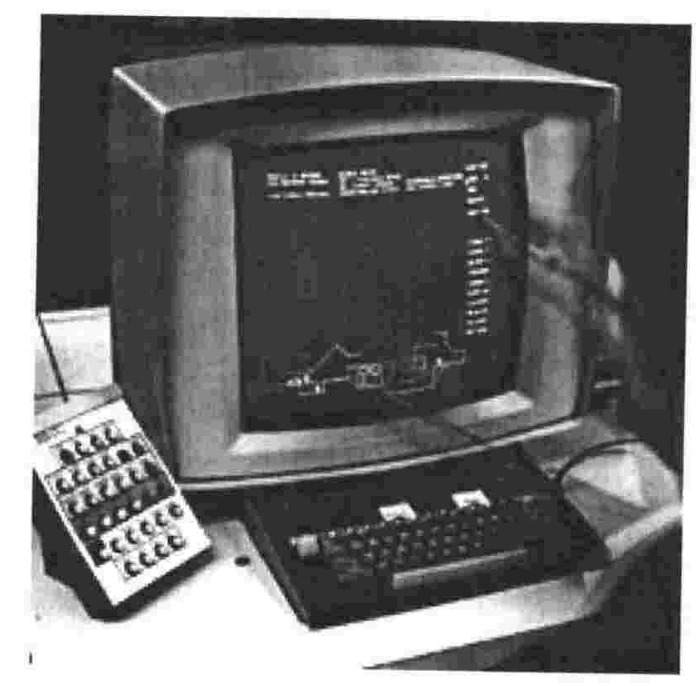

Figure 8.8 The Architecture Machine (Source:

http://depts.washington.edu/dmgmedia/0.ntt_cs/1.introduction/3.ArchMaq.html)

The possibilities of design automata were investigated by both academia and practice. Due to the price and expertise needed to run the machines, only a handful of academic laboratories were engaged in this research, for example the ABACUS lab at the University of Strathclyde, and the Architecture Machine Group at MIT. In practice, the expense of the large machines meant only a few large design firms had access to them developing their own software to help in the design process. In both groups the capabilities of technology facilitated the use of the computer as calculation tools related to systemic analysis and evaluation. When implemented, design decision support by the computer tended to be either generative or evaluative. Generative software usually produced "jumping points" (optimised floor plans, structural diagrams) when relevant data was input by the designer. Evaluative software on the other hand analysed the design data input in the computer and returned a score (degrees of good, bad or ok), which the designer used to inform the next iteration.

An example of a generative program is the Building Optimisation Program (BOP) developed by Skidmore, Owings and Merrill (SOM), one of the more 
active firms in this area. When given the desired square footage and the dimensions of a site, BOP used rules of thumb to determine the number of floors and number of elevators; it then designed the core, optimised the structural bay size and generated a preliminary cost estimate. In the beginning it would output a floor plan on a printer, and then later on a plotter. Another generative program SOM also developed was a hospital programming application (that generated detailed space programs for hospitals on a department-by-department basis). A helpful program also developed was SARAPI (Storage and Retrieval of Architectural Programming Information). This was used to store and analyse program information gathered in client interviews (Fallon 1997).

One instance of an evaluative program was Package for Architectural Computer Evaluation (PACE). Developed by the Building Performance Research Unit at the University of Strathclyde, PACE undertook the appraisal of a set of criteria relevant to built form layout and was intended to be used at the outline proposal stage of design (Markus et al. 1972). The architect inputted information about the project being considered by means of a teletypewriter into a timeshare computer. This information included building type, location, number of occupants, geometrical information (broken into spatial elements, floor height, shape etc.), site geometry, construction (glazing, insulation) and activity. The computer then presented to the designer: costs (capital and running), spatial performance, environmental performance and activity performance. The computer at the end of the output invited modification of the input information, asked the designer to qualify the design performance (good or bad) and printed a paper tape that could be used to generate eight perspectives of the proposed project. In light of the output the designer then chose to redesign or re-examine the original scheme.

The initial energies of the researchers promised an improvement in the quality of architecture through the possibility of an automated design process. Researchers strove to discover a means of modelling how designers think so as to produce software (or hardware) that executed all or parts of the process. The apparent numerical, logical and rational capabilities of the computer facilitated this exploration and thus the role of drawing or visualising was not paid much 
attention. The search proved difficult however since most of the models prescribed and coded had little to do with how architects actually designed. This was ultimately the stumbling block of this research direction.

\section{Fall of Design Methods Movement}

The 1970s witnessed a waning in interest and change in attitude towards design methodology. Despite lots of writings and academic posturing, there was no practical evidence of actual use of the methods that could justify the arguments of the protagonists. Horst Rittel (1972) himself when asked what kinds of problems design methodology had successfully tackled replied that he did not know of any building that had been "done discernibly better than buildings done in the conventional way" (Rittel 1972). In 1971 Alexander himself felt that the development and study of design methods had failed to contribute to better design. His advice at the time to other researchers was to "forget it; forget the whole thing" (Cross 1984). Archer himself regretted wasting time:

In retrospect, I can see that I wasted an awful lot of time in trying to bend the methods of operational research and management techniques to design purposes (Archer 1979).

The unpredictable and contradictory nature of the design process contributed to this new attitude. Even though the movement had been going for about a decade, the first known attempt to discover how designers actually designed was in the early seventies when a group of designers were analysed designing a bathroom (Eastman 1970). With this and similar research, researchers slowly realised that the systems engineering techniques of military and space missions were not suited to the "wicked" problems of planning and design (Cross 1984). One example of this questioning influenced by the new evidence is the ever changing "models of design". The more researchers observed designers, the more design models were redefined. In the sixties when the field tended to be prescriptive (mostly on paper) the design task was separated into two stages analysis and synthesis or programming and design. This model however was based on the assumption that a design problem could be examined and understood before designing itself took place. After observing and interviewing designers the later analysis - synthesis - evaluation model was refuted by some researchers who claimed an alternate model of conjecture - analysis (Lawson 1984; 
Broadbent 1984) or in the case of Darke (1984); generator - conjecture - analysis (Darke 1984).

Despite empirical studies, researchers still attempted to apply science to design methods. For instance, Broadbent (1984) offered conjecture - analysis as a model for a third generation of design methods. He based it on Karl Popper's "conjectures and refutations" model of scientific method. In Broadbent's opinion, the role of the designer was to make expert design conjectures, making them open to refutation and rejection by the people for whom they were made (Cross 1984). This opened the door to participatory or argumentative design.

These revelations sought to redraw the problem of automated design. The design process at this point had been developed and promoted within theoretical frameworks as rational and capable of being programmed into the computer. In trying to present (or prescribe) the design process as rational or logical, researchers discovered the following:

- Design processes take several forms depending on the individual. It cannot be predetermined.

- The design process according to commentators is neither linear nor logical (Lawson 1997). It is an iterative process that involves a lot of to and fro before even the first presentation for criticism.

- An exact methodology was limited to the solution of functional problems (Asanowicz 1999).

These facts influenced researchers to radically rethink CAAD.

\section{The Second Decade}

Coinciding with changes in the approach to design methods was a significant change in direction of CAAD. The "fall" of the design methods movement during the 1970s, meant disillusionment with the feasibility of an intelligent machine, which was based on a rational model of design (Bazjanac 1975). Research shifted from the intelligent machine that in Negroponte's words "generates design with little human intervention, interpret sketches and diagrams and modify occupied environments" (Negroponte 1975) to the 
computer as a graphic tool. The difficulty of realising intelligent systems based on design reasoning thus contributed to increased research interest in simple drafting systems.

The advent of the storage tube graphic display from Tektronix (Figure 8.9) contributed heavily to this direction also. This was reinforced by an increase in the number of in-house minicomputer systems that were powerful enough to handle graphics.

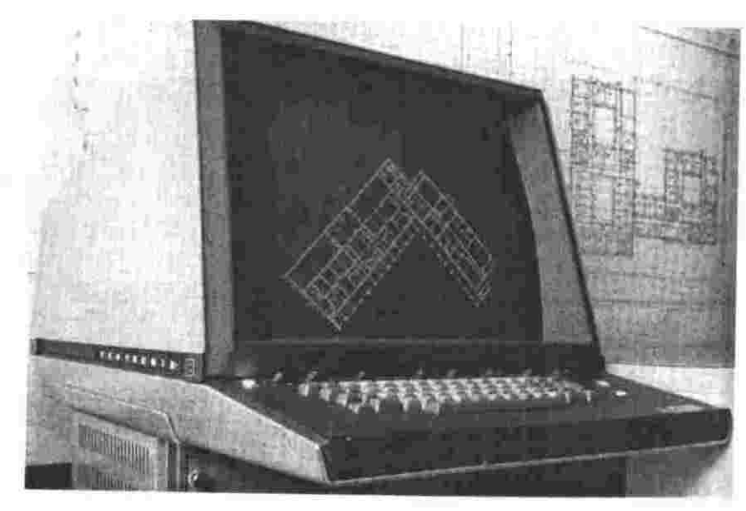

Figure 8.9 Tektronix 4014 (Source: Fallon 1997)

Maver reminisces about this:

These devices triggered frantic research and development effort to encode the mathematical laws of perspective geometry in order to generate 3-D 'wire-line' representations of building; the early algorithms were not sophisticated enough to supptess the "hidden-lines" which had to be removed manually, one by one! (Maver
1998).

The most popular use for these machines in addition to engineering tasks (structural analysis and design) was 3D mass modelling. The tasks however tended to be evaluative as they were sometimes used to investigate visual impact in urban and rural contexts.

Design support continued in the form of purpose built integrated CAAD systems which found actual everyday use in real public sector organisations like the Scottish Special Housing Association (SSHA) (Tweed and Carabine 1999). Unfortunately the difficulties of maintaining software to meet the escalating expectations of the end user marked the end to large-scale university based CAAD (Tweed and Carabine 1999). Commercial software developers in 
contrast concentrated on more generic products (mainly $2 \mathrm{D}$ drafting) that appealed to a much wider market than architects. Architects and engineers still developed their own design software with some using the commercial products as platforms for their own software development. The primary use of the computer consequently became a tool for representation.

\section{The PC Revolution}

In 1981 IBM introduced the 5150 PC and redefined the notion of computing. The personal computer ${ }^{27}(\mathrm{PC})$ removed the computer from special rooms in academia and corporate headquarters and placed it onto the desks of the workers facilitating the personal workspace and individualised computing. The introduction of the Apple Macintosh in 1984 brought the Graphic User Interface (windows, clicking as against typing) and the mouse as the main interaction with the tool eliminating the command line and improving ease of use. The PC also turned the computer industry on its head making the development of software into the most lucrative sector of the industry and negating "personal programming". Twenty years later, the PC is as ubiquitous as a household appliance (more than half of all U.S. households have one).

Architecture and its relationship with the computer changed dramatically with the introduction of the PC. In 1976, 30 percent of the 2500 most active architectural and engineering firms in the United States were involved in computing (Radford \& Stevens 1987). By 1981, the year of the PC, the number of firms using computers grew to 65 percent (Radford and Stevens 1987). The increase in architectural consumers created a market for the wide variety of commercial CAD software with a broad price range (Fallon 1997).

The 1980s also oversaw a gradual diversification in computer use in practice. At first, the use of computers for office management tasks like word processing, specification writing, spreadsheets, and project scheduling and cost management far outweighed the use of computing as a standard tool in the architectural design process. Drawing boards and sketchpads existed for some

\footnotetext{
${ }^{27}$ The personal computer was not a new concept as Apple Computer had released a successful "desktop" computer 5 years earlier and Hewlett-Packard had used the term "Personal Computer" as far back as 1968. It was however the entry of IBM into the market that gave legitimacy to the concept of the personal computer and hence its popularity.
} 
period alongside the new tool. The steady increase in power and reduction in the cost of hardware eventually made commercial CAD systems popular in design practice (Lee 1999). This popularity created vigorous competition between $\mathrm{CAD}$ vendors ensuring rapid improvements in usability and features along with steady price reductions. Design firms eventually retreated from developing their own software to buying off-the-shelf "solutions" bolstering the commercialisation of CAD.

In due course, the driving force behind computers in architecture became productivity. The perceived benefits of the computer outside of being a management tool were efficiency and speed and thus it was used almost exclusively for production drawings. Firms set up special "departments" made up of CAD personnel (somewhat like architectural draftsmen) who would input design data manually generated by the designers into the computer. A cursory review of mainstream architectural magazines of the 1980 s reveal debates about whether the computer was worth the investment, hype and promises of academics and enthusiasts. Such was the attitude towards computing that the worthiness of the computer in practice was evaluated by comparing its relative cost (still expensive) to a drafting table. Little was said however about the computer's worth as a support for design.

If the $80 \mathrm{~s}$ witnessed the inauguration of architectural computing in the mainstream of architectural training and practice, the 90 s firmly established digital technology in the field. With faster, cheaper hardware and multi-featured software, the affordability and flexibility of the personal computer moved it from the offices of medium to large sized design firms and into small or single person firms and architectural schools. The prevalence of three-dimensional (3D) modelling, rendering, animation and multimedia presentations broadened the emphasis from only production to include schematic design and design development. CAD became a necessity in every architectural office; in much the same way word processors completely substituted typewriters. By the end of the 90 s, in relation to advances in technology, the use of the computer focused on more sophisticated data representations. In this environment, the CAD industry prospered, relegating the use of the computer to a little more than an electronic pen. The design of new standardised, general-use CAD applications for PCs 
were focussed on enhancing the production of images, rather than helping architects design in the early, conceptual stages of design.

\section{The Information Superhighway}

The globalisation of architecture and further developments in technology moved CAAD further away from the design machine scenario. The Internet, a global network linking millions of computers, grew in the $90 \mathrm{~s}$ from a government and academic niche to a mainstream communications medium. Its effect on architectural computing was evident, as architects turned to network collaborative tools and Internet-based communication to facilitate project coordination in the mid-1990s (Allbritton 2002; Laiserin 2002). The benefits of extranets (private networks on the internet) seemed obvious and project web sites were touted as a necessary part of practice. Project extranets were said to allow everyone on the project team the ability to work from the latest set of CAD drawings, with a record of e-mails and other documents for all to see, creating a reliable paper trail.

\section{Design Research during and after the 1980's}

In the field of design methods, the period of the 1980's initially saw a marked change of focus or interest. The study of design was no longer directed towards an improved or effective process. Rather, it was directed towards the development of cognitive models that could aid in the development of computational design tools. The field of design studies had once again become closely aligned to the field of CAAD.

This was seen clearly in the formation of research centres that focussed on integrating both fields. The centre that demonstrates this trend quite distinctly is the Key Centre of Design Computing and Cognition at the Faculty of Architecture, University of Sydney. The goals of the centre include:

- developing "theories, models and methods of designing as a process" (Gero and Maher 1997). 
- using the theories, models and methods of design as the basis for "considering computer support or automation of specific design tasks" (Gero and Maher 1997).

The emergence of advanced hardware and software technologies supported this direction, as researchers saw the potential for the expert support systems that developed from techniques already established in artificial intelligence (Lee 1999). The main goals of artificial intelligence, a long standing branch of computer science, is/was to build machines that demonstrate the ability to learn and reason, pattern recognition, understanding of speech and consciousness, all of which are features of human intelligence (Zarnowiecka 1999). These goals hence found form in expert systems (which at present perform such complex tasks like financial problems, air route planning, and playing chess).

The development of expert or intelligent systems in architecture, however, evolved very little. Despite new AI technologies like neural networks and fuzzy reasoning, researchers found expert systems unable to deal with ambiguous information (much like that found in the design process). Progress required a closer understanding of how designers actually design. To develop this understanding, projects in design methods research included direct observation of designing, surveys of designers' perceptions and, protocol studies of individual and collaborating designers. The expected result of this was a determination of design behaviour, "which has significance for the development of computational tools for designers" (Gero and Maher 1997). This determination, however, revealed the difficulty of applying computers to the design domain. CAAD research as a consequence shifted "from the automating or reasoning of design to the more sophisticated design tools" (Lee 1999) of CAD.

\section{Current State of the field}

In architecture, at the start of the twenty-first century, the computer is responsible for impressive images, the analysis of proposed solutions and the communication of ideas. The role of the computer in architecture (practice, research and education) has expanded from being a dream of select researchers to encompass four main roles: 
Visual Representation - In 2003, the speed and power of technology has fostered the proliferation of multimedia tools and revolutionised how architects present and propagate their ideas. The computer is increasingly being used to replicate drafting, simulate perspectival views and "construct" sophisticated, photorealistic images. Architectural experience is further represented temporally through the use of walkthroughs and associated animation software that create fully immersive virtual realities.

Information Processing - The number crunching tasks afforded the computer in the past has been enhanced with an exponential increase in processor speeds and vast memory storage. This increase in the information processing capabilities of the tool has been recognised and exploited through the use of specialised databases, facility management software, project management software and other tools that add value to practice. Not only has the ability to manipulate information enhanced practice, but also the ability to numerically translate information has allowed the construction of previously "unbuildable" forms through Computer Aided Manufacturing (CAM).

Simulation modelling - Increasingly, the computer is being used as a design aid that evaluates prepared solutions. Increased sophistication in these evaluation tools has produced extremely accurate lighting simulators, embodied energy simulators, environmental analysis tools, room acoustic simulators and other such tools. It is widely acknowledged that access to this information allows the designer the opportunity to make more informed decisions about the design of buildings. Unfortunately, for this information to have value, quite precise information has to be supplied at a later stage of the design's development.

Communication and collaboration - The advent of Internet technologies and innovative web tools has created the proverbial global practice. The connectivity afforded by these digital tools has boosted new levels of coordination in the building industry as Computer Mediated Collaboration processes connect industry players separated by space and time.

This array of impressive applications establishes the computer at the centre of the architect's craft. Despite this significance, computers exist in architecture today without challenging or reassessing how the early stages of design could 
generate architecture that was sustainable, cost-effective and a delight to users. Direct and early use of computers as design tools in the architect's office is virtually nonexistent.

\section{CAAD Research}

A similar circumstance exists in the realm of CAAD research. CAAD research has expanded phenomenally to become a significant part of most schools of architecture. CAAD research units exist within leading universities and most schools have at least one faculty member who teaches and conducts research in CAAD. As a result CAAD research at present is extremely diverse and multi faceted. Research areas include:

Case Based Reasoning - using previous design episodes as starting points for new design.

Shape Grammars - realising the potential for automation of the design process through the definition of sets of grammar rules and vocabularies.

Computer Mediated Collaborative Design - investigating the combination of computers and the Internet to facilitate collaborative design between various designers.

Virtual Spaces - exploring the metaphor for physical spaces in the virtual environment for "socialising", "working" and "learning".

Evolutionary systems - using genetic algorithms in design to search for suitable values of design variables which achieve the best performances in a resulting design or designs.

Drawing Recognition - investigating representations of design information (graphic and non-graphic) for information retrieval, processing and interpretation.

Jabi 2001; Gero, Chase, and Rosenman 2001; Dokonal and Hirschberg 2003).

As demonstrated, CAAD research has certainly been impressive and farreaching. Like practice, however, priorities in research have focussed on the integration of design and construction through better information management, communication and the improvement of visualisation tools. Any research that 
deviates from this norm tends to be forward thinking and separated from existing challenges. While it is true that most mainstream software tools are the result of a ten to fifteen year research and development cycle, there is a need for research today to be more related to or immersed in defining a greater role for the computer in the design process.

\section{A New Paradigm}

It has been argued elsewhere in this thesis that design is analogous to conversations. If we use this analogy in the context of CAAD we will see that the computer has to some extent been involved in the conversations of designers. Originally, the proponents of the design methods movement observed that the quality of design conversations in design had deteriorated due the demands of technology and other factors. They sought to make these conversations more effective and efficient by prescribing systematic ways of designing and dealing with the content of the conversations. The computer, a logical systematic tool, was recruited as an intermediary in the conversations between designer and design ${ }^{28}$. Eventually researchers admitted that design conversations were "wicked". Design was no longer seen as rational or logical, but rather messy and indeterminate - something the computer simply was not. This nature of the design activity proved the computer was a bad candidate for direct intervention into design conversations.

Technology's capabilities (graphics) facilitated a different approach to the computer's inclusion into design conversations albeit in a somewhat lesser role. Focus was also directed towards other strengths of the tool, and computers are no longer seen as potential design support, but were rather used for the "printing out" and evaluation of concepts and ideas.

For the computer to be brought earlier into design conversations, the relationship between man and machine has to be re-evaluated. According to Terzidis (1999), there are three possible scenarios for the machine to relate to man in the design process. In the liaison, the computer can:

1. Complement the human thinker.

\footnotetext{
${ }^{28}$ During the 70 s the building user was included in the conversations through participatory design.
} 


\section{Extend the process of thinking.}

3. Replace the human thinker

In the first scenario, the computer provides useful information, advises, appraises and assists the designer. This scenario admittedly is the current situation of CAAD. It is especially seen in the use of CAD tools, evaluation and visualisation software. The current form of expert systems also exists within this sphere by providing the designer with useful information to be used as leverage during the design process. The computer becomes an amplifier (or tool) for the conversations.

In the second, the computer extends the designer's perspective by allowing the exploration of alternative possibilities. The introduction of new electronic media, fast computations, and large memory capacities has made it possible to visualise abstract entities, verify their existence and project behaviour. This is done through the use of mathematical models and simulations projected on screens as if they were physically there. In this scenario, the computer becomes the environment where the conversation takes place.

The computer has far superior intellectual capabilities than the human designer in the third scenario. This has been the main thrust of researchers as they strive to realise computers that simulate human thinking to such a degree that they perform tasks which are highly intellectual like design (Terzidis 1999). This, however, is a vision of the future and remains elusive, as long as there is still a lack of understanding of the learning, the creative, and judgemental processes that comprise design. In this situation, the designer is excluded from the conversation.

In 1970 Negroponte took the position that "a machine could do anything better than an architect could do it" (Negroponte 1970). In hindsight (and after 30 years of trying), this can be seen to be quite far from the truth. The human designer is no longer regarded as replaceable by the computer. Because we know little of the design process and we lack a comprehensive model for integrating the abilities of man and machine into a complete process, ways of amplifying the products of the conversation has been the focus of research. 
The scenario advocated by this thesis is to facilitate design, not automate it. It is proposed that this might be achieved by developing a practical symbiosis (between human and computer capabilities) where the division of labour is based on the strengths of the participants. The result would be a complementary, integrated relationship facilitated by the functional allocation of man-machine tasks. This is by no means an original idea, however, it needs restating. If this idea is pursued, the computer becomes a partner in the design conversations rather than a tool, environment or proxy.

It, therefore, becomes important to determine what properties of man and machine can be best exploited to facilitate or support design decisions. It has already been established that computers are poor at dealing with information that is half formed, fluid or partially defined. Unfortunately this is characteristic of the information used in design. Qualities like judgement, interpretation and creativity, that are needed to handle such information, are unique characteristics of human thought. On the other hand, humans are very slow in complex calculations or in memorising large amounts of information, while a major advantage of the computer is high-speed computation or sifting through large volumes of information.

This association implies a role for the designer that emphasises the processing of high-level abstract information. A complementary role for the computer would be to sifting through vast relationships, calculating and making connections between pieces of information.

While it may take time to adequately allocate the optimum tasks the notion of strength allocation is relevant to the notion of experts and novice. This partnership is directly analogous to the need for two "expert hands" to actively support the novice head for a learning design conversation. The tutors ability to use experience and intuition to qualify a given design situation is best supported by the computers ability to sift through lots of information.

It is argued that owing to the complexity of architecture today, there is a need to use digital technology to actively support the designer. While it seems likely that computers can co-exist or complement in the design environment with man, it is important that the computer plays an integral part in the transmission 
of knowledge and assisting the designer grasp the issues that affect design today. Similar to the notion of the design conversation is the student/tutor conversations. The role of the computer can therefore extend to play an active and complementary part in the dialogue. The strengths of the human tutor lie in judgment and intuition while the strength of the computer expert lies in presenting information about the issue for discussion.

\section{Conclusion}
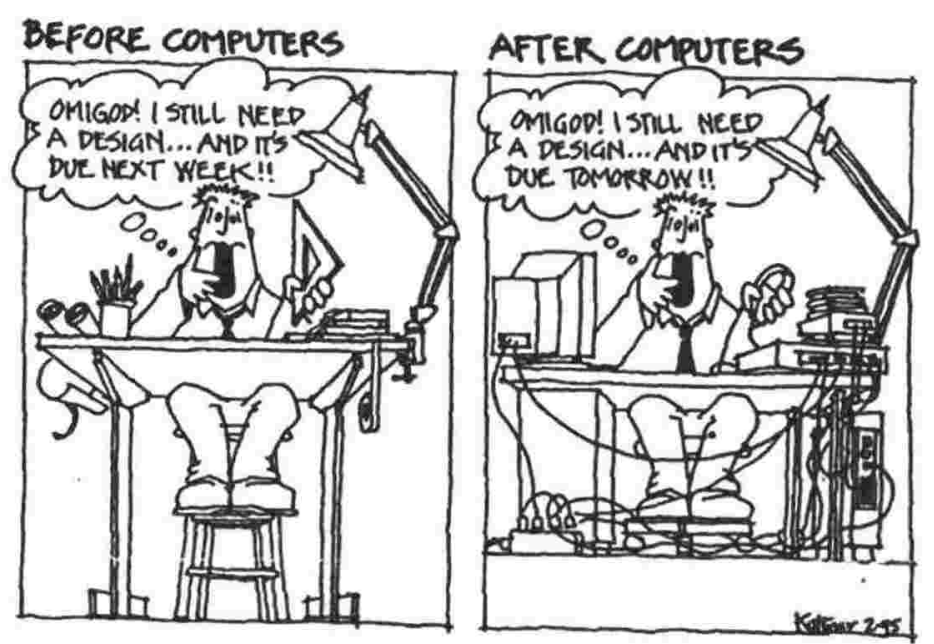

Cartoon by Prter Kuttner, AIA, of Cambridge Seven Associates, Inc.

Figure 8.10 The Computer - before and after (Source: Pressman 1997)

Computers have been a part of architecture for the better part of 40 years. It has developed from the calculation tools of engineers through drafting systems to being the quintessential tool in the practice of architecture. During this transformation CAAD research has shifted between two alternating foci: the computer as a thinking machine (to emulate design - generation, analysis, evaluation); and the computer as a representation tool (drafting, modelling, representing environments). Of the two approaches, the latter prevails today as the primary application of CAAD.

In the early years of CAAD, computer graphics was stunted by the lack of speed and power needed to manipulate information graphically. Instead, and using related research in design methods, researchers used mathematical models and systemic design methods in a bid to automate a (perceived) rational design process. This proved difficult as researchers soon discovered that their 
assumptions about and prescriptions for design did not reflect the "wicked" problems that characterised architectural design. At the time of this realisation, graphics technology became faster and more powerful shifting the utilisation of computers to favour visual tasks. The emphasis of CAAD research subsequently changed from number crunching intelligent systems to more graphical uses like 3D wireframe modelling.

The introduction of the PC in the eighties brought an increase in access, speed and power which intensified this change. Widespread computer use in practice was influenced by the quick development and popularity of computer graphics, the simplification of $\mathrm{CAD}$ systems for personal computers and easy to use hardware and software. With the use of commercial CAD software, drafting and visualisation dominated use while rendering and animation technologies made possible the production of sophisticated, photo-realistic images and virtual environments.

Technology advances in the nineties reignited an interest in artificial intelligence and expert/intelligent systems which even though it remained restricted to academic research, sought to investigate issues of automated design. The inherent difficulties in automating design beyond a few labour intensive tasks were highlighted through the failure to make up any meaningful ground. Since the turn of the century, the increased capabilities of technology notably in the area of graphics and communications (internet and related technologies) has helped to shift focus further away from design decision support.

At the start of the $21^{\text {st }}$ century, it can be argued that computer aided architectural design (CAAD) has made little impact in terms of actually aiding design. Experiences within research communities have shown that the implementation of computer applications in an early stage of the architectural design process still seems to be limited. The power of the computer as a design tool and as a design stimulator is still to be fully exploited.

Fresh effort needs to be directed at exploring a new paradigm where the computer is seen as complementary support to the designer in design conversations. Using the computer to expand the capabilities of the designer can only enhance the design process. Similarly, energies need to be invested in 
determining and exploiting the strengths of the computer needed to enhance and extend the zone of interaction.

\section{References}

Alexander, Christopher. 1963. The Determination of components of an Indian Village. In Conference on Design Methods, edited by John Christopher Jones and D. Thornley. Oxford: Pergamon.

Alexander, Christopher. 1964. Notes on the Synthesis of Form. Cambridge: Harvard University Press.

Allbritton, Chris. 2002. "Extranet use among architecture firms is hampered by skepticism." March 2002. [cited December 2003]. Available from $<$ http://archrecord.construction.com/features/digital/archives/0203news-2.asp >

Archer, L. Bruce. 1979. Whatever Became of Design Methodology? Design Studies 1, no. 1: 17-18.

Asanowicz, Aleksander. 1999. Evolution of Computer Aided Design: Three Generations of CAD. In Architectural Computing from Turing to 2000, Proceedings of the 17th Conference on Education in Computer Aided Architectural Design in Europe, edited by André Brown, Michael Knight, and Philip Berridge, 94-100. Liverpool: ECAADE.

Barrie, Andrew. 2001. Media. Auckland: Artspace; Wellington: City Gallery.

Bazjanac, Vladimir. 1975. The Promises and the Disappointments of Computer-Aided Design. In Reflections on Computer Aids to Design and Architecture, edited by N. Negroponte, 17-26. London:
Mason/Charter Publishers Inc.

Broadbent, J. 1984. Design and Theory Building. In Developments in Design Methodology, edited by Nigel Cross, 277-90. Chichester: John Wiley \& Son.

Cherry, Edith. 1998. Programming for Design: from theory to practice. New York: John Wiley.

Chollet, Laurence B. 2001. The Essential Frank O. Gehry. New York: Harry N. Abrams Inc. Publishers. Cross, Nigel, ed. 1984. Developments in Design Methodology. The Open University Chichester: John Wiley
\& Sons.

Darke, Jane. 1984. The Primary Generator and the Design Process. In Developments in Design Methodology, edited by Nigel Cross, 177. Chichester: John Wiley \& Sons.

Dokonal, Wolfgang, and Urs Hirschberg, eds. 2003. Digital Design, 21th eCAADe Conference Proceedings, Graz (Austria) 17-20 September 2003. Graz: ECAADE; Graz University of Technology.

Eastman, C. M. 1970. On the analysis of intuitive design processes. In Emerging methods in environmental design and planning, edited by G. Moore, 21-37. Cambridge Mass.: MIT Press.

Fallon, Kristine K. 1997. The AEC Technology Survival Guide: managing today's information practice. New York: John Wiley \& Sons Inc. 
Gero, John S. and Mary Lou Maher. 1997. A Framework for Research in Design Computing. In Challenges of the Future, 15th eCAADe Conference Proceedings. Vienna (Austria) 17-20 September 1997

Gero, J. S., S. Chase, and M. Rosenman, eds. 2001. Proceedings of the Sixth Conference on Computer Aided Architectural Design Research in Asia, Sydney 19-21 April 2001. Sydney: Key Centre for Design Computing.

Jabi, Wassim, ed. 2001. Reinventing the Discourse: Proceedings of the Twenty First Annual Conference of the Association for Computer-Aided Design in Architecture, Buffalo (New York) 11-14 October 2001. Buffalo: ACADIA.

Laiserin, Jerry. 2002. "Getting onto the Digital Fast Track." February 2002. [cited December 2003]. Available from <http://archrecord.construction.com/features/digital/archives/0202da-1.asp>

Lawson, Bryan. 1984. Cognitive Strategies in Architectural Design. In Developments in Design Methodology, edited by Nigel Cross, 209-20. Chichester: John Wiley \& Sons.

Lawson, Bryan. 1997. How Designers Think: The Design Process Demystified. Third ed. Oxford: Architectural Press.

Lee, Hwa-Ryong. 1999. The Changing Face of Architectural Computing Research. In Architectural Computing from Turing to 2000, Proceedings of the 17th Conference on Education in Computer Aided Architectural Design in Europe, edited by André Brown, Michael Knight, and Philip Berridge, 1117. Liverpool: ECAADE.

Markus, T. A., P. Whyman, J. Morgan, D. Whitton, Tom Maver, D. Canter, and J. Fleming. 1972. Building Performance. London: Applied Science Publishers.

Maver, Thomas. 1998. Space Odyessy by Computer: Journeys through the Environment. In CAADRLA '98: Proceedings of The Third Conference on Computer Aided Architectural Design Research in Asia, edited by T. Sasada, S. Yamaguchi, M. Morozumi, A. Kaga, and R. Homma, 1-10. Osaka: CAADRIA.

McCullough, Malcolm. 1996. Abstracting Craft: the practiced digital hand. Cambridge Massachusetts: MIT Press.

Milne, Murray. 1975. Whatever became of Design Methodology. In Reflections on Computer Aids to Design and Architecture, edited by N. Negroponte, 30-36. London: Mason/Charter Publishers Inc.

Mitchell, C. Thomas. 1993. Redefining Designing: From form to experience. New York: Van Nostrand Reinhold.

Negroponte, N. 1970. The Architecture Macbine. Cambridge, Mass. \& London: MIT Press.

Negroponte, N. ed. 1975. Reflections on Computer Aids to Design and Architecture. London: Mason/Charter Publishers, Inc.

Pontgratz, C., and Maria Rita Perbellini. 2000. Natural Born CAADesigners: Young American Architects. Basel: Birkhäuser. 
Pressman, Andy. 1997. Professional Practice 101: a compendium of business and management strategies in Architecture. USA: John Wiley \& Sons, Inc.

Radford, Antony, and Garry Stevens. 1987. CADD made easv: A comprehensive guide for Architects and Designers. New York: McGraw-Hill Inc.

Rittel, Horst W. J. 1972. Second-generation Design Methods. In The DMG 5th Anniversary Report: DMG Occasional Paper No. 1, edited by Donald P. Grant and Jean-Pierre Protzen, 5-10. Design Methods Group.

Schmitt, G. 1999. Information Architecture: the basis and future of CAAD. Boston: Birkhäuser.

Tang, H., and John S. Gero. 2001. Cognition-based CAAD: How CAAD systems can support conceptual design. In Computer Aided Architectural Design Futures 2001, edited by Bauke de Vries, Jos van Leeuwen, and Henri Achten, 521-31. Eindhoven, The Netherlands: Kluwer Academic Publishers.

Terzidis, Kostas. 1999. Computers and the Creative Process. In Architectural Computing: from Turing to 2000, Proceedings of the 17th conference on Education in Computer Aided Design in Europe, edited by André Brown, Michael Knight, and Philip Berridge, 43-50. Liverpool: ECAADE.

Tweed, Christopher, and Brendon Carabine. 1999. CAAD in the Future Perfect. In Architectural Computing: from Turing to 2000, Proceedings of the 17th conference on Education in Computer Aided Design in Europe, edited by André Brown, Michael Knight, and Philip Berridge, 18-24. Liverpool: ECAADE.

Zarnowiecka, Jadwiga C. 1999. AI and Regional Architecture. In Architectural Computing: from Turing to 2000, Proceedings of the 17th conference on Education in Computer Aided Design in Europe, edited by André Brown, Michael Knight, and Philip Berridge, 18-24. Liverpool: ECAADE. 


\section{Computers and Architectural Education}

Changes in the architectural artefact on a social, cultural and technological level implies a change in the ways architects are educated (Asanowicz 1997).
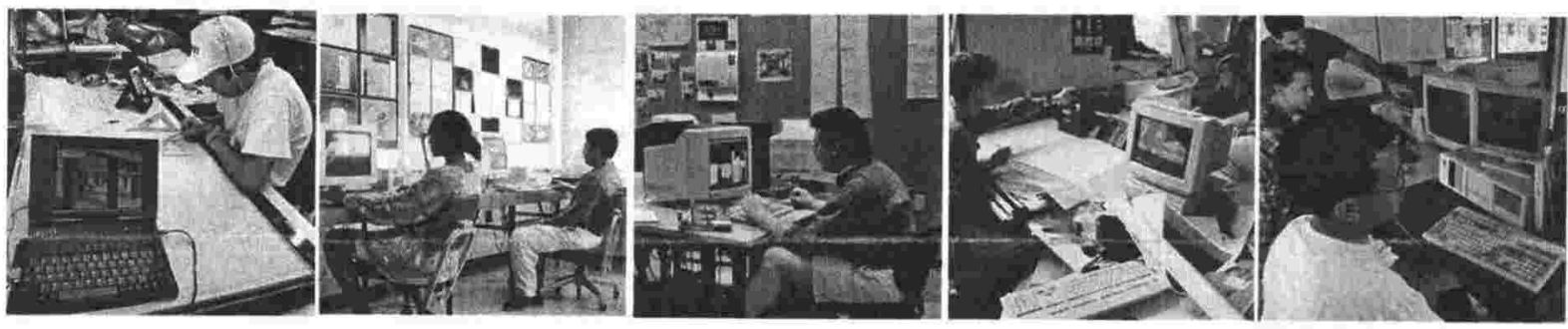

Figure 9.1 Students and computers around 1993. From Left to right: Missouri State University, New Jersey Institute of Technology, Texas A \& M University, University of Oregon, University of South California. (Source: Architecture September 1993 pp. 147-153)

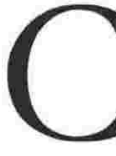

omputers and associated technologies are generally considered important tools in the training of architects. Consequently architectural schools are increasingly embracing technology, relegating the drawing board and t-square into the background, by providing students with the opportunity to gain literacy and competence in digital craft. Since the 1980 s when academic associations were established to promote "good practice and sharing information in relation to the use of computers in research and education in architecture and related professions" (ECAADE 2003), there have been several examples in conference proceedings and journals about new design studios that explore digital approaches to design (Gross 1994; Moloney 1999; Nieman and Do 1999). Evidence from these sources indicates design education has been finding imaginative ways of better integrating digital media into the design process. The studios, as outlined in these papers, also display a rich diversity of approaches that contribute to keeping digital technology at the forefront of school curricula.

Despite this technological immersion, however, students are still lacking in their traditional area of weakness: an understanding of materials, details, construction methods, building codes, and other practical issues (Novitski 1999). The teaching of architectural design proceeds much like it has done before computers were introduced into design schools. Students learn through a 
hypothetical project in situations that make it difficult to link acquired knowledge with application. As argued in Part 1, this is inadequate in educating students about the issues that make buildings work.

The failure of technology to assist in dealing with the current challenges in education demonstrates that there is a need for a reconsideration of the role the computer plays in education and the design studio in particular. Computers can achieve a lot more than produce impressive images, analyse proposed solutions and communicate ideas. According to Tweed and Carabine (1999):

The perfect CAAD system for education would facilitate a leap of understanding students must make if they are to relate their imaginings to the physical realisation of a building (Tweed and Carabine 1999).

The use of digital technology in schools of architecture is the subject of this chapter. As a consequence of this investigation it will be suggested that the current use of computers in schools of architecture has not assisted students to connect with building of real projects. Digital technology is a part of the tools students use to realise architecture. Teaching, however, is done using conventional techniques. The consequence of not using technology to aid teaching is the further shifting of education away from practice and the real world. As argued in chapter 2 this is one of the greatest challenges facing architectural education today. Not using the computer to change the way students learn to design, build and perceive architecture is counter to the widespread effect technology has on society. As Asanowicz (1997) states in the opening quote:

Changes in the architectural artefact on a social, cultural and technological level implies a change in the ways architects are educated (Asanowicz 1997).

The chapter finishes by recommending that digital technology has to be directly used as a teaching tool (and combined with the empowered sketch) to enrich architectural education. It suggests that by looking at the computer as a legitimate tool for teaching in addition to design support we may enhance, even revolutionise, design teaching.

\section{Digital Technology and Architectural Education}

To the student of architecture the computer is not simply a tool; rather it is a key partner in architectural design. Students see the computer as necessary and 
so competence in digital craft is seen as an advantage in design studio. Competence is also accepted as a major advantage when graduates seek job placement in the competitive design industry (Novitski 1999; Do and Gross 1999). It is not surprising, therefore, that computers are an integral part of most, if not all, schools of architecture. No longer is a school's digital prowess marketed by how many computers are in their computing lab or whether they are teaching the latest available software but rather, how well digital media is integrated within design studios and other parts of the curriculum (Cramer and Guiney 2000).

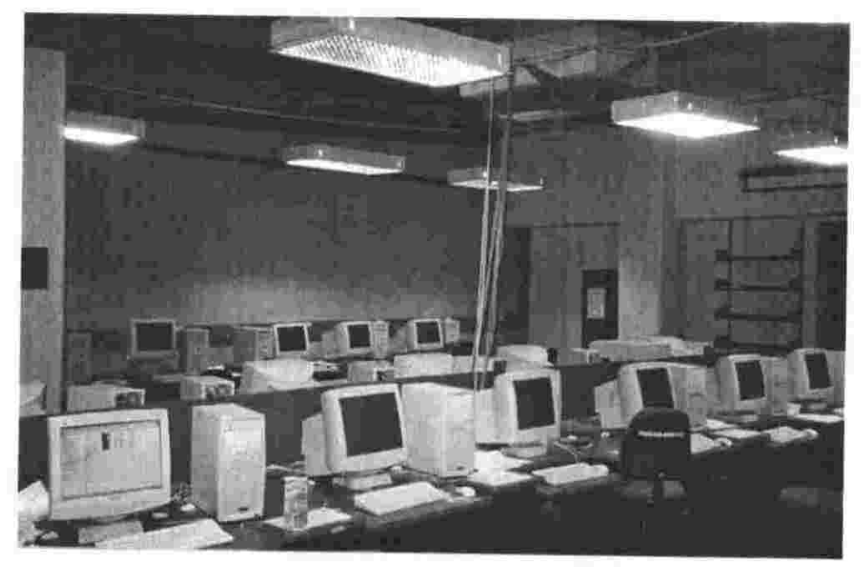

\section{Figure 9.2 Computer lab at the School of Architecture, Victoria University of
Wellington.}

The degree of physical implementation and integration varies from school to school. In one school, studios are fully networked along with multimedia facilities, 3D scanning, rapid prototyping, video editing and other capabilities (Balfour 2001). This school has also embarked on a program to equip every student with a laptop whilst providing network connections for all students in all major classrooms (Balfour 2001). In another school, due to limited resources, faculty were trying to extend creativity (in a foundation year design studio) by using hybrid media (computers along with sketching and physical modelling techniques) (Moloney 1999). The degree of curricular implementation is also diverse. Programs range from a few classes on how to use AutoCAD to "paperless" studios. By finding new and innovative ways in using digital technology in design schools, educators are giving students of 
architecture the ability to represent ideas as well as easily manipulate and use this new media to convey their ideas in a visually convincing manner.

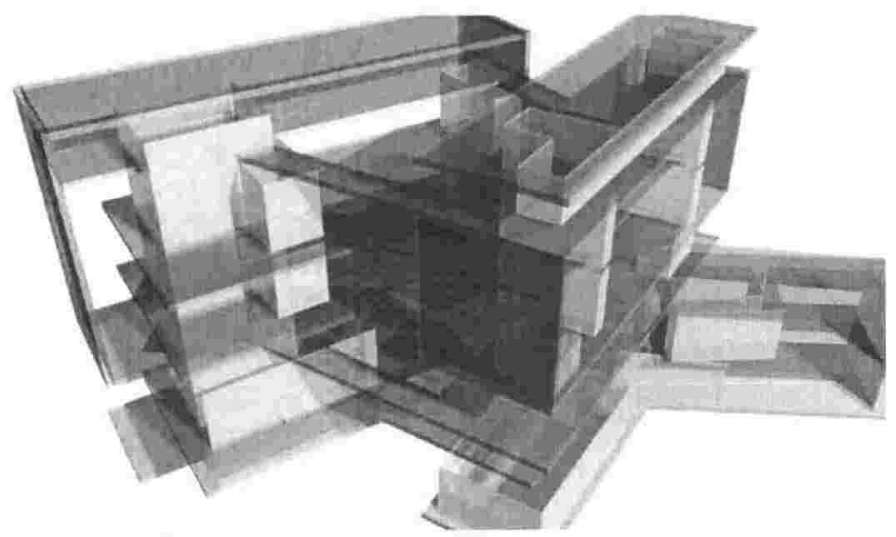

Figure 9.3 Digital Image created in design studio by a student (Source: Chris Hay, Victoria University)

Despite innovative integration, however, the assimilation of the computer into the culture of studio has done little to prevent students from generating seductive images, which embody "little understanding of structure, construction, building systems or even function" (Cuff 2001). With the advanced capabilities of digital technology to creating tich virtual environments, students are likely to be "concerned with instantaneous graphic impact rather than long term experiential gratification of real architecture" (Buchanan 1989). This is a reiteration of the challenges described in chapter 2 that require action.

The computer has to play a greater role in educating the architectural student. It has not been linked directly to the teaching of architecture. Considering computers for the purpose of educating the student has the potential to enhance the students' understanding of an architecture that is cost effective, environmentally friendly and a delight to users. Meeting these challenges requires the reconsideration of the attitudes towards the uses and deployment of computers in education. This is not a simple endeavour. Design computing in schools has a history that has been rooted in academic research, the capabilities of technology and the requirements of the profession. 


\section{A History of Computers in Architectural Education}

The use of computers in schools of architecture by students (and not academics) in the first instance was driven by faculty research. During the midsixties it was restricted to the capabilities of the tool and research interests of faculty (Chapter 8). Teaching about design computing was therefore limited to learning programming. An example of this focus existed at MIT in 1965 where all architecture students were required to take at least one semester of computer programming as a prerequisite to the Bachelor of Architecture degree (Negroponte 1970). These classes were conducted by other departments e.g. computer science and students applied this knowledge back into the projects developed by the academics. The extent of computer use in schools therefore existed only in the realms of research.

During the mid-seventies, architecture faculty responded to the increase in computer use by teaching courses in undergraduate programs with names like "Computers in Architecture". These courses included "how computers worked", some BASIC ${ }^{29}$ programming, and some rudimentary graphics (Shannon and Radford 2001). Because of the rapid developments of the decade, the value in the specific skills learnt had a short lifespan even if the students benefited from the process of learning. By 1985, the commercialisation of CAD created the need for employees with requisite skills. This placed pressure on architecture schools to create CAD courses that taught commands and procedures so that students had the requisite CAD skills to be hireable upon graduation. With easy access to CAD systems and good drawing graphics programs, drawing or visualisation formed the basis of computer courses. This included the teaching of geometric modelling, graphics and image editing and their application in the design studio. In some schools, brave students started to use $\mathrm{CAD}$ in design studios, much to the disapproval of conservative members of faculty (Shannon and Radford 2001).

With the advent of the internet and the World Wide Web (WWW), the computer shifted from being simply a tool that carried out specific tasks and

\footnotetext{
${ }^{29} \mathrm{BASIC}$ is a high-level computer programming language conceived as a simple language for students first learning about computers. As such, BASIC uses English words for many of its functions and allows programmers to use decimal notation (Grolier Electronic Publishing, Inc. 1995).
} 
produced images for a class, to being the communication environment within which much of the class takes place (Shannon and Radford 2001). Aided by advances in $\mathrm{CAD}$ and visualisation technologies that allow the effortless communication of data, images and real time video, the 1990s witnessed the setting up and experimentation of several electronic mediated studios that linked schools of architecture from Tasmania to British Colombia (Laiserin 2002). Researchers and educators began to use the communication technologies of the Internet to conduct spatially separated design studios in which geographically separated students worked on design projects together. Between 1995 and 1997 papers about these experiences began to appear in journals and major conferences giving currency and reality to the idea of Virtual Design Studios (VDS) (Laiserin 2002; Gross, Do, and Johnson 2000).

Today, market forces have placed many firms under pressure to integrate information technologies into practice, and so they prefer to employ architectural graduates with experience in IT. The skills most in demand are skills in computing applications relative to design especially visually and production based, for example architectural drafting, 3D modelling and animation. As a result, training in $\mathrm{CAD}$ and other tools have become a part or the standard curriculum in many schools (Gross 1994). The core toolkit of many schools of architecture therefore, usually, consists of 3D modellers and renderers (FormZ, 3D Studio Viz), a 2D drawing/drafting program (AutoCAD, VectorWorks), some analysis software (Lightscape), image processing applications (Photoshop), page layout applications (CorelDraw) and an integrated application (Microsoft Office) for general computing task. There is, however, usually no evidence of digital teaching aids for studio. Much of the implementation, however, exists in the realms of representation - rendering, animation, and 3D modelling and calculation - energy simulation, lighting studies, acoustic analysis.

Admittedly, there is a significant integration of the computer in education as evidenced in conference proceedings (eCAADe 2001). International conferences have presentations that show that digital technology does not only inhabit studio but has become pervasive in other subject areas from structural design to energy performance and practice management. However, this has 
been influenced primarily by the capabilities of the tool. According to Susan Shannon and Antony Radford:

It is [the] rapid development of the underlying technology rather than educational forces that has driven change in both digital making and teaching using computers (Shannon and Radford 2001).

Cutting edge integration is in the realm of research and experimentation, and despite new and innovative pedagogical approaches to digital media, how design is taught and learned has not been changed. An example of this is the recent phenomena of Virtual Design Studios (VDS), which use the latest information and communications technologies (ICT) and the Internet for design collaboration. Despite their novelty, these "virtual" studios differ very little in their educational structure and outcomes from traditional ways of teaching design. Research has therefore produced tools for teaching that are linked to the capabilities of the technology, and not expressedly aimed at improving the results of design teaching. Since its introduction into education the computer has not played a significantly direct role in informing the young designer of much of what must be considered during the design process.

\section{3: The Computer in the Design Studio}

With a few exceptions the use of the computer in design education today generally focuses on the representation, communication, simulation and form of architecture and exists mainly in the design studio. According to Do \& Gross (1999) in their paper entitled: Integrating Digital Media in Design Studio: Six Paradigms there are six models of integrating the computer into studio: The CAD Studio, The CAD-Plus Studio, The Virtual and Web Design Studio, The Cyberspace Design Studio, The Intelligent Buildings Studio and The Tools and Toys Studio.

While the last three are important models they are highly experimental, not very common and deal mainly with the wider issues of digital technology in architecture. They are generally concerned with issues such as the integration of virtual and physical communities, embedding computation and smart materials into the built environment, and experimental digital design media or future tools of practice (Do and Gross 1999). These issues while being important to 
the ubiquitous nature of technology in society do not directly impact on the problems facing education today.

The first three models, common elements in most design schools, are the most widely used and reflect the standard use of the computer in design studio. The CAD Studio is a computer augmented design studio. As the name implies this studio uses the computer in much the same role as a drawing board or physical model would be used in a conventional studio. In other words, up-to-date design software is used to teach a conventional design studio (Do and Gross 1999). The value of computers as predictors of building performance is given prominence and recognition in The CAD-Plus Studio. In this studio the integration of knowledge in design is addressed with the use evaluation software. Finally, the Virtual and Web Design Studio explores new opportunities for collaboration using the Internet and web technologies. Although Do and Gross (1999) have chosen to separate the studios into separate paradigms, in reality they can be combined to form hybrids.

In arguing about the use of the computer in studio it would be wise to take a close look at its present uses in the context of these studios. In addition to the many diverse approaches to the integration of the computer within the design studio there are three "general uses" or embracing themes that can be strongly linked or mapped to the three studios. The CAD studio for instance acts as context for the use of the computer for imagemaking and visualisation; The CAD-plus studio deals mainly with evaluation software and using the computer for communication and collaboration mainly occurs in web and virtual studios. These uses (already examined in chapter 8) can transcend the various studios and are closely related to similar uses in practice but have their own set of problems related to learning design.

\section{Representation: Image Making, Form Making and Visualisation}

The use most associated with the CAD studio (and indeed design computing) is that of representation. In the CAD studio students realise their design projects using the latest $3 \mathrm{D}$ modelling and other visualisation software to generate multiple views and viewpoints as well as develop elaborate ways of communicating ideas, sometimes exclusively and sometimes with traditional 
tools. The reason for this strong association is not obscure or new. Architectural design has always had a visual bias, which is evident in the strong preference for visual representations. This strong visual culture is based on a primarily visual interaction with the built environment and, as pointed out in chapter 5, the reliance on images has been a constant factor in architectural practice, design and education.

Although visualisation is one of the prime skills demanded for practice it exacerbates the challenges encountered in education. Increasingly final reviews (output from studio) are computer generated, however, the images produced have not shown any greater understanding of architecture. Some teachers argue that the use of CAD in schools encourages more students to work in threedimensions from an early stage. According to them, it tests and extends the students' imagination offering them the opportunity to include things that are often left until the end or never considered at all, such as colour, light, texture, and materials (Novitski 1999; Ferrar 1997). Regrettably it also "encourages shape-making at the expense of internal planning and a preoccupation with presentation rather than content" (Ferrar 1997). This also places undue emphasis on the product. The ease with which the software allows the student to manipulate forms and produce unnecessarily elaborate views fabricates imaginative structures which ultimately loses its grounding in reality.

Modelling and rendering have nothing to do with helping to nurture the student's concept of use, comfort, context or necessarily how these things are brought together to form a sufficiently rich design solution. According to Gross "powerful image-making tools can give novice designers a false sense of achievement and thereby inhibit learning" (Gross 1994). Alan Balfour (2001) expresses his concern in what he terms "software and hardware driven" design. He states:

All representational softwares and the machines on which they run have their own formal and, in some ways, sensual characteristics that, when mastered, not only produce convincing artefacts but also persuade the user that they are personal creations. They give the user rematkable confidence and a sense of fulfilment, so much so that the desire to build is potentially diminished. This is exaggerated by a condition in which products are increasingly more effective than place in establishing status and power (Balfour 2001). 
Students usually go for more appealing forms ignoring environmental and social contexts that cannot be represented adequately. Eventually the proposal becomes more about the product and less about the process and content of architecture.

Another problem with this attitude to using the computer is the sophistication of the software needed to achieve the stated goals. The more sophisticated the program, the more tools and commands it possesses. The more tools and commands the steeper the learning curve. Producing elaborate rendering and photo-realism requires time to learn and use forcing students to spend more time mastering programs and less time learning architecture.

\section{Evaluation: Simulation and Analysis}

Evaluating design performance (lighting, thermal, acoustical, etc.) is an important part of design. Instruction in this important element is usually relegated to speciality courses/lectures, guest lectures in studio, or a specialist in the design review (Do and Gross 1999). The CAD-Plus studio caters to this need by providing computational tools in studio that allows the integration of knowledge about building performance into the design process. A collection of evaluation tools is used in studio to provide information and/or analysis to the student as part of the project while they work. Two types of tools are used: simulation tools (lighting, energy, structural, acoustic analysis) and design case bases.

An excellent example of an evaluation software used in studio is ECOTECT (Roberts and Marsh 2001). ECOTECT is an interactive performance analysis tool developed and used at Cardiff University for use during the early, conceptual stages of design. It provides a three dimensional modelling interface with a range of analysis functions. These functions include:

- overshadowing and solar reflection;

- sun penetration and shading device design;

- solar access and photovoltaic/heat collection;

- hourly thermal comfort and monthly space loads;

- natural and artificial lighting levels; 
- acoustic reflections and reverberation times;

- project cost and environmental impact.

In ECOTECT, a relational modelling system is used in which the role of each element and its relationship to others is automatically derived from the way it is created. Being interactive, the tool allows students to quickly select and compare different surface materials, changes to internal lighting levels, reverberation times, heat loads and internal temperatures at different times of the day and year. For more detailed analysis, data can be exported to a range of application-specific tools. For instance; the RADIANCE radiosity-based lighting simulation package from Lawrence Berkley Laboratories; VRML for interactive 3D visualisation; the DOE-2 and EnergyPlus thermal simulation tools from the US Department of Energy (Roberts and Marsh 2001).

Not all CAD-plus studios have shown much evidence of improvements in teaching and learning; or any differences they have made in the studio. One explanation for this could be the timing of the application. There is usually a minimum amount of information that is needed by evaluation applications before it calculates its analysis. Most evaluation software, while being tremendous help, are used after the project is in advanced stage or at least when the geometry of the project is known. Students usually need to learn about the environmental consequences of their actions before the geometry is known or even contemplated. This doesn't help much when the student is trying to acquire intuitive knowledge and integrate that knowledge into design at an early stage.

\section{Communication and Collaboration}

The use of the computer as a tool for communication and collaboration has created interesting developments in the design studios of architecture schools. The ubiquitous presence of computer communication networks, the Internet, web-technologies and virtual environments in studios have contributed to the development of Virtual Design Studios (VDS). Virtual design studios are:

...design studios where participants are spatially separated and work collaboratively on a single project or work independently but use the studio as a forum for helping each other, peer-criticism, and discussing design issues. In the VDS, all communication between separated participants takes place via remote communication technology, all or 
part of the design process is computer-supported, and the final products are computer documents (Wojtowicz et al 2001).

These studios allow students to communicate, select, and share information with colleagues at different locations. Students from two or more geographically displaced schools of architecture would work on the same design project or separate parts of the same project using software tools for video conferencing, shared whiteboard drawing, chat rooms and multi-user domains to exchange ideas, critiques and dialogue. Reviewers usually offer criticism by email or make virtual visits (through video conferencing) without being in the same room (if indeed a room is used) as the other participants of the crit.

One interesting VDS called CoOL Studio (Collaborative Online Studio for Architectural Design) takes the form of an on-line Internet community. It supports students' learning by facilitating input by distant consultants; providing access to online cases and reference materials; encouraging students to be clear and articulate about their projects; and supporting collaboration among students and design studios. CoOL Studio, through the employment of a CoWeb (an easy way of creating and modifying Web pages without any security measures) allowed students to post their designs in a collection of Internet "rooms" during the term. The "studio" then solicited and monitored feedback from six distant expert consultants (Zimring et al. 1999). Unfortunately the studio merely provided a means for which the "tutor" could be in the studio virtually.

According to its protagonists, advances in technology that permit/allow the safety and communication of data, images and real time video mean that students no longer need to be in the same place at the same time to tackle the same design problem. In the paper entitled: Understanding Virtual Design Studios; Mary Lou Maher, Simeon Simoff and Anna Cicognani argues this point by proclaiming the irrelevancy of designers' location "because the workspace of the studio is distributed across the [network]. Designers are able to enter the studio for interactive and non interactive sessions connecting to the World Wide Web, multimedia mailers, and/or connecting to a video conferencing session." (Cited in Laiserin 2002). It has also been argued that VDS have the potential to "favour collaboration over competition, diversify student 
experiences and redistribute the intellectual resources of architectural education across geographic and socioeconomic (sic) divisions" (Laiserin 2002). While this may be true it does not change the fact that VDS use the same teaching methods as found in the conventional studios - teaching strategies are problem based, learning takes place through conversations in reviews and crits.

The difference between this and conventional studios is that VDS tend to be more about collaborative experiences versus the significance of the design process and the quality of the product. This is fine when teaching teamwork as part of practice or the building team but it does not recognise that some design are personal endeavours. Learning design or developing a personal style tends to be an individual pursuit on the part of the student and is sometimes successful without the "interference" of others. These studios also undermine the pedagogical relationships inherent in studio. Face to face dialogue with tutors are minimal and as demonstrated in chapter 4 this is the most important aspect of education that can bring about change.

\section{A Teaching Tool}

It is generally agreed that the computer is (or should be) an integral part of the studio experience today. However, current uses (representation, evaluation, communication), while important, do not remedy the existing situation in education (a need for the easy transition of graduates into the world of practice). Despite the introduction of computational technologies, the design studio is still characterised by the faults of product orientation, complex building technologies, lack of integration, the pedagogical distance of the tutor, and a non-immersion in reality.

Technology is intoxicating. Balfour (2001) argues that electronic/digital media makes designing "an internalised, constrained and virtual experience in which the creative relationship to the tools and information held within the machine seem to be more stimulating and to hold more promise" than the reality of architecture with its external, diverse and physical stimuli (Balfour 2001). In the experience of the pre-electronic studio these stimuli would be historical, technical, environmental, social and phenomenal. Creating rich imaginative environments that are not well connected to building teal projects invariably 
produces graduates insufficiently prepared for employment, further removing the academy from practice and from building (Cuff 2001). This makes it important that digital technology does more in informing the young designer of much of what must be considered to make appropriate architecture.

There exists in the computer a great potential to significantly enhance how architecture is taught and understood. Architectural design is more than playful interaction with geometric forms, supported by increasingly attractive computer tools. The mere presence of computer-based media in studio does not ensure that students learn that architecture is more than the playful interaction with geometric forms. It is time that the computer goes beyond functioning as an instrumental tool (e.g. in representation and visualisation) to becoming a "Socratic machine" that provides an appropriate environment for design learning. This environment can best allow the student to conceptualise from a wide array of influences, historical, technical etc. that contribute to an architecture that is cost effective, sustainable and a delight to users. The increasing propensity for students to use digital technology in their work also demands a teaching tool that is immersed in an environment closely connected to the design studio and its methods. Thinking about the computer in this way transcends its current uses and transforms it into a tool that actually interacts with the student designer.

\section{Advantages to using the Computer to teach}

As a teaching tool the computer offers many advantageous characteristics:

Speed and reliability - As an information processor, the computer retrieves, sorts, connects, relates and presents information promptly and more accurately in a fraction of the time it would take the designer. It also reliably responds to queries providing a quick "knowledge of results" or feedback, a characteristic that has been shown to be a most important factor in learning (Lawson 1980)(Chapter 11).

Ability to encourage student centred learning (self learning) - When teaching, a lecturer or teacher has proceed at what he or she judges to be the most suitable speed for the class as a whole. The computer, on the other hand, allows the student to 
determine a personal speed for learning. The potential to allow the user to chart his/her own design path through a problem means that the student is able to isolate each of the issues in his/her own way or time and discover about the problem for him or herself rather than being taught or instructed.

Students are not intimidated - During the double $\mathrm{h}$ experiments observations showed that the students were a bit intimidated by the practitioner. An explanation for this response or their resultant passivity could be a fear of seeming foolish to the practitioner. Students often make mistakes, when learning, which seems reasonable at some point only to appear foolish later. According to Lawson (1980), the fear of making such mistakes and appearing silly often inhibits the learning process (Lawson 1997) (First edition 1980). An idea may be ill-formed, half-baked and on the surface seems silly but may also contain some productive elements. The computer, because of its impersonal nature, alleviates this problem by allowing designers or students to try out ideas without the fear of seeming silly.

Information and Media Diversity - The ability to contain and combine different forms and types of information and media allows greater integration in studio of other course content directly related to projects. Inter-connectivity between media, while not ideal, allows greater flexibility and more sharing of information.

Interface - Computers offer the ability to personalise an experience. Similar to self-learning they are able to learn habits and preferences of the user (agents). The ability to interface by voice and other recognition strives to help the user interface easily with the information that is personal to him or her.

\section{Examples of Teaching Tools currently used}

Using the computer as a teaching tool in architecture is not a new idea. Research efforts already exist that attempt to provide instruction/learning tools to assist with the informational needs of the student.

A good example of such a system is DYNAMO (fig. 9.12). DYNAMO (which stands for Dynamic Architectural Memory On-line) is a web-based design assistant for student-architects. It can also be considered a Case-Based Design 
(CBD) tool in so far that it was inspired by the cognitive view underlying CaseBased Reasoning ${ }^{30}$ (CBR). DYNAMO does not use AI for its CBR model but instead aims to facilitate and nurture this way of reasoning within the human designer's mind. The idea is to provide a platform for interaction and knowledge exchange between designs and (student-) designers in various contexts and at different levels of experience. (Heylighen and Neuckermans 2000). There are similar tools like DYNAMO and other tools that approach the same objective using different environments.

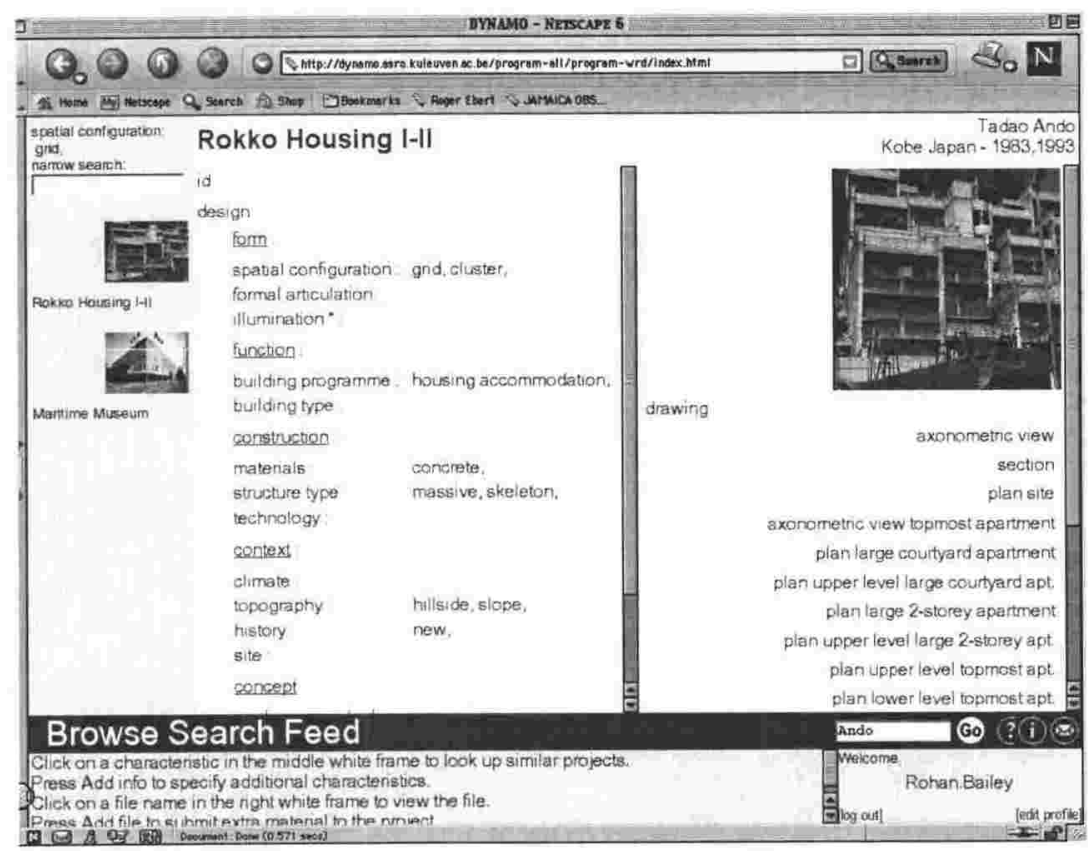

\section{Figure 9.4. A screenshot of DYNAMO}

These tools while helpful to students and allow access to information in new and novel ways, are not particularly compatible with the architect's designerly way of thinking during the early stages of design. There exists a gap (physically and mentally) between the actual sketch of the designer and the digital tool. The designer must first draw the sketch, then realise that similar examples (in the case of DYNAMO) may provide useful information. The designer then consults DYNAMO (or a similar system) to search for relevant cases. In DYNAMO, this requires going to the computer, switching to a web browser, typing in the URL for the site, specifying one or more selection criteria, screening the cases that meet these criteria and picking out the relevant

\footnotetext{
${ }^{30} \mathrm{CBR}$ is a paradigm within the field of Artificial Intelligence (AI), based on a memory-centred model of cognition.
} 
information. The designer then carries the information back to the paper and pencil environment of the sketch. Each step of the process - realising that cases may be useful, finding relevant ones, and transferring the corresponding knowledge to the design - interrupts the design process considerably. In addition to this, the systems rely on the initiative of the designer by sitting passively and waiting for the designer to interact with it. In order to fully integrate the information into the act of designing, users must be able to interact with the material in the design environment. In this respect, an ideal situation would be to locate the teaching tool within the design environment itself instead of through a Web browser or other interface.

\section{Conclusion}

Despite impressive progress made in design computing in the past decade, the impact of computers on practice has not affected much the way architects think and design. In other words, the design process (especially in the early stages) has remained structurally the same. Architects, in some cases, still use pen and paper to work first ideas. Likewise, the presence of digital media in design studios does not necessarily mean that it has changed in any immense way students' understanding of the design process or even their understanding of architecture.

The integration of the computer in design studio in particular takes place in three main realms: image making and representation in the CAD studio, analysis and simulation in the CAD-plus studio, and communication and collaboration in the web and virtual studio. Driven by emerging technologies, these realms help the student determine how architecture is represented, analysed and communicated in studio. Current technology, however, has not been used to exploit and enhance existing teaching methods and processes. While it is clear that there has been tremendous effort to integrate digital media into the studio, there is no evidence that these tools are being used to directly inform and educate young designers about much of what must be considered during the design process. There needs to be a transformation in how students and teachers perceive the computer. Thinking of the computer as simply a representation tool, an analysis tool or a communication tool, affects the 
potential role the computer can play in architectural education. It projects or favours an architecture of form-making, at the expense of an architecture that embraces practical issues.

We have suggested the use of the computer as a teaching tool in design studio, with a mandate to teach students how to design habitable spaces for human endeavour. This is not a new idea, since it has been attempted by others. In these attempts, however, the computer is passive and acts rather like a digital book. Rather than being a passive instrument, the computer needs to become a "Socratic machine". It has to interact with the student, responding to ideas, allowing self-paced learning, while quickly providing feedback. This activity has to occur within the design environment. Using the computer as design teaching support and in conjunction with another interactive tool - the sketch could prove to be the key to producing graduates that can make an easy transition into internship and practice while facing the challenges outlined in chapter 2 . The sketch, however, is a strictly manual tool. Engaging the computer with the advantages of the sketch, in the manner referred to, requires therefore that the sketch becomes digital.

\section{References}

Asanowicz, Aleksander. 1997. "Computer - Tool vs. Medium.". [cited 6 Dec 2000]. Available from $<$ http://info.tuwien.ac.at/ecaade/proc/asan/asanowic.htm>. Challenges of the Future (15th eCAADe Conference Proceedings).

Balfour, Alan. 2001. Architecture and Electronic Media. Journal of Architectural Education 54, no. 4: 26871.

Buchanan, Peter. 1989. What is Wrong with Architectural Education? - Almost Everything. The Architectural Review 1989, no. 07: 24-26.

Cramer, Ned, and Anne Guiney. 2000. The Computer School. Architecture (Sep): 93-98.

Cuff, Dana. 2001. Digital Pedagogy: An Essay. Architectural Record Sept, no. 2001.

Do, Ellen Yi-Luen, and Mark D. Gross. 1999. Integrating Digital Media in Design Studio: Six Paradigms. Paper presented at ACSA National Conference 1999, Minneapolis, MN, USA.

Education in Computer Aided Architectural Design in Europe (ECAADE). 2003. [cited December 2003]. Last updated September 2003. Available online at http://www.ecaade.org

Ferrar, Steve. 1997. Computers and the Creative Process. In Challenges of the Future, 15th eCAADe Conference Proceedings. Vienna (Austria) 17-20 September 1997 
Gross, Mark D. 1994. Roles of Computing in Schools of Architecture. Journal of Arcbitectural Education 48, no. 1: 56-64.

Gross, Mark D., Ellen Y.-L. Do, and Brian R. Johnson. 2000. Beyond the low-hanging fruit: Information technology in architectural design past, present and future. In ACSA Technology Conference (July 14 - 17), edited by William Mitchell and John Fernandez. Cambridge Massachusetts: MIT Press.

Heylighen, Ann, and Herman Neuckermans. 2000. DYNAMO: A Dynamic Architectural Memory Online. Educational Technology \& Society 3: 86-95.

Laiserin, J. 2002. From Atelier to e-telier: Virtual Design Studios. Architectural Record Jan 02: 141-42.

Lawson, Bryan. 1997. How Designers Think: The Design Process Demystified. Third ed. Oxford: Architectural Press.

Moloney, J. 1999. Charcoal, Bits and Balsa: Cross Media tactics in the foundation design studio. In Architectural Computing: from Turing to 2000, Proceedings of the 17th conference on Education in Computer Aided Design in Europe, edited by André Brown, Michael Knight, and Philip Berridge, 110-15. Liverpool: ECAADE.

Negroponte, N. 1970. The Architecture Machine. Cambridge, Mass. \& London: MIT Press.

Nieman, B. R., and Ellen Y.-L. Do. 1999. Digital Media and the Language of Vision. In Media and Design Process: ACADIA 99 Proceedings, edited by O. Ataman and J. Bermúdez, 70-80. Salt Lake City: ACADIA.

Novitski, B. J. 1999. The computer education received by today's architecture students may not provide them with the skills sought by employers. Architectural Record 04.99: pp. 39-40.

Roberts, Andrew, and Andrew Marsh. 2001. ECOTECT: Environmental Prediction in Architectural Education. In ECAADE 2001, 342-47. .

Shannon, S., and Antony Radford. 2001. Digital Making: History, focus of some current research and future research directions for the school of Architecture, Landscape Architecture and urban design. .

Tweed, Christopher, and Brendon Carabine. 1999. CAAD in the Future Perfect. In Architectural Computing: from Turing to 2000, Proceedings of the 17th conference on Education in Computer Aided Design in Europe, edited by André Brown, Michael Knight, and Philip Berridge, 18-24. Liverpool: ECAADE.

Wojtowicz J., T. Seebohm and R. Wright. 2001. "Project 3E: Computational Support Mechanisms for Spatial Literacy in Education: Evaluating Computer-Assisted Spatial Literacy Learning Environments" 2001 [cited December 2002] Available from http://nrhino.ald.utoronto.ca/vds_site/

Zimring, C., S. Khan, D. Craig, S.-u- Haq, and M. Guzdial. 1999. CoOL Studio:Using Simple Tools to Expand the Discursive Space of the Design Studio. Paper presented at the Design Thinking Research Symposium, MIT, Cambridge, MA. 


\section{Sketching in the Digital Realm [or Digital Sketching]}

It is only worthwhile to make drawings on the computer if you get something more out of the drawing than just a drawing (Sutherland 1963, p. 17 cited in Landay 1996).

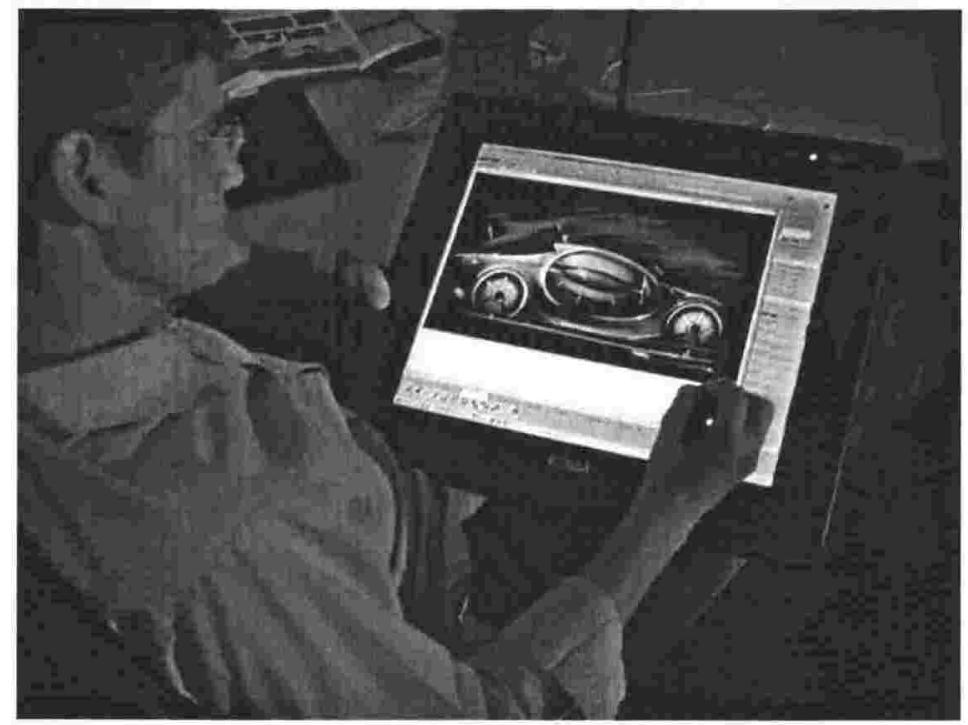

Figure 10.1. Sketching directly on a LCD screen. (Source: http://www.wacom.com)

$\mathrm{I}$ architecture today, the traditional drawing board and tactile skills (sketching and model-making) of designers are increasingly displaced by the skills needed for digital craft. These skills - computer drafting, design and model simulation - are now considered essential for architectural design. In the early stages of design, however, the irrelevance of sketching seems to be an illusion. Physical models are still produced (probably using laser cut laminated objects or by computer controlled milling), and hand sketches are still used. It is clear that designers, to a large extent, still prefer to use hand-drawn sketches to visualize the first notional organizational ideas (Pontgratz and Perbellini 2000; Do 2002).It can therefore be concluded that current digital tools, while being excellent at the communication and visualisation of ideas and concepts, have not been able to facilitate the kinds of design thinking enhanced by the sketch (Tang and Gero 2001). It appears that none of the digital tools available "can bypass creative visual thinking" (Goldschmidt 1994). In reaction to this, 
software developers and design computing researchers have laboured to investigate and address the problem of bringing the computer into the early phases of design. Research attempts to define and refine computer interfaces best suited to sketching have ranged from examining emergent shapes (Soufi and Edmonds 1996) to applications that recognise sketch diagrams made on screen (Gross 1996). Demonstration applications have been built that recognise sketches and provide analytical tools to the user (Do 1998; Leclercq 2001) and prototypes now explore the direct generation of three-dimensional form from freehand drawing input (Gross, Do and Johnson 2000). Sketching applications are also now available to designers from commercial software developers. Regardless of all this innovation, however, it seems that much effort has been concentrated on making the products of sketching digital. The process of sketching (i.e. thinking by drawing), while being neglected, has the potential to be exploited. Using digital technology to boost the interactivity of the sketch can take better advantage of its ability for graphic thinking and - by extension teaching.

In this chapter we will examine the existence of the sketch in the digital realm. Since this concept is not new, the first part of the chapter will simply acquaint the reader with the field. It will comprise of a short history of the digital sketch, an explanation of how the technology works, and a look at current applications, as well as some prototypes implemented by other researchers. While this chapter does not claim to put forward new knowledge, it will restate the computer's potential as a partner in the design process. It will reinforce the notion of the sketch as an integral part of a computer teaching tool, because it is well positioned for empowerment and amplification by digital technology.

\section{Recognition Technology}

While it is not the intention of this work to go into much detail about the technology, it is beneficial to the reader to know in someway how it works. With the benefit of this knowledge the reader can best appreciate the strength of the argument in this chapter as well as the state of the technology today.

Simply put, recognition technologies work by translating input into a form that the computer understands. This input could be speech, handwriting, drawings, 
and/or gestures. This input would be in formats similar to that used for humanhuman communication. Using knowledge that is statistical, linguistic, or deductive in nature to produce associations, the recognition system is trained to associate input data with symbols. These symbols are then used to instruct or elicit some response from the computer. This response is determined by the task of the particular application that requires such input. The task is usually one that requires the "natural" interaction that a keyboard and mouse cannot provide.

Digital recognition is rarely one hundred percent accurate. Since the forms of input are inherently ambiguous, the biggest problems lie in resolving this ambiguity and/or informing the user of it and allowing the user to correct it (Landay 1996). Errors can result in incorrect results (based on the symbols returned or improper translation of input) or no results at all. Since errors are inevitable, the accuracy required by the task is usually carefully considered. A great proportion of research effort is usually dedicated to reducing errors and facilitating more efficient translation.

Digital sketch recognition tries to interpret the marks designers make when sketching. These marks are translated into a form that the computer can understand and respond to. The recognition of drawings and sketches are particularly susceptible to inaccuracies due to the individual, multivalent nature of the sketch. Sketch recognition as determined by research is therefore best implemented when based on context. Fortunately, research has shown that designers represent architectural concepts in a consistent and conventional way (usually based on context) and use a limited set of diagrammatic elements (Do 1998). It is therefore possible to associate symbols and spatial arrangements in a drawing with the designer's intention, or task context (Do 2002) allowing an easier, more accurate means of translating input.

\section{A Short History of Digital Sketching}

The coupling of digital technology and hand sketching is not a new phenomenon. Like most areas of user interfaces and CAAD we can trace this research back to Ivan Sutherland's SKETCHPAD where a light pen was used to draw structured diagrams on display screen (Landay 1996). Digital sketching 
technology (or the promise of it) was used in a limited form as part of Negroponte's Architecture Machine and despite some loss in interest during the 70 s and 80 s, digital tools for architectural design have arrived at a point today where "pen based interaction will allow architects to use the pencil again" (Gross, Do \& Johnson 2000). Current research has provided computational systems that support sketching (Landay 1996, Do 1998) or use freehand sketching as an interface to intelligent systems for design. Ironically, today the main interface for these tools is changing from the use of digitising tablets to instances where one can sketch directly on the LCD display screen. So assured is the field that researchers have now started to experiment with interfaces the size of drawing boards (Fig. 10.2). So diverse is the field that research has also shifted from the mechanics of the idea to possible areas for implementation, for example, as an interface for tools that use diagrams for knowledge and image retrieval, building performance simulation and three dimensional model making (Do 2002). So advanced is the field that digital sketching has now entered mainstream architectural use as AutoDesk, the maker of AutoCAD, has incorporated it in their new product - Architectural Studio. The difference, however, between Sutherland's SKETCHPAD and the sketching tools of today is significant when considering the motives behind the development of the digital sketching.

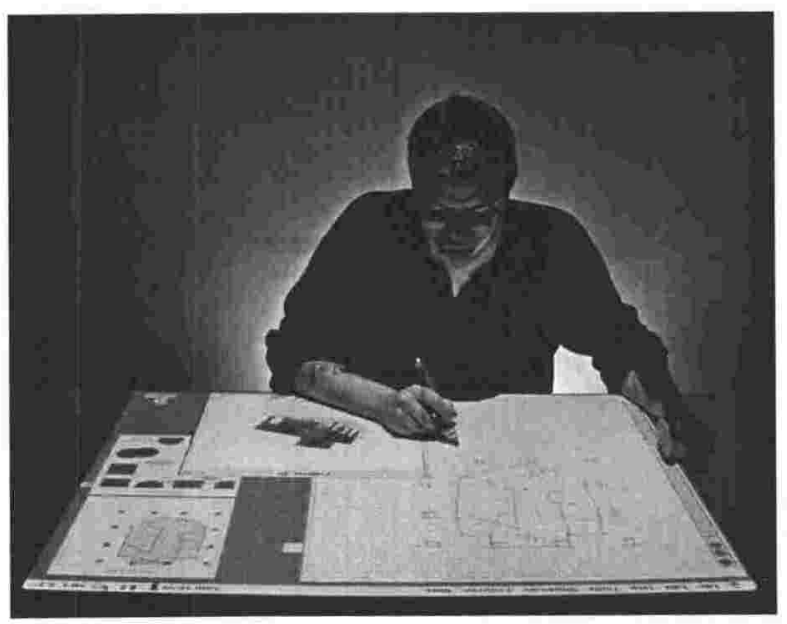

Figure 10.2. The designer sketching on a digital projection the size of a drawing board. (Source: http://www.lema.ulg.ac.be/) 


\section{$\mathrm{HUNCH}$}

Sketch recognition can be traced as far back as the Architecture Machine Group's HUNCH in 1970 (Taggart 1975; Landay 1996). HUNCH was developed at MIT by creators who were "trying to develop (sic) means of communicating architectural intentions and ideas in a useful way to an observing computer" (Taggart 1975). According to Landay (1996), this was one of the early attempts at using inferences about a sketch to transform it into a more finished design. The sketcher, at the time, used a pressure sensitive tablet to record stylus data. As the name implies, $\mathrm{HUNCH}$ (figure 10.3) used guesses about implied intentions to determine what the sketcher probably meant. These "guesses" included: what was meant graphically, in 2-D, what was meant physically, in 3-D, and what was meant architecturally (Landay 1996).

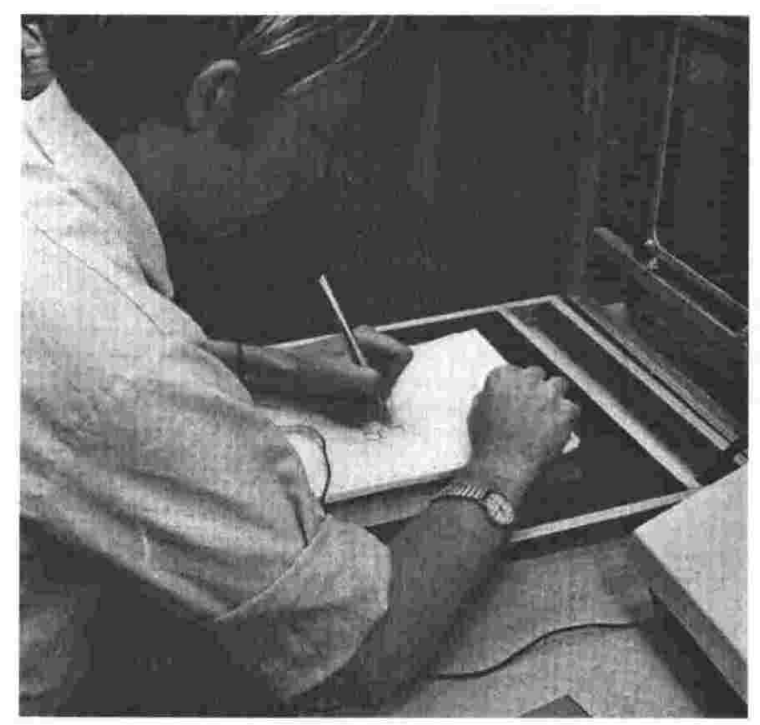

\section{Figure 10.3 Photo of HUNCH in use (Source: Taggart 1975)}

The concept of HUNCH was based on the researcher's recognition that the amount of information contained in the dialogue or "interaction" between architect and sketch was "greater than that which could be contained in the sketch alone, or which the person could carry around in his head" (Taggart 1975). The desire therefore was a computer system that was:

...alert enough to be able to effect a dialogue with the user. It needs to be knowledgeable enough about the subject matter being sketched to be able to ask reasonable (intelligent?) questions, and perhaps to offer some information of its own. In 
short, the computer should be able to enter into a dialogue with the user, in much the same way as someone observing the sketch being created might interact (Taggart 1975).

\section{Interface and Hardware}

HUNCH was just one of several experimental sketch recognition systems generated by interest in machine processing of hand drawn diagrams during the 1970s (Do, Ellen Yi-Luen and Gross 2001). During the 1980s the decline in general interest in sketch recognition coincided with the advent of the Graphical User Interface (GUI) that used the mouse and menu as the main input for drawing. Interest revived in the 1990s with the availability of inexpensive and cordless digitising technologies. The Apple Newton PDA (Personal Digital Assistant) was one of the first applications of handwriting recognition and paved the way for the current set of pocket sized PDAs. These PDAs use pen styluses for pointing, entering text and some graphical input. Recognition is enhanced by using a prescribed writing format called Graffiti (in the case of Palm PDAs). By the year 2000, the technology used in PDAs and touch screens opened users to the concept of marking or pointing directly on the display screen. This created a new market for the use of pressure-sensitive LCD flat screens where you literally draw on the screen with the pen. The best example is the Cintiq LCD tablet sold by Wacom (Fig. 10.4, Fig. 10.1).

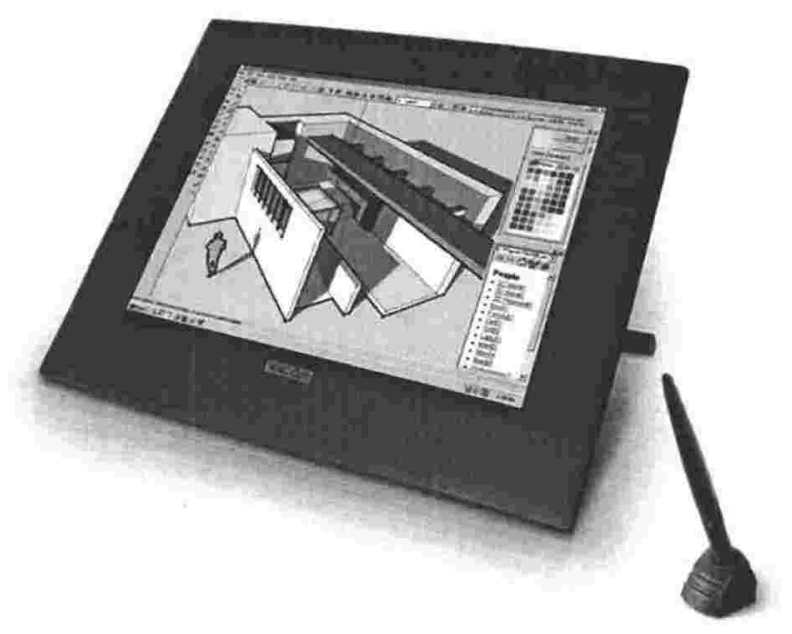

Figure 10.4 The Wacom Cintiq LCD tablet allows the designer to draw directly on screen. (Source: http://www.wacom.com/lcdtablets/Architecture.cfm) 
The interactive pen displays from Wacom ${ }^{31}$ combine an LCD monitor with a patented cordless, batteryless tablet technology. The user is allowed to work with the pen directly on the screen, adjust the incline of the screen, and, in some cases allow the rotation of the work surface as one would a pad of paper for a completely natural work approach (in the opinion of the manufacturer). The batteryless, cordless "Grip Pen" features 512 levels of pressure sensitivity (allowing the designer to control line thickness and pressure). Wacom also claims that the LCD screen promotes a tactile experience:

... to achieve a natural paper-like experience. The surface has two coatings, one to diminish glare and another to provide a texture simulating the feel of paper. These surfaces are also hardened to provide durability and longevity. The LCD itself has been structured to eliminate any screen distortion when the pen tip is pressed against the surface. The result is an incredibly natural and intuitive experience (http://www.wacom.com/lcdtablets/index.cfm).

The development of Wacom's LCD tablet presents an opportunity for a powerful way of initiating the design process on the computer without giving up the ease and flexibility of hand-eye coordination (sketching) which designers are familiar with.

\section{Sketch Recognition Today}

Designers' preference to shun the computer in the early stages of design has led to the development of "concept software". This represents a new direction in computer aided design/drawing applications and interfaces, and is made explicit as major $\mathrm{CAD}$ developers begin implementing this new generation of software. AutoDesk's Architectural Studio (AAS) is a computer-based sketcher that is intended to replace pen and paper. Promotional material claims that it captures original design intent through freehand sketching and volume modelling. It does this by "consciously and deliberately" imitating the process pre-computer and non-computer designers used when they "worked with pencils and markers on multiple layers of tracing paper, perhaps with underlays of photographs, site plans or hard-edged drafted work" (Laiserin 2002). Laiserin (2002) claims however that AAS:

\footnotetext{
${ }^{31}$ Wacom is an American Hardware and Software company that produces graphical tablets and lcd tablets. www.wacom.com for more information
} 
offers everything that was good about [the] process, along with much of what was not so good, too. Plans are plans and elevations, elevations; assembling them into models, whether by extruding from them or pasting them onto the faces of Boolean solids, is not very different on an AAS-equipped computer than it was on a bumwad-equipped drafting board (Laiserin 2002).

AAS is often compared with Sketchup, a product developed by @Last Software

(Fig. 10.5). Sketchup was developed to fill - in the words of the developer - "the growing need among design professionals for a more intuitive and accessible

3D design tool" (http://www.sketchup.com/). Jerry Laiserin speaks about

Sketchup in his review:

Whether the user is working in plan, section, elevation or perspective views, Sketchup continuously infers 3-D geometry from 2-D input. Viewed in perspective, any volume can be stretched or squeezed by gripping its edges or by pushing and pulling on its faces. Constructions of effectively limitless 3-D complexity and detail can be crafted almost as quickly as one can think and draw. In fact, Sketchup is the ideal embodiment of most architects' "thinking by drawing" design process (Laiserin 2002).

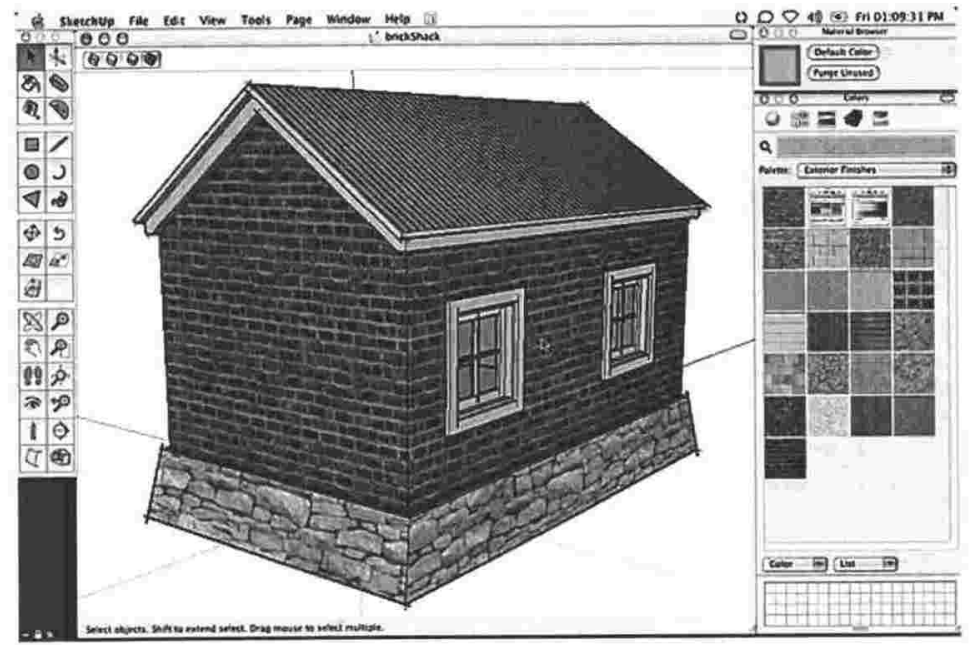

Figure 10.5. A screen capture from Sketchup (Source: http://www.sketchup.com/)

Another application that goes further and integrates both hardware and software is Nemetschek's D-Board. D-Board is a software/hardware combination that offers an advanced, integrated approach to sketching and drafting. The distinction is important in that D-Board has two modes - a sketching mode and a 2D-drafting mode similar to "traditional" CAD. Users draw with a pencil on a pressure-sensitive monitor: freehand and in real time.

The description from the developer's website states: 
The D-Board, a pressure sensitive graphics tablet and pen, opens a new era in drawing. With the D-Board, you design and draw directly on the screen with a stylus. The screen surface is completely flat, so the experience between using the D-Board and drawing on paper is quite similar.

Developed with Plan Quadrate drafting software, D-Board becomes an expressive, intuitive and precise drawing and freehand sketching tool for Architects and designers. It allows ideas to move from initial concept to useable $2 \mathrm{D}$ CAD drawing.

You can easily modify all the characteristics of the stylus: colour, stroke, grade of hardness, thickness, and so on. The pressure sensitivity of the stylus lets you manipulate the color (sic) intensity, coverage, and stroke marks. Just as with a real pencil, the upper end of the stylus works like an eraser. Simply run it over the screen surface and remove the undesired parts of the drawing (http://www.nemetschek.com/).

It should be evident from the three examples that commercial uses of digital sketch technology are aimed directly at getting the designer to use the computer earlier in the process. Effort is understandably placed on easing the entry of data and reducing the rigidity associated with most CAD software. Software packages are therefore more like "electronic markers" or "digital paper" and limited to the capture and interpretation of rough or schematic architectural sketches rather than conceptual sketches. While most research is concentrated on making digital sketching easier and more powerful than sketching on paper (Landay 1996) it does not go far enough to consider and boost its interactivity as an aid to thinking (and by extension - teaching). Despite this oversight the results of current research can easily be adapted to the use of the digital sketch as a means of design thinking and decision making rather than a means of simply capturing, interpreting and editing information.

\section{Relevant Research}

There are three research projects in particular that show tremendous potential in relation to the approach advocated in this work. One is the Electronic Cocktail Napkin (Gross 1996) developed in the mid-nineties by Mark Gross then of the University of Colorado. It allowed architects to sketch their designs on an electronic pad with the computer attempting to recognize common graphic elements found in architectural drawings. The Electronic Cocktail Napkin was then extended by Ellen Do as the basis of the Right Tool Right Time Manager. The Right Tool Right Time Manager basically used the existence of special symbols or configurations to trigger an intention recogniser, which activated specific 
digital tools. The third interesting project is EsQUIsE by Pierre Leclercq, which is a geometrical interpreter of descriptive architectural sketches (Leclercq 2001).

\section{Electronic Cocktail Napkin}

Mark Gross and Ellen Do have designed, since the mid-nineties, a number of systems that use freehand sketching as an interface to intelligent systems for design. These systems include using diagrams for knowledge and image retrieval, building performance simulation, and three-dimensional model making for early stage of design. Two systems are of particular interest to this thesis - the electronic cocktail napkin and the right tool right time manager.

The Electronic Cocktail Napkin (ECN) project was designed to be a prototype diagramming environment that targeted early design activity (Gross 1996). The aim of the project was to support designers in the incremental formalization of the design idea, from conceptual designing to schematic designing. It provided a pen-based interface (Fig. 10.6) that supported ambiguity and non-commitment, parsing and recognition systems analysed the sketches created by the designer and their spatial relationships, and constraint management routines kept the high-level relationship between designer's diagrams (Tang and Gero 2001). At the most basic level of symbolic processing, the system captured stroke data from a digitising tablet and used the pen path and stroke features (speed, corner, aspect ratio) to identify the symbols drawn by the designer (a symbol could consist of a single-stroke mark, or consist of multi-stroke marks). A lowlevel recogniser started the processing and display recognition upon a pen-up action. Designers could also turn off the recognition display, or ask the background processor not to resolve ambiguous symbols until further information was given that helped the program identify the context. It was generally agreed by the researchers on the project that the resolution of ambiguous intentions and the identification of context was an important part of the tool. This was necessary because the same drawing symbol could mean different things in different contexts (Gross and Do 1996). For example, a circle on a floor plan could mean a column, while a circle outside and above a building section with a line penetrating the building envelope, would be the sun 
and light ray. Ellen Do further investigated the relationship between intention and context in her work on the Right Tool Right Time Manager.

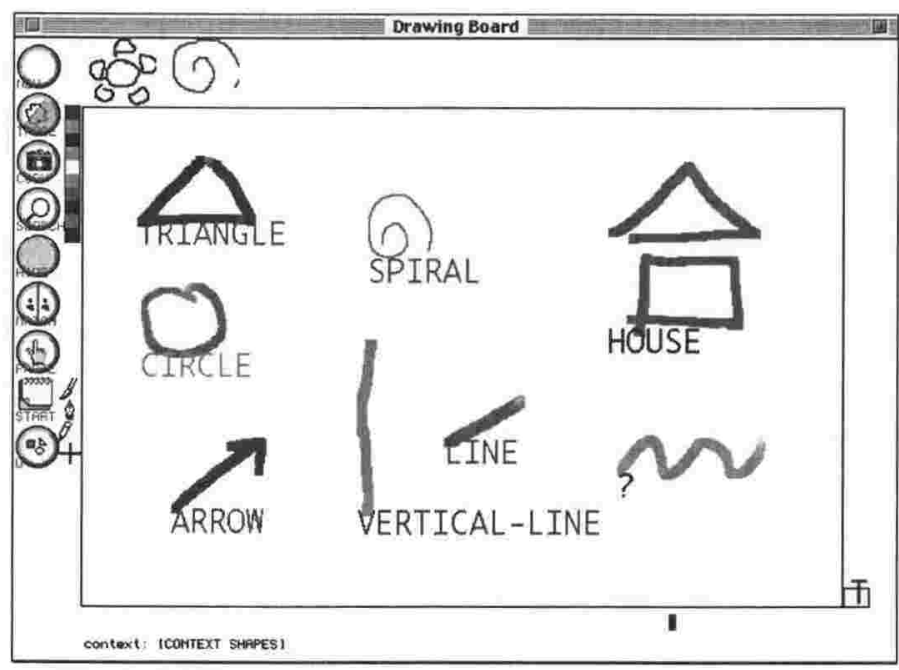

Figure 10.6. The Electronic Cocktail Napkin drawing board

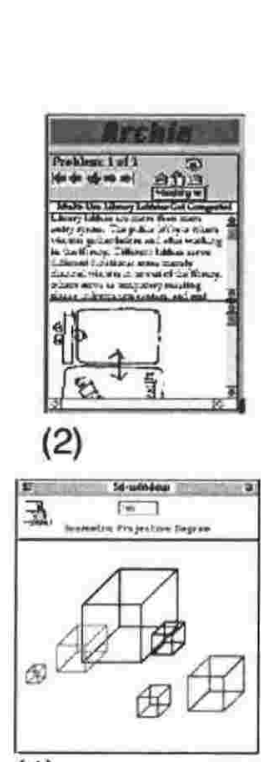

(1) Tools

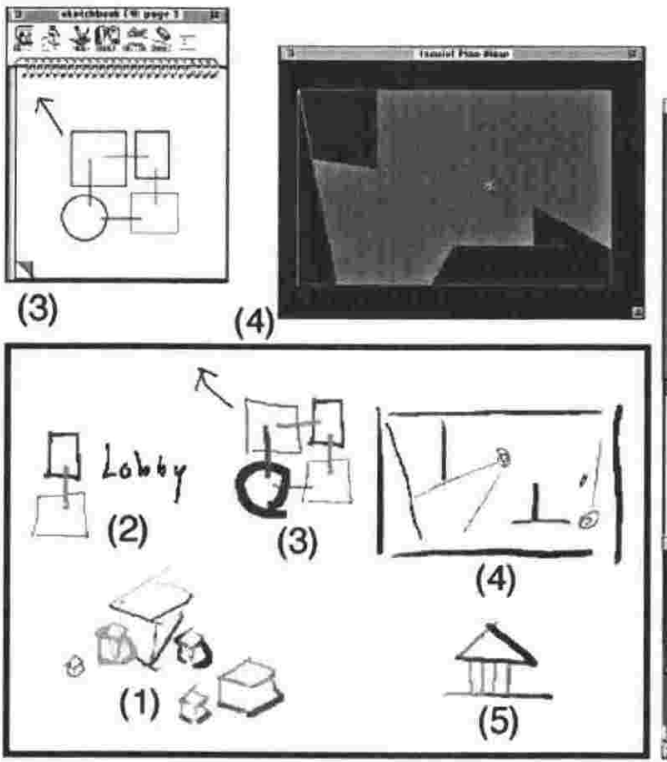

ECN Interface

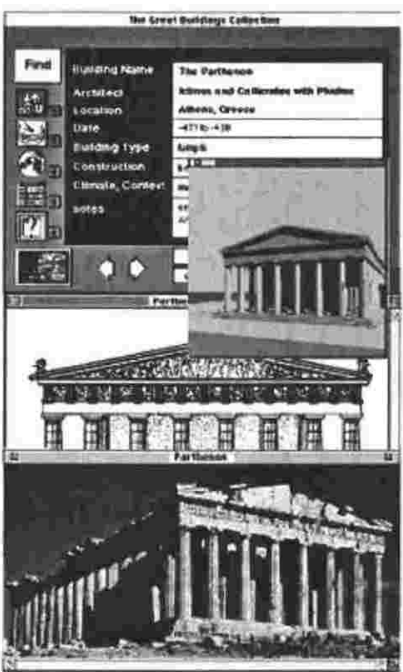

(5)

Figure 10.7. The Right Tool Right Time manager - The symbols and the tools they activate clockwise from left: (1) 3D modelling, (2) Case libraries, (3) Sketch book, (4) Visual Analysis, (5) Slide libraries

(Source: http://depts.washington.edu/dmgmedia/0.intuitive/3.sketch/02RTRT.html)

Right Tool Right Time

Using ECN as a foundation, Ellen Do (who worked as assistant on the aforementioned project) examined through her Ph.D. thesis the viability of an 
intelligent sketch environment that provided designers with the right tools at the right time (Do 1998). Rather than asking the designer to find and select tools for specific design tasks, she explored the notion of automatically invoking various computational tools based on the designer's drawing. Do demonstrated in her investigations that designers used common symbols and markings in their drawings. For example, using Do's own words: “... in Organization activities, architects often draw a bubble diagram to explore functional arrangement of spaces; they draw sight lines and viewsheds when working on visual analyses" (Do 1996). Dubbed RT2 (Right Tool Right Time) the environment used the drawings of the designer as a reflection of the task being worked on. It identified (as outlined in Do's thesis) context based on the existence of special symbols or configurations. An understanding of the context then triggered an "intention recogniser". Once design intention was recognised in the drawing, the system would automatically provide the designer with the appropriate tools for the task at hand. For instance, the system can use the intention and context information derived from the drawing to activate a keyword search on a web search engine or a database. The designer draws a configuration of a computer (monitor and hard drive) and a sunray (sun symbol with arrow that indicates light direction). The system recognises an intention of "monitor glare" and activates the browser to launch a keyword search using a web site. The same interaction can be applied to other knowledge-based systems, a slide library, or a case library (fig. 10.7) 


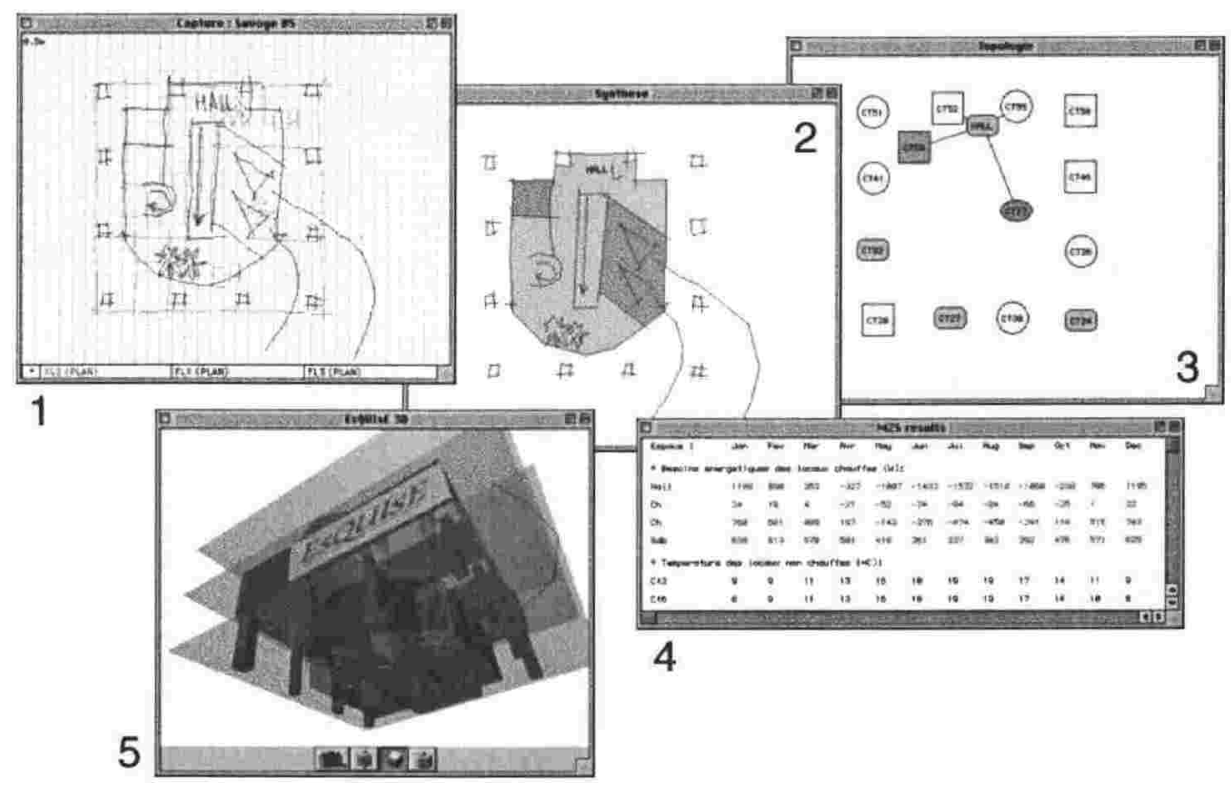

Figure 10.8 EsQUIsE developed by Pierre Leclercq. Clockwise from left: 1 Capture, 2 - Synthesis, 3 - Topologies, 4 - Analysis, 5 - 3D modelling. (Source: http://www.lema.ulg.ac.be/Tools/Esquise/Esquise-Home.html)

\section{EsQUIsE}

Pierre Leclercq also has developed a digital tool that exploits the potentials of the digital sketch. Leclercq describes the aim of his research on his website:

The aim of this prototype consists of composing the spatial semantic representation of the architectural project in order to feed a computer architectural design environment (Leclercq 2002).

Leclercq's software prototype called EsQUIsE interprets the geometrical characteristics of descriptive architectural sketches (Leclercq 2001). EsQUIsE works by using a Wacom digital sketchpad or tablet to capture and interpret the lines of the designer's sketch. It is then capable of deducing, in real time, the spaces enclosed within these lines by "locating its architectural concepts" (functional space, topology) (Leclercq 2002). In addition there is a text recognition and semantic attribution feature for captions that identify the function of each space. Finally, there are two procedures, carried out successively, to compose the spaces and deduce the topological relations in the architectural project being conceived. The resulting architectural representation can be then sent to the usual software programs for assessing building performances (e.g. thermal and lighting evaluators). 


\section{A Design Partner}

EsQUIsE, the Cocktail Napkin and the Right-Tool-Right-Time manager demonstrate that a digital sketching interface is possible. They also demonstrate that a pen-based or "calligraphic" interface can be used in a variety of domains or contexts in the design process. Designers can now use freehand sketches and diagrams to index and retrieve databases or to activate knowledge-based information systems and provide information for simulation programs. Most importantly, these investigations show that it is indeed possible to have the computer act as a design partner where the language of "conversation" is the sketch. According to Do, these tools are frameworks of knowledge capture. One can use the graphic recognition of the system and add to the framework more modules and functionality to support design (Do 2002).

With the appropriate approach and use of the framework, the interactivity of the digital sketch can be considered and boosted as an aid to thinking (and by extension - teaching). A digital design partner would take an approach that takes advantage of the "information exchange" inherent in the sketch and employs the ideas of Do, in particular. It would help design thinking by "guessing" the intentions of the designer and making information available for appropriate design decisions to be made. As demonstrated in RT2 it is possible for intention to be deduced by the computer. Intention can be connected to related activities or information and fine-tuned as the designer reacts and adds more information to the sketch. The ultimate aim of the digital sketch would be to provide the right information at the right time.

\section{Conclusion}

From the arguments presented in Part 2 it is clear that the sketch is a part of the designer; not a tool to be used as an appendage. As argued, the importance of the hand sketch as a means of communication, thinking and learning makes the act of sketching (in whatever form) an essential ingredient in the interaction between designer and ideas, student and teacher, and novice and expert. This interaction or dialog involves the constant interpretations of the sketched image, (and then the inscribing of (re) interpretations of this idea over the original), which makes up the design process. This dependence of the sketch 
has resulted (until recently) in designers' delaying the use of the computer in the design process to the later more defined stages. In an effort to introduce the computer earlier in the process, commercial software developers have employed a number of approaches to the situation. These approaches have ranged from simple "sketch" interfaces to inputting geometrical (2D and 3D) data directly on the display area. Recent hardware advances enhance these approaches. For instance: When used with a Wacom Cintiq (an LCD tablet), sketch-based software like AutoDesk Architectural Studio and SketchUp from @Last Software provide a calligraphic work environment for architectural designers. This sketch-based approach bypasses the process of scanning and tracing paper drawings, and releases the designer from adapting awkward technical, precise, digital drawing tools. Unfortunately this direction does nothing to inspire or enhance the usefulness of the sketch.

Current approaches to the digital sketch focus on representation and drawing procedures, rather than the cognition based capabilities of the sketch. With the Electronic Cocktail Napkin and similar projects like EsQUIsE, we can now consider using sketching in the digital realm as a direct means of thinking and decision-making, rather than as a means to automatically generate forms and shapes for consideration. A result of this is the idea of a cognition based digital sketch, linked with ideas of teaching design by providing young designers with valuable information at the appropriate moment in the design process. By displacing (or changing) the sketch from a passive to an "interactive and smart" medium we can open up greater opportunities for the sketch in the zone of interaction. At this point we can propose the development of a digital teaching tool for young designers (students) that would use the sketch as the method of learning and interface. This would link the three areas of this thesis computers, sketching and design education.

\section{Intelligent Sketching for Education}

In the preceding sections of this thesis we have argued the following:

- Due to the magnitude of reasons, design education is finding it hard to instil in students responsible attitudes towards an architecture that is cost effective, meaningful, constructible and a sensory delight to its users. 
- Design studio relies on the sketch - the premier thinking tool of designers as the central element of the zone of interaction for the transference design knowledge.

- Unfortunately the sketch today is not potent enough to handle the vast amount of information needed to make design decisions especially when employed by students that lack the experience needed to make quality judgements.

- The sketch needs to be empowered so that it can act as an expert "hand" that gives prompts and clues, ensuring that students at least catch on to important issues in design.

- Too often is the computer used for visual tasks not related to cost effectiveness, constructibility and sensory delight but rather related to issues of theory, form and aesthetics. A new attitude needs to be developed towards the use of computer in architectural schools.

The resolution to these issues lies in the existence of the intelligent sketch - a combination of the computer and the sketch. The computer's ability to process (connect, relate, store) large amounts of information with the ability of the sketch to reveal more information than invested in it makes a valuable combination. In this combination, the computer reads sketched images, "knows" what the designer is investigating and offer the appropriate advice for the sketch shown. This information would be sourced parallel to the sketching process and include design issues, technical information, theoretical concepts, or building standards/codes. The intelligent sketch in turn forms a part of a digital design coach in the design studio. This would present the computer as a teaching tool and design partner for students of architecture. The computer would no longer be perceived as alternative media to physical models and pen based systems but rather as a tool to be used in the learning of design ability which is the primary purpose of design education. This tool would be an excellent way of exposing students to the benefits of visual thinking as well as informing them of some of the oft-neglected fundamentals of architectural design. The sketch, for the student, becomes intelligent, supporting and informing exploration while allowing the student to make more intelligent, well- 
informed and confident decisions about architecture. The intelligent sketch then reinforces the thinking capabilities of the sketch, changes attitudes in computer usage and helps design education produce students that are confident in designing buildings that are practical, sustainable and constructible.

We have now defined the acceptable situation for meeting our challenges - a digital teaching tool. We already know that it will employ the intelligent sketch, it will teach students about design and will change attitudes about computers. A design assistance tool that provides clues would allow the student to look at sketches in a different light showing or exposing them to hidden treasures embedded in the sketch. Using this experience, students will look at the sketches that they make carefully and expectantly, in anticipation of recognising unintended patterns and relationships. The students would then take this attitude and knowledge to the "zone of interaction". The tool would then contribute positively to how students use and perceive the sketch. It would also provide a means of revitalising design education (through the relationship of student and master). The question that now remains is - what would such a tool look like?

\section{References}

Do, Ellen Y.-L. 1998. The Right Tool at the Right Time - Investigation of freehand drawing as an interface to knowledge based deign tools. Ph.D. Thesis, Georgia Institute of Technology.

Do, Ellen Yi-Luen. 2002. Functional and Formal Reasoning in Architectural Sketches. In American Assocation for Artificial Intelligence, AAAI Spring Symposium SSS02, 25 - 27 March 2002, edited by Tom Stahovich, James A. Landay, and Randy Davis, 37-44. California: Stanford University.

Do, Ellen Yi-Luen, and Mark D. Gross. 2001. Thinking with Diagrams in Architectural Design. Artificial Intelligence Review 15, no. 1/2 (Mar): 135-49.

Goldschmidt, Gabriela. 1994. On visual design thinking: the vis kids of architecture. Design Studies 15, no. 2: $158-74$.

Gross, Mark D. 1996. The Electronic Cocktail Napkin - computer support for working with diagrams. Design Studies 17, no. 1: 53-70.

Gross, Mark D., Ellen Y.-L. Do, and Brian R. Johnson. 2000. Beyond the low-hanging fruit: Information technology in architectural design past, present and future. In ACSA Technology Conference July 14 - 17), edited by William Mitchell and John Fernandez. Cambridge Massachusetts: MIT Press. 
Gross, Mark D., and Ellen Yi-Luen Do. 1996. Ambiguous Intentions. In Proceedings, ACM Symposium on User Interface Software and Technology (UIST '96), 183-92. Seattle, WA: UIST.

Laiserin, J. 2002. "Picture This: Sketchup2.1 and Piranesi3." 30 Nov 2002. [cited Jan 2003]. Available from <http://www.laiserin.com/features/issue14/feature02.php>.

Landay, James A. 1996. Interactive Sketching for the Early Stages of User Interface Design. Ph.D. Dissertation, Pittsburgh, PA: School of Computer Science, Computer Science Division, Carnegie Mellon University.

Leclercq, P. 2001. Programming and Assisted Sketching: Graphic and Parametric Integration in Architectural Design. In Computer Aided Architectural Design Futures 2001, edited by Bauke de Vries, Jos van Leeuwen, and Henri Achten, 15-31. Eindhoven, The Netherlands: Kluwer Academic Publishers.

Leclercq, P. 2002. "EsQUIsE: Sketch recognition in design." July 2002. [cited April 2003]. Available from <http://www.lema.ulg.ac.be/Tools/Esquise/Esquise-Home.html>.

Pontgratz, C., and Maria Rita Perbellini. 2000. Natural Born CAADesigners: Young American Architects. Basel: Birkhäuser.

Soufi, B., and E. Edmonds. 1996. The cognitive basis of emergence: implications for design support. Design Studies 17, no. 4: 451-63.

Taggart, James. 1975. Sketching, An informal dialogue between dialogue and computer. In Reflections on Computer Aids to Design and Arcbitecture, edited by N. Negroponte, 147-61. New York: Mason/Charter Publishers, Inc.

Tang, H., and John S. Gero. 2001. Cognition-based CAAD: How CAAD systems can support conceptual design. In Computer Aided Architectural Design Futures 2001, edited by Bauke de Vries, Jos van Leeuwen, and Henri Achten, 521-31. Eindhoven, The Netherlands: Kluwer Academic Publishers. 
Part 04

Towards a Design Coach 


\section{Defining a Digital Design Coach}

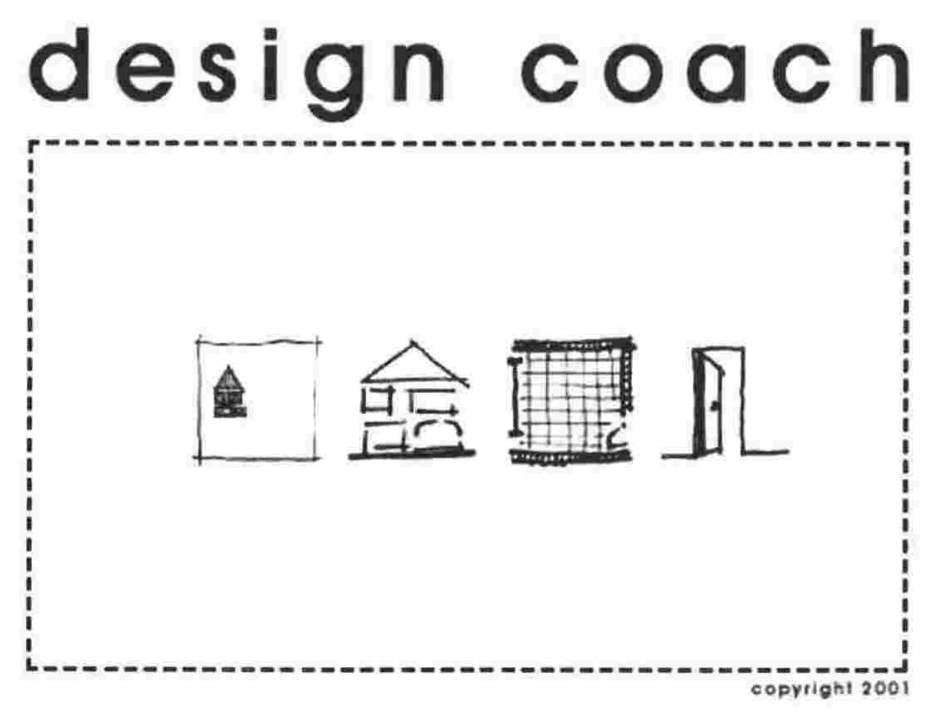

Figure 11.1. Opening screen for design coach prototype

he transformation of architectural teaching and learning, from the
building site to the studio, in academia has come at a price. This has
resulted in the central relationship between student and teacher in
design education, being proven inadequate to deal with the rapid changes in technology and society in the $21^{\text {st }}$ century. At the centre of this relationship is the sketch. It has been proposed so far in this thesis that by using digital technology to empower the sketch, we can allow students to confidently use (through reading and analysis) their sketches to design buildings that are fit for purpose, cost effective, sustainable and a delight to clients and users.

Specifically, in this thesis we have so far:

1. Highlighted the current challenges facing architectural education.

2. Drawn attention to the importance of the "empowered" sketch and its potential influence on architectural design and education.

3. Demanded a teaching role for the computer in design studio that was linked to the direct learning of design ability. 
The intersection of these three domains (design education, sketching and computers) is the key to creating a system, tool, or aid that helps students develop conceptual ideas that reconcile disparate elements into a habitable, environmentally friendly and architecturally responsible whole. The development of such a tool if implemented properly would also enrich the zone of interaction, facilitating a renewal in the architectural education process. The form and embodiment of this solution can take different forms. The form supported by this work is a digital teaching tool that infers design intentions from the sketches students use when designing. The system (which we will call the Design (oach) then informs the student about the design situation by presenting the student with issues related to that particular situation. The student reads the sketch in conjunction with this and is made aware of the implications and consequences of his/her moves. $\mathrm{He} /$ she then changes stance or acts accordingly. When meeting with the master, this awareness allows a higher level of student-master dialogue culminating in a higher convergence of meaning.

This part (comprising three chapters) presents the concept for a digital design coach; a teaching tool for architectural design studio. Chapter Eleven outlines the concepts or principles that the design coach should adhere to. These concepts acknowledge the importance for the tool to reflect the nature of design tasks, facilitate learning and be accessible to all learning types. Chapter 12 describes the tool, as it is intended to be. Mention will be made of a current prototype of the tool, although it should be noted that the design coach in its current form, was built to investigate the kinds of information that would stimulate students and therefore will not be presented as the proposed system ready for implementation. Chapter 13 describes two experiments designed and conducted to investigate students' reaction to the information embedded in the prototype of the tool. This chapter will also discuss the strengths and weakness of the current implementation, the future of the coach, and recommend suitable research directions. 


\section{Behind the tool}
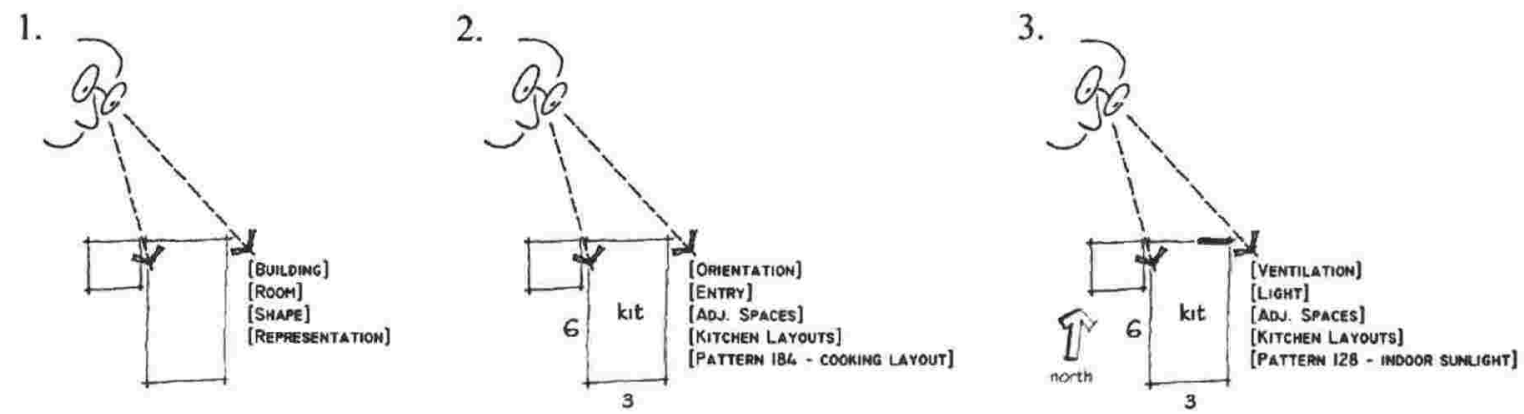

\section{Figure 11.2 Using the Coach}

Consider the following scenario. John, an architectural student, is designing a kitchen. He designs on the computer using a drawing tablet or screen for his task, making a single mark or series of marks on the drawing surface. For each mark John makes on the screen a prompt appears and offers a list of issues influenced by that mark or series of marks. As shown in figure 11.2, our designer draws a box on the screen, a prompt appears and asks questions about the nature of the box - is it a room, or a building or just a shape (rectangle)? These questions seek to give currency (in the mind of the student/designer) to issues of scale and size and the implications thereof. John responds verbally (using speech recognition), 'circles' the issue that interests him or ignores the prompt and continues to sketch (further defining a context for the design). The prompts change accordingly. He defines the context by writing the room name and adding dimensions. The computer then "asks" questions about orientation, nature of adjoining room, egress, etc. as well as provides information from alternate sources (in the example pattern 184 from C. Alexander's Pattern Language (1977) is offered). The orientation of the diagram is indicated and subsequently information appears relating directly to the consequences of orientation to the design task. Issues such as ventilation (wind direction) and light (sun paths) feature in addition to further issues about room layout. These are all presented in such a way for John to ignore and simply carry on, or accept and investigate. This "conversation" (making a mark and responding to the prompts) continues throughout John's design. When John meets with his design tutor to discuss his design, he is able to articulate his problems specifically, ask relevant questions and accept/understand some of his tutors 
statements. This discussion is facilitated by the coach which revealed to John the issues involved in his scheme. He asks the tutor about the importance of ventilation in relation to his ideas about space and home. The tutor responds by demonstrating the moves of validating such decisions or giving John feedback, in the form of criticism, on his attempt at reconciling his issues.

The scenario presented, though simplistic, is the suggestion of a teaching tool located at the meeting point of design education, sketching and computers. As observed in the scenario, conceptually the design coach detects and interprets the marks designers make when sketching in order to determine a context for the issue being investigated. It then presents the designer with related issues, additional information about the issue or offers connections to higher or lower level issues. The student subsequently reads and extracts more information from his sketches than before the coach. The information gleaned also makes the student more aware of the interconnectedness of design issues eliciting more balanced responses to design situations.

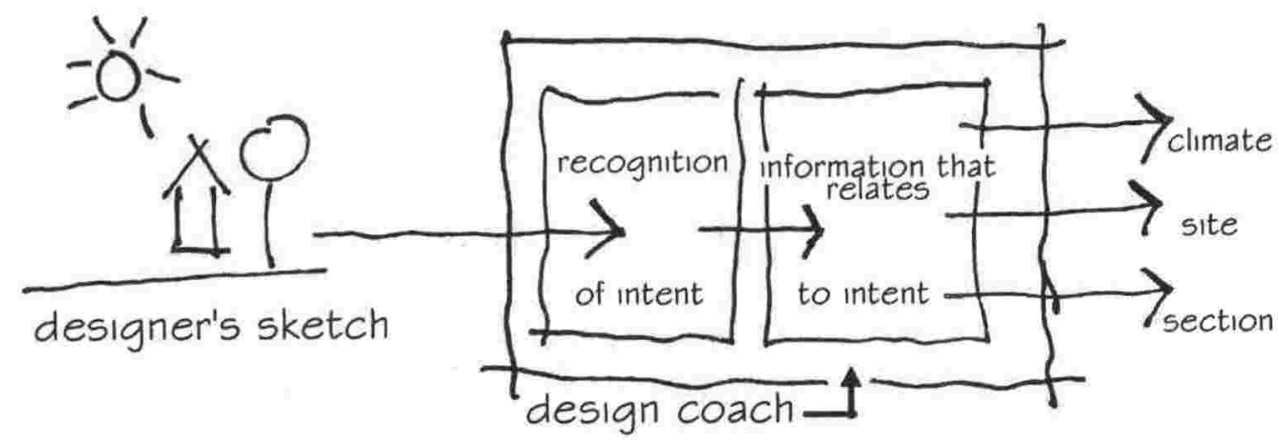

Figure 11.3. Conceptual diagram of a design coach.

The design coach therefore comprises of two main components (figure 11.3). The first (a sketch recognition component) involves recognising the sketch and inferring an intention or issue under investigation and the second (an information component) involves relating specific information to the inference and the communication of such information as clues about the design situation. It has been proven that it is indeed possible for a computer program to "recognize drawing symbols and, based on those symbols, activate different design tools." (Do 1998). As work on the sketch recognition component has 
already been done (Chapter 10), the main discussion in this chapter, as regards to the design coach, will be primarily about the content of the tool.

The nature of the tool's content is significant. While it is crucial for the tool to recognise architectural intent from a personal sketch, the information communicated determines the tool's value. It ascertains how far students will be exposed to the kinds of issues that are involved in the design of real buildings. It is this information that determines the extent to which the design coach will respond to the challenges of architectural education.

\section{Concepts of the Design Coach}

The previous three parts of this thesis have laid out the basic aims that the tool must seek to satisfy. These are:

- To make architectural students aware of the issues that contribute to sustainable, responsible architecture.

- Recognise the importance of the sketch as a means of thinking and learning, and empowering the sketch through the use of digital technology.

- Institute a new attitude towards computers in architectural education

To achieve these broader objectives the proposed tool has to be based on its own "local" principles.

The content of the design coach is based on several assumptions. First, in order to be useful to the design process and teach students about the issues involved in designing, the structure of the content must somehow relate to the structure of design problems. Secondly, for the student to learn, the issues revealed by the coach must contain the kinds of information that serve as clues to ground the student in the realities of design. Third, use of the computer as a teaching tool must be consistent with theories related to computer assisted teaching and learning. Finally, design learning is personal and idiosyncratic therefore a universal approach must be found so that all designers are included in the learning advantages of the tool. 


\section{Design Problems}

The nature of design problems has implications for the design coach. In architecture school, design studio is seldom comparable to other subjects or courses offered to students. It is also different from what most students have experienced in prior educational environments. Previously, when a problem was given in a course, the students know that a solution or set of solutions already exists for that problem. This solution was usually found by applying (in accordance with a learned method) acquired knowledge to the problem. The problems encountered in design studio, on the other hand, have no known results. They cannot be solved by a process of logical reasoning or by applying a series of learned formula. While some technical aspects of the design problem may be predictable, the context, nature and emphasis of the problem (which sometimes is not clearly defined) determine the emergence of the solution (which is expected to be original). Providing students with a design coach that assists in design studio therefore, cannot be as simple as providing a tool with the answers. For students to fully appreciate the diversity, complexity and multivalency of design problems, the design coach must reflect the inherent nature of design problems.

\section{The Nature of Design Problems}

Design problems are special. Unlike crossword puzzles and mathematical problems, design problems are considered ill-defined, indeterminate or "wicked". According to L Bruce Archer (1979):

An ill-defined problem is one in which the requirements, as given, do not contain sufficient information to enable the designer to arrive at a means of meeting those requirements simply by transforming, reducing, optimizing, or superimposing the given information alone. Some of the necessary further information may be discoverable simply by searching for it, some may be generateable by experiment, some may turn out to be statistically variable, some may be vague or unreliable, some may arise from capricious fortune or transitory preference and sonic may be actually unknowable. In addition, once known, some of the requirements may turn out to be incompatible with one another (Archer 1979).

In 1972 Horst Rittel identified ten properties of "wicked" problems (Buchanan 1995) that are consistent twenty-five years later with what Bryan Lawson (1997) considers important characteristics of design problems and solutions as they relate to the nature of design today. For the design coach to reflect the nature 
of design, these characteristics pose limitations that determine the approach of the coach.

In the content structure of the coach the information cannot be seen to be definite because "design problems cannot be comprehensively stated" (Lawson 1997). According to Rittel, they have no definitive formulation (Buchanan 1995). All pieces of information or aspects of the problem can never be stated at the start but rather should emerge with the formulation of a solution. It should be clear to students that problem and solution are dynamically related. It should also be clear that design problems have variables and influences that change as the situation, context and events, making "every wicked problem is unique" (Lawson 1997).

Unlike puzzles or mathematical problems where the task ends when a correct answer is recognised, design problems have no definite end. As Rittel postures: "wicked problems have no stopping rules" (Buchanan 1995). Lawson (1997) describes the design process as endless and attributes identifying an "end" to experience and judgement. This implies that the coach cannot have boundaries or stopping points, but must be perceived as "endless".

Design problems lack definition. It follows therefore that there can never be a complete or definite list of solutions. Since the solution depends on a myriad of variables chief of which is the biases of the designer then there will be a varied amount of valid solutions. If there is a multitude of solutions, there will also be an equal amount of valid approaches or "methods". This corresponds to Rittel stating that "in solving wicked problems there is no exhaustive list of admissible operations" (Buchanan 1995). The coach should be flexible enough to allow or accommodate different approaches to design. It should provide multiple directions to the same problem. For as Rittel says; "for every wicked problem there is always more than one possible explanation" (Buchanan 1995), meaning there can never be a right answer, true or false, but rather an appropriate response, good or bad, which is based on an adequate balance of the concerned variables. 


\section{Structure}

The design coach has to reflect the uniqueness of design problems, have no boundaries, cannot be fixed, have no stopping rules and accommodate the uniqueness of the designer. This, however, demands a structure. Both Rittel and Lawson agree, "Every wicked problem is a symptom of another, 'higher level', problem." (Buchanan 1995; Lawson 1997). Lawson confirms this further by stating, "design problems tend to be organised hierarchically"(Lawson 1997). This particular quality relates mostly to the structure of design problems and so presents the best opportunity for a corresponding structure for the design coach. The organisation of the design problem, therefore, embodies the multidimensional and interactive nature of design.

The design of a building is a kind of multivariable problem. Along with technical issues, there are issues of human occupancy and human use to be addressed as well as a level of responsibility to a larger context (client, users, physical setting, or socio-cultural condition). These issues are themselves "miniproblems" that the designer has to solve. A good illustration of this is the multidimensional qualities of windows.

The Window

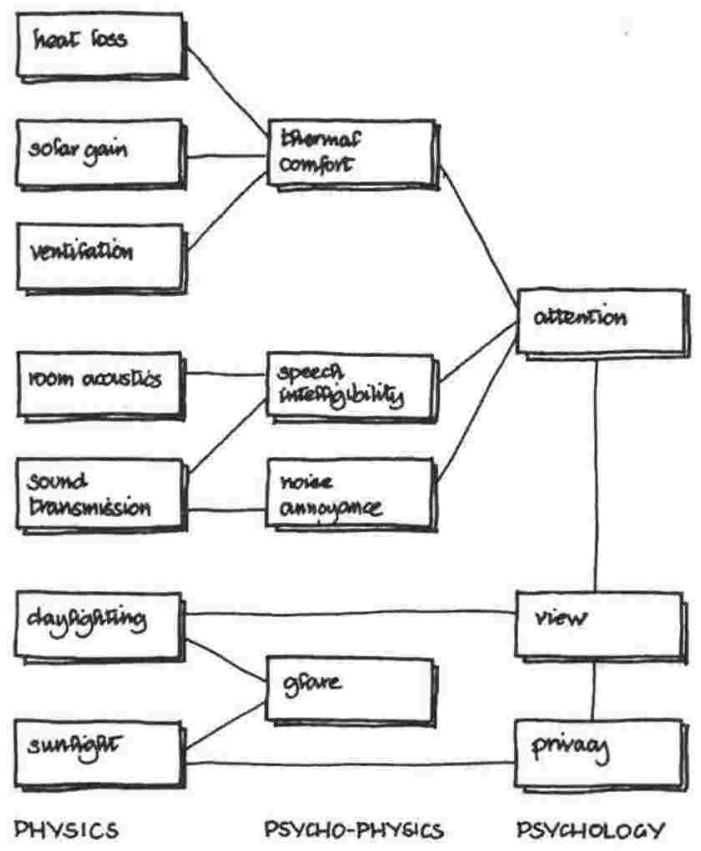


Figure 11.4 Some of the complex array of issues concerning windows. (Source: Lawson 1997)

When examined closely, it is obvious that there is more to the lowly window than that which meets the eye. The issues that confront the designer with respect to windows can be divided into pragmatic issues, social (or psychological) issues and a mixture of both. Pragmatic issues relate to, among other things, the orientation of the window and the amount of sun that particular window will be exposed to. This affects light and heat, in turn determining the size of the windows, which also establishes the amount of ventilation allowed. Poetic or social issues involve such issues as view, connection to outside, privacy and the symbolism attached to windows in a particular culture. Both types of issues simultaneously have ramifications on the size of the window, its orientation, its position in the wall (centre, one side, whether it is a window wall or not), and the activities that surround it. All this is indirectly related to the size of the room, the activities that take place in it, the height of the space and where you enter the space. This further affects the position of the room involved, its relationships to other rooms in the house and so on making the myriad of issues involved in one window more than what the beginning designer can adequately visualise during design.

When given a project in studio students of architecture are expected to deal with a vast array of information that characterises the design task. In order to make appropriate decisions they are required to draw on an extensive body of knowledge derived from the other parts of the curriculum and seek out additional information appropriate to the task. From this they are expected to extract the information relevant to each particular design task. This is difficult since the student usually has none or little appreciation of how to relate the issues or even what the factors initially are. It is beneficial to the student to be somewhat aware of most of the issues (hidden and obvious) involved in the design situation as well as how they are connected. An awareness of these issues while not giving the student a ready solution will allow a competent reading into the realm of possibilities ensuring a richer solution for criticism.

The pedagogical basis of the design coach should therefore entail breaking the design problem down and presenting or revealing its smaller "problem states" 
(or its position in higher level context) to the student. This would give the student a greater appreciation of the issues involved in the design situation, allowing him/her the opportunity to comprehend the design process as an accumulation of problems that need to be considered individually and collectively.

\section{Pattern Languages}

The idea for breaking design problems into malleable pieces is by no means original. Christopher Alexander in his seminal essay - The Determination of components of an Indian Village (Alexander 1963) - and book - Notes on the Synthesis of form (Alexander 1964) - first suggested breaking down or decomposing problems into smaller inter-related issues or problem states as a means of solving design problems. Alexander in his work of the time spoke of breaking design problems down as one would an arithmetic problem. He uses the example of adding two and two and calculating the seventh root of a fifty-digit number. The first can be done simply in the head while one has to find a simple way of writing down and breaking the latter into smaller simpler problems before a solution can emerge (Alexander 1964). In his essay and book, Alexander outlined a method of listing the requirements of the design and stating which pairs of requirements interacted positively or negatively. This information would then be fed into a computer that would determine workable clusters (in which requirements were heavily interrelated but relatively unconnected to other requirements). This resulted in breaking down the problem into independent sub-problems, simple enough for the designer to understand and solve (Lawson 1997). 


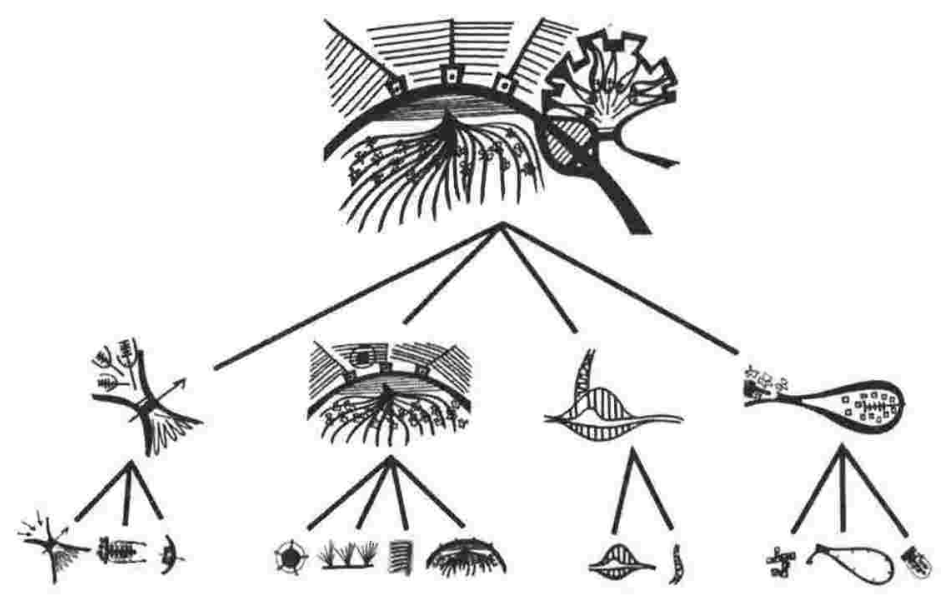

Figure 11.5 Decomposition of issues related to the design of an Indian village (Source: Alexander 1964)

While Alexander's method was rational and reasonable in the early years of the design methods movement, he was subsequently dissatisfied with the rational direction of the design methods, which resulted - in his own words - in an increase in the rigidity of the design process and a worsening of the quality of design (Mitchell 1993). This disappointment saw him (since his denouncement) addressing the more qualitative aspects of architecture resulting in the publication in 1977 of $A$ Pattern Language, "a rich, huge, and instructive set of guidelines" (Saunders 2002). This work, carried out with his team at the Centre for Environmental Structure at the University of California, Berkeley, formulated a "pattern language" which consisted of 253 patterns ranging from the largest scale - towns - through buildings and down to construction details. Alexander gave each pattern a name, a diagram of its spatial layout, the rationale for its inclusion, and a specification of the links between the given pattern and those related to it at a larger and smaller scale (Mitchell 1993). The information was presented in such a way that readers could judge it for themselves and modify it "without losing the essence that is central to it" (Alexander 1977).

Alexander's earlier methods has been heavily criticised over the years (Lawson 1997; Saunders 2002). Chief among the criticisms is the notion that the problem has to be well defined for us to determine all the components and their relations. As discussed earlier, design problems are rarely well defined, therefore it would be difficult to create complete, defined clusters from inadequate 
information (that changes as the solution is formulated). Another criticism is the fact that Alexander's requirements and relationships all have equal value and equally strong connections. This runs counter to the true nature of design problems. With design problems it is more important to satisfy some requirements than others and some requirements are more closely related than others (Lawson 1997). While these criticisms are valid, they however do not discount the notion that design consists of several interconnected problems. A Pattern Language illustrates this by becoming (perhaps unintentionally) a "smorgasbord for selective consumption" (Saunders 2002). Treated as a system of interlocking parts, users of the patterns can pick and choose ideas, connect them like Lego ${ }^{T M}$ blocks, and end up with idiosyncratic compositions of odds and ends that work together. The designer, in addition, gains an appreciation of the relative position of the "favourite" patterns within the whole composition.

With reference to Alexander's method of decomposing the problem, design issues in the design coach must be connected to other issues that reveal more about the problem as you explore them. As determined earlier every variable in design is linked in one way or another to every other design issue. Therefore each piece must be connected to one other (or two other pieces) and revealed as you trace the connections, for example, the problem of ventilation is related to opening, which is connected to light and view; light is connected to orientation, size, and height. The solution then, is finding a suitable method or approach to create a "map" of the problem that the student can use to navigate his or her way through the task.

Structuring the information in the coach in this way has several advantages:

1. It gives students the ability to "read" design issues connected to design situations whilst learning about them. This reinforces the issues in the mind of the student permitting an appreciation of related problems.

2. By understanding or gaining an appreciation of the "pattern" of issues involved in certain aspects of the design problem, the student is best equipped to recognise similar patterns, even in remotely related projects.

3. The most important premise in teaching design is to let the student understand that design is a conscious activity (Uluoglu 2000). Being 
deliberate during the process makes for a more skilled designer. Approaching the structure of the tool in this way, demonstrates to the student that the changing nature of the problem is dependent on decisions taken, hence encouraging more conscious "moves" in the design activity.

4. The student has the opportunity to construct knowledge based on his/her own biases. By presenting multiple issues there is no danger of regulating design response since it is totally dependent on the value the designer places on each issue.

5. The student has the opportunity to reflect on the task by reviewing each issue and their connections.

\section{Computer Assisted Learning Theories}

While it may be novel to implement a digital tool that assists in studio to expose students to the issues that affect architecture it is also prudent to make sure that such implementation is done with due consideration to the relationship between Computer Assisted Learning (CAL), Computer Assisted Teaching (CAT) and relevant learning theories. The development of $\mathrm{CAL}^{32}$ has been inextricably linked with the development of learning theory, as it has evolved over the last twenty years. While the link between the two is not necessarily straightforward cause and effect, there are a range of issues and influences in learning theory that determine the direction one takes when employing a strategy for CAL. In order to be successful the designer of the CAL program has to understand the task, determine the model of learning used, and ascertain whether the proposed tool will be appropriate for the type of material and/or the type of learner intended.

At present there are two dominant learning theories: programmed learning (instructivism) and constructivism. The programmed learning model, which has been linked to behaviourism, theorises that for success, the task to be learned should be broken down into small steps. Each step would then be practised,

\footnotetext{
32 Broadly speaking Computer Assisted Learning (CAL) is achieved by an interaction between a sophisticated program and the student(s), with no human teacher being involved (in theory). Computer Assisted Teaching (CAT) on the other hand occurs when the computer is used by the teacher as a sophisticated presentation tool where different media can be combined into one multimedia. In this work though we are dealing with both CAL and CAT, we will use the term CAL to refer to both.
} 
with correct responses rewarded by offering the next step. Continuous review of what has been learned reinforces the learning until the whole topic has been mastered. In constructivism, it is argued that students are individuals (bringing with them different experiences and cognitive abilities) and only learn things they see as relevant to their own needs. In order for learning to be meaningful, they should be allowed to construct their own model of the topic being learned. In other words students learn "deeply" by adding new knowledge to their existing knowledge that already "fits" their current framework (Unknown 2000). This would be achieved by "holistic" teaching at the student's own rate while involving the student in decisions about what is being learned. Compared to instructivism, constructivism is a meta-theory (made up of lots of influences and perspectives) and is widely accepted as modern cognitive theory (Anonymous 2000). It should be noted that this latter learning model reflects that method of teaching advocated by Donald Schön and employed in design studio.

Different forms of CAL are based upon these two pedagogical philosophies. For example; programs based on instructivism (linear programs) present the user with small pieces of information per screen. This is followed by a question and a set of options. If the student answers the question correctly, he or she is moved on to the next screen. An incorrect response would lead to the question being repeated. On the other hand, programs that embrace a constructivist viewpoint provide the opportunity for different learners to learn at different speeds and in different directions. These "branched" programs give students the chance to explore the consequences of their decisions (like a game of chess, where decisions made early on influence the whole direction of the game). These programs are often used when there is often no clear-cut answer to any particular question (Unknown 2000) as in design.

Despite the fact that there is such difference between these two philosophies and others, there are common aspects of each that are used in modern teaching (and fit well into CAL applications). For instance; though largely discredited, techniques from behavioural theory, like repetition and reinforcement through feedback and motivation, are still recognised today as important in the process of learning. The point is, in developing software tools for learning the software 
designer must be prepared to refer to different theories or explanations of learning. All theories of learning, whether they are "psychometric, humanistic or behaviouristic" are valuable in comprehending certain kinds of learning (Open Learning Technology Corporation 1996). By taking a varied approach the software designer can discover the most appropriate way of addressing a particular learning situation. It is therefore acceptable that the design coach should incorporate aspects of various learning viewpoints. The design coach should include (but is not limited to) the following principles:

Student centred learning - The idea of student centred learning is associated with cognitive views of learning and constructivism. This teaching approach emphasises the importance of providing control over the learning experience with the learner, rather than with the teacher or instructor (Open Learning Technology Corporation 1996). Design studio uses this approach since students are required to find their own way through design with only periodic intervention from the studio tutor.

In order to facilitate and maintain this independent understanding the design coach must embody and support student centred learning. This would, among other things, allow the student to develop a position or positions towards architecture influenced by his/her own experiences and biases. To achieve this, the tool must allow enough flexibility for experimentation yet be structured enough to emphasise motivation and rewards, keys to developmental learning. This structure must employ scaffolding ${ }^{33}$ to enhance the students' grasp of concepts. Through the use of prompts, the coach must present information in pieces prompting students thinking as they participate in design and allowing them to build up knowledge.

Feedback - Feedback is an important concept in learning. It involves providing learners with information about their responses, since knowledge of performance is necessary to correct mistakes and develop new plans. Feedback can be positive, negative or neutral and is almost always external (i.e. provided by the tool or teacher). Critical variables when employing feedback include the length of time between the response, the tone of feedback, the choice of an

\footnotetext{
${ }^{33}$ Scaffolding is the term used in learning theories to define the form of guidance that helps students carry out tasks that might ordinarily be too difficult.
} 
appropriate 'step size' (i.e. how much information to present at once) and how often feedback should be provided.

While it is important for the tool to provide feedback on issues of choice it is crucial that the tool permits adequate feedback to be given by the design tutor. It must be clear enough to allow students the ability to articulate information about the design situation (when discussing their choices with the tutor) to get valuable feedback. It has to be also closely supported by the tutor.

Dual coding - According to learning theories about dual coding, learners are much more likely to learn effectively if information is presented both verbally (or in written form) and visually, simultaneously (Open Learning Technology Corporation 1996). This reinforces the notion of the powerful language of designing which, as claimed by Lawson (1997), comes about through the combination of words and pictures and echoes Schön's (1985) meta-language where the master describes (using words) what he/she is demonstrating (using pictures).

Images are usually represented in CAL software as an illustrative medium and not as an application of dual coding theory. In the design coach images coupled with words must play an essential role in the cognitive processes of learning. Lawson in referring to Nigel Cross states that by studying both together the development of design ideas will not be "creative" leaps but rather "bridges" between ideas. This happens as words enable transitions between ideas, which "look abruptly different if we only look at drawings" (Lawson 1997). This combination will also give the student command of his/her visual library and a better grasp of reading and representing issues in the sketch.

Motivation - Motivation is a pivotal concept in most theories of learning. Behavioural theories tend to focus on rewards while cognitive theories deal with goals. In many instances, motivation is closely related to feedback. Receiving a reward or feedback for an action usually increases the likelihood that the action will be repeated. For example, a person needs to be motivated enough to pay attention while learning; inadequate feedback about performance can decrease motivation to learn. Computers are often cited as a means of improving motivation for learning in students through feedback. 
The design coach should employ at least four qualities for the motivation of students. It should challenge by providing information that involves uncertain outcomes, hidden information or randomness. Second, it should arouse the curiosity of students. This happens when they believe their knowledge structures are incomplete or inconsistent. The tool's information should be relevant to the studio task, as students need to see the relevance of any endeavour. Finally, the information should also be engaging so as to pique the interest of the student.

Transfer is defined as improved performance on one task as a result of something acquired on a previous task. It is essential in learning as almost all theories of learning consider transfer in one way or another. For instance, behavioural theories usually discuss transfer in terms of stimulus/response generalisation while cognitive theories tend to discuss transfer in terms of the restructuring of knowledge. Social learning theories often deal with transfer through modelling or imitation (Open Learning Technology Corp. 1996). Regardless of the approach to learning, it is imperative for the coach to present information in such a manner, that the student can reassemble the acquired information in a different context.

Reflection is a crucial part of learning. Fundamental to the constructive approach to learning is the idea that meaning cannot be imposed or transmitted by direct action (i.e. teacher handing out knowledge), but rather, that knowledge has to be created by the learner through the transformation of personal experience (Webster 2001). Considering and reflecting on the learning process promotes deeper learning and the ability for the student to review an educational journey is an important characteristic of a CAL tool. The design coach as consequence of this idea must allow and promote reflection.

Scaffolding is also an important part of computer-assisted learning. With reference to Vygotsky's theory of learning; the assistance students receive when tutors or more capable peers provide information and support necessary for the intellectual growth of the student is termed scaffolding (Open Learning Technology Corporation 1996; Nicholl 1998). Scaffolding, when used in the context of CAL, however, can also signify support materials and support 
processes (Open Learning Technology Corporation 1996). To adequately provide the educational benefits of scaffolding the design coach is mandated to give active support to the student rather than exist as an assistance tool.

\section{Towards a Design Coach}

To summarise; in order for the design coach to conform to selected learning theories as they apply to CAL applications, it has to:

1. Allow students to independently construct their own knowledge (student centred learning).

2. Adequately motivate students.

3. Facilitate the transfer of ideas from design situation to design situation.

4. Accommodate instances of both visual and textual information.

5. Facilitate student reflection.

6. Provide opportunities for a richer teacher/student feedback.

7. Utilise the notion of scaffolding.

\section{Dealing with Learning Styles}

One of the most important components in the construction of learning tools and techniques is the learner. When considering the learner it is essential that the learner's style as well as their approach to learning is well considered and accommodated before any attempt at implementation. Failure to do this can result in the exclusion of a significant portion of the intended learners. As discussed in Chapter 4, designers are taught to develop an idiosyncratic and extremely personal design process. It has been argued that different designers have different views of the world (Rittel \& Webber cited in Powell 1987) and so view and assimilate information in diverse ways (Powell 1987). These two facts are reflected in the myriad of different approaches students take to learning and doing design. Only one on one coaching by the most flexible of design teachers, therefore, can fully support students' individual learning needs. As we agreed earlier, providing each student with such support would be prohibitively expensive. Understanding how students learn, why there are differences 
between students' learning and the characteristics of learning styles allows for greater inclusion or specific exclusivity when designing tools and techniques for teaching. Comprehension could also be used to predict what kind of instructional strategies or teaching methods would be most effective for a given individual and learning task.

\section{Learning Styles}

Learning styles are determined by several factors. The general theory of measuring and determining learning styles indicates that students' learning preferences are a factor of varied environmental, emotional, sociological, physical and psychological conditions (Price, Dunn, \& Dunn, 1991 cited in Open Learning Technology Corporation 1996). Different combinations of these learning conditions come together to form an individual learning style profile. Since preferences are largely biologically determined, it would be difficult to change a learner's learning style. It would be wiser therefore that CAL development takes into consideration learning styles rather than trying to modify them (Open Learning Technology Corporation 1996). The design coach therefore is mandated to consider and accommodate various learning styles.

\section{Powell's Learners}

J. A. Powell (1987) provides a comprehensive means for this consideration by suggesting four private frames of reference through which designers assimilate information. Through research and studies at Portsmouth's Design Information Research Group, Powell (with some reference to Kolb) suggested "an improved, but still realistic, strategy to make architects to learn (sic)" (Powell 1987). Through rigorous study, Powell and his team described "architects particular learning predispositions and their handling of their interpersonal engagements in the world..." (Powell 1987). According to Powell, each learning type or "style" by creating "its own inherent, self-sustaining, perceptual bias, will capture a particular mirroring of reality" (Powell 1987). His four "learning" types gives us a reasonable way of predicting architectural students' response to the sorts of information contained in the coach. It can be argued that using this knowledge would increase the chances of students learning from the coach. 
Powell's "learners" are as follows:

The rigorous designer learner understands the real world through "abstract thoughts and mental constructions". They attempt to construct a reasonable understanding of the world by seeking out underlying patterns in information. "Information properly organised and fed into their minds bit-by-bit will be retained by these memories" (Powell 1987). Well structured, logical information is therefore seen as valuable. Powell adds:

In linguistic terms simile is the most appropriate form of metaphor for these designers, where a new idea or topic is explained by likening it to another e.g. the wall insulation is like a blanket. Information is sought that is reinforcing (Powell 1987).

Dynamic learners view the world as concrete and physical. They can only cope with information in short bursts and therefore enjoy fast acting learning processes like brainstorming (Powell 1987). Because these learners require quick feedback, information that is challenging, immediate and gives a general sense is favoured above clarity and accuracy. Case based reasoning (examples of similar situations) usually helps in the understanding of basic principles. Dynamic learners are also independent, assertive, do not like to be led, and prefer to be in control. Their learning therefore has a propensity to be self-directed discovery.

The focussed learner's world is also concrete, physical, and objective. They evaluate the world through their "extraordinary physical sensory abilities of sight, hearing, touch, taste and smell" (Powell 1987). Their generic learning style is that of reflective observation where they understand their reality as a montage of information from which useful parts can be removed. As a result, they readily accept relevant information.

Conveying information to the focussed learner requires metaphors that are practical, useful and strongly conservationist. Such metaphors should be direct and hard-hitting having no potential to change form, alluding to similarities between objects and employing direct substitutes of one object for another to aid description.

The contemplative designer learner's real world is the abstract, non-physical world of feelings and emotion. Their generic learning style is a combination of abstract patterning and reflective observation. They are team workers, and as a 
result, the sharing of information is an identifiable characteristic making them easily influenced by information.

All contemplative designer learners strive to find the existence of a unique wholeness in life, by carefully studying the many facets of that whole. For them, the fluid, ambiguous flow of information can be perceived as having latent patterns waiting to be found through proper analytical exploration. The use of allegorical metaphor (describing subjects in the guise of others) enables them to make sense of seemingly unrelated sets of information or objects. Their ability to dislocate themselves from the world gives them the potential for fairly dynamic innovation in such respects (Powell 1987).

\section{Universality}

In defining these four learners Powell's concern was only in improving the way in which information is transferred to designers. He claimed:

...this desire extends to our development of all systems and processes that will help to make designers to learn better; our learner description should be seen in this light as summary communication strategies to aid this process of transferring information towards architects (Powell 1987).

These categories therefore, do not represent the individuality of students' design learning processes. A further claim was made that the behaviour of designers could at least be given a "tolerable degree of approximation". This approximation represented by the four categories "could be used to enhance information transfer" if communication to designers was adapted to conform to the four learning types. Powell makes the disclaimer:

It is not our intention for it to be seen as a new educational design method, showing, as the ultimate perspective, our four designer contexts. On the contrary, the four world perceptions presented here try to create an "essential pluralism", to show us how many other typologies can be brought to bear on the problem (Powell 1987).

If we map and consider these four groups in the information generated by the design coach, there is a good chance that the student will not reject the information. The information in the tool therefore should:

1. Allow self directed discovery (dynamic learner, rigorous designer learner) 
2. Be quick and relevant with little required commitment (dynamic learner, focussed learner)

3. Be generalised and applicable to similar situations (dynamic learner)

4. Employ different forms of metaphors as a means of transmitting and reinforcing ideas (rigorous designer learner, contemplative designer learner).

5. Demonstrate clear connections between pieces of information showing the big picture where possible (rigorous designer learner, contemplative learner and focussed learner).

6. Have the ability to share information and incorporate information from other sources (contemplative designer learner)

7. Allow reflection (focussed learner)

8. Allow a dual existence of abstract concepts and practical facts. (Contemplative learner, rigorous learner and focussed learner)

\section{Sketching}

At the risk of contradiction; the earlier statement that the nature of the content of the tool is significant to the tool's value is only half the story. It does not take into consideration a much deeper tenet. The use of the sketch as interface is a very important part of the tool. It is a fundamental guiding principle. As declared in the introduction, the digital sketching and intention recognition component of the tool has already been examined and demonstrated by the Right-Tool-Right-Time system developed by Ellen Do and reinforced by the work of others in the field. The RTRT system "detects drawing symbols and configurations, uses them to infer the designer's intent and task context, and then provides appropriate design tools to support decision making for that task" (Do 1998). It is intended that the RTRT system (or similar technology) become the "engine" for the design coach or rather, the software architecture on which the teaching tool will be based. Although the benefits of this intention have been discussed in Chapter 10 it is important to reiterate them here. 
The sketch as a base or engine for the tool is founded on several reasons. It is the most efficient and effective way of compelling the student to directly engage with the design information. When the student is engaged and otherwise immersed in the information (embodied by the sketch), he/she can begin to control the output. This control results in experimentation, as the student understands implications, connects or relates responses to corresponding actions and sees the sketch as more than just a tool for representation. These connections and implications take on greater meaning because the student is immediately engaged in the task. It becomes personal because it responds to the students own particular way of representing the world. The student begins to read into sketches (even without the computer) and retrieve the hundreds of questions and issues embedded in the visual image. In the end the student achieves a guiding principle of architectural education - learning by doing.

\section{Conclusion}

Using a design coach to teach students of architecture about design issues should be established on selected (often unrelated) principles and use the sketch. These selected tenets, which range from overarching learning theories to the structure of content, govern the effectiveness of the tool. If we pool the requirements from each tenet we can arrive at a more comprehensive prescription for the basis of the teaching tool (fig 11.7). Providing support for this would be the interface - digital sketching.

One of the most important tenets is encouragement of student centred learning. For the coach to fulfil this aim of self-directed discovery, it must motivate, challenge, arouse the curiosity and command the interest of the student. This would be facilitated by information that is, among other things, relevant to the studio task. The knowledge created by the student courtesy of the coach would be more meaningful to the student since it is based on the student's own biases and values (placed on the issues and connections presented by the tool). 


\begin{tabular}{|l|}
\hline \multicolumn{1}{|c|}{ A. Content Structure } \\
\hline \hline + Break up problems for easy \\
reading \\
+ Connect and relate issues \\
+ Facilitate awareness of \\
conscious decisions \\
+ Equip Student with ability to \\
recognise similar patterns \\
+ Dependent on student's biases \\
and experience \\
+Allow review of decision map \\
\hline
\end{tabular}

\begin{tabular}{|l|}
\hline B. CAL Learning Theories \\
\hline \hline + Student centred \\
+ Facilitate feedback \\
+ Dual Coding \\
+ Motivate Student \\
+ Allow easy transfer \\
+ Foster Reflection \\
+ Scaffolding \\
\hline
\end{tabular}

\begin{tabular}{|l|}
\hline \multicolumn{1}{|c|}{ C. Learning Styles } \\
\hline \hline + Allow self directed discovery \\
+ Information Applicable to similar \\
situations \\
+ Employ metaphors \\
+ Demonstrate clear connections \\
+ Quick relevant information \\
+ Allow reflection \\
+ Dual existence of abstract and \\
concrete information \\
\hline
\end{tabular}

\title{
Student Centred $\mid$ A. Dependent on student's biases and experience C. Allow self directed discovery
}

\author{
A. Allow review of decision map \\ Promote Reflection B. Foster Reflection \\ C. Allow reflection, Facilitate feedback \\ Facilitate Transfer $\mid \begin{aligned} & \text { A. Equip Student with ability to recognise similar } \\ & \text { B. Allow easy transfer } \\ & \text { C. Information Applicable to similar situations }\end{aligned}$ \\ Connect Information $\mid \begin{aligned} & \text { A. Connect and relate issues } \\ & \text { C. Demonstrate clear connections }\end{aligned}$
Multi-format information $\mid \begin{aligned} & \text { B. Dual Coding } \\ & \text { C. Dual existence of abstract and concrete }\end{aligned}$
}

Figure 11.6. Consolidated principles on which the design coach should be based.

Information from the coach would also allow easy assimilation and acknowledgment of the relationships and connections that make up the structure of design problems. This can be offered as a decomposition of issues that the student can "assemble" according to his or her personal creativity. This will enable a deeper understanding of the nature of each piece and the variety of combinations possible.

Promoting the construction of knowledge through the critical review of actions is an important characteristic of architectural education. The design coach should provide the student with the opportunity to review each issue and their connections. This can be achieved by presenting a history of moves that reflect on the task being attempted.

The ability for the student to transfer knowledge from one design situation to another is another goal of the coach. Design information has to be encountered in one "space" and reassembled in a different context. For this to happen the coach should present information (issues and combinations of issues) in such a manner that it is easily read in other situations. This can be achieved by information that; is not context specific, is generalised and applicable to similar 
situations, employ different forms of metaphors as a means of transmitting and reinforcing ideas. Presenting design issues for effective transfer reinforces the issues in the mind of the student permitting an appreciation for related design problems. The student, by understanding or gaining an appreciation of the "pattern" of issues involved is best equipped to recognise similar patterns even in remotely related projects.

For the tool to be inclusive and accessible to a variety of users with different learning and design styles it must attempt (at least) to be universal. Added to this requirement is the presence of dual coding - the use of information presented both verbally (or in written form) and visually (images). The tool therefore must employ multiple formats for the information offered. The information therefore, as far as possible, should be simultaneously, a combination of words, pictures, abstract concepts and practical facts.

Emulating the structure of design problems has as its primary goal the illustration of connections. For the coach to be of value to the education of the architect it must reveal the connections or relations between design issues. This can be done by breaking the design problem down and presenting or revealing its smaller "problem states" to the student. Demonstrating clear connections between pieces of information and showing the big picture where possible will illustrate to the student or provide the means of understanding how the pieces come together. This would give the student a stronger grasp of the various issues involved in the design situation, allowing him/her the opportunity to see the design process as a means of combining and reconciling (connecting) disparate design considerations.

The master also plays an important part. While we have advocated student centred learning as a desirable feature of the tool, we cannot ignore the value of the design tutor to the coach. The coach will open the student to self discovery and present ideas for pursuance. It would be the tutor's duty, in relation to this, to "validate" the student's own decisions and directions instilling confidence in the student.

Answering the challenges facing architectural education involves recognising the value of process and the issues that make architecture. A design coach that 
enhances the interaction between student and teacher can support this. For this digital design coach to be of great value to design education it must use the sketch as the means of interface. It must encourage student directed learning, and allow the transfer of ideas by clearly connecting issues through different information formats. The student should also have the opportunity to review and reflect on the information acquired. Based on these statements or assertions, we now have a set of principles on which to guide and base the physical embodiment of the design coach.

\section{References}

Alexander, Christopher. 1963. The Determination of components of an Indian Village. In Conference on Design Methods, edited by John Christopher Jones and D. Thornley. Oxford: Pergamon.

Alexander, Christopher. 1964. Notes on the Synthesis of Form. Cambridge: Harvard University Press.

Archer, L. Bruce. 1979. Whatever Became of Design Methodology? Design Studies 1, no. 1: 17-18.

Buchanan, Richard. 1995. Wicked Problems in Design Thinking. In The Idea of Design: A Design Issues Reader, edited by Victor Margolin and Richard Buchanan. Cambridge, Mass.: MIT Press.

Do, Ellen Y.-L. 1998. The Right Tool at the Right Time - Investigation of freehand drawing as an interface to knowledge based deign tools. Ph.D. Thesis, Georgia Institute of Technology.

Lawson, Bryan. 1997. How Designers Think: The Design Process Demystified. Third ed. Oxford: Architectural Press.

Mitchell, C. Thomas. 1993. Redefining Designing: From form to experience. New York: Van Nostrand Reinhold.

Nicholl, Trish. 1998. "Vygotsky, Vygotsky Centennial Project: Massey University's Virtual Faculty". [cited 3 Jan 2003]. Available from <http://www.massey.ac.nz/ ALock/virtual/trishvyg.htm>.

Open Learning Technology Corporation. 1996. "Learning with Software: pedagogies and practice Learning Concepts.". [cited 3 Jan 2002]. Available from <http://www.curtin.edu.au/learn/unit/05474/lconcepts.htm>.

Powell, J.A. 1987. Is Architectural Design a Trivial Pursuit? Inaugural Lecture presented at Portsmouth Polytechnic, Portsmouth, England, 25 March 1987.

Saunders, Willam. 2002. Ever more popular, ever more dogmatic: The sad sequel to Christopher Alexander's work. Architectural Record May 2002: 93-96.

Uluoglu, Belkis. 2000. Design knowledge communicated in studio critiques. Design Studies 21, no. 1: 3358. 
Unknown. 2000. "Computer-assisted learning: Can computers replace teachers?" 11 Feb 2003. [cited 15 Feb 2003]. Available from <http://www.stir.ac.uk/departments/ humansciences/education/ict/CD_Roms.html>.

Webster, Helena. 2001. The Design Diary: Promoting Reflective Practice in the Design Studio. presented at Architectural Education Exchange 2001 - Architectural Educators: Responding to Change, Cardiff, Wales, 11th -12th September 2001. 


\section{Testing the Digital Design Coach}

The proof of the pudding is in the eating (unknown)

\section{digital design coach}

choose a position on the matrix to start project

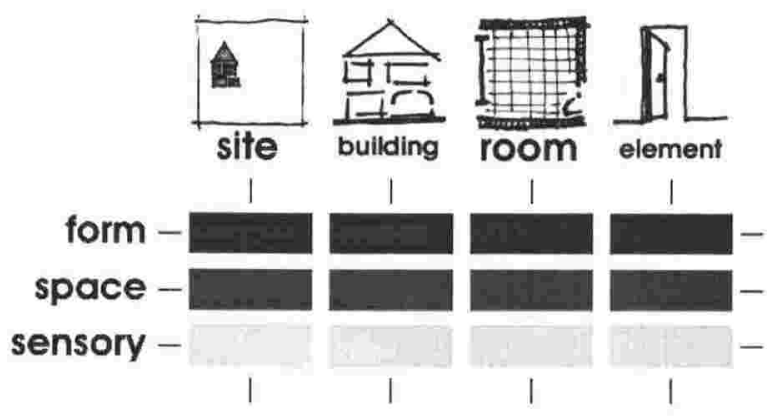

Figure 12.1 Starting matrix for design coach

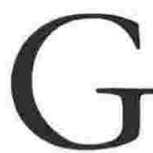

rounded theories eventually have to be tested. In parts one, two and

three of this work, the challenges and opportunities that face architectural education, sketching, and computers were examined and highlighted. It has been determined that the implementation of a teaching tool, a design coach, could be a possible catalyst for the enhancement of the design studio. In Chapter Eleven, we defined a set of concepts or principles that should serve as the foundation for a design coach. It is presumed that based on these concepts, the resulting system will greatly assist the student of architecture grasp the relevant ideas needed to make architecture work. In turn this awareness will also enhance the zone of interaction between student and master. This presumption, however, remains conjecture, unless it is proven to be feasible. Conducting usability studies was the approach taken in this research to predict the feasibility of the system.

This chapter illustrates the implementation of two usability studies conducted with differing versions of the design coach. The first was performed on a preliminary prototype and involved four architecture students. Testing was 
done in a pseudo-experiment format that resembled the head and hand experiment introduced in Chapter 6. The tested model was revised, upgraded, and retested in a design studio of seventy-plus students. Data collection for the tests consisted of design protocols and questionnaires in the first case and questionnaires in the second. After presenting the results, the chapter interprets the data, and ends with recommendations for further upgrading and testing.

\section{Experiments}

The design coach proposed by this study will be capable of processing and interpreting a freehand sketch. Having determined an intention from this interpretation, it would present the student with concerns, connections and references related to the issue under investigation. The sketch recognition, interpretation and intention recognition abilities of the coach has already been investigated and tested extensively by Gross, Do and others (Chapter Ten). It can be readily acknowledged, therefore, that this aspect of the tool has been generally proven viable. The reaction of the student to the issues, connections and references - in short, the content - embedded in the tool has not, however, been tested. This aspect of the tool is by far the most important, and therefore requires investigation.

In this research, investigating the usability of the design coach would primarily entail examining its effectiveness as a means of providing relevant information to students. Such an investigation should seek to determine:

1. How students respond to the specific information structure proposed.

2. How students react to different information formats.

3. If the use of teaching assistants (computer based) affects the student's knowledge base used in the designing process.

4. How the design coach compares to a human tutor.

5. If the use of the coach affected or was affected by, the passivity or proactive attitude of the student.

Determining this information can only be achieved by exposing the subject (student) to the tool and testing his/her reaction to it. Two such situations were 
set up, using prototypes of the content and structure of the information component of the tool.

\section{Preliminary test}

The first usability study chose to evaluate the student's response to "structured" objective knowledge in the form of a "rigged hand". Using the double $h$ arrangement described in chapter six, the subject (student) played the role of head while the researcher assumed the role of hand, and operated a desktop computer that contained the design coach prototype. During the interaction, the hand (researcher) supplied the head (student) with information via the computer, with various questions and suggestions related to the design task. The hand, in this sense, could be regarded as "programmed" or "rigged" with information relative to the task. This circumstance was used in two distinct situations or conditions. In the first condition, the hand (researcher) sketched whilst operating the prototype ${ }^{34}$. In the second condition, the head (student) produced his/her own sketches while the hand (researcher) operated the prototype only. The rationale behind using the two situations was to:

- Determine how much influence sketching has on information retrieval.

- Determine how much influence the student's level of initiative has on retrieving information.

In both conditions, the researcher attempted to be as impartial as possible to limit any influence on the results. The main reason for the researcher operating the computer was due unfortunately to practical reasons: time and scheduling (the time required for training the student to operate the system and know what information was available was limited) and maintaining some control (compensation would have had to be made for the added handicap of the student struggling with the software).

\section{Subjects and Setup}

Four subjects participated in this study. All four were students from the second year of the B. Arch course at Victoria University of Wellington. Design

\footnotetext{
${ }^{34}$ Similar to the practitioner's activity in the heads and hands experiment in Chapter Six.
} 
experience of the four was therefore limited only to first year design (where little if any building design took place). It can be safely noted that the students were designing a full building for the first time.

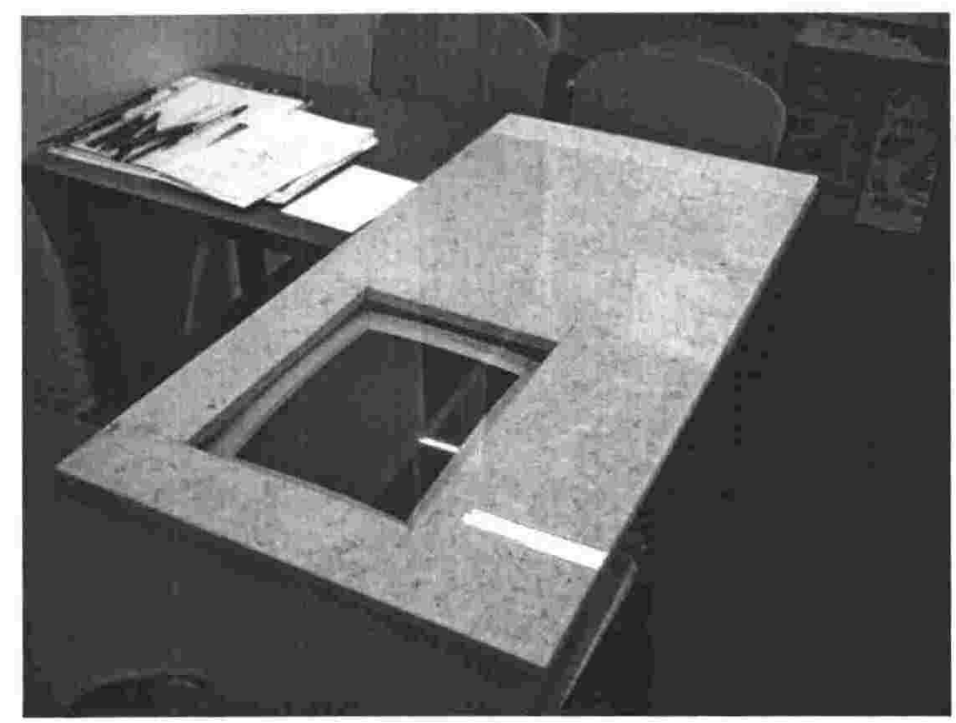

\section{Figure 12.2 Set-up for the first testing of the design coach.}

Whilst the interaction of the subjects was somewhat similar to the double $h$ experiment, the set-up was vastly different (Figure 12.2). As part of the physical set-up, the monitor of the computer was "embedded" in the drawing desk so that the screen was on the same viewing and working plane as the desk. The information was therefore presented alongside any sketching activity (emulating the idea of the LCD graphic screen). It was hoped that this change from a "normal" monitor set-up, would prevent the designer from looking up from paper to the screen (an activity which interrupts the designer's interaction with the sketch).

The design task - a studio in the city - was the same project used in the double $\mathrm{H}$ experiment discussed at length in Chapter 6. All sessions lasted approximately sixty minutes excluding time used to read the brief and answer the questionnaires given at the end of the session. At the end of the exercise students were given a questionnaire asking to evaluate the set-up, experience and content they were exposed to. 


\section{The Prototype}

The design coach prototype was a simple system developed for the experiment. It was basically a collection of HTML documents (web pages) containing graphic and text based information on various design issues. A manual system equivalent would be flash cards with images and pictures on each card. The major difference between the prototype and flash cards was the interconnectedness of the information (Figure 12.3). In the flash card system each card is an entity in and of itself. In the prototype each screen had (along with images and information) hyperlinks that when clicked, connected each issue to every other issue.

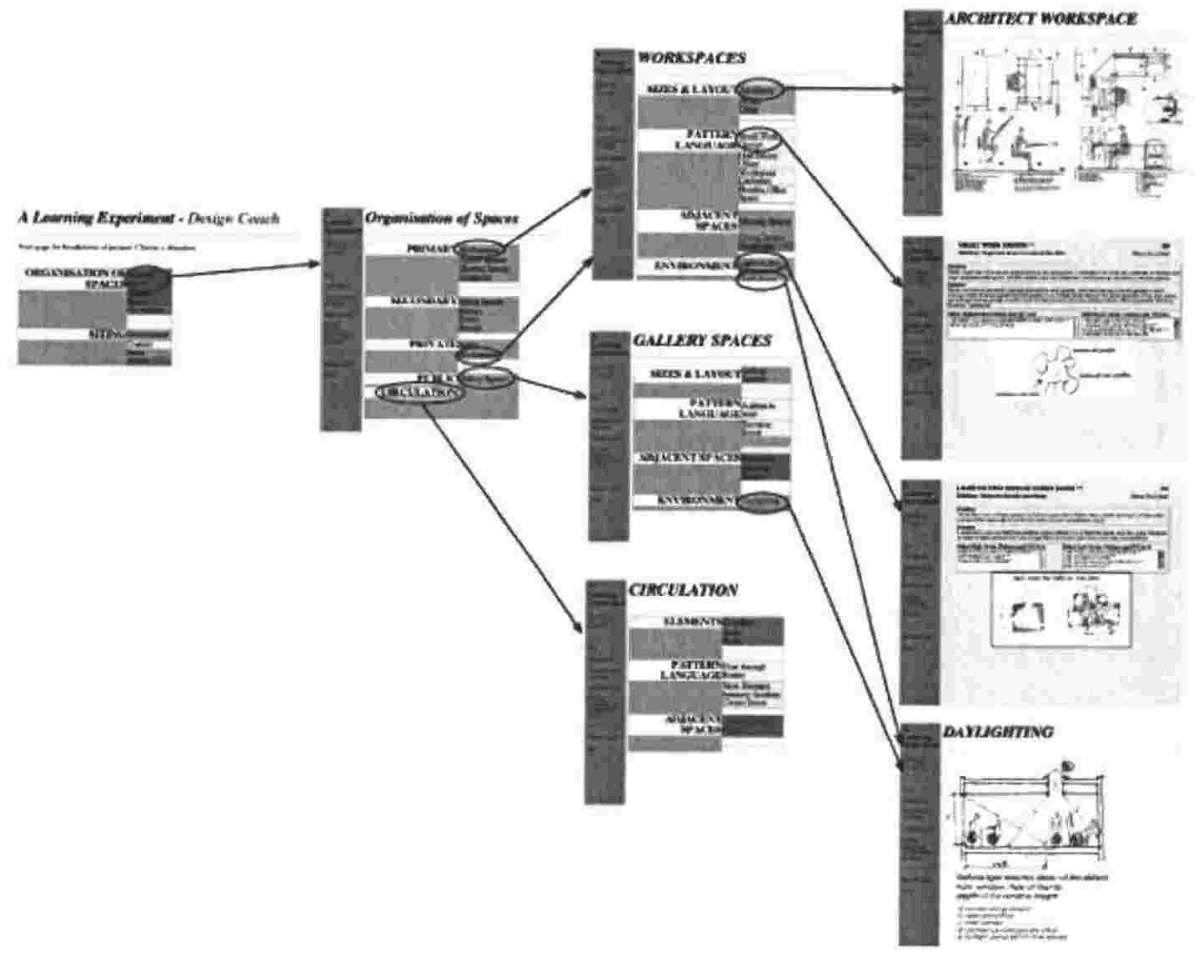

Figure 12.3 The interconnectedness of the information. 


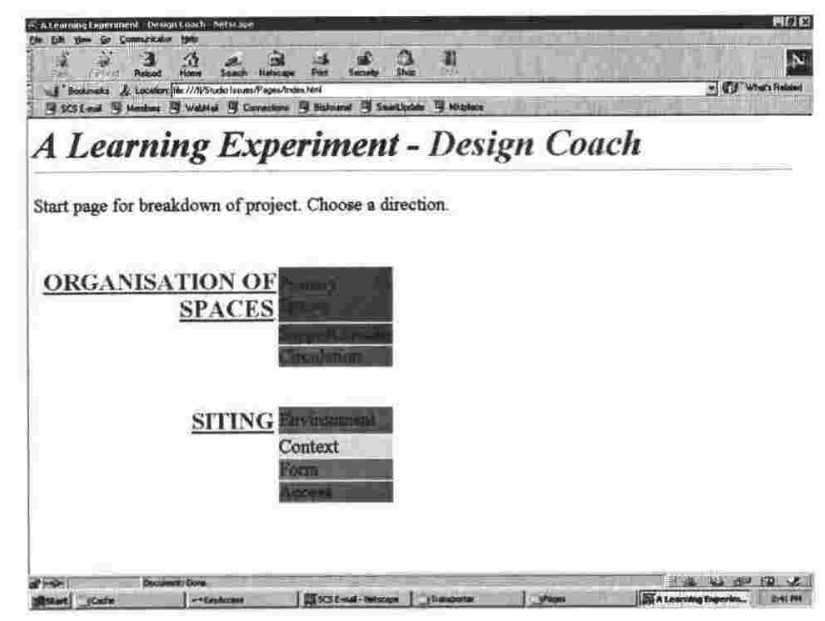

Figure 12.4. Opening screen of prototype.

During the test the subjects interacted with the design coach through screens. The opening screen of the prototype (Figure 12.4) broke down the task into two categories (siting and space organisation), effectively presenting the student with two options for "entering" the coach. These were further divided into:

- Organisation of space: primary spaces, support spaces, circulation

- Siting: environment, context, form, and access.

Clicking on one of these options revealed the standard screen layout that the user interacted with for most of the design session (Figure 12.5). This layout had the main issue (and subsequent sub-issues) to the right, and on the left, presented wider issues related to the issue being contemplated. At the bottom of the left "side bar", program information (the brief) was provided along with basic human data. 


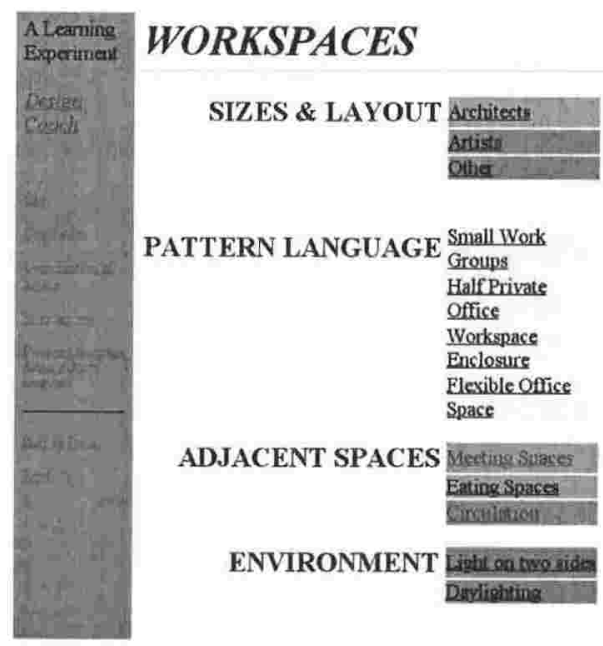

Figure 12.5. A page from the preliminary prototype

The common screen layout was further divided into two types of screens. The first type consisted of a list of information relevant to the task (Figure 12.5). Clicking on an item in the list moved the user to another list screen that provided more options or to the second screen type. This latter screen type contained information in the form of text and/or images (Figure 12.6). The material used was adapted from several sources, for instance C. Alexander's Pattern Language, and consisted mainly of dimensional and practical information such as: stair dimensional information, room dimensions and layouts, kitchen plans, ceiling heights, climatic information and anthropometrical information.

After accessing the required information, the user had the option of returning directly to the start (opening) page or retracing his/her steps backward a screen at a time. 


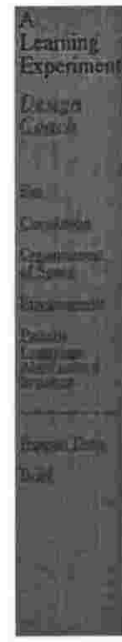

\section{DAYLIGHTING}

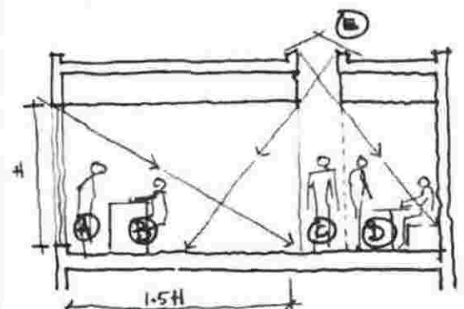

Natural light reaches desks $<4.5 \mathrm{~m}$ distan

from window. Rule of thumb:

depth $=1.5 \times$ window hieght.

of corridor olong winoow

bl open plan office

c) inner caridor

ef rootight giving light to inner spocos

\section{Figure 12.6 Screen with information}

\section{Greta and Ben}

\section{Experience}

Two students (Greta and Ben) took part in the first situation (where the hand sketched). As observed in earlier subjects (the double $\mathrm{H}$ studios and the double $\mathrm{H}$ experiment), both students were initially uncomfortable with the arrangement. Both subjects reported extreme frustration initially (Ben's comment was that it felt "unnatural") with not using their hands to design. They eventually got used to the situation after the first ten minutes, and progressively interacted positively with the rigged hand. In addition to not using their hands, both students also got used to the idea that, during the session, the "hand" would constantly refer to the coach as a means of helping design decisions or as a means of raising questions.

Of the complete experience, Greta commented that it was challenging and interesting while Ben found it "better than working alone". In both cases they found the prototype extremely helpful. Both reported that they believed that they designed faster than usual. They also indicated that they had, in fact, learnt from the experience and were made aware of some aspects involved in architectural design. 


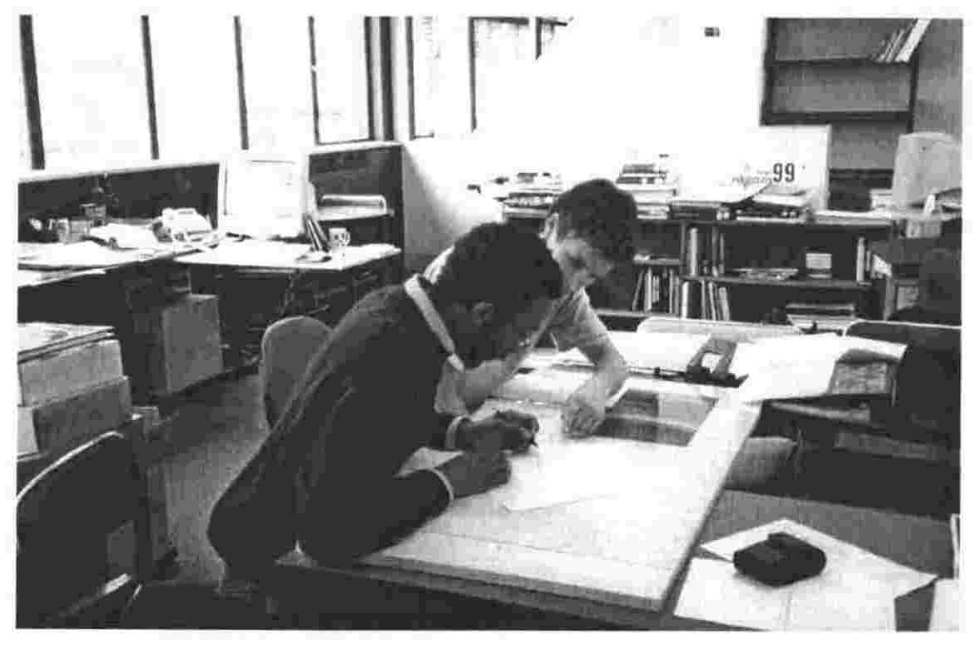

Figure 12.7 Ben (on the right) directing the hand.

\section{Content}

With regard to the content of the design coach, the students indicated that some aspects of the tool could be improved. Both students at various times during the exercise requested "real" examples of the issues presented. According to Ben, "It [the prototype] was a useful source of ideas, but could have [used] actual examples". Both students also commented on the graphical content. Ben requested more graphical information and claimed that the textbased information took too long to read. Interestingly, this was contrary to the fact that he requested information from "pattern language" (which was text based) frequently. This contradiction indicated the value of the particular material to the student. Greta on the other hand, thought the diagrams presented were "too detailed" for the level of information she needed. She claimed to use the dimensional examples to get a "feel" for the requirements. The students did not comment about the structure/presentation (information layout and connectedness of the information) of the prototype. In fact, they seemed not to notice it.

\section{David and Louise}

\section{Experience}

The second condition that involved the other two students (David and Louise) consisted of the subjects producing their own sketches while the researcher 
operated the coach (at their request). Because they were in control of the sketching, there was no frustration with regards to using their hands. It should also be noted that in this condition the researcher had less impact on the students' interaction with the coach since the researcher's contribution was limited to presenting information when requested. The interaction of the student with the rigged hand was therefore a lot different than in the first episode.

Both students to some extent ignored the design coach and so had less interaction with the rigged hand than in Ben and Greta's experience. It was observed that the students designed for long stretches (4-8 minutes) without consulting or looking at the information on the screen. Sometimes they covered it with the drawings. They, however, consulted the rigged hand when they appeared "stuck". These "consultations" tended to be for technical information mostly e.g. dimensions for entries, ceiling heights, toilet dimensions, etc. This lack of interaction did not, however, diminish the value of the tool to the subjects. David (who used it more than Louise) didn't look at the screen for much of the session but he admitted that it was a "cool" idea.

Of the complete experience, David and Louise exhibited different reactions to the exercise. Louise thought it was a bit distracting as she usually researched first then designed. She then remembered (according to her) during the design process important things when or, as she needed them. David felt that the exercise went well to the extent that the prototype could answer the problems that arose. He did feel pressured to interact with the computer though. In contrast to the first experimental condition both subjects did not feel they designed any faster than usual. Responses to learning were also mixed. David was neutral when asked about exposure to aspects of designing, and Louise did not think the experience exposed her to aspects of designing, but as she explains:

"I wouldn't have thought about certain aspects if they weren't there, but I neglected to use them."

When asked if anything was learnt from the exercise, David indicated some (he did not elaborate) positive effects while Louise did not think she learnt because: "I didn't use the design coach." 


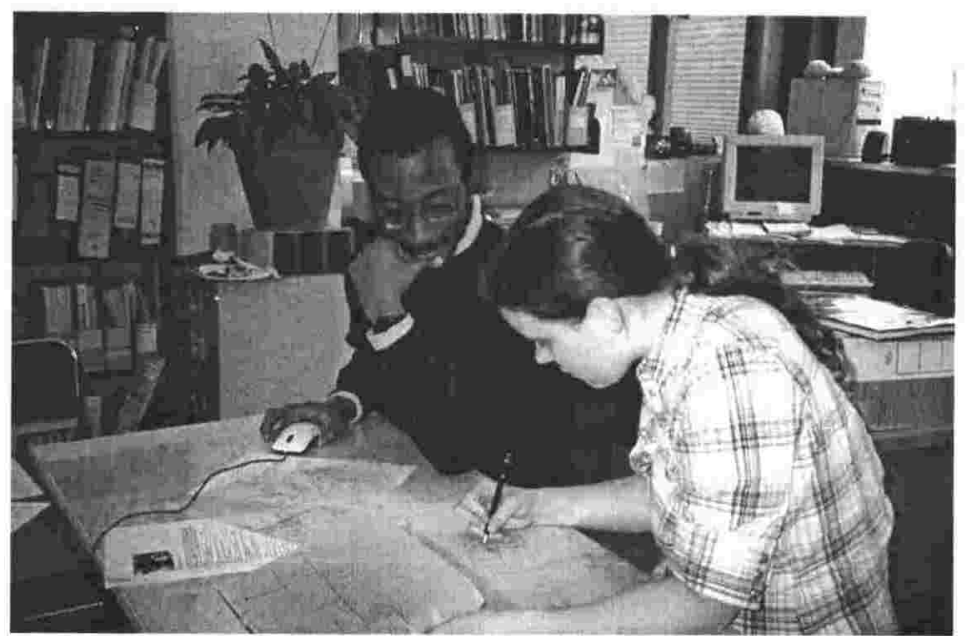

\section{Figure 12.8 Louise sketching with the researcher observing. Note drawing covering screen.}

\section{Content}

With regard to the content of the prototype, the students mainly requested information that would assist them with situations they were unfamiliar with. Both likened the coach to a sort of dictionary (to "look up information") or a checklist (to "check whether you have taken all the design aspects into account"). They also demanded more graphical material and more information to choose from ("broader database"). The idea of connected information was appreciated (according to the students).

\section{Results from the exercise}

Generally, the students were receptive towards the component of the coach tested. The following issues, however, emerged out of the four tests:

- The need for actual examples

- The need for graphical information.

- The information offered should be relevant to the level of investigation.

- The appreciation for diversity of information.

- The requirement for the coach to be proactive. 


\section{Actual Examples}

Three of the four subjects requested actual examples of the design issues offered to them by the coach. This indicated a need for concepts and ideas embodied within an existing situation. This also relates to the student looking around the physical room of the experiment to "visualise" scale and materials. This phenomenon may also be related to the use of precedents in classes or the need to process and understand new information by "seeing" it in a "familiar" context. Regardless, this information suggests that to get the design information across to the user effectively, it might be essential to place it in some form of reality or "real" context.

\section{A Graphical Coach}

During the tests, students requested more visual material and spent little time reading the text-based information. One possible explanation for this preference, could be the visual nature of the task. Another explanation could be the need to translate and incorporate such visual information into the sketch. Such requirements suggests that it is beneficial to include visual representation of the information conveyed, reinforcing the notion of dual coding as discussed in Chapter 11. For the tool, therefore, any textual information should be accompanied by (at least) an explanatory sketch or image. Such graphical information must also have the potential to be assimilated easily into the sketch. 

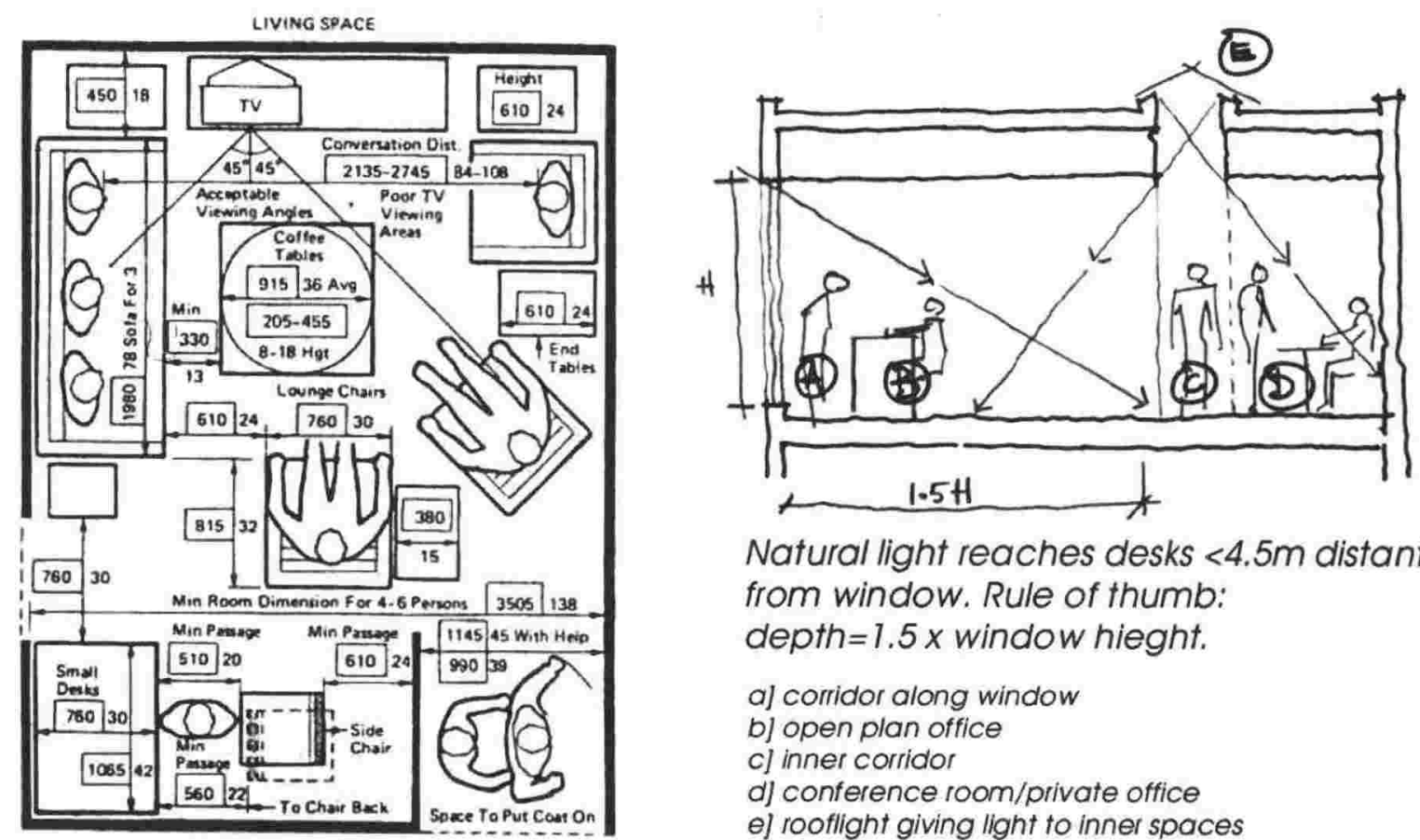

Natural light reaches desks $<4.5 \mathrm{~m}$ distant from window. Rule of thumb: depth $=1.5 \times$ window hieght.
a] corridor along window
b) open plan office
c] inner corridor
d) conference room/private office
e] rooflight giving light to inner spaces

Figure 12.9 A detailed graphic (left) and a more general graphic (right) from the prototype.

\section{Scale of information}

During her test, Greta complained that some of the presented images were too detailed for adequate use. The other students spent some time studying the images requested before moving on in the process. This complaint and delay in designing implies the need for the user to readily use the information without having to slow the process. As with graphics, the students needed to easily use (or incorporate) the information accessed into their design sketches. Any delay could result in the student being frustrated, abandoning the idea and moving on. In the case of the design coach, if the level of information was more than or less than the information required, there would be a high chance that the student may reject it. The information available has to be tailored to the design situation or scale of investigation, at a particular point in time. It has to provide just the relevant information at the right time and at the right scale (of thinking), to preserve the efficiency of the activity. 


\section{Diverse forms of information}

The case of Ben and the pattern language content illustrates the need to allow a diversity of information types and sources. Even though Ben complained about the textual nature of the pattern language information, he still insisted on locating and using it. One reason for this, could be that the information appealed to his personal thinking style and notion of how architecture comes together. In contrast to this, Louise did not refer to the pattern language, but rather referred to the dimensional information available. The information provided therefore has to be universal so that it can accommodate different thinking styles.

\section{A Proactive Coach}

The contrasting experiences of Group One (Ben and Greta) and Group Two (David and Louise) demonstrate that the system cannot be passive nor can it rely solely on students' initiative. In group one, both subjects used the design coach a lot more than the students of the second condition. This could be attributed to the insistence of the rigged hand (researcher), who presented the design coach information at every decision point. It could also have been attributed to the screen of the computer being always in their field of vision (they could not cover it by drawing on top of it because the rigged hand sketched on the other side of the desk).

Group one also had the perception of designing faster while Group two felt they did not learn or design any faster. One explanation for this response is the fact that in the former case, the rigged hand was constantly prompting and questioning - pushing the process along. In the latter situation this was not so. The apparent reason for this lies in the fact that the design situation had hardly changed or was no different from their usual design situation.

As pointed out in Chapter Six, students responded positively to prompting, especially when it came from an expert "hand". This therefore indicates the need for the coach to be proactive. The student can then choose to ignore or accept its advice. This idea is supported by Do (1998) (Do 1998) when she states: 
Embedding information tools into drawing environments is a key strategy for getting designers to use them. If information is not ready-to-hand, a designer will be reluctant to stop drawing to look it up. (...) it would be helpful if needed information were accessible through sketches and diagrams.

For the coach to be readily used, it also has to be within the field of vision and an integral part of the experience. For it to be effective it has to be a part of the design environment - as part of the sketch.

\section{The Revised Design Coach}

Prototype

The prototype was subsequently revised and upgraded to accommodate those findings related to the information element of the coach. The conclusions taken into account included; the use of diverse forms of information, graphical information, and scale of information. This revision is the most current version of the design coach and is supplied as an appendix in the form of a Compact Disc. See appendix $\mathbf{5}$ for instructions for use.

At present, and contrary to our arguments against the passivity of the sketch, the design coach still relies on the user's initiative. The proactive nature of the tool (advocated for earlier in this thesis) could not be implemented because it was the part most determined by the sketch component. The current prototype employs more graphics than before but also maintains some text-based pages. The data was organized into categories related to scale and design concerns. It also has a wider diversity of information adapted from several sources, for instance: Sun, Wind o Light: Architectural Design Strategies by G. Z. Brown; Architecture: Form, Space and Order and Building Construction Illustrated by Francis Ching; Pattern Language: Towns, Buildings, Construction by Christopher Alexander; Human Dimension and Interior Space: A Source Book of Design Reference Standards by J. Panero and M. Zelnik and Room In Context: Design Beyond Boundaries by Katherine Benzel. 


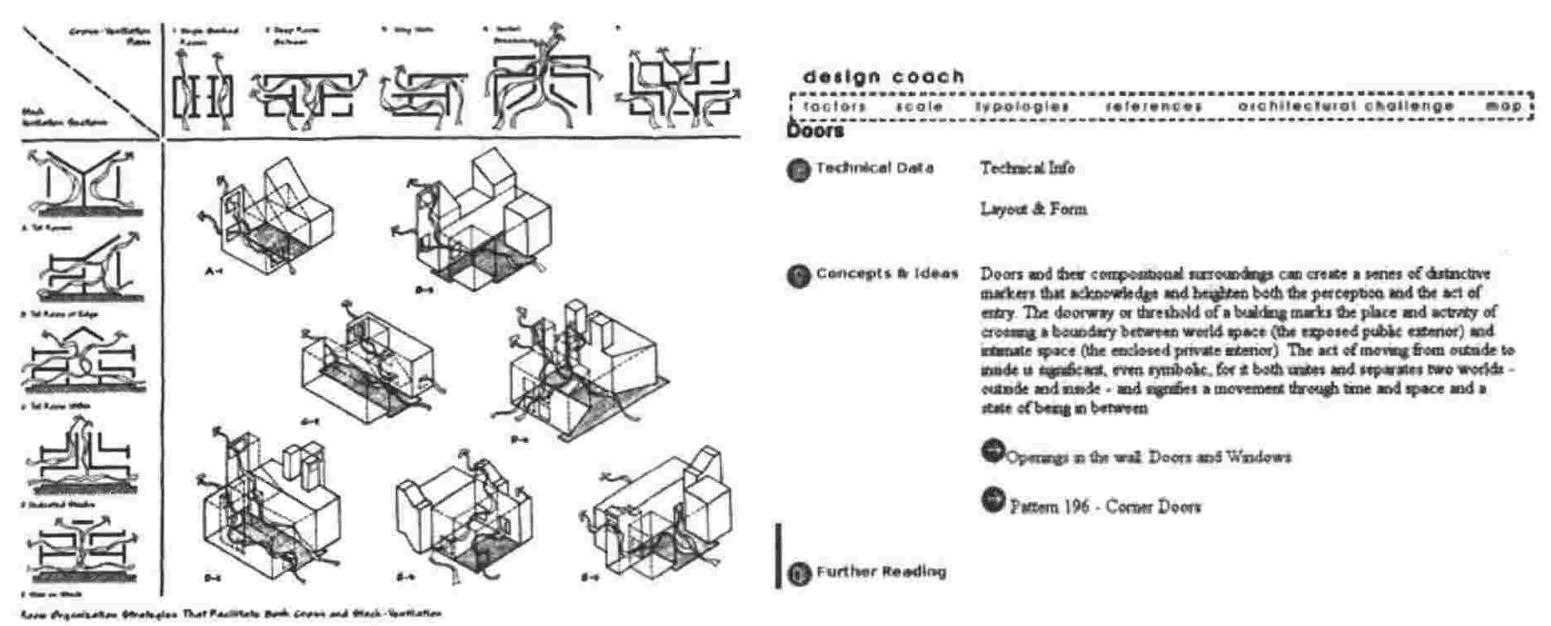

Figure 12.10 Examples of graphic information and text based information

The current prototype also uses web technology (based on the notion that hypertext - being non-linear - facilitates the idea of making connections) as the primary method of delivery. Web technology allows the combination of traditional media, such as text, images and graphics, with 3D-models, computer animation, video and sound. Due to time constraints in preparation of the tool for testing, however, the coach prototype only included traditional media. The information format available to the coach therefore, was text, images and a combination of both.

There were several advantages to continuing with web technologies. In this manner, the options presented on the screen will allow the user the opportunity of following whatever thread of interest that is relevant to the investigation of the moment. For user experience, the web tools were easy to use due to the users' familiarity with the web browser interface. The advantages for hardware are in the web system which allows multiple users across a network with the possibility for direct access over dial up lines (students didn't have to access it from school labs). With access from other points outside of the schools the coach had to be easy to use with different platforms. From a content creation perspective the web format allowed a short creation time (using templates) and the ability to include graphic images and text directly in the web pages without expert help. 
The choice of categories were also inspired by the course ARCH 212 where the coach was eventually used. The content was also divided into a hidden hierarchy (mainly for file organisation) consisting of five levels of information from the general which were basically decision pages to the specific which contained most of the details. A typical decision page would include a list of options or issues from which to choose. The designer would then be taken to another decision page or information page that outlines the issue under consideration, highlights connections and recommends further literature. (See Appendix 5 for further descriptions).

Also available was additional support information where the designer had the option of going to various scales, checking a bibliography or using the search page of the site to find specific information. This information was made available by a menu (Fig 12.12).

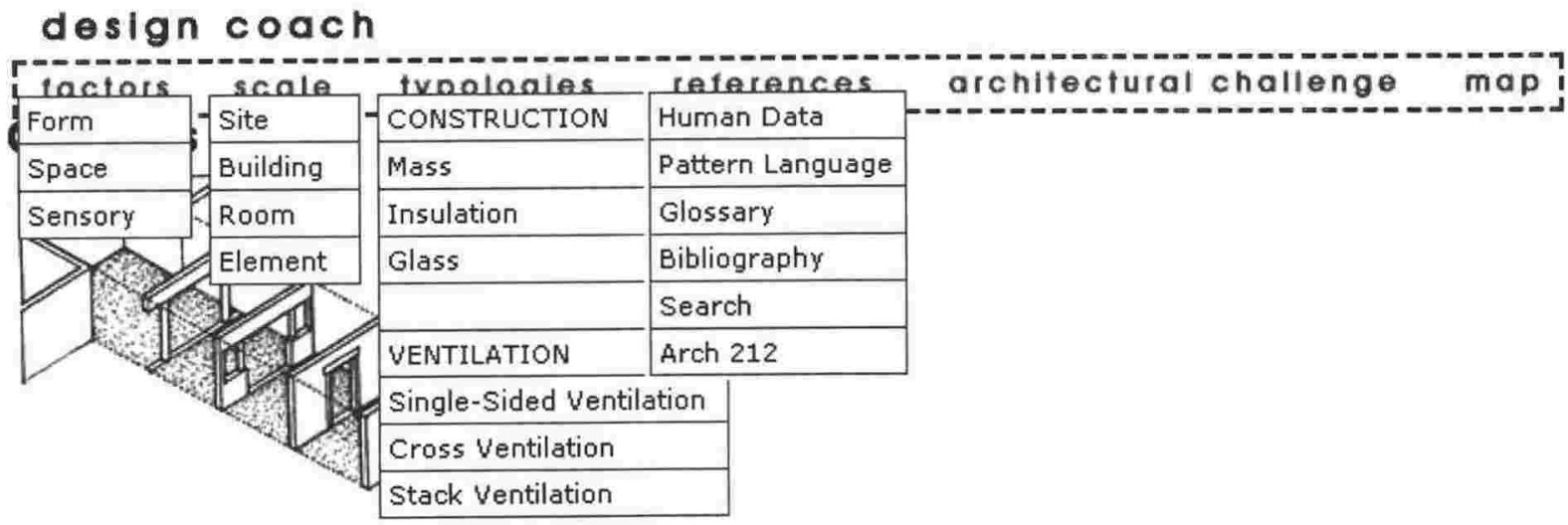

Figure 12.12. Menus available in the design coach

\section{The Coach in Design Studio}

The revised prototype of the design coach was tested in a design studio course during the second semester of 2001 at Victoria University of Wellington School of Architecture. The studio (ARCH 212) is a core course for the second year of the five-year professionally recognised Bachelor of Architecture degree; hence it was mandatory that they participate in the studio. ARCH 212 consisted of $70+$ students, divided into six groups. The studio was coordinated by a senior member of faculty who was assisted by five tutors (three from practice and two practitioners who were also postgraduates) each supervising a group of 
students. The theme of the design studio was "Incorporating the Sensory into the Making of Architecture" and its central aim was to provide a basic grounding in environmental science and its use in informing, validating and enhancing architectural creativity. This was achieved by encouraging students to explore how architecture is perceived and understood through our senses. Specifically, the focus was on thermal, acoustic and visual sensory inputs and how they can be used in making architecture. The course used the concept of bome as the vehicle for these explorations (manifested in four assignments). The first assignment dealt with site analysis and visual spaces; the second assignment focused on acoustic spaces; the third, thermal spaces and the final sought to bring all these aspects and other spatial elements of house together on the site into a holistic, resourceful home. In addition to regular studio teaching, the course was supported by twice weekly lectures on the principles of building science, environmental control and sustainability used in the project. Students in the course were also required to use the computer to evaluate building performance, and at least generate presentation drawings, in order to gain skill in the use of a range of computer programs in developing architectural ideas.

The assignment used to test the idea of a design coach was Assignment Three Thermal Delight. For the assignment, students were asked to design a house for two people, a musician and a glass artist. These "clients" were the same that they designed spaces for in the previous two assignments (visual and acoustic) on the same site (explored in assignment one) in Khandallah (a Wellington suburb). In this project, students were asked to design living and bathing spaces from both quantitative and qualitative viewpoints to achieve thermal comfort and delight in the principal inhabited spaces. The accommodation was to include a living, formal dining, casual dining/kitchen, two to three bedroom suites, a bathing space, storage, entry, space for two vehicles and circulation. Part of the challenge to students was the incorporation of thermally related rituals into the design by creating a strong thermal focus to the living space and a bathing space that celebrates sensuality. 


\section{Procedure}

The design coach designed for this studio was, as stated before, a revision of the prototype used in the first usability test and supplemented with information of relevance to the assignment. This included reference material from thermal textbooks, information on houses, and other ergonomic information. The design coach was then placed on the school's Intranet and Internet network (internal and external web site), so that it could be accessed not only from the computer lab at school, but from any computer connected to the Internet. Access however, was limited to students of the ARCH 212 design studio.

During the first lecture of the project, where students were introduced to the program and procedure of the project, students were given a tour of the coach (a demonstration of how the prototype worked) and advised as to its location on the school website. All students participating in the studio were allowed to use the tool for as long and as often as they liked, without fear of punishment or reward. At one point prior to introduction, it was suggested that the class be split into two groups - one using the coach and the other not. However, this was denied by the course coordinator on the basis that some students might have viewed this as an unfair advantage. If this had been done it would have allowed for a direct comparison between using the coach and working in the traditional modes, with the acknowledgment that the different tutors would be the variable between the two groups. Help support existed in the form of a bulletin board (or forum) in the digital teaching environment BLACKBOARD - used by the University for supplemental course delivery. Students were invited to post comments and suggestions, have questions answered, and report technical problems.

Aside from having access to the design coach, the design project was conducted as usual. Students met in the studio roughly eight hours per week for the next three weeks, spending much of this time either working alone or discussing their project with the studio tutors. It is important to note the fact that the teaching context was not distupted by the use of the coach and it was easily accessible for students to integrate it with their usual processes. 
Evaluation of the coach was carried out by questionnaire and casual conversations with the students. The questionnaire, given after students had submitted their projects and were being assessed, examined whether the design coach succeeded in engaging students and helped their project in any way. With an eye to future improvements, the questionnaire also asked how students liked aspects of the tool, such as the interface, choice of issues, images or selection criteria. Based on the students' responses to the questionnaires, we will try to answer (among others) the following questions:

1. Did the Design Coach succeed in engaging students to explore the design issues involved?

2. What factors stimulated or hampered this engagement?

3. What information content and format was most preferred?

\section{Student Reaction}

Based on students' replies to the questionnaires we will attempt to evaluate elements of the coach that students preferred and what elements didn't work. Of the seventy-plus students who participated in the studio, only thirty-seven (37) (more than 50\%) filled in the questionnaire. While this could represent a reasonable response, these results cannot be assumed to represent the opinions of all the students in the studio in general, nor all architecture students as a whole. It does however provide a good basis to determine the kinds of things students will look for in a design coach.

The questionnaire comprised of fifteen (15) fixed response questions. Students' responses (where relevant) were measured on a ranking of 1 to 4.1 being " a lot" and 4 being "not at all". It sought information on how reference material was used ( 2 questions) and how the coach was used in relation to the project (13 questions). A written section of the questionnaire, which comprised of four questions, sought specific information about content. See Appendix 4 for full results. 


\section{Experience}

Of the 37 students who completed the questionnaire, 31 respondents examined the Design Coach for the project and six did not. This statistic suggests that garnering interest in the coach was reasonably successful. 16 or roughly $50 \%$ of respondents said they used the coach upwards of $40 \%$ for their thermal design project $(\mathrm{Q} 4)^{35}$. Respondents were hampered from using the Design Coach more often for a variety of reasons; "too complex information", "too much information" and contrastingly, "not enough information". $50 \%$ of the reasons fell under the heading "other" (Q5). The reason, however, given by those who did not use it was mainly time constraints (Q3).

The coach also made a good impression on the students. When asked how they liked the design coach, $86 \%$ found the information in the Design Coach adequate (Q16). The question whether they planned to use the coach for future studio projects, was answered positively by all respondents $(89 \%$ said yes (Q15)), except for one. With regards to learning, 93\% of the students felt they learnt something from the coach and of that portion, $62 \%$ were in the mid to top range $(\mathrm{Q} 12)$. 82\% found the Design Coach helpful in informing their tutorial sessions, with half of this finding it very helpful (Q13).

Compatibility of the coach to individual design processes was positive. $93 \%$ felt that the Design Coach (in its current form) is slightly to very compatible to their design process (Q12) and that the Design Coach exposed them to aspects of the design process (Q13).

\section{Content}

The coach was considered a good reference source. To establish the coach's contribution as a reference source, students were queried about consulting outside sources or other reference material. 33 of the respondents usually consulted outside sources/reference material when designing (Q1). 28 respondents said they consult outside sources/reference material most or all of the time and do so in the early stages of designing (Q2), and $96 \%$ of respondents consulted external sources/references when doing the thermal

\footnotetext{
${ }^{35}$ These (Q\#) references relate to questionnaire in appendix 4
} 
design project (Q7). 25 out of 29 found the information adequate for the project (Q16) and more specifically 97\% thought that the Design Coach exposed them to issues involved in designing a thermal house (Q14). 66\% however felt that the Design Coach did not inspire them to seek other reference material (Q6). This could mean that the design coach did not do a good job at showing the way to other reference sources; or alternatively it could mean that the coach contained all the information the students needed.

The structure of the content was appreciated and proved simple to understand and navigate. The interconnectedness of the information was well appreciated as $60 \%$ felt the system of hyperlinks between different ideas and issues helped most of the time to a lot (Q8). 65\% did not find it difficult to locate required information while 6\% found it very difficult (Q17). There were some dissenters however that requested a clearer path to the information; more links to the starting page; a clearer, more informed cross-referencing system (perhaps with a description of what issues link to or "maybe an expandable link tree (like on discussion board etc)").

In an effort to appraise the information choices, students were asked to list information that most assisted with the development of their projects (Q17). Among the information listed were:

- Information related to the theme of the studio - thermal design (insulation, R-value data, sun spaces, solar gain, passive solar designs) and ventilation (wind speed information, wind shelter by trees, ideas for cross and stack ventilation).

- Climatic information (orientation, solar and weather data, prevailing wind direction)

- Spatial Information (room sizes and room organisation (entry, circulation/connections))

- Information about fireplaces and hearths including sizes and examples of hearths, and the rituals of bathing.

- Anthropometric information (stair heights, kitchen heights/reaches)

- Explanation of the project information.

- Patterns from Christopher Alexander's pattern language 
Students were also asked to list information or content that they thought was missing. Among those listed were:

- Specific examples of applications/references to actual architecture "...so one can see the information in modern context and practice", "photos of houses as examples rather than diagrams" and "photo images of examples to help inspire students". One student was quite specific:

"I would like to see some form of present day context. These are good methods and inspirations, but a lot of us need to see actual architecture to further explore and understand the ideas. Examples of houses, virtual tours of such methods ate the next step of understanding for us - a complete understanding, not just the analysis, but that is a huge ask! But it would be an absolutely full and brilliant resource then!!"

- Outside links and paths on the World Wide Web to such information.

- Calculations (or capability to calculate) or formulae for some of the thermal information (e.g. R-values).

- Information on single sided ventilation ${ }^{36}$.

- "Perhaps some more theoretical information"

Students also requested that the information should be "less straight from the books" and be standardised within the design coach:

"Maybe standardise information to one overall format? Unless it is intended to be a collection of other resources."

It was also compared to reading a book:

"Excellent range of material. I find looking through a book easier, however. I guess, because this is new, it will take time to refine and make it an option for me in researching material."

\footnotetext{
${ }^{36}$ The project assigned three types of ventilation to students - single sided, cross and stacked. Single sided ventilation was not represented in the design coach information because of an oversight.
} 


\section{Information Format}

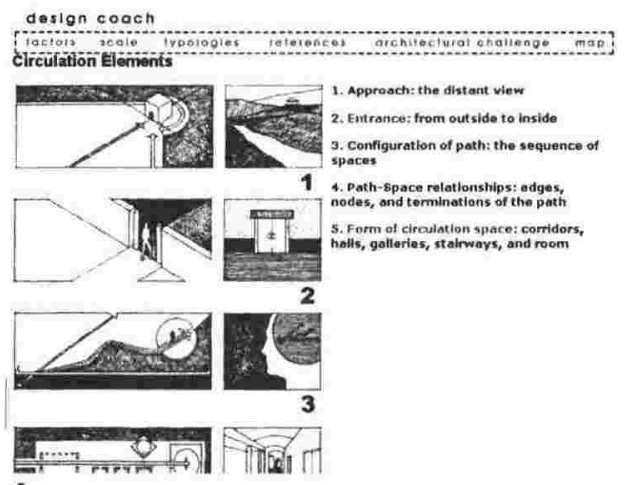

A Information from 'Form, Space and Order'

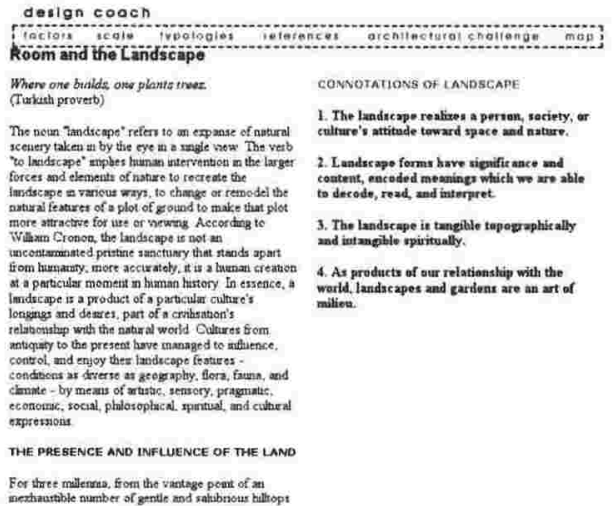

C Information from "The Room in Context"
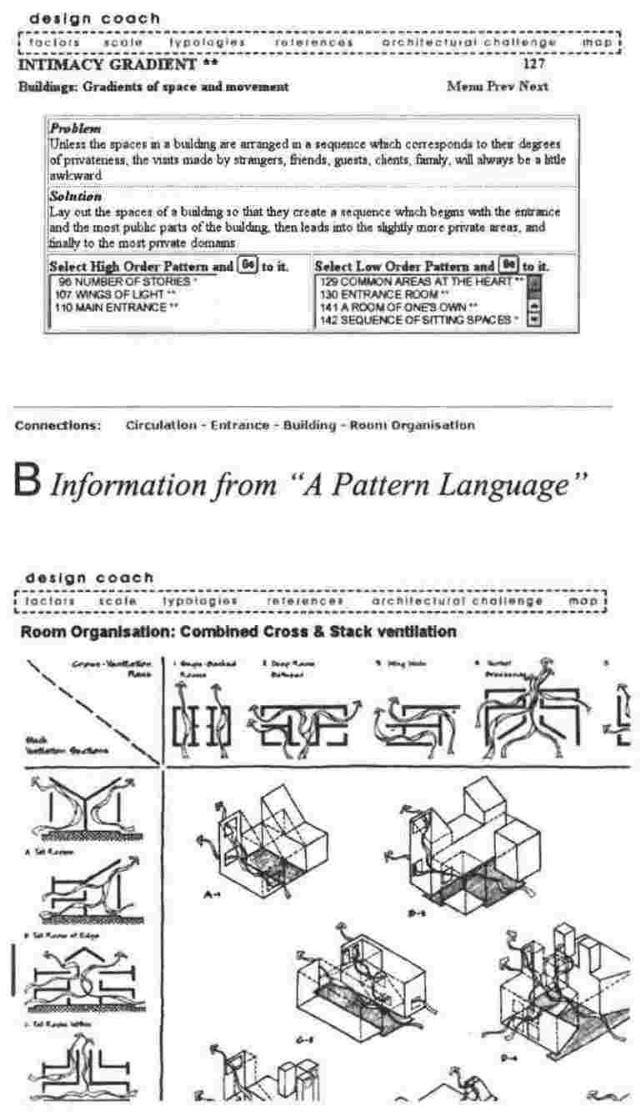

D Information from "Sun, Wind and Light"

Figure 12.13 Examples of information types.

In the design coach there were four main types of information format.

- Graphic information with text accompaniment (A),

- Information from C. Alexander's Pattern Language (B),

- Textual information on abstract ideas (C), and

- Information that consisted of only diagrams (D).

In addition there were hybrids of these types.

When asked to choose the most design-friendly format, the students responded well to type $\mathrm{D}$. This could have been attributed to the visual nature of the format, and as explained earlier, the need to incorporate such information into visual thinking. There are however, dangers to this as one student pointed out: 


\section{Discussion of Results}

The information received was enough to answer essential questions about the coach. However, the questionnaire was by no means perfect, and there was more that could have been learnt about the experience, content and presentation. Additional information could have included:

- Elements that may have influenced student engagement with the tool, such as whether or not students had a PC at home, enjoyed surfing on the Internet, or used CAD software to model their project.

- If the student used the references recommended by coach and if those references helped in any way.

- Whether the extensive links and visual graphics helped to extend knowledge.

- If the students could visualise other uses for the coach

- Did the coach affect the student-teacher relationship

Using the advantages of web technologies, more information could have been gathered through electronic data gathering. For instance:

- By assigning each user - student or studio teacher - a user name and password, we could have kept track of who logged on to the web pages, when, and for how long,

- Registered the most popular pages and

- Determine a map of the steps students used to access particular pieces of information.

\section{Reaction}

Reaction to the prototype was positive generally, however, the following issues came out of the questionnaire results:

Actual examples - Students needed to see actual physical examples of the issues presented.

Wider network - The information in the coach needed to be more connected to wider sources of information. This could be clearer references, and a closer connection to the Internet. 
Graphics - Students responded to more graphical material. Perhaps a means of quickly conveying information graphically that fits in with the student's sketch is needed.

Navigation - A much clearer map of the information was needed. A means of tracing the path or thread of information would have eased any navigational problems.

Not a book - The tool had to be seen as supplementary information to books and as more contextual (related to the task itself). Standardisation of the information for the digital environment seems to be a solution.

\section{Conclusion}

Determining the feasibility of an idea is an important activity. In this way one can chart or revise a course of action towards making the idea concrete. After laying down some principles for the design coach (chapter 11), two usability studies were conducted to determine student's reaction to the information component of the digital design coach. A prototype was designed that lacked the sketch recognition component ${ }^{37}$, and depended on web technology for communication. In the first test, four students were given access to the prototype of the tool and closely monitored. The test used two situations "rigged hand" and sketching for themselves. After this study, the tool was upgraded and tested in a design studio. The studio (which looked at issues of thermal design), incorporated the prototype which was oriented towards the main theme.

The tool was well received on both occasions with some reservations. In the first instance there is significant evidence in students' responses that they found the coach valuable and beneficial (or at least the idea of it). In the second study, three-quarters of the participants effectively made use of the tool, and nearly all of the respondents would like to use it again in the future. When asked how they liked specific aspects of the prototype, students were either neutral or positive. Positive reactions to the coach included:

"I thought it was a very useful tool, and it certainly made the research project much easier."

\footnotetext{
${ }^{37}$ Since this component has already been proven to work only the information component was tested.
} 
"The design coach is a great way of starting off an assignment (gaining ideas and information)."

"I felt that the design coach covered the basics really well, but lacked more advanced information."

Specific aspects of the tool that were viewed favourably by the student included:

- Access to information on the computer

- Interconnected information

- Diversity of information

Specific aspects that was seen as important to students were:

- Actual examples of the issues presented

- Graphical information

- Relevant information for the scale of investigation and the task at hand.

- Links to wider information sources.

Even though the results imply that the majority of students found the design coach to be a useful contributor to their design process during the project, wider questions however remain unanswered. For instance did engagement facilitate learning? This seems to be related to the students' attitude to engaging with the coach. It is a worry that students would not have engaged with the coach more if it were not part of the study. Perhaps the student needed to be convinced of the benefit of the coach. As stated by Zimring et al (1999) “...the most effective approach to getting students to use a learning environment is to convince them that it is useful for getting their tasks done, first, and then for learning" (Zimring et al. 1999). Other aspects that needed further investigation included the quality of students' final project, the influence of factors like frequency, duration of use, computer skills, etc. and the contribution of the tutor in its success or failure. Questions about the tool developing and improving long-term attitudes to and understanding of architecture, cannot be determined, as it is too early to tell. Monitoring and interviewing students during their time in school (and after) could help in determining if the coach made any impression on them. 
The prototype presented here cannot be seen as representative of the proposed design coach, as the usability studies outlined in this chapter concern only the information component of the design coach. As discovered in previous chapters, students respond more readily to prompting and sketching is an important part of any tool. The current prototype lacks these features. The tool is still to be upgraded and tested with both components together in a studio situation.

Despite this lack of information (or need for more studies) there is enough here, to indicate a feasible format for the information component of the teaching tool. The tests have demonstrated that the final tool must include relevant information (right information at the right time), in a mainly graphical format. The information must be as diverse as possible, to accommodate broad preferences. The information must be internally as well as externally connected and highly relational. Finally and most importantly, the information must be firmly connected to reality, providing actual, concrete examples of the information in use. With these characteristics the coach can be developed and tested, so as to play an important part in architectural education.

\section{References}

Do, Ellen Y.-L. 1998. The Right Tool at the Right Time - Investigation of freehand drawing as an interface to knowledge based deign tools. Ph.D. Thesis, Georgia Institute of Technology.

Zimring, C., S. Khan, D. Craig, S.-u- Haq, and M. Guzdial. 1999. CoOL Studio:Using Simple Tools to Expand the Discursive Space of the Design Studio. Paper presented at the Design Thinking Research Symposium, MIT, Cambridge, MA. 


\section{The Design Coach}

"The idea is simple: talking, pointing and looking should work together as part of a multimodal (sic) interface that is less about messaging back and forth (the basis of time sharing) and more like face-to-face, human-to-human conversation" (Negroponte 1996).

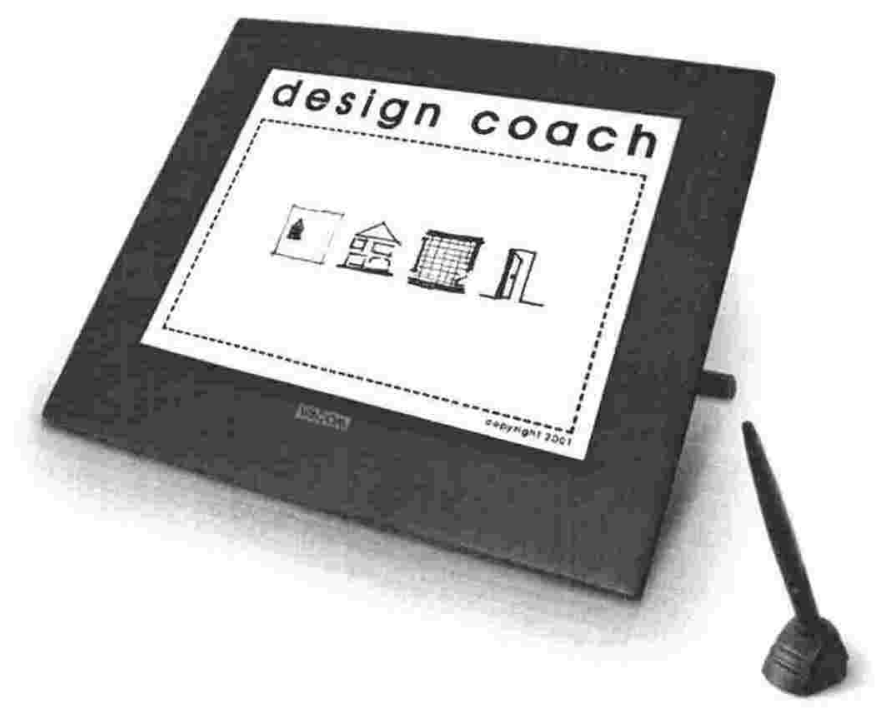

Figure 13.1. Digital Design Coach. (Source of original image: http://www.wacom.com)

his dissertation advocates establishing the computer as an integral and complementary part of the "space" where the student meets the master (the zone of interaction). The form of this intervention, as proposed, would be a digital teaching tool or expert that detects and interprets the marks students make when sketching. In detecting and interpreting the students' intentions, the tool would provide suitable clues to allow a comprehensive reading of the design issues embedded in their sketches. It is intended for this "reading" to subsequently enlighten the architectural student about design issues that create affordable, sustainable and liveable architecture. The enlightened student (with an acute awareness of the issues involved) then engages in a more intelligent and well-informed dialogue with the tutor in the zone of interaction. The zone of interaction, as a result, becomes a richer educational experience for both student and tutor. 
In Chapter 11, we outlined the assumptions and principles that governed the spirit and creation of such a tool. In chapter 12, we tested a prototype of the information component of the tool. This chapter contemplates the future physical (or digital form) of a digital design coach that fulfils the assumptions set out in Chapter 11 and implements the findings of chapter 12. It should be noted that the tool described in this chapter is not an existing artefact. This description should therefore be accepted as speculative, restricted and not necessarily accurate. It does, however, offer an ample vision of the design coach. For brevity, the description will strive to highlight some of the more important features expected of the tool. The chapter ends with a revisit to Schön's studio with Quist and Petra. This time, however, Petra has the design coach at her disposal. Through this scenario, we will describe the tool's intended operation and the expected results.

\section{The Design Coach}

The design coach we will describe assumes the role of an "expert hand" (Chapter 6) that "observes" and monitors the student's sketching activity. As the hand sketch is entered into the system, and as ideas develop, the design coach highlights the issues that may need consideration, for example: spatial qualities; heat gain; light; orientation; ventilation. It "injects" information that is fit for purpose, cost effective and meaningful into the drawing action by displaying questions, clues and prompts about the design situation. The design coach aims to make the student more aware of architectural consequences by highlighting and emphasising these issues effectively, providing the student with an ability to read, acknowledge and balance the hundreds of factors that influence design.

While the coach assists in designing, the primary value of the tool, however, occurs when the student sits with the design tutor. With an awareness gained from the coach, prior to the meeting, the student is cognisant of the issues involved, asks the "right" questions and understands the criticism and advice on the issues. The digital sketch, therefore, acts as a mediator in the relationship. The tutor's contribution to the discussion then centres on validating or giving 
credit to the student's attempt and demonstrating, to the student, various ways of criticising and engaging with it.

Fundamentally, the design coach is a large flexible database that presents relevant information based on the sketched information of the user. Achieving the results outlined above contributes to the form being significant.

Any effective description of the tool and how it is expected to work involves breaking the tool down into its functional operations. The tool would have to be a seamless integration of software and hardware that fits unobtrusively into the design process. As with other digital tools, the coach has to have a means of gathering information from the user, and a means of giving feedback. In order to provide feedback, the tool has to detect the intentions of the user (or at least determine what the input is about). User comprehension and value is dependent of the structure of knowledge in the tool and maximum effectiveness is governed by the experience of using the tool. These operations could be categorised as distinct parts, namely - interface (input and output); recognition; knowledge (or content) and experience (fig. 13.2).

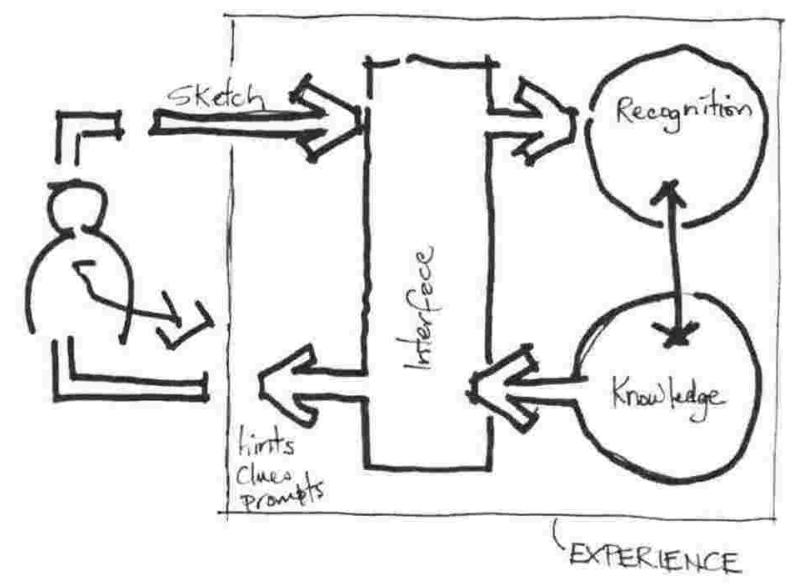

Figure 13.2. Parts of the design coach.

While it is convenient to adequately describe the coach as separate parts, it should be noted that there exists an acute inter-dependency among the parts. Input (or sketching), while being open at first, becomes dependable on each subsequent response by the coach. The tool's response is dependent on the quality of the input gleaned and the accuracy of the recognition components. 
Response is determined by coordination between the information structure and the "perceived" intention gleaned from input. Data output (clues, hints, prompts - presentation of the information) determines the user's comprehension of the situation and subsequent sketch marks (input), completing the cycle. The experience of this cycle determines whether the student accepts or rejects the validity of the coach.

\section{Interface}

As stated, especially in chapters 5 and 10, sketching has to be an essential part of the tool. Like the sketch, an important aspect of its form has to be its "conversational" nature. The interface (or communication) with the design coach hence becomes an important part of its operation and will accommodate the user through various forms of input and output (fig. 13.3).

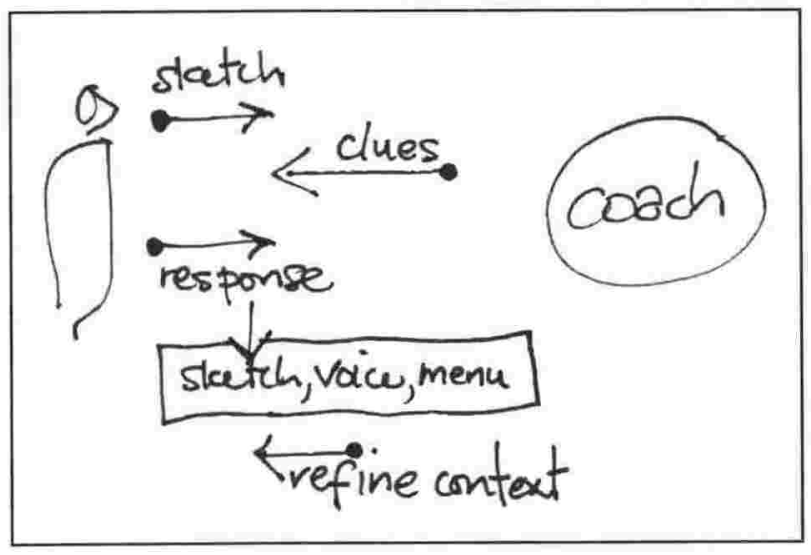

Figure 13.3. Interface with the coach should be like having a conversation. Input

To take advantage of the versatility of the computer and capture the multimodal nature of conversations, information will be entered into the system in three ways:

1. Sketching on an LCD tablet.

2. Using voice (through voice recognition technology).

3. Clicking or tapping on menus, tool palettes, icons, and buttons. 
LCD Tablet - The sketch will be the principal means of interfacing with the tool. The main interface for the coach would then be an LCD Tablet that allows the user to draw directly on the screen. While an "ordinary" tablet and stylus could be used, this would require the user to look from tablet to screen continuously, an action contrary to actual sketching. The digital sketch would be used in three ways. The first would be to determine or establish first intentions, providing data for the "clues" or suggestions. Secondly, subsequent sketch marks would confirm or refine the user's intentions generating other suggestions from the tool. Finally, sketching gestures (or marks) could be used to issue commands.

Voice Recognition - Voice is increasingly being used today as an intuitive means of interacting with technology. In the coach, voice recognition will be used to issue keywords - context, scale, and subject etc. - to support the recognition of intention. Voice will also be used to confirm or issue commands, choose clues or hints, or refine information.

Palettes, menus, icons and dialog boxes - In addition to sketching and voice, the user will communicate with the tool through WIMPy (Windows, Icons, Menus, Pointing) technology. Here, the stylus (or pen) is used for pointing, clicking and dragging in addition to drawing or sketching. Through this interface, clicking (or tapping) will be used to select clues or tools as regulated by menus, icons and dialog boxes. This interface provides familiarity with the current WIMPy interface used by modern computing.

\section{Output}

It has been stated elsewhere in this thesis that the passivity of the sketch is one of the factors that limits the potential benefits of the sketch to learning. An "assertive" role (offering information to the user through cues and prompts) was suggested for an empowered sketch that would inform the student of the issues embedded within a particular design situation. The output plays (what the user sees) an important part in conveying this assertion since it determines the level of assimilation (whether the user accepts or rejects) of the information offered. 


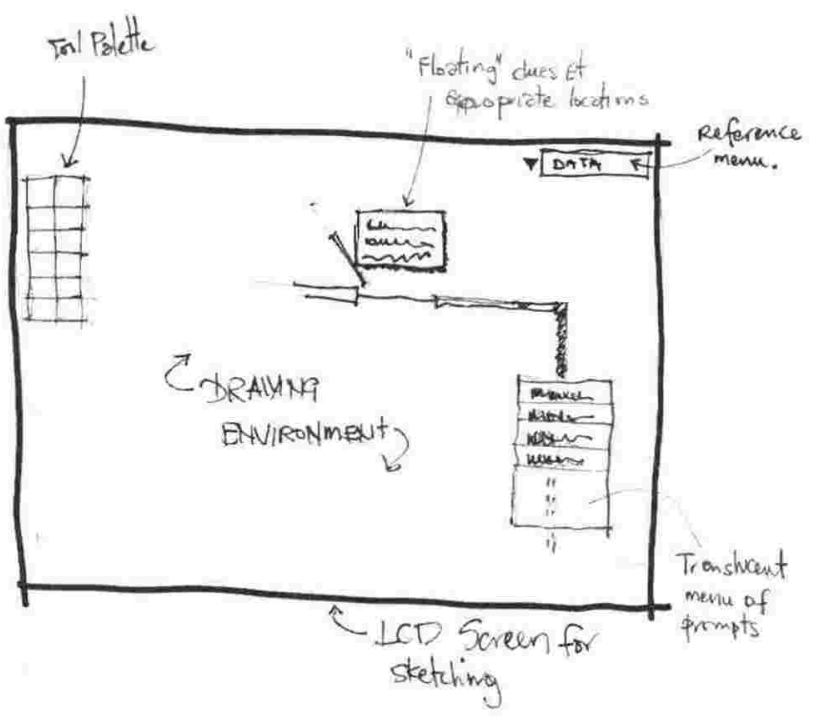

Figure 13.4. Proposed Interface Layout.

The proposed coach is intended to be a part of a digital drawing environment that the user uses to sketch (fig 13.4). To retain the sketching environment, the display of information would therefore be as unobtrusive as possible, yet constantly within the visual field of the designer's drawing. The coach's output would be represented as an overlay (a transparent "window") on top of the sketch environment. Information would then be presented as a list of choices connected to particular marks. These lists would include information clues, options for controlling the interface, and links to other reference sources. The user would then respond by speaking, clicking or continuing to draw. To reflect the changing nature of issues, the information displayed would change with every stroke and mark as the context is developed and determined by the designer. After making suggestions the coach would wait for a "reply" to confirm or refine a particular clue. If none were forthcoming, the coach would retain the list at the particular mark for a specified time (fig. 13.5).

USHAG THE COACH

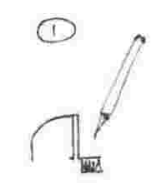

[DRAN]

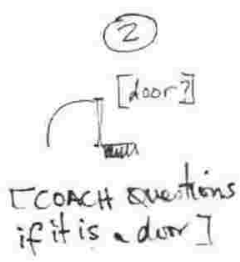

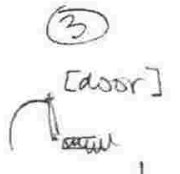

[Press retorn, say" "yes"

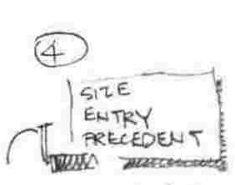

EPResent list of clues as transparent froating window

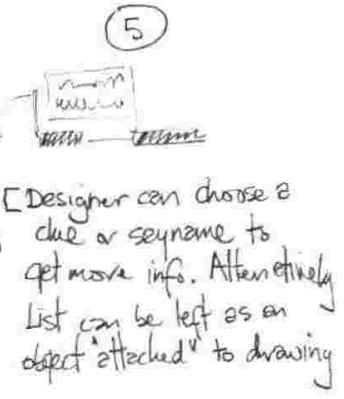




\section{Figure 13.5. Sequence of events while using the coach.}

As the designer chooses to refer to a particular piece of information (precedent, strategy, fact) the small unobtrusive window widens to an information "card" or window that is no bigger than an index card. This window would not be transparent since, here, the information is the focus.

\section{Recognition}

If sketching is the major means of input for the coach, then recognising the marks the user makes and translating these marks into intentions becomes an essential function of the tool. Other researchers have demonstrated this function and have proven that it is possible for a computer program to recognise symbols in a sketch and, based on those symbols, activate different design tools (Chapter 10). The coach would therefore use similar principles (used by a number of such tools - notably Right Tool Right Time and EsQUIsse) as the "engine" of its operations.

Accuracy (and speed of recognition) is important. This is dependent on whether to program attempts to recognise the idiosyncratic sketches and diagrams of the user or uses a "standard sketching language" for easy recognition. The coach would employ one or the other of these two approaches. The first method would be time consuming because the coach would have to be "trained" to recognise the user's sketch style. Its advantage lies in allowing the user to sketch naturally. The latter method would be similar to the handwriting system employed by the Palm operating system for handheld PDAs ${ }^{38}$. In the coach, "standard" diagrams or symbols would be predetermined (e.g. a man, the sun, wind) (fig. 13.6). The user then learns, combines and uses the symbols programmed in the coach to communicate intentions. While this method allows for faster error-free recognition, it has the disadvantage of using symbols and diagrams that are not personal to the designer.

\footnotetext{
${ }^{38}$ This system employs an alphabet that is essentially the single-stroke version of the Latin alphabet. This means the user writes each letter without lifting the stylus.
} 


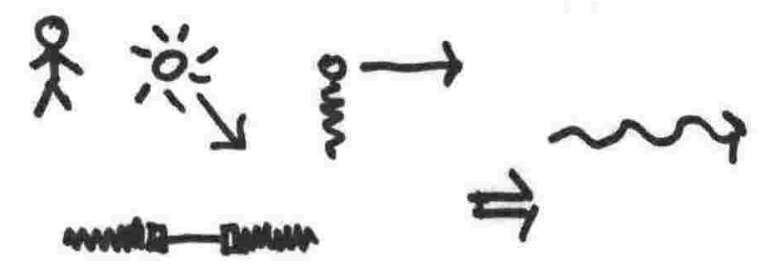

Figure 13.6. "Standard" Diagrams.

\section{Content}

As postulated in Chapter 11, the content of the coach determines the value of the tool. It was further stated that the content of the coach must respect the structure of design problems and the nature of architectural ideas. Accruing a high value for the tool requires breaking down design ideas (or issues) into independent "sub-ideas" or simply employing the idea of chunking.

Chunking, as an idea, is consistent with concepts discussed earlier in Chapter 7. It was discovered that the expert visualises information or knowledge as segments of relevant and coherent units (or chunks) to be retrieved for manipulation. The designer in using the chunks, constructs his/her own syntactic and semantic network or framework of knowledge based on personal biases and experiences. This network, hence, becomes a hierarchical tree with nodes and connections to nodes that represents in its construction an architectural knowledge personal to the designer only. The network is given form through the designer's conjectures and its physical manifestations (sketches, models) allowing didactic criticism from a more capable peer or tutor. The aim of the coach, therefore, would be to provide the relevant pieces and connections (knowledge) for the students to assemble or construct chunks. The student would then "present" these chunks (or their construction) to the tutor.

\section{Chunks}

The building blocks of the coach that contributes to the construction of chunks would be knowledge units (KU), nodes and information units (fig. 13.7). In the coach, each unit of information would represent a part in the hierarchical tree of an entire design idea or what we will call a Knowledge unit (KU). At one level, a 


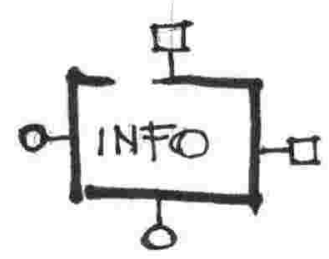

NODE

$\mathrm{KU}$ can represent a combination of any number of issues. At another, that same KU can be a basic unit in a larger structure (KU or chunk). For instance, if a single design idea (or $\mathrm{KU}$ ) is about allowing light in a space for reading. This could comprise issues that deal with windows (opening size, opening shape), artificial lighting, ambient lighting, task lighting, orientation, etc. At another level, this design idea would be a part of a wider idea - designing a reading room - which would also include in combination with our first $\mathrm{KU}$, issues for making a room quiet for reading, and comfortable furniture for reading. This chunk, a space for reading, would then become a part of the designer's knowledge about the much wider issue of designing a library.

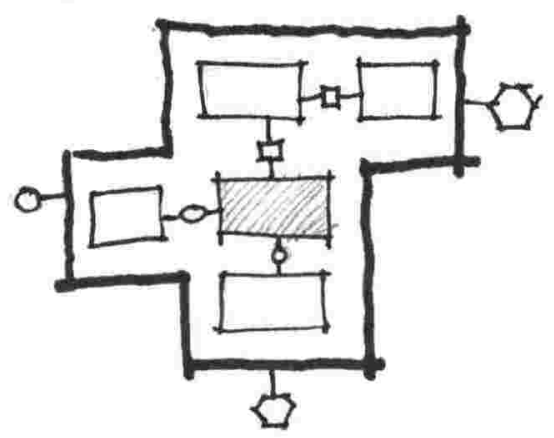

KNDWLEDGE

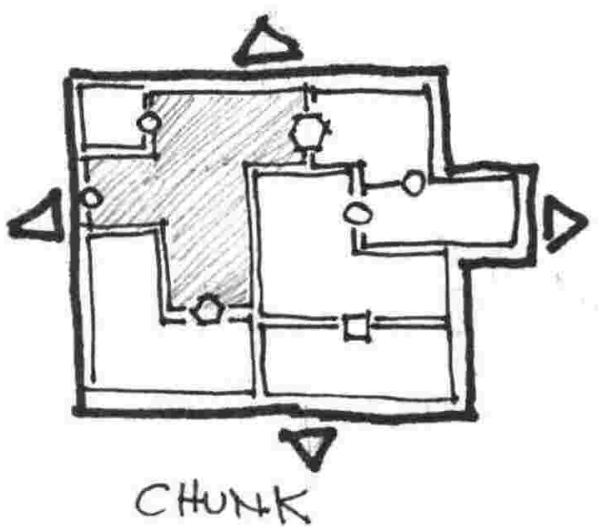

Figure 13.7. Nodes, Knowledge Units and Chunks

Chunks are therefore a combination of knowledge units (e.g. allowing light for reading). Knowledge units $(\mathrm{KU})$ are a combination of nodes (windows), which in turn consists of information units (opening size to light ratio) and connections. A chunk can be thought of as a network of connected KUs and nodes (each node being a piece of information and its connections) creating a complex tree of knowledge. Chunks would be user-composed and occur outside of the tool (in the head of the designer). What characterises the chunk and opens it to criticism is how the KUs are combined and the determined path or map of connections that defines the chunk and the manifestation of that chunk as a design proposal. The analysis and synthesis of the relevant chunks or simply, the proposal would be presented to the tutor. The proposal - the chunk, its connections and relations - will then become a qualitative unit for analysis and criticism by the teacher. Optionally, however, some chunks could 
be predetermined or "channelled" by the tutor, for instance, to determine a special focus or lesson for the design studio.

\section{Elements and Structure}

The design coach would offer the following types of knowledge units:

Precedent knowledge: This would comprise of examples of buildings and other architectural artefacts that illustrate a collection of nodes being considered. Precedents would be important as "real life" points of reference throughout the structure of the content.

Conceptual knowledge: This KU represents ideas that are more abstract and less specific to a particular building or example. Some concepts would be universal and some would be unique to particular viewpoints or theories. Universal concepts would include such notions like ordering principles. Particular concepts would be user-determined or related to the theme of the studio. Such concepts could comprise of ideas like sustainability and green architecture.

Design Strategies: This knowledge type is more about the combination of issues applied to arrive at some desired result. They are the rules of how particular nodes get implemented in different situations. An example of a strategy would be preferred layout strategies for solar gain.

Knowledge Units (regardless of type) would comprise of related nodes which in turn are comprised of connections and information units. Information units are single pieces of information (more often analogous to a leaf in the tree) that could include rules of thumb, ergonomic data, climatic data, typical room sizes, design and reference data as found in selected texts. While the information described is quantitative, the unit could also contain such conceptual ideas as found in Christopher Alexander's Pattern Language or Simon Unwin's Analysing Architecture. Information would take the form of diagrams, text, photos, references, and video/animation. In addition to statements, the information unit would also include information on further reading and reference sources.

In order to allow the construction of a chunk or $\mathrm{KU}$, the design coach defines connections and relationships between pieces of information. Connections act 
as doors or gateways between related information units. They control how the information units, both conceptual and concrete, come together, affect each other, create nodes and the resultant knowledge units. Connections could be universal (pre-determined by the tutor) and/or idiosyncratic (defined by the student).

For clarity and usability, each element (KU, Node, Info Unit) of the content would be structured alike. In addition to the information offered, they would comprise of the following seen or hidden parts:

Label or Tag - Each element will have a name, label or tag for purposes of indexing, searching, manipulation and retrieval. Indexing implies a preset method of retrieval (i.e. determining relations), however, the degree of predetermination is the prerogative of the user or design tutor.

Type - The nature of the element, i.e. node or KU or information unit is also a stored characteristic.

Genealogy - A list of "parents" (wider issues) and "children" (lesser issues).

Scale - Content will be categorised and considered in terms of 4 scales: component or elements, rooms, buildings and site.

User defined Categories - These allow information to be based on the focus of the studio or the preferences of the user; for example, climate, sensory or Caribbean architecture.

Position - This field registers the position of the unit within the structure of the content and within the assembled chunk of the user. It also enables backtracking.

\section{Experience}

A rewarding experience is an intrinsic part of the effectiveness of any digital tool. In the case of the design coach, such an experience could lead to continued use of the tool, the ability to design effectively and efficiently, and the cultivation of an awareness of the issues that affect architecture. Achieving these benefits is dependent on the tool being easy to learn, easy to use, easy to 
control, flexible, unobtrusive, customisable, and intuitive. The following highlights some of the key elements that can contribute to this:

Graphic user interface: The graphic user interface (GUI) of a digital tool includes the interaction metaphors, visual characteristics and concepts used to convey function and meaning on the display. Interactions with the graphic design, navigation buttons, location of hypertext links and predictability of cause and effect would give the coach a familiar "look and feel" to contemporary digital design tools.

Direct Access to Information - The coach would aim to provide the required design information in the fewest possible steps using an efficient hierarchy of information and minimising the number of steps needed to access information.

Simplicity and Consistency - Because the user will depend on the design coach for timely and accurate work-related information, the interface must be simple, consistent, predictable and logical. To achieve this the coach would use a consistent design, with the same basic layout, graphic themes, and behaviour among information types.

Open Modules - Employing a strategy of open modules allows expandability and cross-fertilisation of the knowledge in the tool. In the design coach, the teacher would "plug in" or install a particular module for use in a special studio. For example, a module could address issues related to primary schools or libraries. This ability to be modularly additive and subtractive could allow the user/student to add and change the connections, nodes and information units on the fly. Cross-fertilisation occurs when users exchange their constructed modules.

Customisation - Makes the coach flexible enough to accommodate individual evolving needs, preferences and insights. This will ensure that the experience of using the tool is personal. It would be highly valued if the student could add new clues, make new connections, create new points of departure and in general customise the content to match their own particular biases. Allowing some control over content also forces the user to think about the issues (where, at what level do they fit in to the larger context). 
Reflection - Allowing the user to save paths and events (like bookmarks in a web browser) provides for backtracking and reflection. This enables the designer to revisit "moves" or "arguments" and reflect on decisions made so, when needed, the coach can provide the user with an overview of design decisions and act as a reflective design diary.

\section{Using the Coach}

So far, we have examined the design coach as distinct parts. To get a clearer picture of the vision, it would perhaps be helpful to "see" the sum of its intrinsic parts in action.

Our "observation" takes place in the same studio as Schön's, however this time it is wired for high bandwidth network communications, students are using LCD tablets at their drawing boards, a large portion of the work is being printed on a large format printer and a laser mill is available for cutting physical models. Petra, our design student, is developing her response to the design of an elementary school. Petra is in the diagrammatic phase of her project, she has been working on the problem for some time and will meet with Quist, the studio master, in a few hours.

\section{The Site}

She copies the site plan from the studio's server and imports it into the design coach. Petra's subsequent sketched information is entered on a Wacom LCD graphic tablet. She starts by drawing a series of rectangles that represents classroom blocks on the site. In a corner of the screen, in the proximity of the boxes, a transparent box appears with a list - [site, building, room, component]. Petra vocally answers "SITE" (optionally she could tap the word SITE on the list). The coach responds with another list - [topography, layout, landscape]. Petra indicates topography and the coach responds with - [flat, steep, medium]. She says (or taps) "steep" and the coach searches for and presents precedent and design strategies for dealing with topography. Looking at the enlarged window, Petra considers design strategies for tackling such a "screwy" site. She sees that butting forms along the contours would not work, sees an example of how it is done and makes adjustments to her design. Petra continues to sketch, moving 
from idea to idea by drawing, redrawing, and overtracing. The coach would respond by changing the list of options, ideas and clues as Petra's ideas change. Petra changes to drawing a section. This is done by saying "section" and drawing a line across the contours on the screen. She then draws her boxes on the slope to represent classrooms. The coach responds by offering information about cut and fill. The studio master (Quist) has already loaded a special site module that describes the project site and the particular design issues the student is expected to address. The module presents various strategies for cut and fill as well as various rules of thumb. The module offers external sources for dealing with slopes (e.g, retaining wall design).

Eventually Petra can forgo the step-by-step questions from the coach and simply say site, steep, cluster formation, precedent. Alternately, she could set the coach to respond to a design situation after a considerable amount of information is on the screen or at her command.

Having established a sectional profile for the classroom blocks, Petra moves on to the individual classrooms. To indicate her change of scale she says, "room". She draws a box roughly the size of a classroom and the coach responds [sensory, layout, meaning, precedents]. Also loaded on the coach is a module specifically about designing for education. Highlights of Petra's session includes the coach showing her good architectural examples of schools that satisfy the size, cost and program and context similar to the one being designed and providing information on lighting in classrooms.

\section{The Dialogue}

While the tool aims to inculcate awareness of architectural issues in the student, success of the coach is best measured through the ensuing dialogue between student and teacher.

Eventually Quist meets Petra at her desk. Petra begins the conversation by speaking about her experiences in trying to resolve the layout of the blocks on the slope given. To illustrate her activity, she presents a "map" configured by the coach that shows the decisions she made during the design. These decisions are connected to her sketches and show the decisions behind her forms. Quist 
can now start to speak with Petra about her design without preliminary probing because most of the design decisions are displayed for examination. Quist explains that she approached the task well and comments on the validity of some of the decisions she made, pointing out missed opportunities and praising novel uses of the information offered. He spends some time explaining that by manipulating the cut/fill ratios and information on landscape, she could have subtly created some special places that related more to the landscape. She understands what he means having spent some time fiddling with the ratios herself and briefly looking at the landscape option on the list. The connection between the two that was not apparent to her before, means more now that it has highlighted by the tutor.

\section{Conclusion}

In this chapter, we have presented the vision of the design coach that assists the student of architecture in developing an awareness of design issues. While this vision cannot be claimed to be wholly accurate, it has strived to indicate the important elements needed in such a tool to accomplish the ideas set out in earlier chapters.

The design coach when developed should address four crucial areas - interface, experience, recognition, and knowledge. A well thought out interface will allow a conversational interaction with the tool. This would be achieved by a multimodal input that uses sketching, voice and a familiar GUI simultaneously and interchangeably. Output would be assertive yet unobtrusive, constantly changing yet simple to comprehend. Supporting the interface with accessability, openness and customisation will offer an experience that is easy, flexible and personal.

Generally, knowledge is accomplished by assembling bits of information. The design coach must provide relevant bits of architectural information at the right time based on the designer's intentions. Recognising these intentions and permitting connections between these bits of information, enables a virtual construction of relevant knowledge to create chunks of understanding. The design coach that fulfils these requirements will be a valuable tool in design studio, ultimately adding value to the desk crit. 


\section{What is the Design Coach?}

While the coach has the potential to be a valuable teaching tool in studio, it is perhaps wise to clearly state its use and purpose to avoid any confusion. Firstly, the design coach is a digital tool to be used in the design studio to support the zone of interaction (occupied by teacher and student). It is not intended to be a substitute teacher or learning tool in lieu of personal face-to-face contact. The design coach is a second "expert" with a raison d'etre of providing information to enhance the interaction between student and teacher. The first expert (the tutor) is still needed to emphasise the connection between abstract and concrete and general and personal. The design coach will be used to supplement and support traditional face-to-face desk based design teaching, not to replace such contact. The coach will only establish the basis on which the tutor can communicate with students. With the coach the tutor will now have a little more room to nurture personal creativity in the student with the computer providing the general knowledge (which does not have to be repeated from one student to the next).

The design coach will be a supplement for design studio instruction that consists of various subjects that is useful for learning architectural concepts. These would range from Christopher Alexander's pattern language to ergonomic data, climatic data or rules of thumb. It makes no value judgement on the issues but presents them as items/ideas or possible directions for the student to consider and raise in the desk crit. This is similar to a book, however the design coach is different because it does not exist outside the design process and cannot stand alone.

Having the computer in the role of a design studio aid or helper doesn't seek to replace creativity but rather inform it. The coach is based on definitions and ways of breaking down architectural information into manageable units but also seeing the relationships and connections between the units prior to and during composition. This facilitates a good understanding of the object being "assembled" because of the intimate knowledge of the parts and how they fit together. 
Adding a design coach (as a second expert) to the interaction between novice and expert (design tutor), allows students greater freedom in constructing their own knowledge. It also facilitates the transfer of ideas from design project to design project and allows reflection. Through the conscious consideration of interface and content, this tool has the potential to provide opportunities for a richer teacher/student dialogue that exists in the virtual world of reality. Such existence, it is hoped, would lead to graduates of architecture that can transit from academia to practice effortlessly.

\section{References}

Negroponte, N. 1996. Being Digital. New York: Vintage Books. 
Conclusion 


\section{Conclusion}

"Ideal conversation must be an exchange of thought, and not, as many of those who worry most about their shortcomings believe, an eloquent exhibition of wit or oratory." - Emily Post

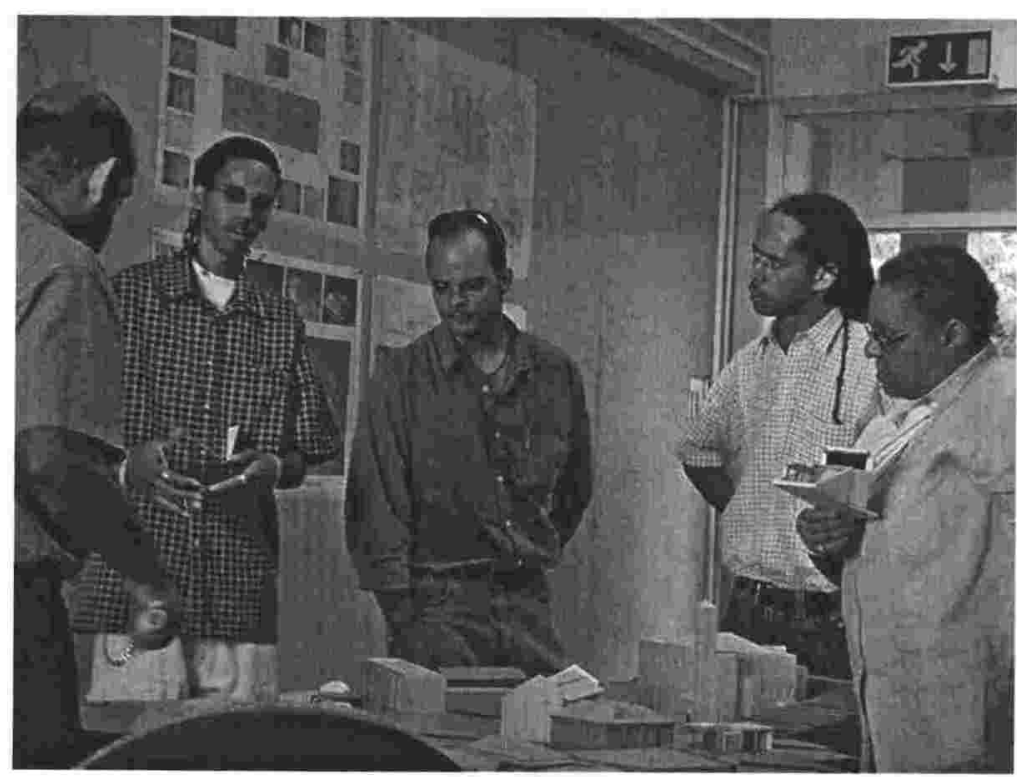

Figure c.1. Architectural education is about conversations.

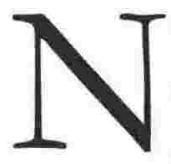

Tew social and cultural norms, new materials and building types and current trends, like sustainability, have contributed to the complexity of architecture today. As a result, schools of architecture are under pressure to provide graduates of architecture with the requisite skills that characterise good design thinking strategies as well as support responsible design. Unfortunately, the practical knowledge base provided by the current model of architectural education has proven inadequate to deal with the rapid changes in technology and society in the $21^{\text {st }}$ century.

This situation has not escaped the attention of critics and educators. One of the most persistent criticisms of architectural education is the claim that graduates seem to lack the skills needed to make the transition from academia to practice less arduous. Well-documented reports commissioned by professional bodies over the last few years indicate a growing divide between the worlds of architectural education and practice. Most sources claim that students need 
greater exposure to real and practical architectural experiences. They also recommend that, within the context of the design studio, there should be a better balance/integration between the study of design, and the study of practical issues giving more attention to such "practical" matters like sustainability, energy conservation and community. It is further recommended that this can only be achieved by incorporating pragmatic experience with realistic constraints and issues into the current models of teaching architecture.

This thesis sought to meet the challenges posed by the current model of education. Achieving a better balance between the study of design and the study of practical issues like sustainability, energy conservation and community meant providing an innovative and effective approach that integrated design education with sketching and design computing. This approach was confirmed by:

1. Determining that aspect of architectural education that had the greatest influence on the current situation.

2. Establishing the importance of the sketch in mediating and facilitating the conversations between head and hand.

3. Demonstrating the differences between novice and expert.

4. Demanding a greater, more relevant role for the computer in architectural education.

5. Suggesting the implementation of an "expert" teaching tool that interacts with the student through sketching, providing for a more informed dialogue between student and master.

These steps were facilitated by an exercise in qualitative research that utilised a number of inquiry tools - literature surveys, discussion forums, questionnaires and empirical studies - to define a digital tool that could elegantly redress the situation.

\section{Design Education}

\section{The Academy}

It was established (chapter 1,2 ) that the movement of the architectural student from the building sites of antiquity to design studios located in academia, was 
one of the factors that has contributed to the challenges that face design education today. A characteristic of this transformation is the separation of design from the realities of building. With no investment in a tangible product, the student instead relies heavily on idealised notions of architecture. It was also suggested that a remedy to the situation might entail providing design (an integrative activity) with the requisite technical knowledge base (currently delivered in a different environment).

\section{The Design Studio}

The main instrument for the dissemination of design and technical knowledge, and the vehicle most likely to have an effect on meeting this challenge was determined to be the design studio (chapter 3). The design studio socially, physically and pedagogically occupies premier position in design education. It is the place where the student acquires the skills of integrating architectural knowledge and the many elements of architectural education. The current model of studio education encompasses the identification of a design problem, followed by a series of defined events or dialogues, resulting in a design solution presented to and evaluated by a jury. The success of the Socratic "give and take" that occurs during these events is dependent on the information available to the parties, for use during a particular conversation. Of all the conversations the student encounters in design studio, the one that is most affected by the nature and quality of information is the dynamic relationship between student and master.
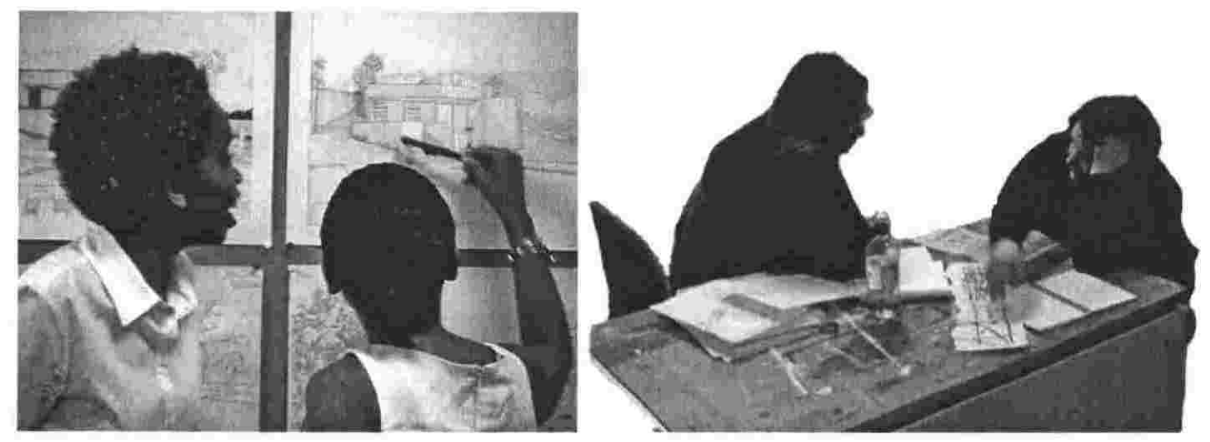

Figure c.2. The teacher student dialogue is the most important part of design education. 
Whereas design studio is the most important element of design education, the student-master discourse is the linchpin that gives the design studio definition and validation (chapter 4).

Architecture today entails greater sensitivity to the needs of building users, society and the environment. This "social" sensitivity, coupled with the technical complexity of buildings, can only be achieved with more than a passing knowledge of the issues. In this environment, the master-apprentice discourse has been unable to keep pace with the changing context of society and practice. With widespread changes in technology and society, many design teachers struggle to balance teaching practical concerns with teaching students how to think critically and abstractly, contributing to a shortfall in the students' practical knowledge (Fig. c.3).

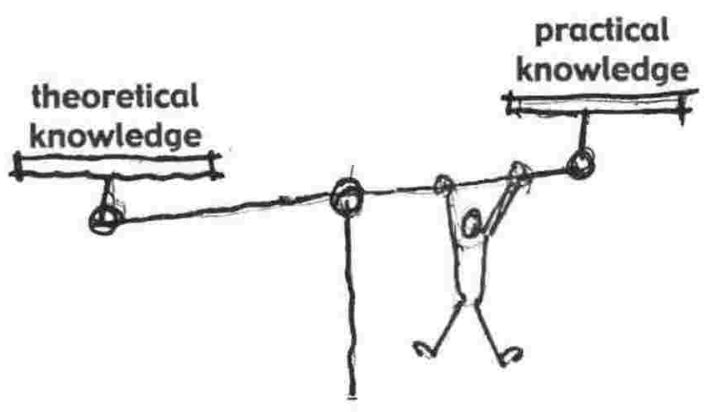

Figure c.3. The master in the struggle to balance theory and practice.

The zone of interaction

Assisting students to gain more than a passing knowledge of the practicalities of architecture requires the reconfiguration of the mental and physical "space" where the student and master interact. This space - the zone of interaction has always been a part of the master/apprentice model of teaching. On the sites of antiquity this zone would have been located on or in the building itself. The apprentice learnt through direct exposure, the connection between design ideas and their built consequences. Today, the contemporary studio cannot always provide students with an actual building to test and experience first hand, and so the zone of interaction occurs in the virtual world of drawings and models (Figure c.4). 

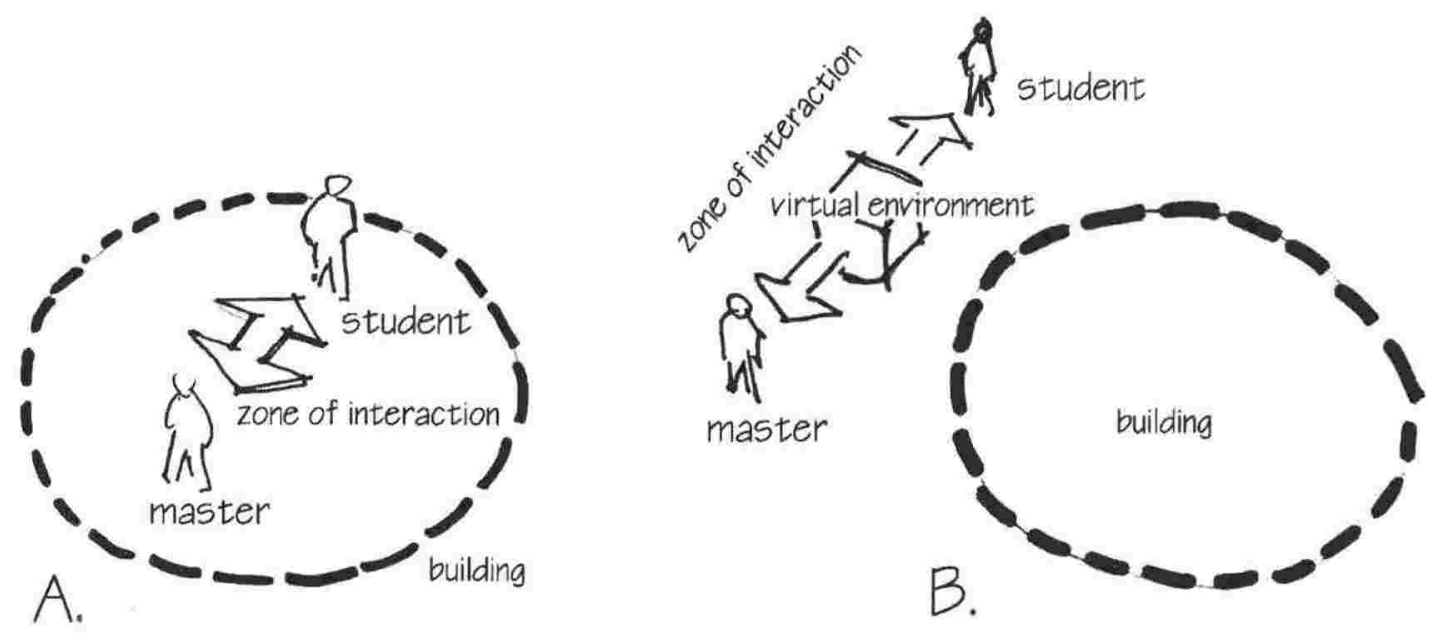

Figure c.4.The sites of antiquity (A) provided a context for the zone of interaction while today, $(B)$ the zone exists outside of the reality of the building.

The virtual world, while having a clear advantage over real sites (they allow experimentation and focus), displaces the student's learning from the realities of architecture. In it, the student (who has little experience of the "real" world) struggles to define a realistic model of the problem and is willing to suspend "physical rules" and ignore limitations. It is therefore left to the master to reveal the realities lacking in the students' proposals subsequently reducing the time afforded to other aspects of teaching design.

Donald Schön has written about how meaningful knowledge is if the transference of that knowledge is made in the midst of the student engaging with a task (and perhaps stuck in it). Practical knowledge is, therefore, given greater currency if interaction happens in the context of reality (or the rules of such reality). Since, in most instances, it is physically impossible to teach within an actual site, the alternative would be to embed the rules of reality in the virtual environment, which is usually manifested in representations of the virtual environment or sketches. 


\section{The Sketch ${ }^{39}$}

Chapter 5 determined that the most important design skill that a designer can develop is the ability to create, manipulate and interpret design concepts/issues through the sketch. The sketch (whether two or three dimensional) is the designer's way of "seeing" the issues involved in a design situation. Design decision-making therefore, relies on the skill to identify and recognise the multiple design issues embedded within a hand-drawn sketch or rough physical model. Command over sketching depends on the ability to "see". The average beginning student of architecture, however, lacks the experience and knowledge base to see the issues the expert/master can intuitively visualise. Ironically as a passive tool, the sketch relies on initiative from the designer. It cannot tell the student any more than his/her limited knowledge about the design situation embedded in the sketch. This hinders flexible decision-making and progress.

The dissertation reported on a unique protocol experiment that empirically demonstrated that students respond well to an "expert" that looks at their sketch, asks the right questions or provides the right clues that makes the design situation more legible (chapter 6,7). Since it would be expensive and time consuming to provide such a person for every student, it was suggested that this ability should be embedded in the design tools of the student. This suggests that the sketch should move from being less passive to an interactive position where it prompts and cues the student about aspects of the design situation. An expert sketch would increase the student's awareness of the situation and provide the opportunity for the student to meet the teacher on terms rarely existing in the present dialogue. With the context of the discussion already established prior to the meeting, the student is cognisant of the issues involved, asks the "right" questions and understands the criticism and advice (the teacher gives) on the issues. The empowered sketch, therefore, acts as a mediator and facilitator in the relationship. The thesis further argued that this empowerment is possible through the use of digital technology.

\footnotetext{
${ }^{39}$ As stated earlier in the thesis, sketching does not only refer to marks made on paper but also other tools that help design thinking (e.g. rough physical and digital models). The emphasis of the thesis however, is on the sketching seen in the works of Da Vinci, Corbusier, Kahn, Aalto and others and is seen as an integral part of the tradition of architectural design.
} 


\section{The Computer}

The computer was discussed in light of its ubiquitous presence in design education and practice (chapter 8). Despite this, designers to a large extent still prefer to use hand-drawn sketches to visualize the first notional organisational ideas. Current digital tools, while being excellent at the communication and visualisation of ideas and concepts, have not been able to facilitate the kinds of design thinking enhanced by the sketch.

Efforts to shift the computer in this direction have proven perilous and have consolidated the computer's position in design education as a visualisation, analysis and communication tool (chapter 9). It was argued that, engaging the computer as an integral part of early design required rethinking the manmachine paradigm. Exploiting the inherent strengths of the computer, namely sifting through vast relationships, calculating and making connections between pieces of information, can enhance and extend the zone of interaction. Empowering the sketch and exploiting the computer in this way mandates that the sketch be digital (chapter 10). This is indeed possible since research attempts at digital sketching have resulted in applications that recognise sketch diagrams made on screen and provide analytical tools or generate threedimensional form.

\section{The Design Coach}

The implementation of a digital teaching aid to the zone of interaction could help students reconcile disparate elements into a habitable, environmentally friendly and architecturally responsible whole (Chapter 11, 12, 13). While there could be many ways of implementing such tool, the direction advocated by this thesis is a design coach that comprises of two main components (chapter 11). The first (a sketch recognition component) involves recognising the sketch and inferring an intention or issue under investigation. The second (an information component) involves relating specific information to the inference and communicating such information as clues about the design situation. The digital sketching and intention recognition component of the tool has already been demonstrated by recognition systems developed by Ellen Do and Pierre Leclercq. It is intended that these systems (or similar technology) could become 
the "engine" or underlying recognition principles on which the tool will be based.

The use of the sketch as interface for a design coach is the most efficient and effective way of compelling the student to directly engage with the design information. This allows the student, interacting with their computer augmented sketches, to read into sketches the questions and issues embedded in the visual image and perceive the sketch as more than a representation tool.

While it is crucial for the tool to recognise architectural intent from a personal sketch, the structure and content of the information determines the tool's value. The content of the design coach, it is suggested, should be based on several assumptions. First, in order to be useful to the design process and teach students about the issues involved in design, the structure must somehow relate to the structure of design problems. Secondly, the content must contain the kinds of clues that ground the student in the realities of design. Third, use of the computer, as a teaching tool, must be consistent with theories related to computer assisted teaching and learning. Finally, design learning is personal and idiosyncratic therefore a universal approach must be found to all learning types must be included in the learning advantages of the tool.

A prototype was built to investigate students' reaction to the information content and structure of the tool (chapter 12). Two experiments using this prototype received positive responses from students.

The final form of the design coach would be an integrated sketching environment that assists the student of architecture to realise ideas that are affordable, sustainable and a delight for users. It would be capable of processing and interpreting a freehand sketch and, having determined an intention from this interpretation, present the student with issues, connections and references related to an issue under investigation. The student reads the sketch in conjunction with this information and slowly becomes aware of the implications and practicalities of his/her moves. The system would aid this process by actively addressing issues of interface, content, recognition, and user experience. In the end, the sketch, for the student, becomes an intelligent tool that supports and informs exploration. It becomes a ladder or scaffold that 
supports the student and allows meaningful critical dialogue between student and master about the design process. The use of the tool would enhance the dialogue between student and teacher epitomising the use of appropriate and innovative technology to create affordable, sustainable and liveable architecture.

\section{Conversations}

An elemental part of Vygotsky's theories of learning was the zone of proximal development. The inherent value of the zone of proximal development depended on effective dialogue between the parties involved. Schön's notions about reciprocal reflection in action require a Socratic "give and take" or conversation to achieve a convergence of meaning. Graphical thinking is a conversation between head and hand. The underlying premise of this dissertation has been the idea that these conversations have a formidable influence on the architectural graduates ability to transit easily from university to practice, exhibit sensitivity to the needs of building users, society and the environment, and engage in architecture that is culturally and socially significant, safe, purposeful, sustainable and responds to the aspirations of its inhabitants. The aim of the thesis, thus, has been primarily about enhancing these conversations.

The significance of this goal lies not in the definition of a tool but rather in acknowledging or recognising the importance of conversations - teacher and student, student and sketch, student and computer - to architectural education. At present, there exists within the zone of interaction an asymmetrical relationship between student and teacher that legitimises a hierarchical (master/apprentice) structure. This can be perceived as counter-productive to creating a student centred learning environment. The student in his/her encounter with the master often feels obliged to accept the master's opinions, facts and information because he/she has no information to question or suggest alternatives. The zone of interaction with its requisite power imbalance, and the conversations that occur within it require reconsideration. Effective dialogue is achieved through the meeting of "equals". It cannot exist when one participant has to spend most of the conversation attempting to "pull" the other up to a comparable enough level for fruitful discussion. For students to 
gain more from this interaction, they must have an opportunity to raise themselves to a level of understanding that facilitates an easier convergence of meaning. The thesis has demonstrated that addressing this inequality is an important subject matter for architectural education research.

Of lesser significance is the demonstration that the computer can surpass current applications in visualisation and communication to become an effective teaching tool in architectural education. The thesis has indicated that, by enhancing available content material and delivery as well as providing a shared body of self-access materials, computers can facilitate or prepare students with learning strategies and attitudes that creates an efficient culture of self-learning.

This research has also reinforced current thinking about the value of the sketch. It has shown that the sketch is not only an important part of architectural design, but it is also an essential tool in the dialogue between expert and novice. The work in this research as regards the unique protocol analysis linking conversations between head and hand, expert and novice, lays the foundation for further studies of this nature. Furthermore, it has demonstrated that in combination with digital technology, the sketch can provide the designer with information reflecting the hundreds of questions, issues, connections and implications embedded in the visual image.

\section{Limitations of this Research}

This work is by no means perfect. While the work has presented a new paradigm as regards education, it cannot claim to be authoritative. The limitations that precludes this from happening is concerned mainly with testing of the ideas with human subjects. One instance is the double h studies. Because it was novel and unique, there existed no prior examples of coding. A more thorough coding regime could have revealed more scientific data about the relationship between novice and expert. The study, however, was not about the data exchanged in the protocol and the thinking processes involved. Rather, it was about the exchange itself and so the information gleaned from the protocols, while not true scientific data, was enough to arrive at a conclusion. While this does not affect the qualitative observations of the experiments, it is 
one of the variables that prevents the information from being conclusive or scientific.

Other limitations exist in the design studio tests of the prototype. Despite the positive attitude of the students, there was no conclusive way of proving that the students were in any way better off by using the coach. Second, the tutors were not actively involved in testing and commenting on perceived changes to the zone of interaction. The limited exposure of the prototype (one studio project in one school of architecture) and the lack of a fully functional prototype (with sketch recogniser) also precludes the arguments presented in this work from being conclusive and fully representative of even general behaviour. Despite this limitation, there is enough anecdotal evidence to warrant and justify further investigations (probably in other contexts).

\section{Future Directions}

Research is not simply about the search for information but is more about using the information found to generate new ideas. It is quite obvious that a work of this nature is by no means complete. There are many future research paths that could support and extend the scope of this thesis.

It has been stated that the relationship between student and teacher is a significant ingredient in architectural education. At present, there is no discernable research into this important relationship. Future work in this area would involve developing an adequate coding regime for analysing protocols of the zone of interaction. Results and conclusions from this investigation could lead to a deeper understanding of studio based teaching, better teaching practices and (relevant to this work) a more valuable coach.

Parallel to such study is the further development of the coach to include a sketch recogniser (probably in partnership with established researchers in the field) for testing. A crucial test of this new prototype would be to record students' reactions to the tool and examine the resulting dialogue between teacher and student. This would involve two situations - a teacher advising a student who designs alone and a teacher advising a student who designs with the design coach. A comparison of the quality of these encounters would provide more information about the viability of the coach. It would become 
important also to test the tutor's reaction to the new tool and if in fact his/her job is made easier.

Further research can be directed towards the content of the coach (perhaps as a stand alone product). With the ideas generated in this work, researchers can now investigate ways of presenting information that complements the sketch, develop special content and/or repackage existing reference books (e.g. The Metric Handbook).

Architectural practice also stands to benefit from this work as it opens up opportunities for the development of practice specific information tools. Architects would have the opportunity to keep abreast with new technical knowledge. A tool for practice would provide assistance on specialised fields. Practitioners, for instance, could install building type modules (e.g a hospital) that provides relevant advice about the special subject while the designer works. Specialist software could also facilitate how the architect communicates and converses with consultants. The resulting conversation would be open since the practitioner would be aware of the issues involved, ask the right questions and get the relevant advice from the specialist.

Finally, this research has opened up new directions into the fields of design education, sketching, and computers in education. It has provided the idea of a tool that enriches and supports students (who have limited design vocabularies) with practical and poetic design ideas, and enables a more intelligent, wellinformed and confident conversation with the studio master. This idea, in and of itself, opens the door to various other studies aimed at improving and raising the quality of architectural conversations.

\section{In the End}

This thesis has identified a significant challenge to architectural education. It has shown the difficulties in providing students with a practical knowledge base that is adequate to deal with the rapid changes in technology and society in the 21st century. This thesis proposes meeting this challenge by using digital technology to empower the sketch, enhance the zone of interaction and develop students' awareness of the practical issues of design while thinking critically and abstractly. 


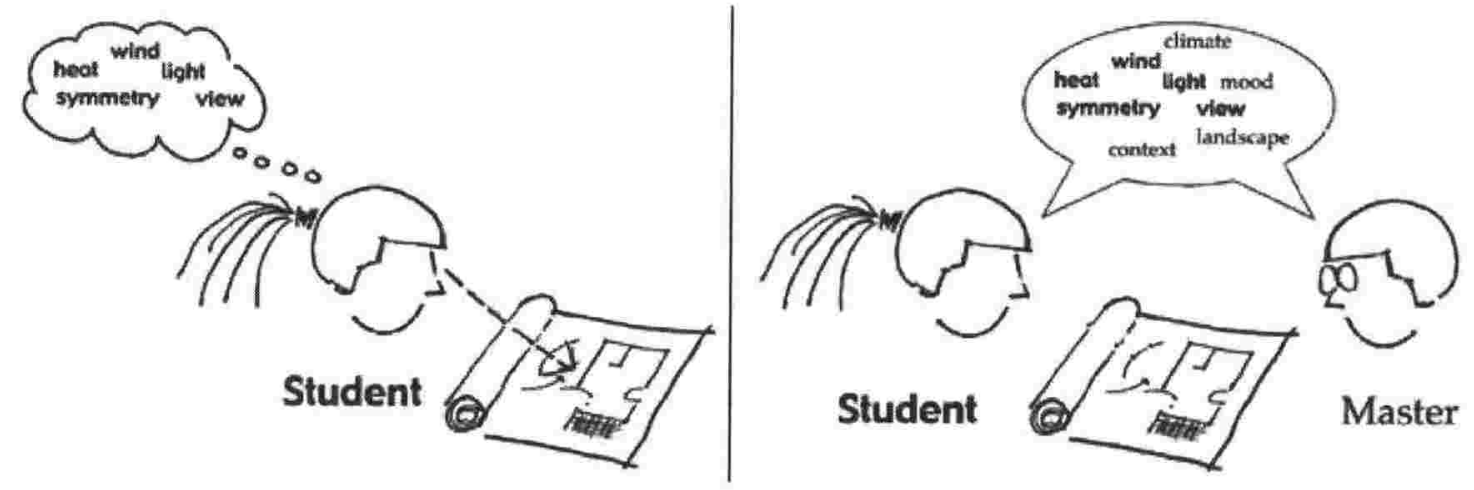

Figure c.5. Results of the intelligent sketch

Having being exposed to the intelligent sketch the student then meets the master with an acute awareness of the issues involved in the task. This awareness allows a higher quality of student-master dialogue culminating in a higher convergence of meaning. In the end, the student gains adequate critical thinking and problem-solving skills while using appropriate and innovative technology to learn about the things that make architecture affordable, sustainable and liveable.

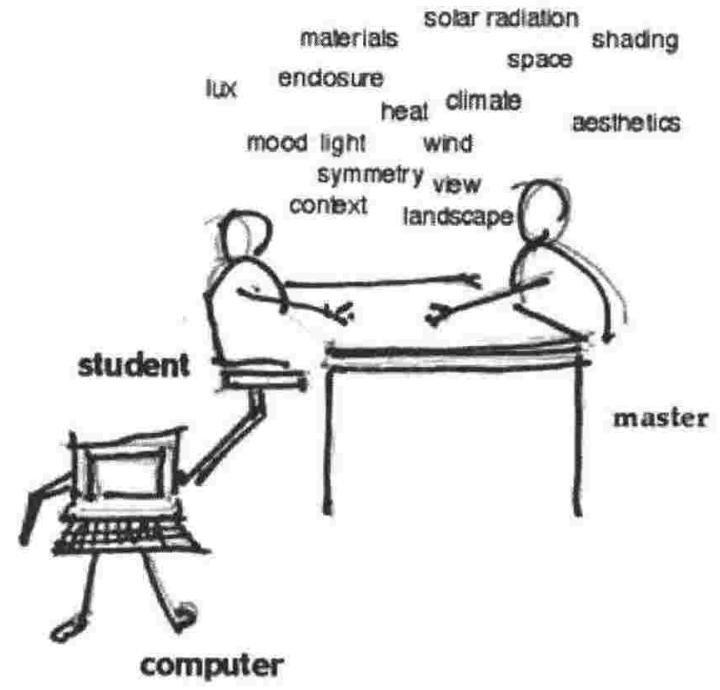

Figure c.6. The computer becomes a scaffold or support for the zone of interaction. 
Appendices

- A1 - 
A2 - 


\section{Appendix 1: Questionnaire for Double H Studios}

Name:

(Note: You do not have to write your name if you wish to remain anonymous)

Please circle the number which best describes your response:

The first set of questions deal with your own personal design preferences.

[1] What do you understand by the word Sketch?

[2] How often do you sketch when designing?
1 All the time
2
3sometimes
4
5never

[3] How often do you sketch when communicating (exchange ideas etc.)?
1 All the time
2
3 sometimes
4
5never

[4] What is the average time (in one sitting) you would spend on any design activity? Hrs

[5] When sketching, what medium do you use most?

"Pen" Type (felt tip, pencil, pen or other):

"Paper" Type (Sketching tissue, tracing, plain or gridded paper or other):

[6] What representation do you use most when designing/sketching (rank in order of frequency 1 is most, 5 is least)?

Plan __ section __ elevation ___ perspective other

[7] How early do you begin to use a scale rule?

$\begin{array}{lllll}1 \text { Very early } & 2 & 3 & 4 & 5 \text { design development }\end{array}$

[8] What scale do you usually start designing at?

$\begin{array}{llll}\text { None } & 1: 100 & 1: 50 & 1: 25\end{array}$

[9] When "moving to a new idea" or representation in the process do you

A] Redraw from scratch the main ideas 
B] Mark the new idea on the existing sketch

C] Trace previous sketches implementing new ideas on the trace.

[10] How often do you consult outside sources/reference material when designing?

$\begin{array}{lllll}\text { 1All the time } & 2 & 3 & 4 & 5 \text { never }\end{array}$

[11] How early do you use reference material at the start of design activity?

$\begin{array}{lllll}\text { 1Very early } & 2 & 3 & 4 & 5 \text { design development }\end{array}$

[12] How helpful or compatible to your design process would you say a computer (in its present state) is?
1A lot
2
3
4
$\mathbf{5}$ Not at all

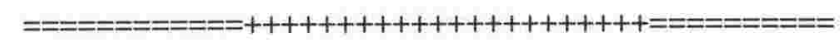

The next set of questions are about the "head and hand" exercise done in Studio.

[13] How did you find the exercise?

[14] How much do you think the exercise exposed you to aspects of the design process?
1A lot
2
3
4
5 Not at all

[15] How much did you learn from the experience?

$\begin{array}{lllll}1 \text { A lot } & 2 & 3 & 4 & 5 \text { Not at all }\end{array}$

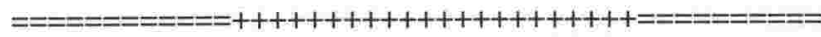

These questions pertain specifically to botb roles you played.

\section{Hand}

[16] Did you feel that you had any stake in the design?
1A lot
2
3
4
5 Not at all

[17] Did you have any problems representing data?
1A lot
2
3
4
$\mathbf{5} \mathrm{Not}$ at all

[18] Did your partner(s) have any problems with your images?
1A lot
2
3
4
5 Not at all 
[19] How difficult was it to produce images that the head could understand?

$\begin{array}{lllll}\text { 1Very } & 2 & 3 & 4 & 5_{\text {Not at all }}\end{array}$

[20] How much of a difference do you think it would have made if you didn't see the brief at all?
$1 \mathrm{~A}$ lot
2
3
4
5 Not at all

[21] How often did you refer to the info booklet on behalf of the head?
1A lot
2
3
4
$\mathbf{5}_{\mathrm{Not}}$ at all

Head

[22] Do you think you designed any faster than normal?
1A lot
2
3
4
5 Not at all

[23] Was the task achievable in the given time period?

Yes

No

[24] Did you feel free in designing or were you restricted in anyway?

Yes

No

[24b] If you answered yes to above, in what ways were you restricted?

[25] Did you have any difficulties in interpreting the images presented to you?
$1 \mathrm{~A}$ lot
2
3
4
5 Not at all

[25b] What difficulties did you have, if any, in interpreting the images presented to you?

[26] How much do you think the design belonged to you and not "shared"?
1A lot
2
3
4
$\mathbf{5}_{\mathrm{Not}}$ at all

[27] How frustrated were you by not having to use your hand to sketch?
1Extremely
2
3
4
5 Not at all

[28] How much was the design affected by you not using your hands?
1A lot
2
3
4
5 Not at all 
These questions are more general to the exercise.

[29] Would it change anything if the hand were a computer?
1A lot
2
3
4
$\mathbf{5}$ Not at all

[30] In what ways do you think it would or should change?

[31] Was the information provided in the info Booklet adequate?

Yes

No
A Basic Human Data
B Vehicles
C Stairs
D Sanitary Provisions
E NZ Sun Data
F Daylighting
G Cost Data
H Workspaces for Architects
J Workspaces Reception
$\mathrm{K}$ Gallery and Meeting
L Residential Spaces

M Kitchen LayoutN Bathrooms

O Information from Pattern Language

[32] From the information above, write the corresponding letters for the three most and least relevant to that stage of the design process and the most and least helpful to the exercise (done in studio):

The most relevant information

The least relevant information

The most helpful information

The least relevant information

What information would you add?

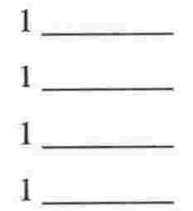

2

$$
2
$$

2

2

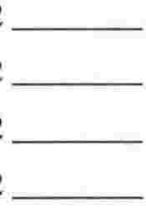

3

3

3

3

[33] If there are any additional comments about the exercise or the info pack that you would like to make you can do so here.

\section{Thanks for your responses!}




\section{Appendix 2: Instructions \& Questionnaire for Protocol Analysis Participants}

\section{GENERAL INSTRUCTIONS to PARTICIPANTS}

In order to produce valid and helpful data from the design protocol it would be appreciated if the following were kept in head:

- Verbally report on what you are thinking as long as it doesn't affect what you are doing. This, however, is not essential.

- This is a pilot study so it's OK to criticise the experiment and make suggestions.

- Ignore the observer (and recording apparatus) as much as possible yet not hesitating to ask questions that pose a problem in achieving the stated objectives of the exercise.

\section{RULES of ENGAGEMENT}

This study is about the meeting of the "hand" and "head" to achieve a design solution.

One person is the "bead"; this person does the designing. The other person is the "band"; this person does the sketching.

\section{In a nutshell:}

The bead basically tells the hand what to do. The hand has the responsibility of coming up with an image that would greatly assist the head to grasp the problem and progress towards the design solution. Therefore to proceed in the design process the bead has to know (or at least have a fair idea) what to ask the band for.

The duties specifically:

\section{Hand:}

1] To follow instructions of the bead, only asking questions as it relates to the image (except in 3)

2] Draw or illustrate concepts that you think would enhance the understanding of the head. The hand has a right to ask what projection/representation to illustrate (plan/elevation/section/3D) and what scale if any. 
3] Advise on the consequences to other design domains that are not being investigated. The hand has a right to point out potential problems and discrepancies overlooked that has to do with the objective (practical) side of the design.

\section{Head:}

1] To design a solution relying on images and information presented by the hand

2] Ask specifically for the image/information needed to make decisions. The head has a right to tell the hand exactly what is necessary in the image and what is redundant.

3] Set out and specify the kinds of questions you want the band to ask

4] Request any "non-visual" information from the band i.e. solar paths, distances, max. room widths, stair configurations etc.

If there are any comments or ideas that come up during the session make a note of it for the post session discussion. Also keep in head that we are going to look at the video evidence at a later date.

\section{END of DESIGN TASK}

Design should go as far as the end of the schematic design stage i.e. showing the client a rough layout of the proposed scheme. The design task ends generally when the head considers it ready for "drawing up" (i.e. ready for technical drawing/entering on the computer).

The following minimum however, is desired:

Floor plans (to some scale); Site section (to some scale); Elevation and/or another section (to some scale); and a $3 \mathrm{D}$ sketch (optional)

\section{Brief for Experiment I}

An architect and her husband who is an Artist/sculptor have just inherited along with a small sum of money, a small piece of property within the city. They want to use the other part of the inheritance $(\$ 100,000)$ to build a small studio from which to work and a gallery to display and sell artwork (their work along with that of other artists). They do not know how much space is required for the various activities but do not want spaces that are either minimum or too generous. Some of the spaces required are as follows: 
- Studio(s) for 2 (artist and architect)

- Studio for 2 employees (of the architecture firm)

- Workshop

- Reception Area (and space for receptionist/gallery hostess)

- Meeting Space

- Bedsit (for overnight sessions) with two separate "sleep spaces" along with kitchenette, shower etc.

- Space for eating

- Adequate Storage

- Public Gallery to show work of client and other artists

- Media space - for 6 seated (if need be) to show slides etc.

\section{Brief for Experiment II}

A writer, her husband, teenage son (19) and daughter (16) have just inherited along with a small sum of money, a small piece of property by the beach. They want to use the other part of the inheritance $(\$ 100,000)$ to build a vacation home on the site. They do not know how much or how many spaces is required for the various activities. They however, do not want spaces that are either minimum or too generous. The spaces specifically requested are as follows:

- Sun deck with Barbecue area

- Living/Entertainment Area

- Changing Spaces for when they have a beach party

- Parking Space for 4-6 cars

- Five separate "sleep spaces" (capable of accommodating overnight guests if necessary)

- Adequate Storage for water sports equipment

- A Study/den for the writer

- Media space - for DVD etc.

The clients also want specific qualities like good views, airiness and an informal sense of place incorporated. 


\section{Pre-Protocol Questionnaire}

\section{Subject Information}

Name:

Occupation (student/practitioner):

Design Education (Years):

Design Practice (Years):

1] What do you understand by the word Sketch?

2] How often do you sketch when designing?

$\begin{array}{lllll}\text { 1 All the time } & 2 & 3 \text { sometimes } & 4 & 5 \text { never }\end{array}$

3] How often do you sketch when communicating?

$\begin{array}{lllll}\text { 1All the time } & 2 & 3 \text { sometimes } & 4 & 5 \text { never }\end{array}$

4] When sketching, what medium do you use most?

Paper Type

\begin{tabular}{lllll}
\hline Sketching tissue - & 1All the time & 2 & 3sometimes & 4 \\
5never & & &
\end{tabular}

Bond paper - A4- Larger? 1All the time $\quad 2 \quad 3$ sometimes 4

5never

Tracing paper - A4 - Larger? 1All the time $\quad 2 \quad 3$ sometimes $\quad 4$

5never

Other?

"Pen" Type

Felt tip - 1All the time

$2 \quad 3$ sometimes 4

5never

Pencil soft - 1 All the time

$2 \quad 3$ sometimes 4

5never

Pencil hard - $\mathbf{1}$ All the time

2

3sometimes

4

5never

Pen - 1All the time

$2 \quad 3$ sometimes

4

5 never

Other?

5] What representation do you use most when designing/sketching (avg. percentage)?

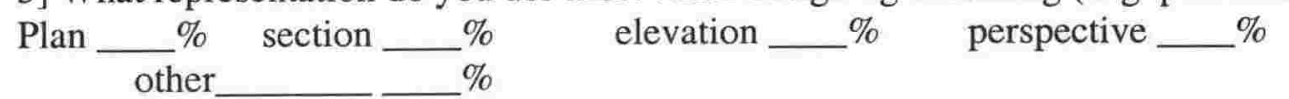

6] About how much time (in one sitting) do you spend on design activity? hrs 
7] How often do you consult outside sources when designing?

$\begin{array}{lllll}\text { 1All the time } & \mathbf{2} & \mathbf{3}_{\text {sometimes }} & \mathbf{4} & \mathbf{5}\end{array}$

8] How early do you use reference material at the start of design activity?

$\begin{array}{lllll}1 \text { Very early } & 2 & 3 & 4 & 5 \text { design development }\end{array}$

9] How early do you begin to use the scale rule?

$\begin{array}{lllll}1 \text { Very early } & 2 & 3 & 4 & 5 \text { design development }\end{array}$

What scale do you start designing at?

$\begin{array}{llll}\text { None } & 1: 100 & 1: 50 & 1: 25\end{array}$

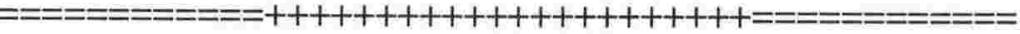

\section{Post Experiment Questionnaire - Hand}

1] How did you find the experiment?

2] Do you think you had any stake in the design?
1A lot
2
3
4
$\mathbf{5}$ Not at all

3] Did you have any problems representing data?
1A lot
2
3
4
5 Not at all

4] How hard was it to produce images that the head could understand?
1 A lot
2
3
4
5 Not at all

How much difference do you think it would have made if you didn't see the brief before?
$1 \mathrm{~A}$ lot
2
3
4
$\mathbf{5}$ Not at all

\section{Post Experiment Questionnaire - Head}

1] How did you find the experiment?

2] Do you think designed faster than normal?

$\begin{array}{lllll}\text { 1A lot } & 2 & 3 & 4 & 5 \mathrm{Not} \text { at all }\end{array}$

3] Did you feel free in designing or were you restricted to one type of solution?
1A lot
2
3
4
5 Not at all 
4] Was the task achievable in the given time period? $\mathrm{Y} / \mathrm{N}$

5] Do you think the design belonged to you and not "shared"?
$1 \mathrm{~A}$ lot
2
3
4
5 Not at all

6] How frustrated were you by not having to use your hand to sketch?

$\begin{array}{lllll}\text { 1Extremely } & 2 & 3 & 4 & 5 \text { Not at all }\end{array}$

7] Was the design affected by you not using your hands?

$\begin{array}{lllll}\text { 1Extremely } & 2 & 3 & 4 & 5 \text { Not at all }\end{array}$

8] Would it change anything if the hand were a computer?

$\begin{array}{llllll}1 \text { A lot } & 2 & 3 & 4 & 5 \text { Not at all }\end{array}$ 


\title{
Appendix 3: Transcript and Protocol Analysis of "Stair Sequence" in Double H experiment
}

\author{
Subjects - Practitioner: Amanda Bulman - Hand $(\mathrm{H})$ \\ - Student: Amy Matthews - Head (M)
}

\begin{tabular}{l|l} 
Code & \multicolumn{1}{|c}{ Protocol } \\
\hline & $\begin{array}{l}\text { Mo00 } \\
\text { M: Right we are going to start off by drawing a kind of replica } \\
\text { of the site plan but you can just draw on this if you like um } \\
\text { and or even yeah just draw on the actual paper itself save } \\
\text { drawing it up. Um there is going to be two floors so this is } \\
\text { going to be the ground floor and ... main entrance will be from } \\
\text { St Johns Lane. } \\
01: 29 \text { Video } \\
\text { M: Okay so it will be from St John Lane, the reception area } \\
\text { will run around to St Johns Lane and go back approximately } 4 \\
\text { meters and on the side of that, lets say the left hand side, um } \\
\text { there will be a stair well which will go down below the ground } \\
\text { so will go } 3 \text { levels going to go down underneath the ground } \\
\text { say it will have to be } 2 \text { meters to allow for carrying um pieces } \\
\text { of art so it be } 2 \text { meters wide and stretching the entire of that } \\
\text { distance. }\end{array}$
\end{tabular}

\section{$02: 46$ Video}

M: At the end of where that space finishes interiorly.

$\mathrm{H}:$ Am I allowed to ask questions?

Observer: Yeah

$\mathrm{H}$ : When you say that the stairwell continued do you mean that the whole thing is 2 meters wide.

M: Yep.

$\mathrm{H}:$ And it just goes like that?

M: However long it takes to get head height down, lets call it 2 meters

H: so $2.2,2.2$

M: so the depth of the stair is approximately .2 lets call it 11 steps.

H: Got 12 .

M: Cool.

H: Okay Yep.

M: Alright so lets $\ldots$ at the end of that space that we have just drawn so approximately where you have drawn that line you know half way along um we are going to have another staircase which will raise up to the second floor but this one is going to be .......

Observer: You can ask her the point of where and stuff like that.

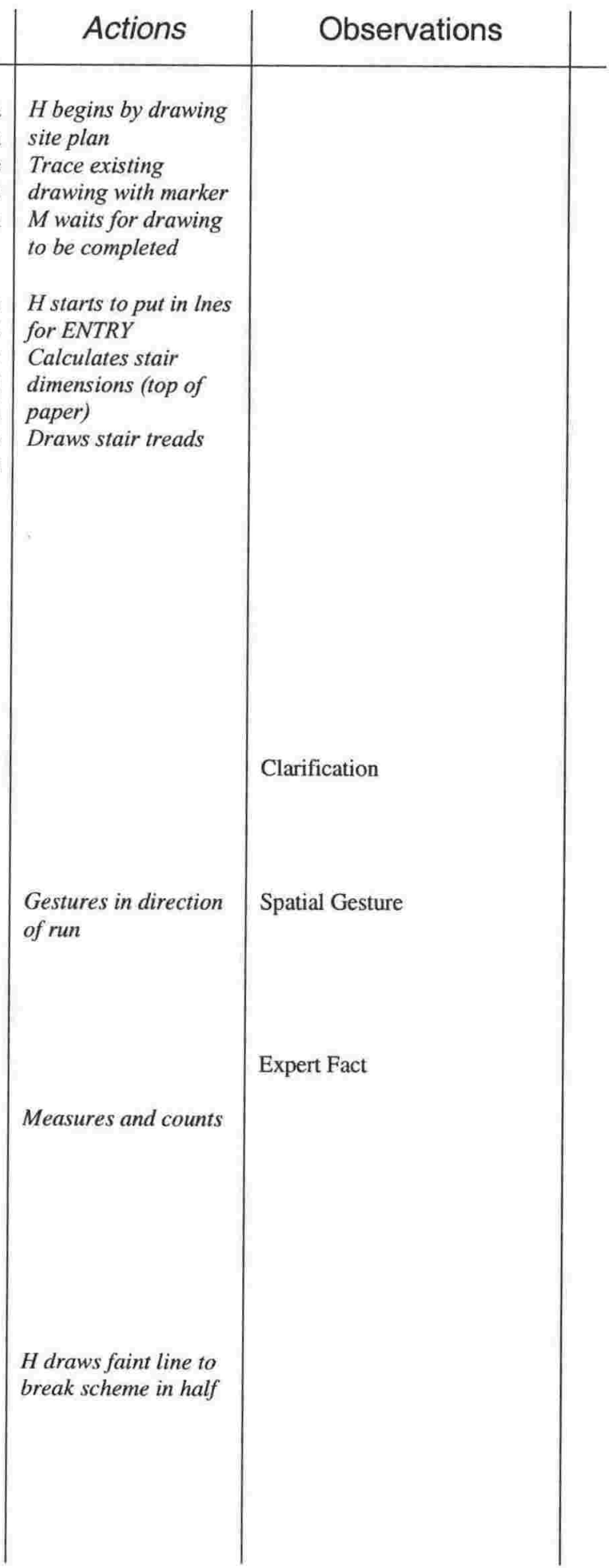




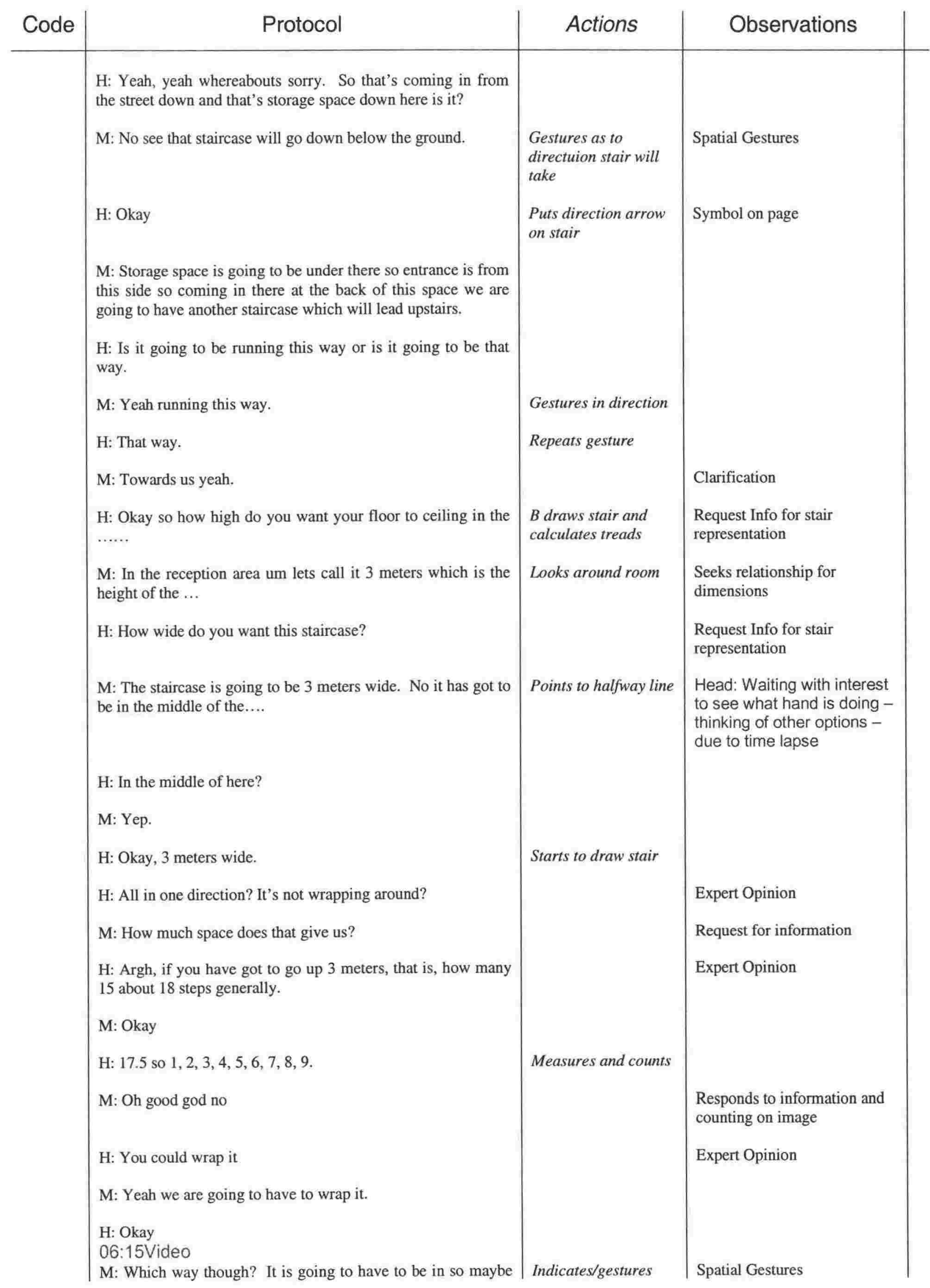




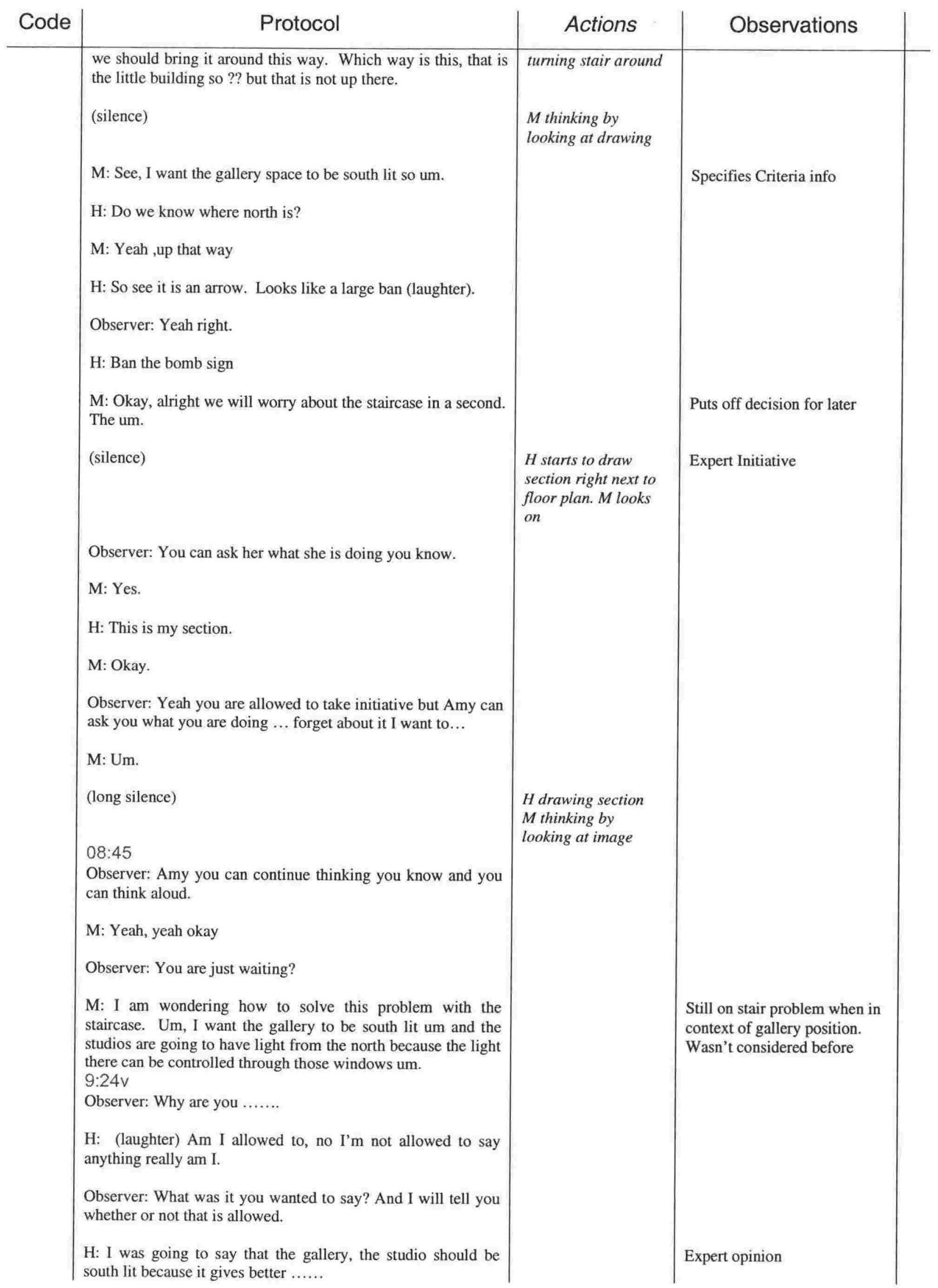




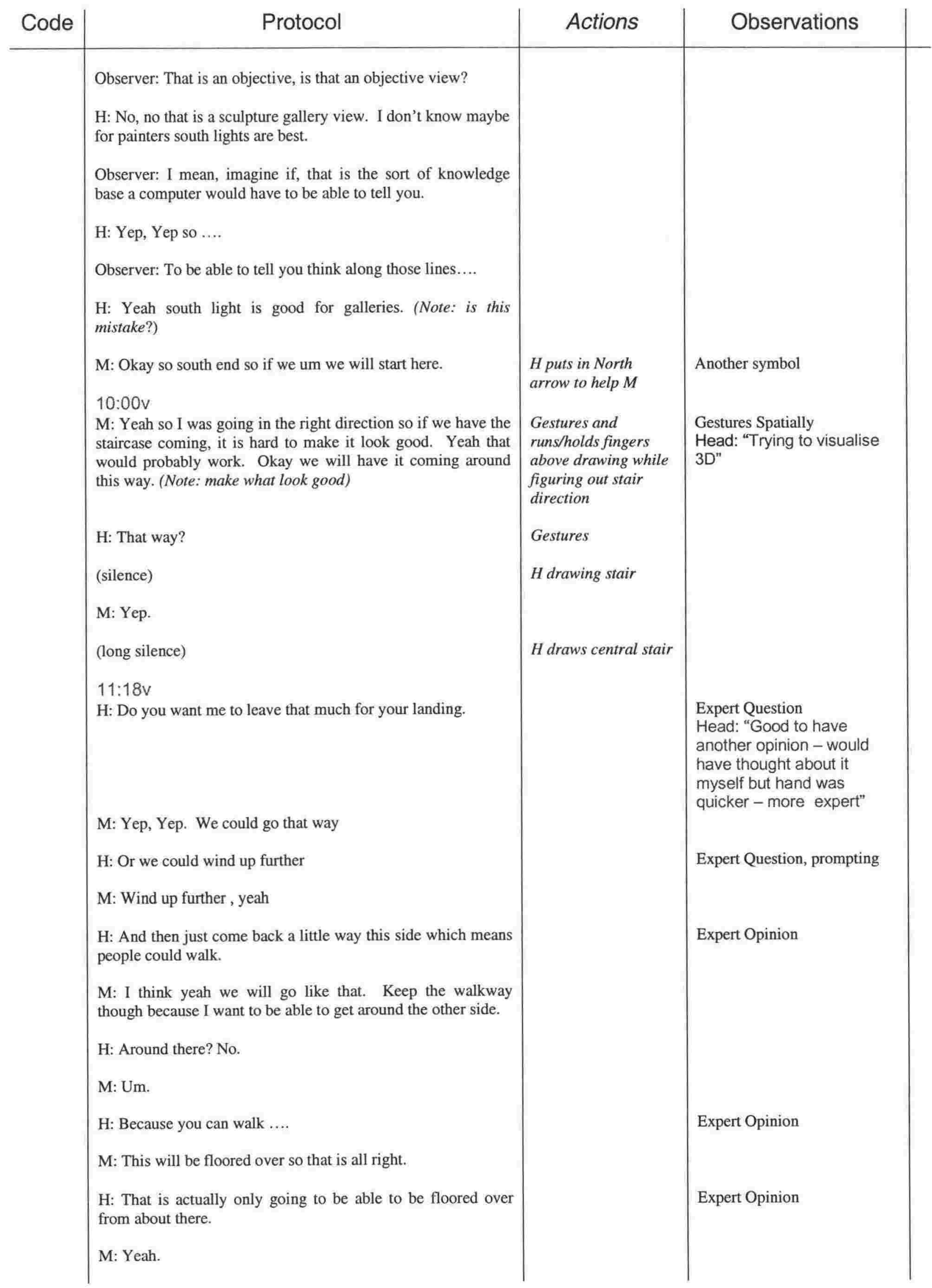




\begin{tabular}{|c|c|c|c|}
\hline Code & Protocol & Actions & Observations \\
\hline & $\begin{array}{l}\text { H: So do you want to move that that way so that is going down } \\
\text { here we are on that level. } \\
\text { M: Okay because we are still on the base plan, um we need to } \\
\text { be able to get from this front lobby space through to the back } \\
\text { so there is going to have to be some kind of walkway. } \\
\text { H: Are you are going to need to get to the stair so you could } \\
\text {... } \\
\text { M: How can you get to the stair? } \\
\text { H: So you could .... } \\
\text { M: The stair is going down this way, Yep. } \\
\text { H: So if you want to go up this stair you probably don't want } \\
\text { to walk right around it. } \\
\text { M: Yep okay so what we need is actually a wee area here to } \\
\text { start going up the stairs. } \\
\text { (Long silence) } \\
\text { H: Okay is that enough? } \\
\text { M: Yep. } \\
\text { (silence) }\end{array}$ & $\begin{array}{l}\text { H erases and draws } \\
\text { M thinking } \\
\text { Hembellishes - } \\
\text { Darkens stair }\end{array}$ & $\begin{array}{l}\text { Expert Opinion } \\
\text { Head: "Again, would have } \\
\text { thought of this but hand } \\
\text { was quicker in observation" }\end{array}$ \\
\hline
\end{tabular}


-A18 - 


\section{Appendix 4: Design Coach Questionnaire Results}

[1] How often do you consult outside sources/reference material when designing?

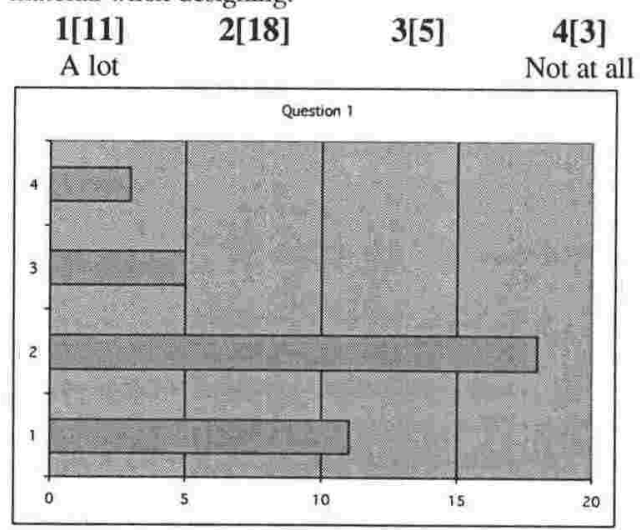

[2] How early do you use reference material when designing?

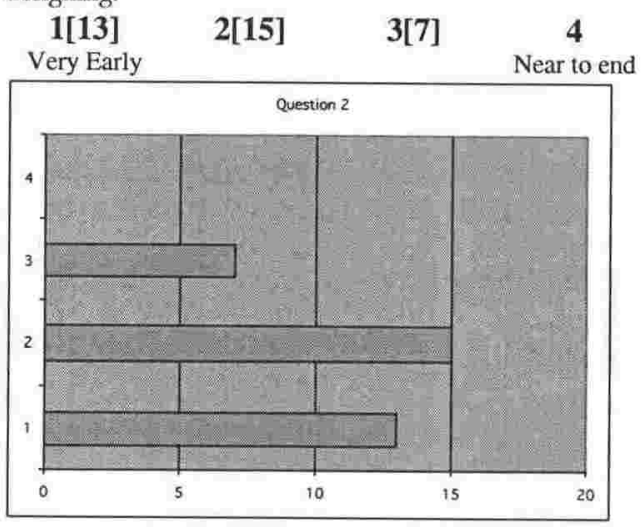

[3] Did you examine the design coach?

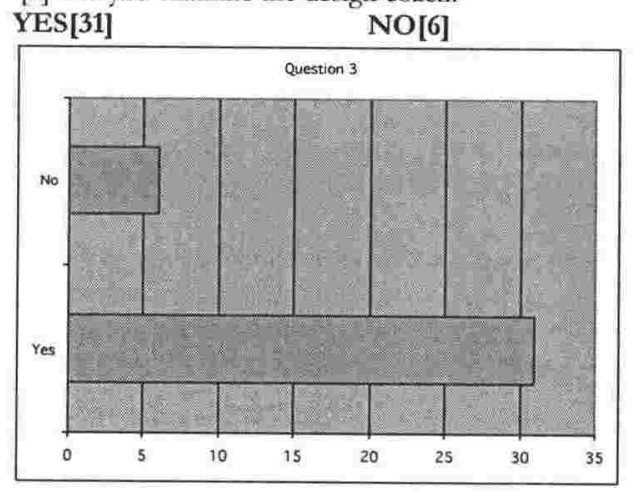

If you answered No, state one reason why you did not examine the design coach:

Did not have time

Not really interested in computer drawing No Time
No Good Reason

Didn't get round to it

Would have liked to but was working on concepts more.

[4] To what extent did you use the coach for your thermal design project?

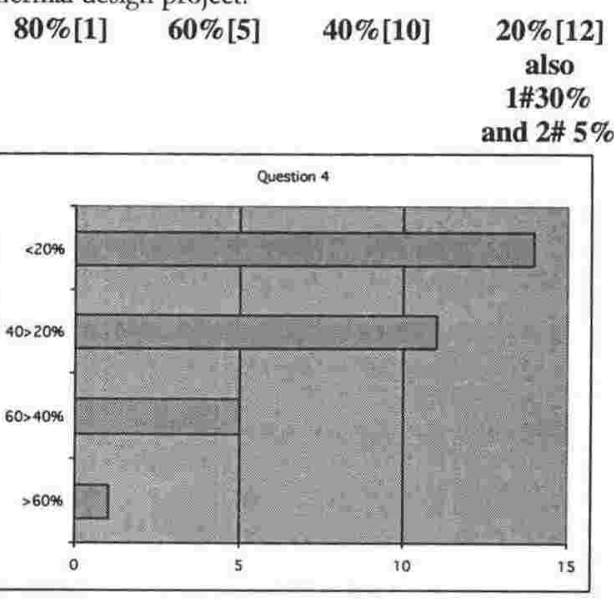

[5] What prevented you from using it more? (Tick all that apply)

- Too complex[2]

- Irrelevant

material[4]

- Connections did not - Other[15] work[7]

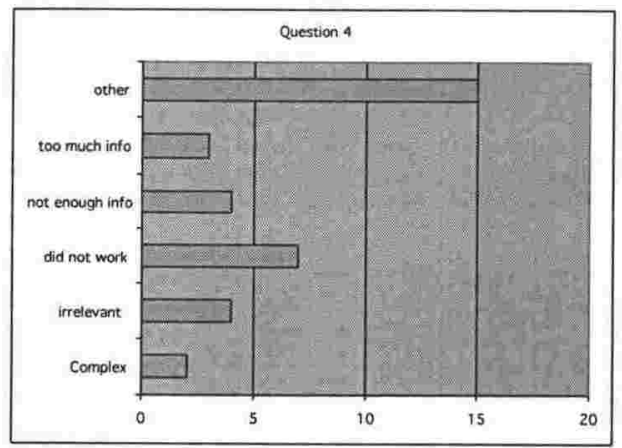

[6] How much did the coach inspire you to seek other reference material?

1[1]

2[9]

3[13]

4[7]

A lot

Not at all 


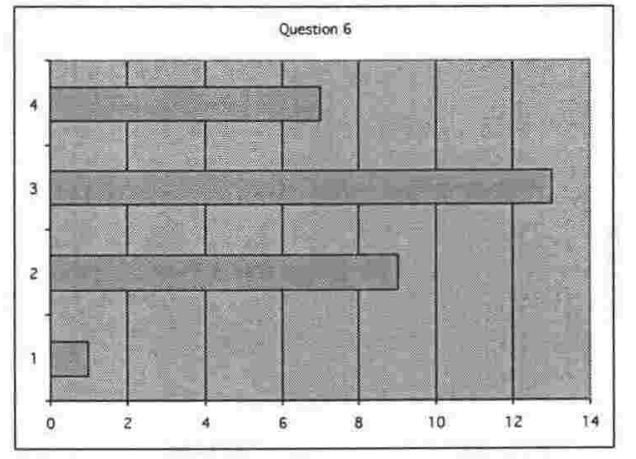

[7] How often did you consult other outside sources/reference material when doing this project?

$\begin{array}{llll}1[3] & 2[15] & 3[12] & 4[1]\end{array}$

A lot Not at all

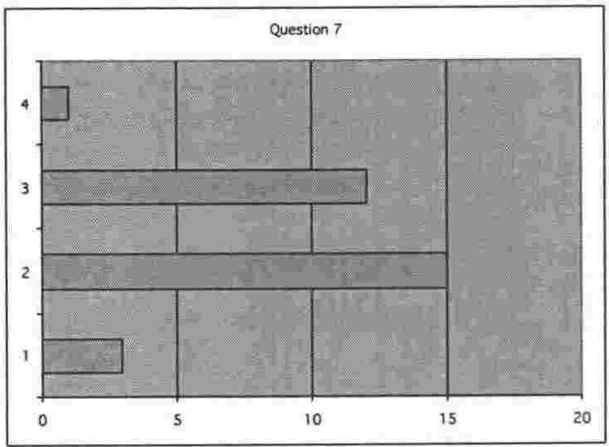

[8] How much did the system of making links between different ideas and issues help you?

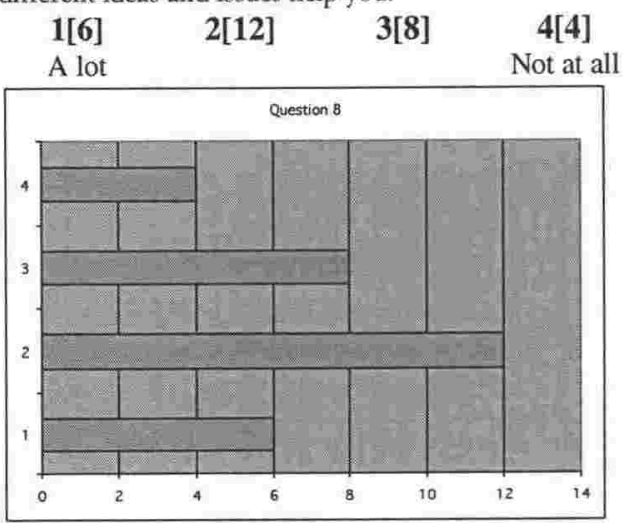

[9] How helpful or compatible to your design process would you say the coach (in its present state) is?

1[5]

A lot

2[14]

$3[9]$

$4[2]$

Not at all

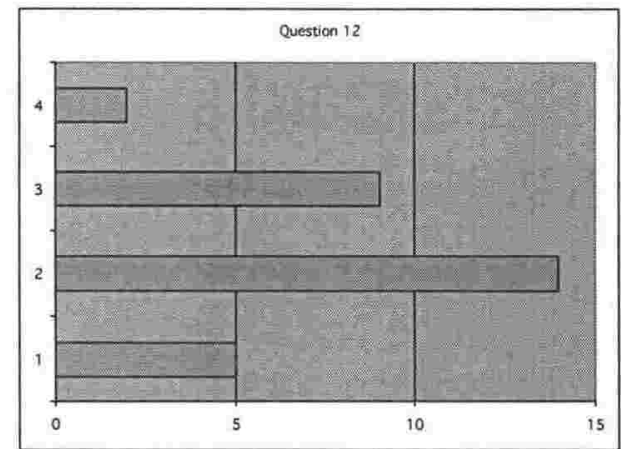

[10] How much do you think the design coach exposed you to aspects of the design process?

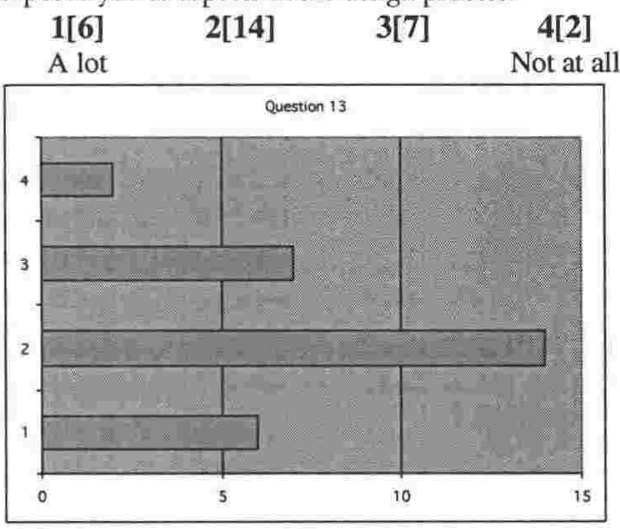

[11] How much do you think the design coach exposed you to issues involved in the design of a thermal house?

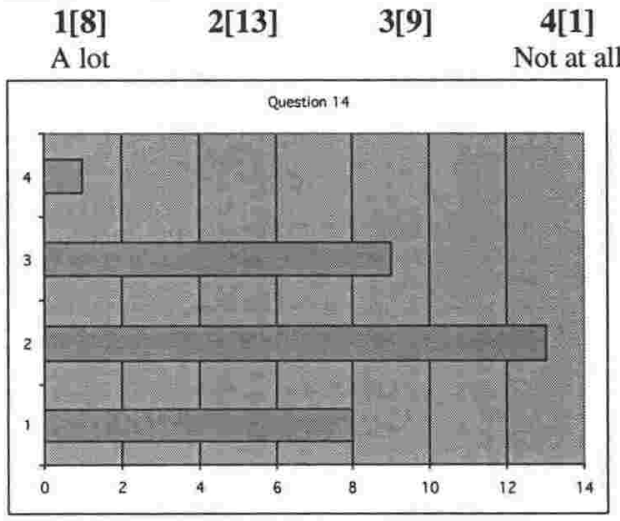

[12] How much did you learn from the design coach?

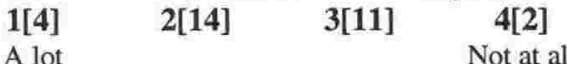




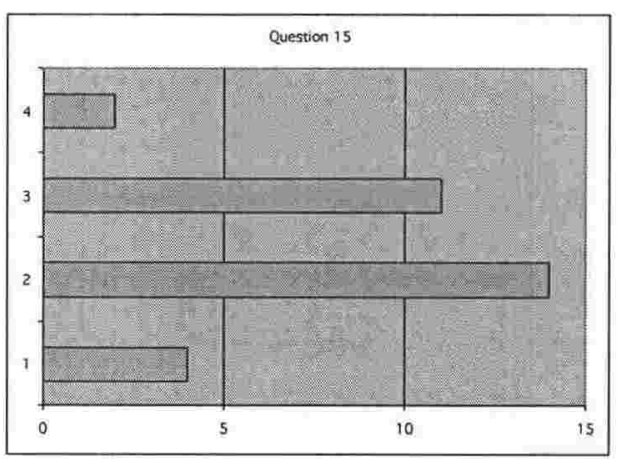

[13] How helpful was the design coach in informing your tutorial sessions?

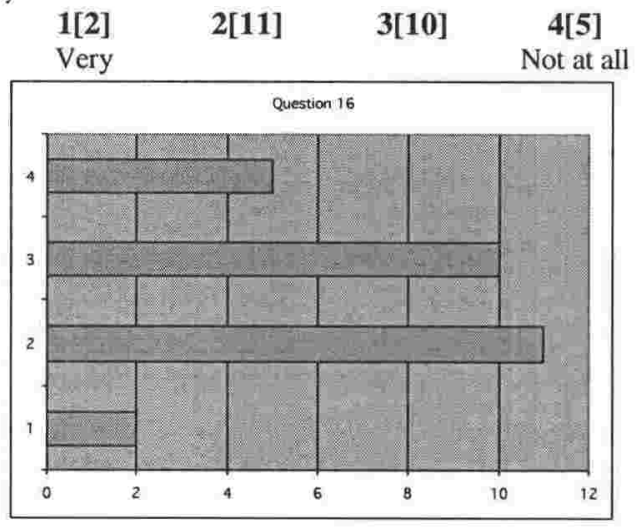

[14] How difficult was it to find required information?

$\begin{array}{cccc}1[2] & 2[9] & 3[16] & \begin{array}{c}4[3] \\ \text { Not at all }\end{array}\end{array}$

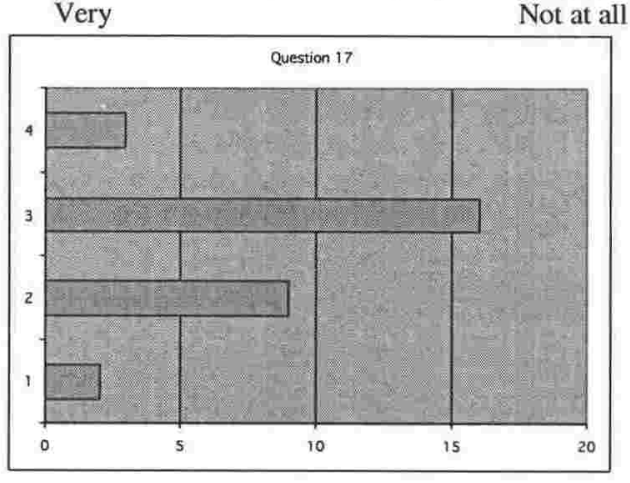

[15] Do you plan to use the coach for other studio projects?

Yes [25]

No[1] +3 maybes

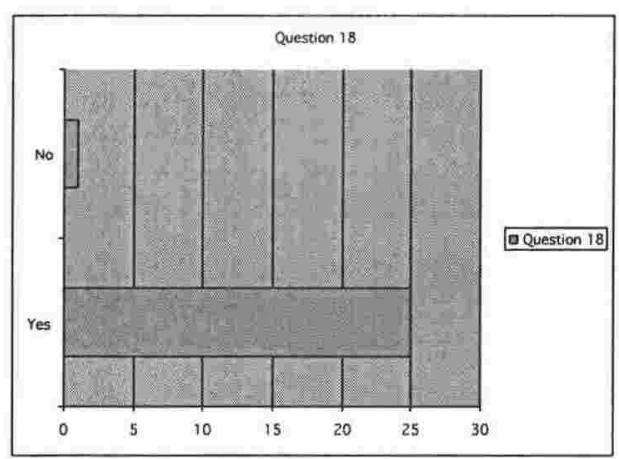

[16] Was the information provided in the design coach adequate?

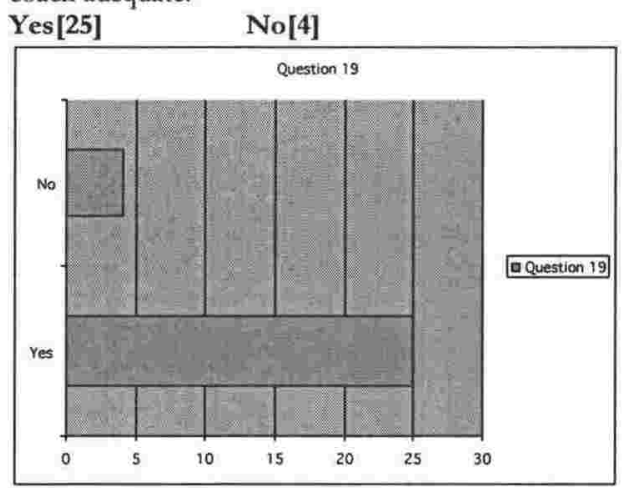

[17] Could you list at least three pieces of information that assisted in the development of your project?

1. Calculation methods

2. Insulation, Door sizes

3. R-values, Ventilation, Room Sizes

4. Wind direction - prevailing, Stairs dimensions

5. Sizes of hearth, General information about insulation, thicknesses etc, thicknesses

6. Orientation, room spaces

7. Explanation of the brief, Dimensioning and sizes, Examples of hearths and the rituals

8. Diagrams of ventilation

9. Solar gain, Ventilation, Site

10. Solar information, Materials information, Orientation information

11. Stack ventilation designs, Weather data, $R$ value data

12. Technical information on staircase, Pattern on hearth, Pattern on bathing

13. Garage layout, Kitchen heights/reaches

14. Room dimensions, Ways of massing, Ventilation

15. Ventilation analysis, Sun collection analysis

16. Sun spaces, Room organisation, entry

17. Ventilation systems, Room sizes, Circulation/connections

18. Fireplace size/ideas, Room dimensions/kitchen layout 
19. Dimensions of spaces, Windspeed information, Ideas of different types of stack ventilation, Recommend insulation values

20. Mass typologies issues

21. Site / winds

22. Passive solar designs, Overhangs, Wind shelter with trees

[18] From the screen shots right, write the corresponding letters for the three most and least relevant to the design process and the most and least helpful to the thermal house project:

The most relevant information

$1 \mathrm{D}[13], \mathrm{A}[9], \mathrm{B}[4], \mathrm{C}[4]$

$2 \mathrm{~A}[12], \mathrm{C}[5], \mathrm{D}[5], \mathrm{B}[2]$,

$3 \mathrm{~B}[12], \mathrm{C}[5], \mathrm{A}[3], \mathrm{D}[1]$

The least relevant information

$1 \mathrm{~B}[10], \mathrm{C}[7], \mathrm{A}[5], \mathrm{D}[3]$,

$2 \mathrm{~B}[10], \mathrm{C}[\mathrm{G}], \mathrm{A}[\mathrm{5}], \mathrm{D}[1]$,

$3 \mathrm{C}[7], \mathrm{A}[7], \mathrm{D}[3], \mathrm{B}[1]$,

The most helpful information

$1 \mathrm{D}[18], \mathrm{B}[4], \mathrm{C}[3], \mathrm{A}[3]$,

$2 \mathrm{~B}[9], \mathrm{A}[8], \mathrm{C}[5], \mathrm{D}[2]$,

$3 \mathrm{~A}[7], \mathrm{B}[7], \mathrm{C}[3], \mathrm{D}[2]$,

The least helpful information

$1 \mathrm{~B}[10], \mathrm{C}[8], \mathrm{A}[4], \mathrm{D}[0]$,

$2 \mathrm{~B}[7], \mathrm{C}[7], \mathrm{A}[6], \mathrm{D}[0]$,

$3 \mathrm{~A}[8], \mathrm{B}[5], \mathrm{C}[4], \mathrm{D}[1]$,

What information would you add?

- More pictures/diagrams

- Photo images of examples to help inspire students

- Photos of houses as examples rather than diagrams

- More text

- Calculations

- Information on single sited ventilation

- Single sided ventilation

- Specific examples of applications/references to actual architecture that applies this information. Further links and paths to such information. Some can see the information in modern context and practice

- Entrance page to site. More clues as to what is where.

- Perhaps some more theoretical information

- Hard to say. It was probably there, but I didn't see it.

- design coach is alright at moment

- Many relevant?

- Not much more - it is comprehensive enough

[19] Which of the screens would you consider 'design friendly"? (List all that apply and include any not shown) A

A, B, D Anything with not too much on one page

A, C, D

Pattern language less, so many links to patterns weren't there.
A, D 3 We like pictures.
A, D Graphics immediate reaction and
connection
$\mathrm{B}, \mathrm{C}$
C
C Easy to read
C, A
D 4
D More visual, i.e. drawings rather than text

D, A 3 Visual graphics. Diagrams help

D, C

Most

All

All interesting, all useful

All were relevant

It's like a book. It is not interactive. The screens are fine.

Clear font.

Graphics

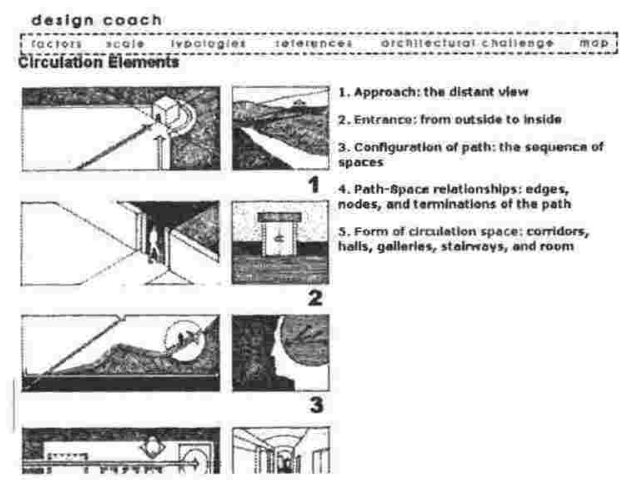

A Information from 'Form, Space and Order'

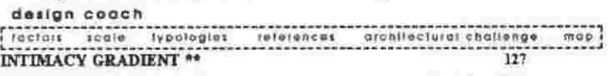

Buildings: Gradients of opace and movemort $\quad$ Meiw Prer Next

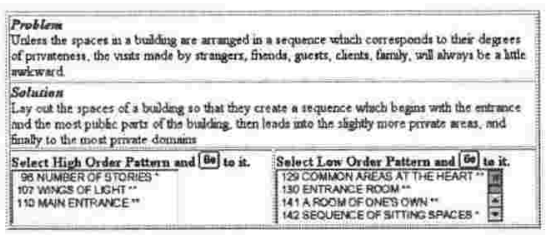

Connections: Circulation - Entrance - Building - Room Organisation

B Information from "A Pattern Language" design cooch

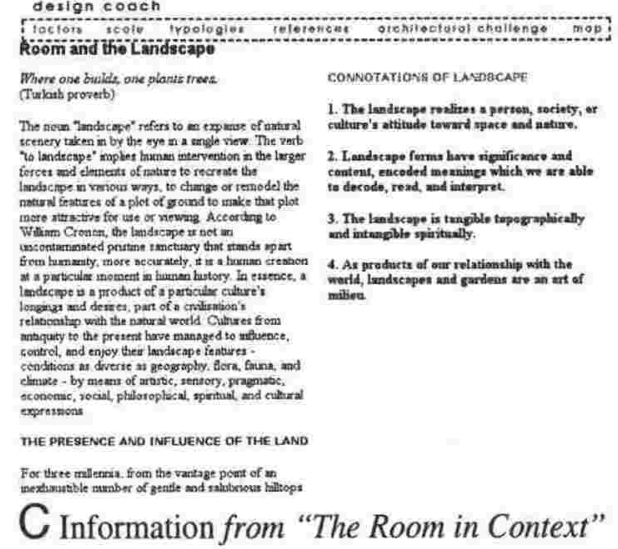


design coach

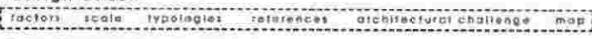

Room Organisation: Combined Cross \& Stack ventilation
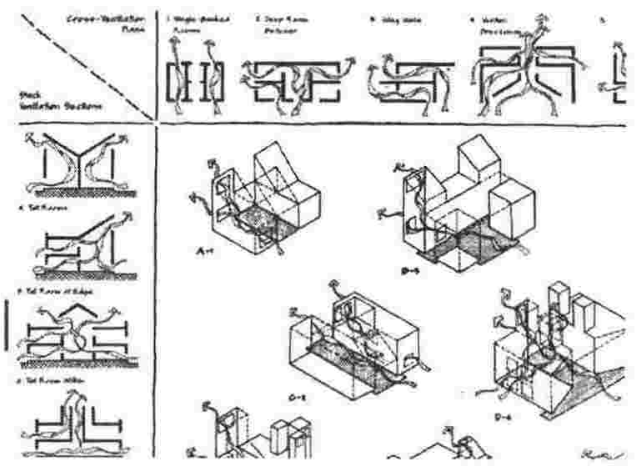

D Information from "Sun, Wind and Light"

[20] If there are any additional comments about the design coach that you would like to make you can do so here.

Probably too broad and would be better if focussed on an individual design.

Easier navigation of site.

I felt that the design coach covered the basics really well, but lacked more advanced information.

Reading a book is still a bell of a lot better.

Pictures and diagrams are more belpful than lots of written information.

The extensive links and visual graphics belp to extend knowledge and gain it quickly.

The design coach is a great way of starting off an assignment (gaining ideas and information).

More links to the bome page. More clear path to find relevant information (a bit of a maze).

Am still confused about the bome page menu process. I always bad to use the search engine to find what I needed.

More cross referencing in a clearer form, ie links at bottom like there is already, but also a description of what they lint to ... or maybe an expandable link tree (like on discussion board etc), so if you are trying to find everything on a subject you can search thoroughty.

I would like to see some form of present day context. These are good methods and inspirations, but a lot of us need to see actual architecture to furtber explore and understand the ideas. Examples of houses, virtual tours of such methods are the next step of understanding for us - a complete understanding, not just the analysis, but that is a buge aske! But it would be an absolutely full and brilliant resource then!!

The map (index is good).

Less information straight from books.
Maybe standardise information to one overall format? unless it is intended to be a collection of other resources.

I thought it was a very useful tool, and it certainly made the research project much easier.

None, quite satisfied with the Design Coach as it is.

Excellent range of material. I find looking through a books easier, however. I guess, because this is new, it will take time to refine and make it an option for me in reseanting material.

I found a tendency to almost directly follow illustrations in my design and not develop them further, $i$ e tended to use those shapes and sections without extra development.

Good bolistic approach. 
- A24 - 


\section{Appendix 5: Using the Design Coach Prototype}

\section{First Steps}

The Design Coach will open automatically when the included CD is inserted. Otherwise double click on the file "index" to access the prototype

The first screen of the design coach you will encounter is the title screen as below:
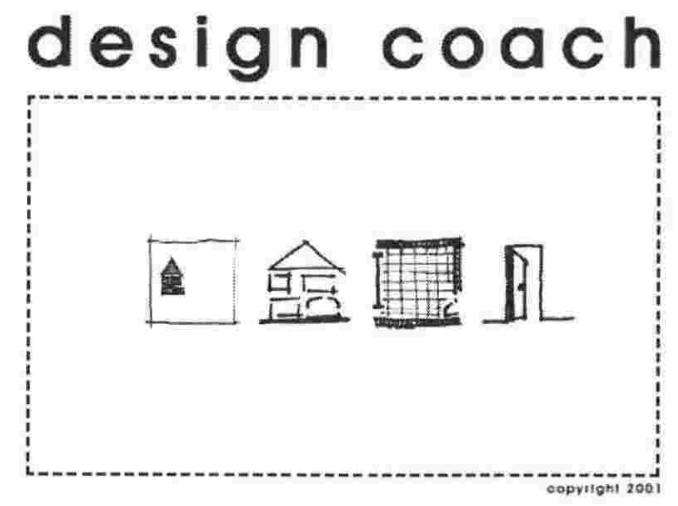

To open the coach itself simply click anywhere on the title screen. This will bring you to the start page.

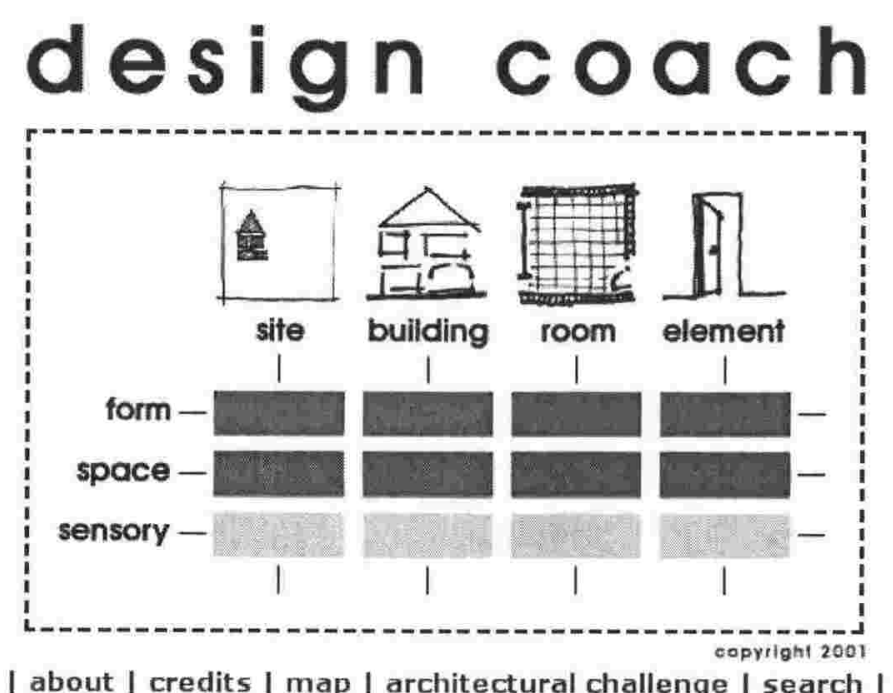


The start page is comprised of a matrix with four scales - site, building, room, element; and three factors within those scales; form, space and sensory. These three are represented by three colours - Blue, Red, Yellow. Clicking on any coloured block will present you with an information page regarding the factor of that scale and links to further information regarding that subject.

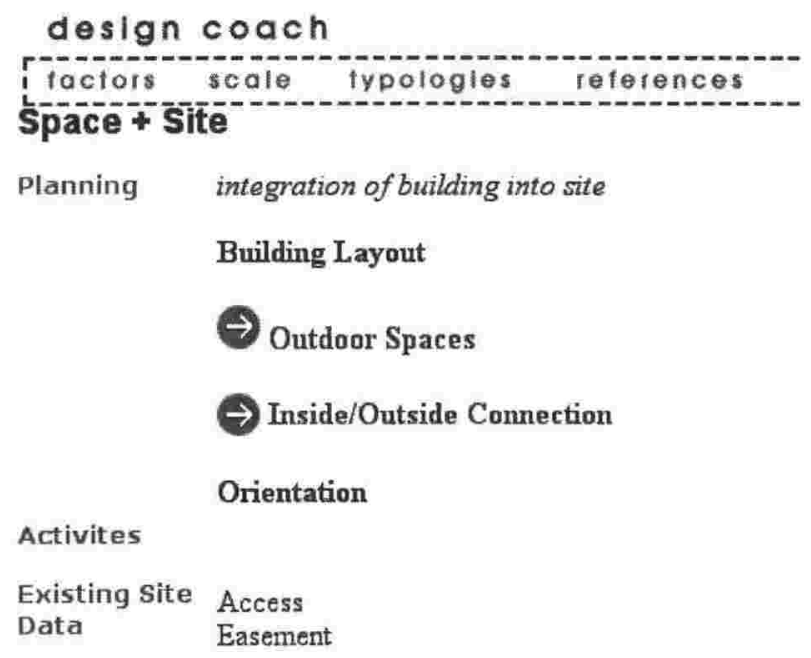

For instance, if you click on the Space/Site red block will open a page with links to information on Building Layout and Orientation.

Also on the start page are auxiliary choices:

About - Gives you vital information about the design coach.

Credits - Information about the team that worked on the coach.

Map - List of all the pages available in the coach

Architectural challenge - an assignment brief of the studio project that was used to test the coach

Search - A search page for the coach

The navigation section deals with how to move around from this point and how to get the results you want from the coach. 


\section{Navigation}

Once past the start page, you will see a page with links to other pages containing information relating to that subject. For instance, clicking on the form/site block will direct you further to the information you require, related topics that may be of interest, further reading and references. Each page branches the subject out further until you have narrowed down to information you require. For example, if you want information about solar radiation. This would be your process:

- Click Blue form/site block then click on topography.

design coach tactors scale typologles references architectural challenge map Topogräphỳ

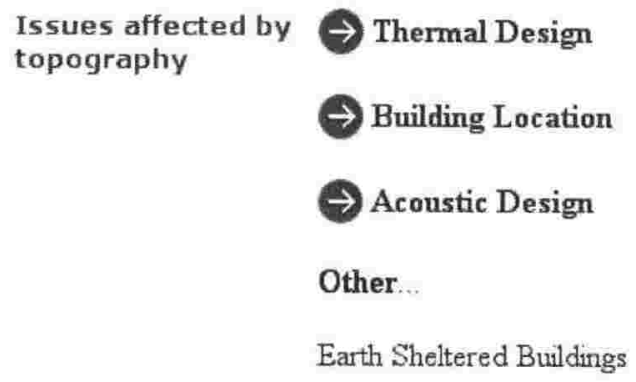

Connections: Form+Site - Landscape - Form -

Physical factors - topography. This page shows a list of the issues affected by topography thermal design, building location, acoustic design and earth sheltered buildings. Each of these is a link to further information on that subject. Also you will see a section called Connections, which is a list of links to related pages. For instance, on the Topography page you will see connections to Form+Site, Landscape and Form.

\section{- Click on Thermal design.}




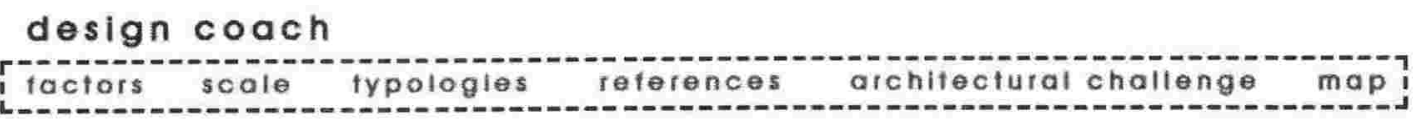

\section{Topography: Thermal Design}

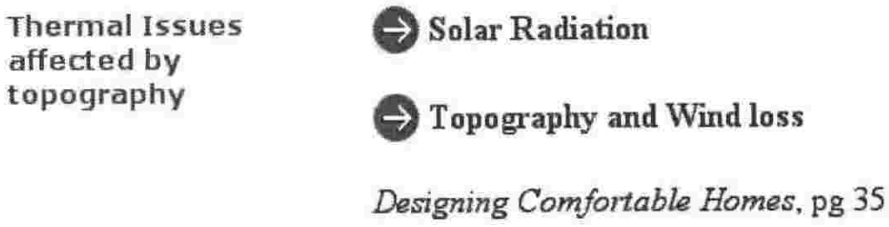

References Sun, Wind \& Light, pg 27

The Climatic Dwelling, pg 76

Connections: Topography - Thermal Design - Wellington Sun Data - Sun Shadow - Wind issues - Building Location - Acoustics

This page shows a list of thermal issues affected by topography - Solar Radiation and Topography and Wind Loss. Once again each option links to a page with further information on this subject.

Also on this page you will see references to related published works listed. Where possible the designer has linked these references. For instance if you click on the reference Sun, Wind and Light, you are taken to the contents page of Sun, Wind and Light, Architectural Design Strategies and the relevant Chapters are highlighted. Click on the relevant chapter and you are taken to that a copy of that page - just like looking it up in the physical book itself.

- Click on Solar radiation. 
design coach

factors scole pypologies references architecturatchallenge map?

Topography: Thermai Design : Šōar Radiation

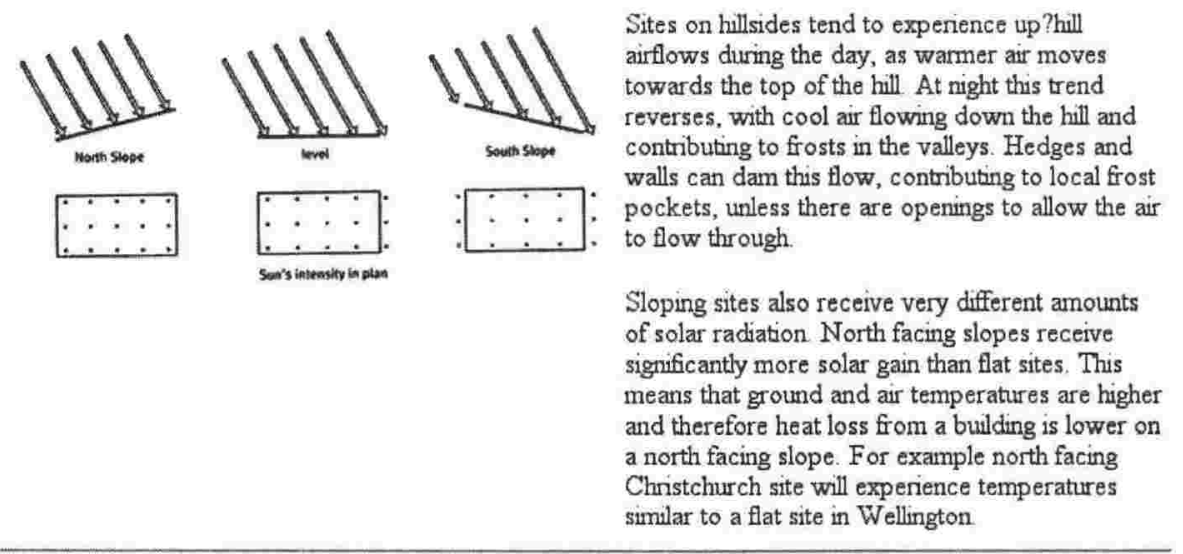

| Connections:Topography - Building Location

This page shows us information and diagrams on solar radiation in relation to thermal design and topography. As always the Connections links are at the bottom of the page

\section{Alternate Navigation}

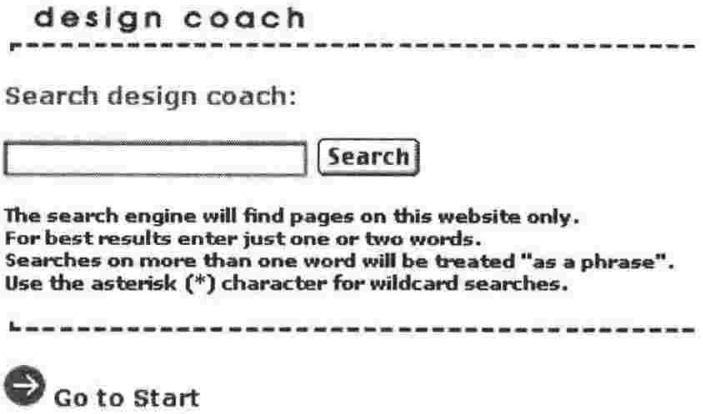

Another method of finding the information you require is to use the Search function on the start page and drop menu. Simply click on Search, enter one or two words best describing the information you require and hit enter or click search. This will bring up all information on that subject held in the design coach and is linked to allow you to click on the item you are interested in and be taken directly to that page. 
design coach

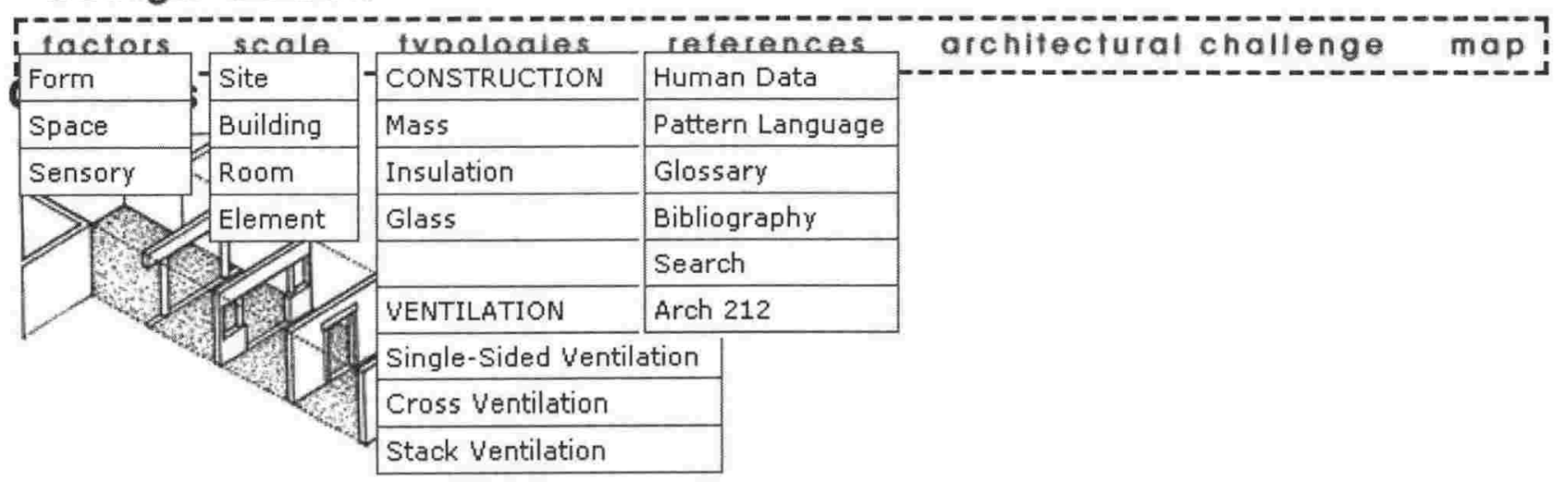

You will have noticed by now drop down menus at the top of every page. They are as follows:

The factors and scale menu will take you to individual scale and factor pages.

The Typology menu shows three types of typologies for construction and ventilation.

The Reference menu shows information and text for further reading on subjects of reference in design, such as human data and pattern language, as well as a glossary and bibliography.

The Architectural Challenge menu shows an assignment brief of the studio project that was used to test the coach.

$$
\begin{array}{|l|}
\hline \text { MENU } \\
\hline \text { Back } \\
\hline \text { Next } \\
\hline \text { Home } \\
\hline
\end{array}
$$

If at any stage you want to go back to the contents page there is a pop-up back/next/home box in the bottom left hand corner of every page. 